\title{
Selective Catalytic Oxidation of Unprotected Carbohydrates
}

Supporting Information

Kevin Chung and Robert M. Waymouth

Stanford University, Stanford, California. USA. 94305

Materials and methods....

Preparative scale oxidation reactions of glycosides and sugar alcohols in acetonitrile / acetonitrile:water

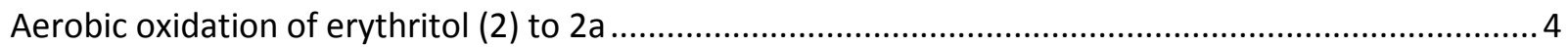

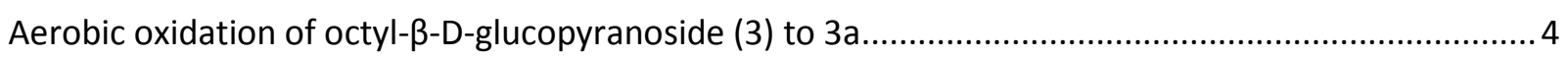

Aerobic oxidation of 1-deoxy-1-azido- $\beta$-D-glucopyranoside (4) to 4 a .................................................. 5

Aerobic oxidation of 4-methoxyphenyl- $\beta$-D glucopyranoside (5) to 5 a ............................................... 5

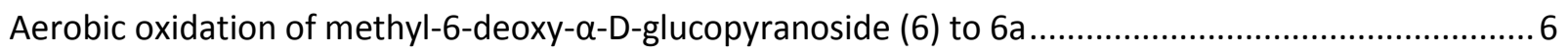

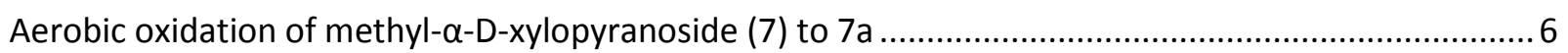

Oxidation of methyl- $\alpha$-L-fucopyranoside in acetonitrile (8) to 8a......................................................... 7

Oxidation of methyl $\alpha$-L-rhamnopyranoside (9) in acetonitrile:water to 9a .......................................... 7

Oxidation of 1,6-anhydro- $\beta$-D-galactopyranoside $(10)$ in acetonitrile to 10 a ...................................... 7

Oxidation of 1,6-anhydro- $\beta$-D-mannopyranoside (11) in acetonitrile to 11 a ........................................ 8

Determination of solvent-dependent glycoside regioselectivity............................................................ 9

Preparative scale oxidation reactions of glycosides and sugar alcohols in fluorinated solvents ...............11

Oxidation of methyl-6-deoxy- $\alpha$-D-glucopyranoside (6) to 6a in 2,2,2-trifluoroethanol......................... 11

Oxidation of methyl- $\alpha$-D-galactopyranoside (19) to 12a in 2,2,2-trifluoroethanol...............................11

Oxidation of methyl- $\alpha$-L-fucopyranoside (8) to $8 \mathrm{c}$ in 2,2,2-trifluoroethanol....................................... 12

Hydroxylamine addition to methyl 3-keto-6-deoxy- $\alpha$-L-glucopyranoside (8c) .................................... 12

Methoxyamine addition to methyl 3-keto-6-deoxy- $\alpha$-L-glucopyranoside (8c) .................................... 13

Hydrogenation of E/Z-methyl-3-O-methyloxime-6-deoxy- $\alpha$-L-glucopyranoside (8e) .........................13

Peracetylation of methyl-3-amino-6-deoxy- $\alpha$-L-glucopyranoside (8f) ................................................ 14

Oxidation of 2-acetamido-2-deoxy- $\alpha$-D-glucopyranose (16) to 16a in 2,2,2-trifluoroethanol................ 14

Oxidation of 2-acetamido-2-deoxy- $\beta$-D-glucopyranose (17) to 17a in 2,2,2-trifluoroethanol............... 14

Peracetylation of 3-keto-2-acetamido-2-deoxy- $\beta$-D-glucopyranose (17) ........................................... 15

Oxidation of 2-deoxy-2-acetamido- $\beta$-D-glucopyranosyl azide (18) to 18 a.......................................... 15

Oxidation of methyl $\beta$-D-arabinopyranoside (13) to 13a in 1,1,1,3,3,3-hexafluoroisopropanol............ 16

Oxidation of methyl- $\alpha$-L-rhamnopyranoside (9) to $8 \mathrm{c}$ in 1,1,1,3,3,3-hexafluoroisopropanol................ 16

Oxidation of benzyl 2,3-O-isopropylidene- $\alpha$-D-mannofuranoside (20) to 20 a .................................... 17 


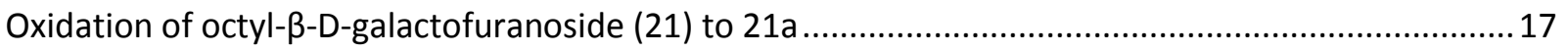

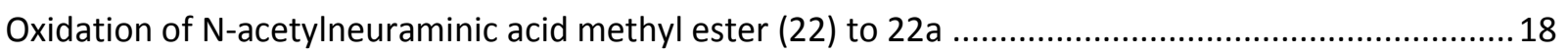

Oxidation of L-threitol ((2S,3S)-1,2,3,4-butanetetrol) (15) to 15a in 2,2,2-trifluoroethanol.................. 18

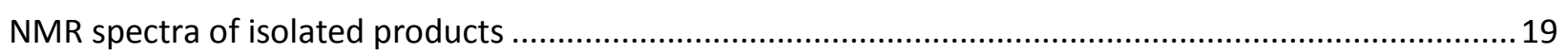

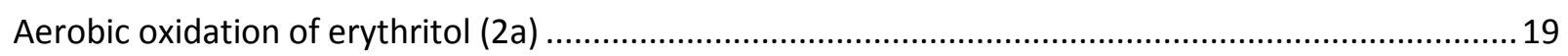

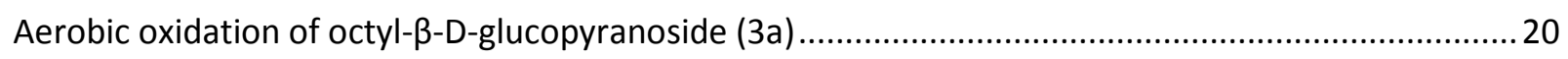

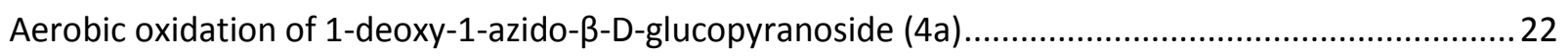

Aerobic oxidation of 1-deoxy-1-azido- $\beta$-D-glucopyranoside (elimination product $4 \mathrm{~b}$ )........................23

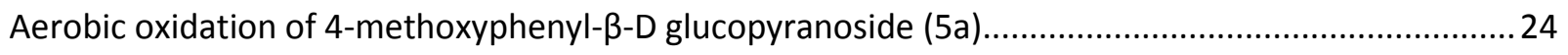

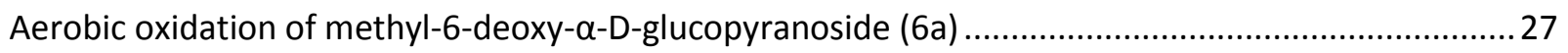

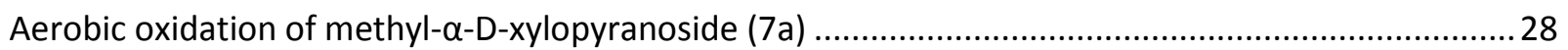

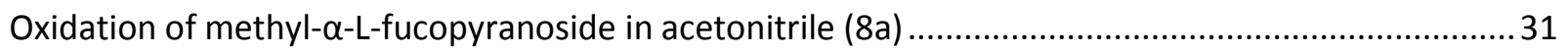

Oxidation of methyl $\alpha$-L-rhamnopyranoside in acetonitrile:water (9a) ...............................................3 34

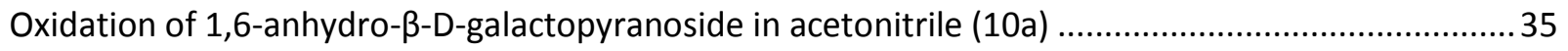

Oxidation of 1,6-anhydro- $\beta$-D-mannopyranoside in acetonitrile (11a) ................................................ 36

Oxidation of methyl-6-deoxy- $\alpha$-D-glucopyranoside in 2,2,2-trifluoroethanol (6a) ..............................40

Oxidation of methyl- $\alpha$-D-galactopyranoside in 2,2,2-trifluoroethanol (12a) ...................................... 41

Oxidation of methyl- $\alpha$-L-fucopyranoside in 2,2,2-trifluoroethanol (8c) ............................................4 44

Hydroxylamine addition to methyl 3-keto-6-deoxy- $\alpha$-L-glucopyranoside (8d) ..................................46

Methoxyamine addition to methyl 3-keto-6-deoxy- $\alpha$-L-glucopyranoside (8e) ....................................49

Hydrogenation of E/Z-methyl-3-O-methyloxime-6-deoxy- $\alpha$-L-glucopyranoside (8f)..........................50

Peracetylation of methyl-3-amino-6-deoxy- $\alpha$-L-glucopyranoside (8g) ............................................5 52

Oxidation of 2-acetamido-2-deoxy- $\alpha$-D-glucopyranose in 2,2,2-trifluoroethanol (16a) .......................53

Oxidation of 2-acetamido-2-deoxy- $\beta$-D-glucopyranose in 2,2,2-trifluoroethanol (17a) .......................54

Peracetylation of 3-keto-2-acetamido-2-deoxy- $\beta$-D-glucopyranose ..................................................56

Oxidation of 2-deoxy-2-acetamido- $\beta$-D-glucopyranosyl azide (18a) .................................................5

Oxidation of 2-deoxy-2-acetamido- $\beta$-D-glucopyranosyl azide (18b) .................................................59

Oxidation of methyl $\beta$-D-arabinopyranoside in 1,1,1,3,3,3-hexafluoroisopropanol (13a) ....................60

Oxidation of methyl- $\alpha$-L-rhamnopyranoside in 1,1,1,3,3,3-hexafluoroisopropanol (8c) ......................61

Oxidation of benzyl 2,3-O-isopropylidene-alpha-D-mannofuranoside (20a) ......................................62

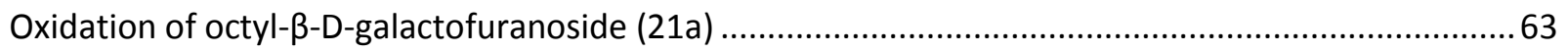

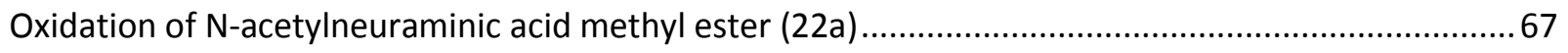

Oxidation of L-threitol ((2S,3S)-1,2,3,4-butanetetrol) in 2,2,2-trifluoroethanol (15a) .........................70

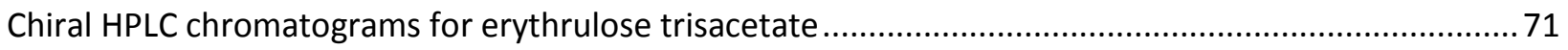

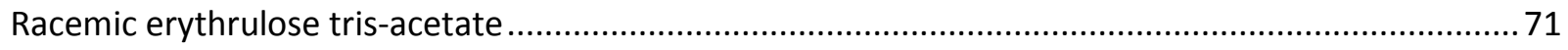


Erythrulose trisacetate from oxidation of L-threitol ((2S,3S)-1,2,3,4-butanetetrol) in 2,2,2-

trifluoroethanol (15a)

Regioselectivity determinations by NMR

Crude reaction mixture: oxidation of methyl- $\alpha$-D-glucopyranoside (12) in 10:1 acetonitrile:water ..... 73

Crude reaction mixture: oxidation of methyl-6-deoxy- $\alpha$-D-glucopyranoside (6) in 10:1 acetonitrile: $\mathrm{H}_{2} \mathrm{O}$

Crude reaction mixture: oxidation of methyl- $\alpha$-D-xylopyranoside (7) in 10:1 acetonitrile:water ......... 75

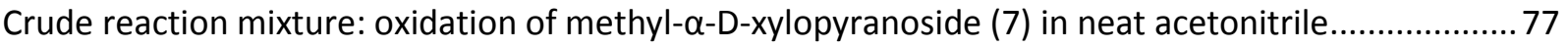

Crude reaction mixture: oxidation of methyl- $\alpha$-L-fucopyranoside (8) in 10:1 acetonitrile:water .......... 78

Crude reaction mixture: oxidation of methyl- $\alpha$-L-rhamnopyranoside (9) in 10:1 $C_{3} C N: D_{2} \mathrm{O} \ldots \ldots \ldots \ldots . . .78$

Crude reaction mixture: oxidation of 1,6-anhydro- $\beta$-D-galactopyranoside (10) in $\mathrm{CD}_{3} \mathrm{CN}$..................88

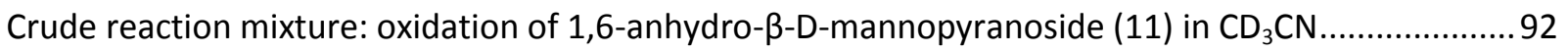

Crude reaction mixture: oxidation of 1,6-anhydro- $\beta$-D-glucopyranoside (14) in $\mathrm{CD}_{3} \mathrm{CN}$..................... 96

Crude reaction mixture: oxidation of methyl- $\alpha$-D-glucopyranoside (12) in 2,2,2-trifluoroethanol ..... 100

Crude reaction mixture: oxidation of methyl-6-deoxy- $\alpha$-D-glucopyranoside (6) in 2,2,2-

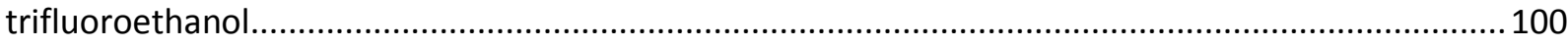

Crude reaction mixture: oxidation of methyl- $\alpha$-D-xylopyranoside (7) in 2,2,2-trifluoroethanol .......... 101

Crude reaction mixture: oxidation of methyl- $\alpha$-L-fucopyranoside (8) in 2,2,2-trifluoroethanol .......... 101

Optimization attempts for the oxidation of methyl 2-acetamido-2-deoxy-a-D-glucopyranoside (16) 102

Crude reaction mixture: oxidation of 2-deoxy-2-acetamido- $\beta$-D-glucopyranosyl azide (17) in 2,2,2-

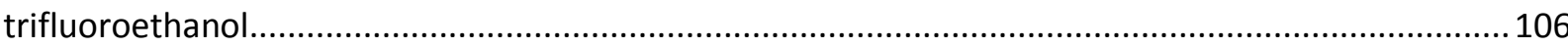

Aerobic oxidation of methyl a-D-xylopyranoside in presence and absence of 2,6-di-isopropylphenol...107

Monitoring of methyl a-D-xylopyranoside oxidation in 9:1 $C D_{3} C N / D_{2} \mathrm{O}$ over time............................... 109

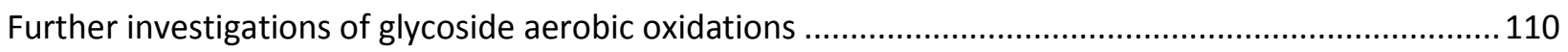

Investigations of alternative solvents for glycoside oxidation............................................................ 116

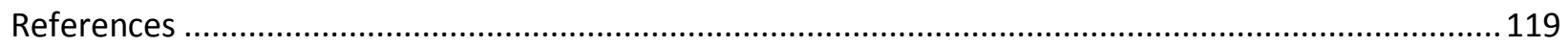




\section{Materials and methods}

Deuterated solvents $\left(\mathrm{CD}_{3} \mathrm{CN}, \mathrm{CH}_{3} \mathrm{OD}, \mathrm{D}_{2} \mathrm{O}, \mathrm{d}_{2}-1,1,1,3,3,3\right.$-hexafluoroisopropanol) were purchased from Cambridge Isotope Laboratories and used without further purification. Glycoside substrates were obtained from Aldrich, Santa Cruz Biotechology, Carbosynth, and TCl America, and were used without further purification. Octyl- $\beta$-D-galactofuranoside was obtained as "octyl-D-galactofuranoside" from Carbosynth, and was shown by ${ }^{13} \mathrm{C}$ NMR to exclusively consist of the known $\beta$ anomer. ${ }^{1}$ Dimethylsulfone internal standard was purchased from Aldrich. The cationic catalyst [(neocuproine) $\mathrm{Pd}(\mathrm{OAc})]_{2}(\mathrm{OTf})_{2}$ was prepared as previously described ${ }^{2}$. Benzoquinone was purchased from Aldrich and recrystallized from hexanes before use. NMR spectra were recorded on an Inova $300 \mathrm{MHz}$, Mercury $400 \mathrm{MHz}$, Inova 500 $\mathrm{MHz}$, or Inova $600 \mathrm{MHz}$ spectrometer. Silica gel chromatography was performed with Fisher 230-400 mesh, grade 60 silica.

\section{Preparative scale oxidation reactions of glycosides and sugar alcohols in acetonitrile / acetonitrile:water}

Aerobic oxidation of erythritol (2) to $2 \mathrm{a}: 12.2 \mathrm{mg}$ of meso-erythritol $2(0.10 \mathrm{mmol})$ was added to a solution consisting of $9.3 \mu \mathrm{L}$ 2,6-diisopropylphenol, $780 \mu \mathrm{L}$ acetonitrile, and $100 \mu \mathrm{L}$ water in a $20 \mathrm{~mL}$ septum-capped vial. $60 \mu \mathrm{L}$ of a $1.67 \mu \mathrm{M}$ solution of [(neocuproine) $\mathrm{Pd}(\mathrm{OAc})]_{2}(\mathrm{OTf})_{2}(0.001 \mathrm{mmol})$ was added. The vial was purged with oxygen for 45 seconds then sealed. The reaction mixture was then heated and stirred at $60^{\circ} \mathrm{C}$. After 22 hours, the reaction mixture was concentrated and resuspended in 15:1 ethyl acetate:ethanol. The resulting slurry was sonicated for 15 minutes, and was then loaded onto a silica gel column, eluting with 15:1 ethyl acetate:ethanol. Evaporation of the relevant fractions gave of $7.5 \mathrm{mg} 2 \mathrm{a}(0.062 \mathrm{mmol}, 62.5 \%$ yield) as a clear oil.

${ }^{1} \mathrm{H}$ NMR $\left(500 \mathrm{MHz}, \mathrm{D}_{2} \mathrm{O}\right) \delta 4.52-4.32(\mathrm{~m}, 1 \mathrm{H}), 4.29(\mathrm{t}, \mathrm{J}=4.1 \mathrm{~Hz}, \mathrm{OH}), 3.77-3.61(\mathrm{~m}, 1 \mathrm{H})$.

${ }^{13} \mathrm{C}$ NMR $\left(126 \mathrm{MHz}, \mathrm{D}_{2} \mathrm{O}\right) \delta 212.86,76.52,66.47,63.51$.

Spectra are consistent with literature. ${ }^{2}$

Aerobic oxidation of octyl- $\beta$-D-glucopyranoside (3) to 3a: $106.8 \mathrm{mg}$ of octyl- $\beta$-D-glucopyranoside 3 (0.365 mmol) was added to a solution consisting of $31.8 \mu \mathrm{L}$ 2,6-diisopropylphenol and $3.4 \mathrm{~mL}$ acetonitrile in a $20 \mathrm{~mL}$ septum-capped vial. $1.9 \mathrm{mg}(0.0036 \mathrm{mmol} \mathrm{Pd})$ of [(neocuproine)Pd(OAc) $]_{2}(\mathrm{OTf})_{2}$ was added. The vial was purged with oxygen for 45 seconds then sealed. The reaction mixture was then heated to $60{ }^{\circ} \mathrm{C}$ and stirred for 20 hours, with the vial uncapped and purged with oxygen at $1,2,3,4,6$, and 8 hours. The reaction mixture was then concentrated to a viscous oil, re-dissolved in a small portion of ethyl acetate, and loaded onto a silica column deactivated with triethylamine. Gradient elution was performed, starting with 1:3 hexanes:ethyl acetate and ending with neat ethyl acetate. Evaporation of the pure fractions gave $73.0 \mathrm{mg}$ of clear oil 3a. Evaporation of impure fractions containing desired 
product and elution through a silica gel using a 1:3 hexanes:ethyl acetate as eluent yielded another 6.0 $\mathrm{mg}$ of pure product $3 \mathrm{a}$, for a $79.0 \mathrm{mg}$ total yield $(0.272 \mathrm{mmol}, 74.4 \%$ yield).

${ }^{1} \mathrm{H}-\mathrm{NMR}\left(500 \mathrm{MHz}, \mathrm{CD}_{3} \mathrm{CN}\right) \delta \mathrm{ppm} 0.89(\mathrm{t}, \mathrm{J}=6.47 \mathrm{~Hz}, 3 \mathrm{H}) 1.27-1.38(\mathrm{~m}, 10 \mathrm{H}) 1.59(\mathrm{~m}, 2 \mathrm{H}) 1.93-1.95$ (m, 2 H) $3.00(\mathrm{~s}, 1 \mathrm{H}) 3.25(\mathrm{dd}, J=10.01,4.88 \mathrm{~Hz}, 1 \mathrm{H}) 3.53-3.58(\mathrm{~m}, 1 \mathrm{H}), 3.68-3.90(\mathrm{~m}, 5 \mathrm{H}) 4.05(\mathrm{~m}, 1$ H) $4.18(\mathrm{~d}, J=10.25 \mathrm{~Hz}, 1 \mathrm{H}) 4.33(\mathrm{~d}, \mathrm{~J}=7.81 \mathrm{~Hz}, 1 \mathrm{H})$

${ }^{13} \mathrm{C} N M R\left(126 \mathrm{MHz}, \mathrm{CD}_{3} \mathrm{CN}\right): \delta \mathrm{ppm} 207.1,105.2,77.9,77.6,73.3,70.5,62.3,32.5,30.3,30.0,29.9,26.6$, $23.3,14.3$

HRMS calc'd for $\left[\mathrm{C}_{14} \mathrm{H}_{26} \mathrm{O}_{6}+\mathrm{HCOO}^{-}\right.$335.1711. Found 335.17208 (ESI-).

Aerobic oxidation of 1-deoxy-1-azido- $\beta$-D-glucopyranoside (4) to 4a: $61.5 \mathrm{mg}$ of 1-deoxy-1-azido- $\beta$-Dglucopyranoside $4(0.30 \mathrm{mmol})$ was added to a solution consisting of $27.9 \mu \mathrm{L} 2,6$-diisopropylphenol and $3 \mathrm{~mL}$ acetonitrile in a $20 \mathrm{~mL}$ septum-capped vial. $1.57 \mathrm{mg}$ of [(neocuproine) $\mathrm{Pd}(\mathrm{OAc})]_{2}(\mathrm{OTf})_{2}$ was added. The vial was purged with oxygen for 45 seconds then sealed. The reaction mixture was then heated to $60{ }^{\circ} \mathrm{C}$ and stirred for 6 hours, after which another portion of $1.57 \mathrm{mg}$ [(neocuproine) $\left.\mathrm{Pd}(\mathrm{OAc})\right]_{2}(\mathrm{OTf})_{2}$ was added. The reaction mixture was purged with oxygen for another 45 seconds and was then sealed. After another 12 hours of stirring at $60^{\circ} \mathrm{C}$, the reaction mixture was concentrated, re-dissolved in a small portion of 10:1 chloroform:methanol, and loaded onto a silica column, and eluted with a gradient from 10:1 to 5:1 chloroform:methanol. Evaporation of the relevant fractions gave $36.5 \mathrm{mg} 4 \mathrm{a}(0.179 \mathrm{mmol}$, $60.0 \%$ yield) of a clear oil.

Note: basic workup results in product decomposition, presumably to the azide elimination product due to the acidity of the $\mathrm{C} 2$ proton.

${ }^{1} \mathrm{H}$ NMR $\left(400 \mathrm{MHz}, \mathrm{CD}_{3} \mathrm{CN}\right) \delta 4.64(\mathrm{~d}, \mathrm{~J}=8.5 \mathrm{~Hz}, 1 \mathrm{H}), 4.26(\mathrm{~d}, \mathrm{~J}=10.2 \mathrm{~Hz}, 1 \mathrm{H}), 4.09(\mathrm{~d}, \mathrm{~J}=9.0 \mathrm{~Hz}, 1 \mathrm{H}), 4.04$ $(d, J=5.5 \mathrm{~Hz}, 1 \mathrm{H}), 3.86(\mathrm{dd}, \mathrm{J}=12.4,2.1 \mathrm{~Hz}, 1 \mathrm{H}), 3.80(\mathrm{~s}, 1 \mathrm{H}), 3.72(\mathrm{dd}, \mathrm{J}=12.3,4.7 \mathrm{~Hz}, 1 \mathrm{H}), 3.43(\mathrm{ddd}, \mathrm{J}=$ $10.2,4.7,2.1 \mathrm{~Hz}, 1 \mathrm{H}), 3.16(\mathrm{~s}, 1 \mathrm{H})$.

${ }^{13} \mathrm{C}$ NMR $\left(101 \mathrm{MHz}, \mathrm{CD}_{3} \mathrm{CN}\right) \delta 206.26,118.41,92.70,80.52,77.21,73.00,62.11$.

HRMS calc'd for $\left[\mathrm{C}_{6} \mathrm{H}_{9} \mathrm{~N}_{3} \mathrm{O}_{5}+\mathrm{Na}\right]^{+}$226.0434. Found $226.0428(\mathrm{ESI}+)$.

Aerobic oxidation of 4-methoxyphenyl- $\beta$-D glucopyranoside (5) to $5 \mathrm{a}: 114.8 \mathrm{mg}$ of 4-methoxyphenyl- $\beta$ D glucopyranoside 5 ( $0.40 \mathrm{mmol}), 37.2 \mu \mathrm{L}$ of 2,6-diisopropylphenol were added to $4.4 \mathrm{~mL}$ of 10:1 $\mathrm{CH}_{3} \mathrm{CN}: \mathrm{H}_{2} \mathrm{O}$ in a $20 \mathrm{~mL}$ septum-capped vial. $2.08 \mathrm{mg}$ [(neocuproine) $\left.\mathrm{Pd}(\mathrm{OAc})\right]_{2}(\mathrm{OTf})_{2}(0.004 \mathrm{mmol})$ was added. After purging the vial with oxygen for 40 seconds, the reaction mixture was heated and stirred at $50{ }^{\circ} \mathrm{C}$. After 18 hours, the reaction mixture was concentrated and resuspended in acetonitrile and 1:5 hexanes:ethyl acetate, with some ethanol added to aid in dissolution. This mixture was loaded onto a silica gel column and eluted with a gradient from 1:5 hexanes:ethyl acetate to neat ethyl acetate. Evaporation of the relevant fractions gave $72.3 \mathrm{mg} 5 \mathrm{a}(0.254 \mathrm{mmol}, 63.6 \%$ yield) of a white solid. 
${ }^{1} \mathrm{H}$ NMR $\left(500 \mathrm{MHz}, \mathrm{CD}_{3} \mathrm{CN}\right) \delta 7.11-6.96(\mathrm{~m}, 2 \mathrm{H}), 6.96-6.80(\mathrm{~m}, 2 \mathrm{H}), 4.88(\mathrm{~d}, \mathrm{~J}=7.8 \mathrm{~Hz}, 1 \mathrm{H}), 4.30$ (dddd, $\mathrm{J}=16.7,10.1,4.8,1.8 \mathrm{~Hz}, 2 \mathrm{H}), 3.97(\mathrm{~d}, \mathrm{~J}=4.9 \mathrm{~Hz}, 1 \mathrm{H}), 3.87(\mathrm{dq}, \mathrm{J}=12.3,2.3 \mathrm{~Hz}, 1 \mathrm{H}), 3.82-3.65(\mathrm{~m}, 5 \mathrm{H})$, 3.43 (ddd, J = 10.1, 4.8, 2.2 Hz, 1H), 3.09 (t, J = 6.3 Hz, 1H). ${ }^{13} \mathrm{C} \mathrm{NMR}\left(126 \mathrm{MHz}, \mathrm{CD}_{3} \mathrm{CN}\right) \delta 205.76,155.72$, $151.27,118.38,114.78,103.27,77.11,76.89,72.49,61.43,55.48$.

HRMS calc'd for $\left[\mathrm{C}_{13} \mathrm{H}_{16} \mathrm{O}_{7}+\mathrm{Na}\right]^{+}$307.0788. Found $307.0786(\mathrm{ESI}+)$.

Aerobic oxidation of methyl-6-deoxy- $\alpha$-D-glucopyranoside (6) to 6a: $71.2 \mathrm{mg}$ of methyl-6-deoxy- $\alpha-\mathrm{D}-$ glucopyranoside $6(0.40 \mathrm{mmol})$ was added to a solution consisting of $37.2 \mu \mathrm{L} 2$,6-diisopropylphenol and $4 \mathrm{~mL}$ acetonitrile in a $20 \mathrm{~mL}$ septum-capped vial. $2.05 \mathrm{mg}$ of [(neocuproine) $\mathrm{Pd}(\mathrm{OAc})]_{2}(\mathrm{OTf})_{2}(0.004$ $\mathrm{mmol}$ )was added. The vial was purged with oxygen for 45 seconds then sealed. The reaction mixture was then heated to $50{ }^{\circ} \mathrm{C}$ and stirred for 4 hours, after which another portion of $2.05 \mathrm{mg}$ $[(\text { neocuproine }) \mathrm{Pd}(\mathrm{OAc})]_{2}(\mathrm{OTf})_{2}(0.004 \mathrm{mmol})$ was added. The reaction mixture was purged with oxygen for another 45 seconds and was then sealed. After another 16 hours of stirring at $50{ }^{\circ} \mathrm{C}$, the reaction mixture was concentrated, re-dissolved in a small portion of 1:3 hexanes:ethyl acetate, and loaded onto a silica column, and eluted with 1:3 hexanes:ethyl acetate. Evaporation of the relevant fractions gave $50.0 \mathrm{mg} 6 \mathrm{6a}(0.284 \mathrm{mmol}, 71.0 \%$ yield) of white flakes.

${ }^{1} \mathrm{H}$ NMR $\left(500 \mathrm{MHz}, \mathrm{CD}_{3} \mathrm{CN}\right) \delta 4.98(\mathrm{~d}, \mathrm{~J}=4.3 \mathrm{~Hz}, 1 \mathrm{H}), 4.37$ (ddd, J = 8.5, 4.4, 1.7, 1H), 3.86 (ddd, J = 9.4, $5.2,1.6 \mathrm{~Hz}, 1 \mathrm{H}), 3.66(\mathrm{dd}, \mathrm{J}=5.3,1.3 \mathrm{~Hz}, 1 \mathrm{H}), 3.62(\mathrm{dq}, \mathrm{J}=9.4,6.1 \mathrm{~Hz}, 1 \mathrm{H}), 3.54(\mathrm{dd}, \mathrm{J}=8.5,1.3 \mathrm{~Hz}, 1 \mathrm{H})$, $3.33(\mathrm{~s}, 3 \mathrm{H}), 1.36(\mathrm{dd}, \mathrm{J}=6.2,3 \mathrm{H})$.

${ }^{13} \mathrm{C}$ NMR $\left(126 \mathrm{MHz}, \mathrm{CD}_{3} \mathrm{CN}\right) \delta 206.74,103.15,78.53,75.90,72.03,55.76,18.97$

Spectral values are consistent with literature. ${ }^{3}$

Aerobic oxidation of methyl- $\alpha$-D-xylopyranoside (7) to 7a: $328 \mathrm{mg}$ of methyl- $\alpha$-D-xylopyranoside 7 ( $2.00 \mathrm{mmol}$ ) was added to a solution consisting of $186 \mu \mathrm{L}$ 2,6-diisopropylphenol and $20 \mathrm{~mL}$ acetonitrile to a $250 \mathrm{~mL}$ round bottom flask with an attached condenser. $10.4 \mathrm{mg}$ of [(neocuproine) $\mathrm{Pd}(\mathrm{OAc})]_{2}(\mathrm{OTf})_{2}$ $(0.02 \mathrm{mmol})$ was added. The vial was purged with oxygen for 45 seconds then sealed. The reaction mixture was then heated to $60^{\circ} \mathrm{C}$ and stirred for 6 hours. The reaction mixture was then concentrated to a viscous oil, re-dissolved in a small portion of ethyl acetate, and loaded onto a silica column deactivated with triethylamine. Gradient elution was performed, starting with 1:3 hexanes:ethyl acetate and ending with neat ethyl acetate. Evaporation of the relevant fractions gave $237 \mathrm{mg} 7 \mathrm{a}(1.445 \mathrm{mmol}$, $72.7 \%$ yield) of a clear oil that solidified to a white solid.

${ }^{1} \mathrm{H}$ NMR $\left(500 \mathrm{MHz}, \mathrm{CD}_{3} \mathrm{CN}\right): \delta 3.34$ (br. s., $\left.3 \mathrm{H}\right) 3.47$ (t, J=10.38 Hz, 1 H) 3.52 (dd, J=8.53 Hz, $\left.1 \mathrm{H}\right) 3.61$ (d, $J=5.72,1 \mathrm{H}) 4.02(\mathrm{dd}, J=8.05,10.2,1 \mathrm{H}) 4.34(\mathrm{~m}, 2 \mathrm{H}) 5.00(\mathrm{~d}, J=4.22,1 \mathrm{H})$ 
${ }^{13} \mathrm{C}$ NMR $\left(126 \mathrm{MHz}, \mathrm{CD}_{3} \mathrm{CN}\right): \delta 207.0,118.5,104.1,76.2,73.1,65.3,55.9$

HRMS calc'd for $\left[\mathrm{C}_{6} \mathrm{H}_{10} \mathrm{O}_{5}+\mathrm{Na}\right]^{+}$185.04204. Found 185.04151 (ESI+).

Oxidation of methyl- $\alpha$-L-fucopyranoside in acetonitrile (8) to $8 \mathrm{a}: 71.2 \mathrm{mg}$ of methyl- $\alpha$-L-fucopyranoside 8 (0.40 mmol), $64.8 \mathrm{mg}$ of 1,4-benzoquinone, and $6.3 \mathrm{mg}$ [(neocuproine)Pd(OAc) $]_{2}(\mathrm{OTf})_{2}(0.012 \mathrm{mmol})$ were added to $4 \mathrm{~mL}$ of acetonitrile. The solution was stirred for 8 hours at $50{ }^{\circ} \mathrm{C}$, and then evaporated. The crude mixture was resuspended in acetonitrile and sonicated, and was eluted through a silica gel column with 1:1 hexanes:ethyl acetate. Evaporation of the relevant fractions gave $22.3 \mathrm{mg}$ of an oil 8a that gradually solidified ( $31.6 \%$ yield).

${ }^{1} \mathrm{H}$ NMR $\left(500 \mathrm{MHz}, \mathrm{CD}_{3} \mathrm{CN}\right) \delta 4.93(\mathrm{~d}, \mathrm{~J}=4.4 \mathrm{~Hz}, 1 \mathrm{H}), 4.72(\mathrm{dd}, \mathrm{J}=8.9,4.4 \mathrm{~Hz}, 1 \mathrm{H}), 4.02(\mathrm{q}, \mathrm{J}=6.6 \mathrm{~Hz}, 1 \mathrm{H})$, $3.91-3.76(\mathrm{~m}, 2 \mathrm{H}), 3.37-3.27(\mathrm{~m}, 4 \mathrm{H}), 1.24(\mathrm{~d}, \mathrm{~J}=6.5 \mathrm{~Hz}, 3 \mathrm{H}) .{ }^{13} \mathrm{C} \mathrm{NMR}\left(126 \mathrm{MHz}, \mathrm{CD}_{3} \mathrm{CN}\right) \delta 206.71$, $103.46,77.89,73.72,69.76,55.77,15.49$.

HRMS calc'd for $\left[\mathrm{C}_{7} \mathrm{H}_{12} \mathrm{O}_{5}+\mathrm{Na}\right]^{+}$199.0577. Found $199.0576(\mathrm{ESI}+)$.

Oxidation of methyl $\alpha$-L-rhamnopyranoside (9) in acetonitrile:water to $9 \mathrm{a}: 53.4 \mathrm{mg}$ of (0.3 mmol) methyl $\alpha$-L-rhamnopyranoside 7, $38.9 \mathrm{mg}$ benzoquinone, and $1.57 \mathrm{mg}$ [(neocuproine) $\mathrm{Pd}(\mathrm{OAc})]_{2}(\mathrm{OTf})_{2}$ (.003 mmol) were added to $3 \mathrm{~mL}$ of 10:1 acetonitrile:water. The solution was stirred for 2.5 hours at 50 ${ }^{\circ} \mathrm{C}$ and then an additional $3.1 \mathrm{mg}$ [(neocuproine) $\left.\mathrm{Pd}(\mathrm{OAc})\right]_{2}(\mathrm{OTf})_{2}$ was added. After another 1.5 hours stirring, the reaction mixture was evaporated and redissolved in acetonitrile, and eluted through a silica gel column with 1:2 hexanes:ethyl acetate. Evaporation of the relevant fractions gave $33.0 \mathrm{mg}(0.188$ mmol, 62.5\%) 9 a as a clear oil.

${ }^{1} \mathrm{NMR}\left(600 \mathrm{MHz}, \mathrm{CD}_{3} \mathrm{CN}\right) \delta 4.72(\mathrm{~d}, \mathrm{~J}=1.9 \mathrm{~Hz}, 1 \mathrm{H}), 4.49(\mathrm{dd}, \mathrm{J}=5.6,3.9 \mathrm{~Hz}, 1 \mathrm{H}), 4.34(\mathrm{q}, \mathrm{J}=6.5 \mathrm{~Hz}, 1 \mathrm{H})$, $4.19(\mathrm{td}, \mathrm{J}=3.9,1.9 \mathrm{~Hz}, 1 \mathrm{H}), 3.54(\mathrm{~d}, \mathrm{~J}=5.8 \mathrm{~Hz}, 1 \mathrm{H}), 3.45(\mathrm{~s}, 3 \mathrm{H}), 3.38(\mathrm{~d}, \mathrm{~J}=3.9 \mathrm{~Hz}, 1 \mathrm{H}), 1.21(\mathrm{~d}, \mathrm{~J}=6.5$ $\mathrm{Hz}, 3 \mathrm{H})$.

${ }^{13} \mathrm{C}$ NMR $\left(126 \mathrm{MHz}, \mathrm{CD}_{3} \mathrm{CN}\right) \delta 207.97,101.44,76.27,74.59,70.40,56.02,14.01$.

HRMS calc'd for $\left[\mathrm{C}_{7} \mathrm{H}_{12} \mathrm{O}_{5}+\mathrm{Na}\right]^{+}$199.0577. Found $199.0580(\mathrm{ESI}+)$.

Oxidation of 1,6-anhydro- $\beta$-D-galactopyranoside (10) in acetonitrile to $10 \mathrm{a}: 48.6 \mathrm{mg}(0.3 \mathrm{mmol})$ of 1,6anhydro- $\beta$-D-galactopyranoside $10,39.0 \mathrm{mg}(0.36 \mathrm{mmol})$ of benzoquinone, and $4.71 \mathrm{mg}(0.009 \mathrm{mmol})$ of [(neocuproine) $\mathrm{Pd}(\mathrm{OAc})]_{2}(\mathrm{OTf})_{2}$ were added to $3 \mathrm{~mL}$ acetonitrile. The mixture was stirred for 2.5 hours at $50{ }^{\circ} \mathrm{C}$ and then evaporated and redissolved in acetonitrile. The slurry was eluted through a silica gel column using 3:1 hexanes:ethyl acetate. Evaporation of the relevant fractions gave $31.9 \mathrm{mg}(0.199$ mmol, 66.4\%) 10a as a white solid.

1H NMR (400 MHz, Acetonitrile-d3) $\delta 5.49(\mathrm{~d}, \mathrm{~J}=2.1 \mathrm{~Hz}, 1 \mathrm{H}), 4.76(\mathrm{t}, \mathrm{J}=5.1 \mathrm{~Hz}, 1 \mathrm{H}), 4.62-4.52(\mathrm{~m}, 1 \mathrm{H})$, $4.14(\mathrm{~d}, \mathrm{~J}=6.4 \mathrm{~Hz}, 1 \mathrm{H}), 3.91(\mathrm{~d}, \mathrm{~J}=4.4 \mathrm{~Hz}, 1 \mathrm{H}), 3.82(\mathrm{dd}, \mathrm{J}=6.6,2.1 \mathrm{~Hz}, 1 \mathrm{H}), 3.76(\mathrm{dd}, \mathrm{J}=8.1,0.8 \mathrm{~Hz}, 1 \mathrm{H})$, 3.62 (ddd, J = 8.1, 4.7, $1.2 \mathrm{~Hz}, 1 \mathrm{H}$ ). 


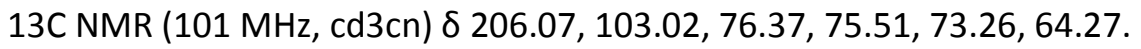

HRMS calc'd for $\left[\mathrm{C}_{6} \mathrm{H}_{8} \mathrm{O}_{5}-\mathrm{H}\right]^{-}$159.0299. Found 159.0297 (ESI-).

Oxidation of 1,6-anhydro- $\beta$-D-mannopyranoside (11) in acetonitrile to 11a: $48.6 \mathrm{mg}$ (0.3 mmol) of 1,6anhydro- $\beta$-D-mannopyranoside $9,39.0 \mathrm{mg}(0.36 \mathrm{mmol})$ of benzoquinone, and $4.71 \mathrm{mg}(0.009 \mathrm{mmol})$ of [(neocuproine) $\mathrm{Pd}(\mathrm{OAc})] 2(\mathrm{OTf}) 2$ were added to $3 \mathrm{~mL}$ acetonitrile. The mixture was stirred for 2.5 hours at $50{ }^{\circ} \mathrm{C}$ and then evaporated and redissolved in acetonitrile. The slurry was eluted through a silica gel column using 1:1 hexanes:ethyl acetate. Evaporation of the relevant fractions gave $43.5 \mathrm{mg}(0.199$ $\mathrm{mmol}, 66.4 \%) 9 \mathrm{a}$ as a clear oil that gradually converted to a white solid.

The compound was isolated as a mixture of monomeric and dimeric forms. Addition of acetonitrile to the isolated compound produced a solution containing almost exclusively monomeric product and left a white residue. Heating the white residue at $60^{\circ} \mathrm{C}$ in a monomer-containing acetonitrile solution for several hours produced a monomer/dimer mixture. Alternatively, heating the residue at $60^{\circ} \mathrm{C}$ in dimethyl sulfoxide allowed the dimer to revert to monomer.

(monomer)

${ }^{1} \mathrm{H}$ NMR $\left(500 \mathrm{MHz}, \mathrm{CD}_{3} \mathrm{CN}\right) \delta 5.55(\mathrm{~d}, \mathrm{~J}=2.3 \mathrm{~Hz}, 1 \mathrm{H}), 4.76$ (ddd, J = 5.7, 2.1, 1.2 Hz, 1H), 4.41 (dd, J = 6.3, $2.3 \mathrm{~Hz}, 1 \mathrm{H}), 4.22(\mathrm{~d}, \mathrm{~J}=6.0 \mathrm{~Hz}, 1 \mathrm{H}), 3.99(\mathrm{dd}, \mathrm{J}=5.9,2.1 \mathrm{~Hz}, 1 \mathrm{H}), 3.79(\mathrm{dd}, \mathrm{J}=8.5,5.7 \mathrm{~Hz}, 1 \mathrm{H}), 3.73(\mathrm{~d}, \mathrm{~J}=$ $6.3 \mathrm{~Hz}, 1 \mathrm{H}), 3.59$ (dd, J = 8.5, $1.3 \mathrm{~Hz}, 1 \mathrm{H})$.

${ }^{13} \mathrm{C}$ NMR $\left(126 \mathrm{MHz}, \mathrm{CD}_{3} \mathrm{CN}\right) \delta 205.36,103.72,78.30,76.63,75.96,65.49$.

1H NMR (400 MHz, d $\mathrm{d}_{6}$-DMSO) $\delta 6.22(\mathrm{~d}, \mathrm{~J}=5.5 \mathrm{~Hz}, 1 \mathrm{H}), 5.63(\mathrm{~d}, \mathrm{~J}=6.4 \mathrm{~Hz}, 1 \mathrm{H}), 5.46(\mathrm{~d}, \mathrm{~J}=2.3 \mathrm{~Hz}, 1 \mathrm{H})$, $4.68(\mathrm{dt}, \mathrm{J}=5.7,1.5 \mathrm{~Hz}, 1 \mathrm{H}), 4.25(\mathrm{dd}, \mathrm{J}=6.4,2.3 \mathrm{~Hz}, 1 \mathrm{H}), 3.82(\mathrm{dd}, \mathrm{J}=5.3,2.0 \mathrm{~Hz}, 1 \mathrm{H}), 3.65(\mathrm{dd}, \mathrm{J}=8.3$, $5.6 \mathrm{~Hz}, 1 \mathrm{H}), 3.48$ (dd, J = 8.3, $1.3 \mathrm{~Hz}, 2 \mathrm{H})$.

${ }^{13} \mathrm{C}$ NMR $\left(101 \mathrm{MHz}, \mathrm{d}_{6}-\mathrm{DMSO}\right) \delta 205.83,103.32,77.58,75.24,64.98$.

(dimer)

${ }^{1} \mathrm{H}$ NMR $\left(500 \mathrm{MHz}, \mathrm{CD}_{3} \mathrm{CN}\right) \delta 5.20(\mathrm{~d}, \mathrm{~J}=2.6 \mathrm{~Hz}, 1 \mathrm{H}), 4.51(\mathrm{~s}, 1 \mathrm{H}), 4.50(\mathrm{dt}, \mathrm{J}=1.3,6.1 \mathrm{~Hz}, 1 \mathrm{H}) 3.94(\mathrm{~d}, \mathrm{~J}=$ 1.1, 7.3 Hz, 1H), $3.86(d, J=6.5 \mathrm{~Hz}, 1 \mathrm{H}), 3.76(\mathrm{~s}, 1 \mathrm{H}) 3.65(\mathrm{dd}, \mathrm{J}=7.3,6.1 \mathrm{~Hz}, 1 \mathrm{H}) 3.61(\mathrm{dd}, \mathrm{J}=6.5,2.7 \mathrm{~Hz}$, $1 \mathrm{H})$.

${ }^{13} \mathrm{CNMR}\left(126 \mathrm{MHz}, \mathrm{CD}_{3} \mathrm{CN}\right) \delta 100.47,95.08,75.24,71.86,69.79,65.57$

HRMS calc'd for $\left[\mathrm{C}_{6} \mathrm{H}_{8} \mathrm{O}_{5}+\mathrm{Na}\right]^{+}$183.0264. Found $183.0268(\mathrm{ESI}+)$. 


\section{Determination of solvent-dependent glycoside regioselectivity, and 2D NMR characterization of axial glycoside oxidation products}

methyl- $\alpha$-D-xylopyranoside 7 (in acetonitrile:water), methyl- $\alpha$-L-rhamnopyranoside 9 , methyl- $\beta$-Darabinopyranoside 13: $0.15 \mathrm{mmol}$ of the sugar substrate, $24.3 \mathrm{mg}(0.225 \mathrm{mmol})$ benzoquinone were dissolved in $900 \mu \mathrm{L} \mathrm{CD}{ }_{3} \mathrm{CN}$ and $100 \mu \mathrm{L} \mathrm{D}_{2} \mathrm{O}$. Approximately $9.4 \mathrm{mg}(0.1 \mathrm{mmol})$ dimethylsulfone internal standard was weighed out and added to the mixture. Reaction was initiated by addition of $2.31 \mathrm{mg}$ [(neocuproine) $\mathrm{Pd}(\mathrm{OAc})]_{2}(\mathrm{OTf})$. The reaction was stirred and heated at $50^{\circ} \mathrm{C}$ for up to 5 hours (until full conversion was reached). Products were characterized via ${ }^{1} \mathrm{H},{ }^{13} \mathrm{C}, \mathrm{COSY}, \mathrm{HSQC}$, and HMBC NMR in their crude reaction mixtures.

methyl- $\alpha$-D-xylopyranoside 7 (in trifluoroethanol), methyl-6-deoxy- $\alpha$-D-glucopyranoside 6, methyl- $\alpha$-Lfucopyranoside 8 oxidations, methyl- $\alpha$-D-glucopyranoside $12: 0.1 \mathrm{mmol}$ of the sugar substrate, $16.2 \mathrm{mg}$ benzoquinone, $4.7 \mathrm{mg}(0.05 \mathrm{mmol})$ dimethylsulfone and $1.57 \mathrm{mg}$ [(neocuproine) $\mathrm{Pd}(\mathrm{OAc})]_{2}(\mathrm{OTf})_{2}$, was added to $1 \mathrm{~mL}$ 10:1 MeCN: $\mathrm{D}_{2} \mathrm{O}$ or 2,2,2-trifluoroethanol. The reaction mixture was stirred at $50{ }^{\circ} \mathrm{C}$, and heated for up to $2 \mathrm{hr}$ (until full conversion was reached). Product yields were determined by analyzing $100 \mu \mathrm{L}$ aliquots in $500 \mu \mathrm{L} \mathrm{CD}{ }_{3} \mathrm{CN}$ by NMR (unless noted otherwise).

methyl- $\alpha$-D-xylopyranoside 7 (in acetonitrile): $0.15 \mathrm{mmol}$ of the sugar substrate, $24.3 \mathrm{mg}$ (0.225 mmol) benzoquinone were dissolved in $1 \mathrm{~mL} \mathrm{CD} \mathrm{CN}_{3}$. Approximately $9.4 \mathrm{mg}(0.1 \mathrm{mmol})$ dimethylsulfone internal standard was weighed out and added to the mixture. Reaction was initiated by addition of $2.31 \mathrm{mg}$ $[(\text { neocuproine }) \mathrm{Pd}(\mathrm{OAC})]_{2}(\mathrm{OTf})$. The reaction was stirred and heated at $50{ }^{\circ} \mathrm{C}$ for 3 hours (until full conversion was reached), and then monitored by ${ }^{1} \mathrm{H}$ NMR.

1,6-anhydro- $\beta$-D-galactopyranoside 10, 1,6-anhydro- $\beta$-D-mannopyranose 11, and 1,6-anhydro- $\beta$-Dglucopyranose 14: $0.15 \mathrm{mmol}$ of the sugar substrate, $24.3 \mathrm{mg}$ benzoquinone, approximately $4.7 \mathrm{mg}$ $(0.05 \mathrm{mmol})$ dimethylsulfone and $2.31 \mathrm{mg}$ [(neocuproine) $\mathrm{Pd}(\mathrm{OAc})]_{2}(\mathrm{OTf})_{2},(0.0045)$ was added to $1.1 \mathrm{~mL}$ $\mathrm{MeCN}$ or 2,2,2-trifluoroethanol. The reaction mixture was stirred at $50{ }^{\circ} \mathrm{C}$, and full conversion was reached by $2.5 \mathrm{hr}$. Product yields were determined by analyzing $100 \mu \mathrm{L}$ aliquots in $500 \mu \mathrm{L} \mathrm{CD}_{3} \mathrm{CN}$ by NMR (unless noted otherwise).

2-deoxy-2-acetamido- $\beta$-d-glucopyranosyl azide $17: 0.05 \mathrm{mmol}$ of the sugar substrate, $8.1 \mathrm{mg}$ benzoquinone, $4.7 \mathrm{mg}$ dimethylsulfone, and $1.3 \mathrm{mg}(0.0025 \mathrm{mmol} \mathrm{Pd})$ was added to $0.5 \mathrm{~mL} 2,2,2-$ trifluoroethanol. The reaction mixture was stirred at $50{ }^{\circ} \mathrm{C}$. Product yields were determined by analyzing 50-100 $\mu \mathrm{L}$ aliquots in $500 \mu \mathrm{L} \mathrm{CD} \mathrm{CDN}_{3}$ by NMR.

Control experiments reveal that the oxidation of 7 with with benzoquinone in $\mathrm{CD}_{3} \mathrm{CN}$ occurs with similar selectivity to that in $\mathrm{CD}_{3} \mathrm{CN} / \mathrm{D}_{2} \mathrm{O}$; moreover, the aerobic oxidation of 7 with di-isopropylphenol $(0.05$ $\mathrm{mmol}$ ) according to the protocol of Table 1 yielded a similar mixture (74/15) mixture of 3- and 4-ketoses respectively (Table S2, Supporting Information). 
Table S1. Chemoselectivities for oxidation of glycosides in acetonitrile ${ }^{a}$

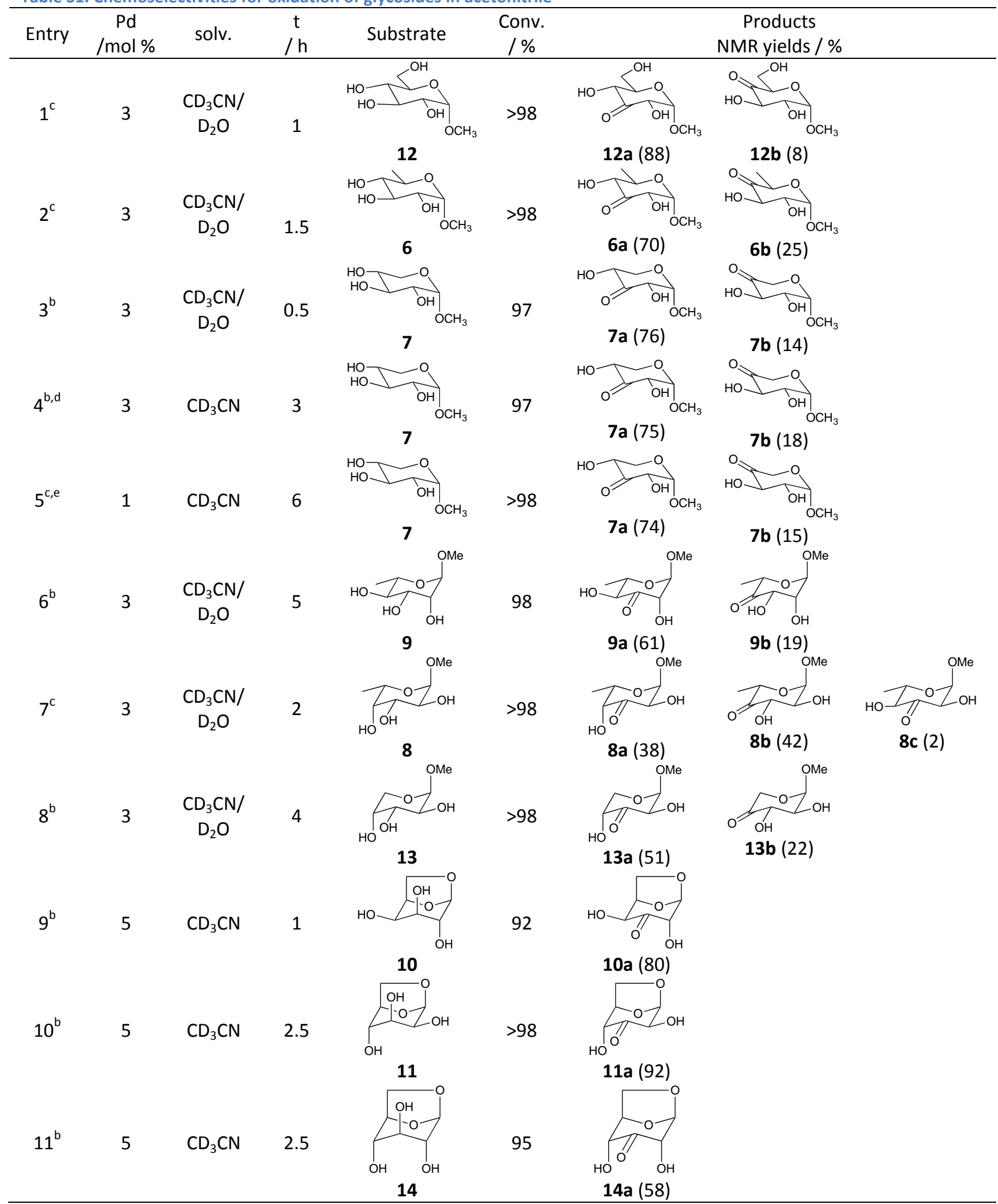

\footnotetext{
${ }^{a}$ Reactions carried out at $50^{\circ} \mathrm{C}$ in $\mathrm{CD}_{3} \mathrm{CN}: \mathrm{D}_{2} \mathrm{O} 10: 1$, with 1.5 equiv. benzoquinone (vs. substrate), with dimethylsulfone as internal standard ${ }^{b} 0.15 \mathrm{mmol}$ scale, ${ }^{\mathrm{c}} 0.10 \mathrm{mmol}$ scale ${ }^{\mathrm{d}}$ neat $\mathrm{CD}_{3} \mathrm{CN}$ solvent ${ }^{\mathrm{e}} 1 \mathrm{~mol} \%$ $\mathrm{Pd}$ with $1 \mathrm{~atm} \mathrm{O}_{2}$ and $0.05 \mathrm{mmol}$ 2,6-di-isopropylphenol
} 
Table S2. Chemoselectivities for oxidation of glycosides in fluorinated alcohol solvents ${ }^{a}$

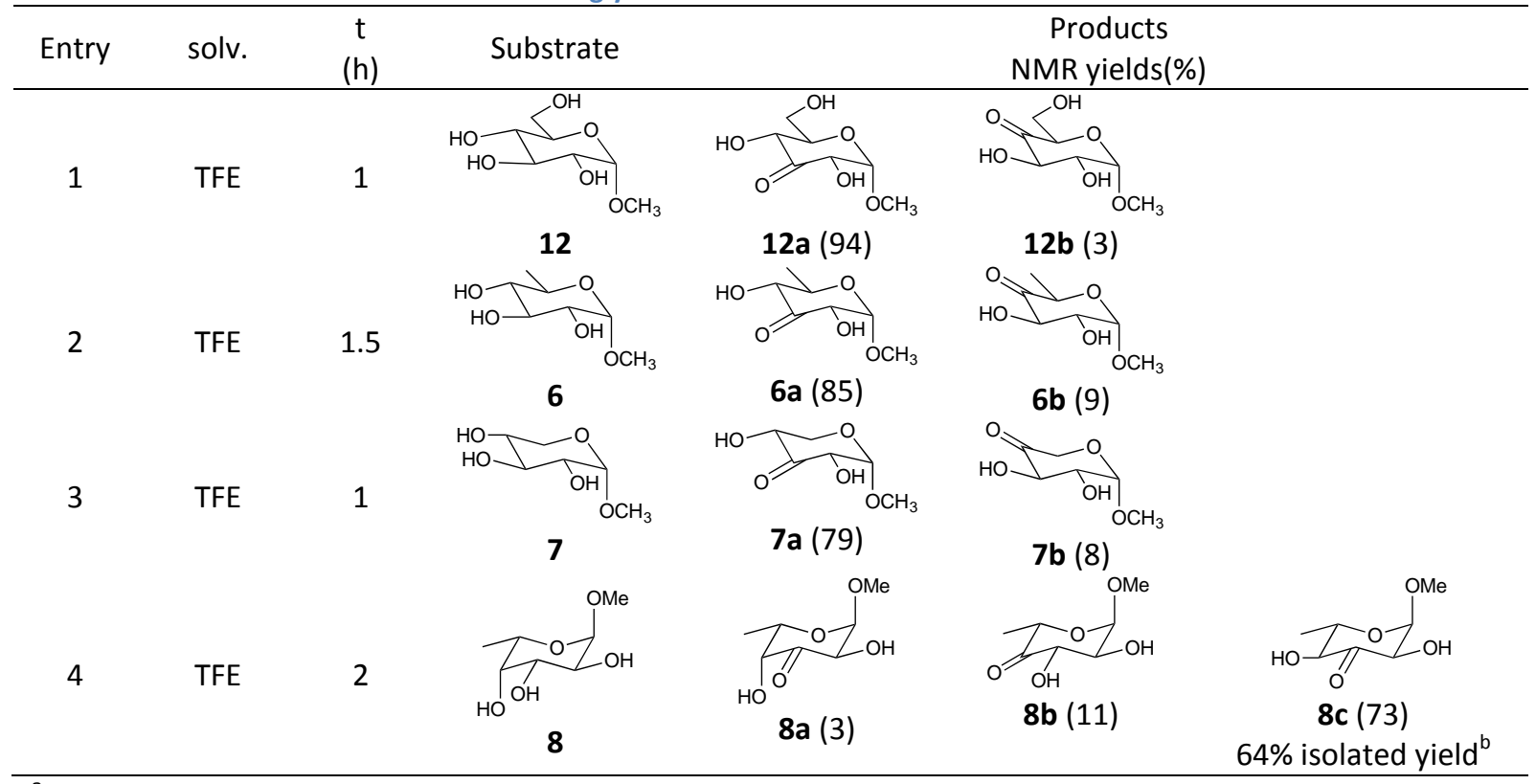

${ }^{\mathrm{a}}$ Reactions carried out at $50^{\circ} \mathrm{C}$ in TFE with $0.1 \mathrm{mmol}$ substrate, at 3 mol\% Pd with 1.5 equiv. benzoquinone (vs. substrate), with dimethylsulfone as internal standard.

Preparative scale oxidation reactions of glycosides and sugar alcohols in fluorinated solvents

Oxidation of methyl-6-deoxy- $\alpha$-D-glucopyranoside (6) to 6 a in 2,2,2-trifluoroethanol: $71.2 \mathrm{mg}$ of methyl-6-deoxy- $\alpha$-D-glucopyranoside $6(0.4 \mathrm{mmol})$ was added to a solution consisting of $48.0 \mathrm{mg}$ benzoquinone ( $0.44 \mathrm{mmol}, 1.1 \mathrm{eq}$ ) and $4 \mathrm{~mL} \mathrm{2,2,2-trifluoroethanol} \mathrm{in} \mathrm{a} 20 \mathrm{~mL}$ septum-capped vial. 6.26 $\mathrm{mg}$ of [(neocuproine) $\mathrm{Pd}(\mathrm{OAc})]_{2}(\mathrm{OTf})_{2}(0.012 \mathrm{mmol})$ was added. The reaction mixture was then heated to $50{ }^{\circ} \mathrm{C}$ and stirred for 2 hours, after which the reaction mixture was concentrated, re-dissolved in a small portion of 1:3 hexanes:ethyl acetate, and loaded onto a silica column, and eluted with a gradient from 1:1 to 1:3 hexanes:ethyl acetate. Evaporation of the relevant fractions gave $59.8 \mathrm{mg} 6 \mathbf{6 a}(0.339 \mathrm{mmol}$, $84.9 \%$ yield) as white flakes.

${ }^{1} \mathrm{H}$ NMR $\left(500 \mathrm{MHz}, \mathrm{CD}_{3} \mathrm{CN}\right) \delta 4.98(\mathrm{~d}, \mathrm{~J}=4.3 \mathrm{~Hz}, 1 \mathrm{H}), 4.37$ (ddd, J = 8.5, 4.4, 1.7, 1H), 3.86 (ddd, J = 9.4, $5.2,1.6 \mathrm{~Hz}, 1 \mathrm{H}), 3.66(\mathrm{dd}, \mathrm{J}=5.3,1.3 \mathrm{~Hz}, 1 \mathrm{H}), 3.62(\mathrm{dq}, \mathrm{J}=9.4,6.1 \mathrm{~Hz}, 1 \mathrm{H}), 3.54(\mathrm{dd}, \mathrm{J}=8.5,1.3 \mathrm{~Hz}, 1 \mathrm{H})$, $3.33(\mathrm{~s}, 3 \mathrm{H}), 1.36(\mathrm{dd}, \mathrm{J}=6.2,3 \mathrm{H})$.

${ }^{13} \mathrm{C}$ NMR $\left(126 \mathrm{MHz}, \mathrm{CD}_{3} \mathrm{CN}\right) \delta 206.74,103.15,78.53,75.90,72.03,55.76,18.97$

Oxidation of methyl- $\alpha$-D-galactopyranoside (19) to 12a in 2,2,2-trifluoroethanol: $64.3 \mathrm{mg}$ of methyl- $\alpha$ D-galactopyranoside 20 (monohydrate form) $(0.30 \mathrm{mmol}), 48.6 \mathrm{mg}$ of 1,4-benzoquinone, and $1.57 \mathrm{mg}$ [(neocuproine) $\mathrm{Pd}(\mathrm{OAc})]_{2}(\mathrm{OTf})_{2}(0.003 \mathrm{mmol})$ were added to $3 \mathrm{~mL}$ of 2,2,2-trifluoroethanol. The solution was stirred for 2 hours at $50{ }^{\circ} \mathrm{C}$, and then evaporated. The crude mixture was resuspended in neat ethyl 
acetate and sonicated, and was eluted through a silica gel column deactivated with triethylamine with neat ethyl acetate eluent. Evaporation of the relevant fractions gave $40.3 \mathrm{mg} 12 \mathrm{a}$ as a clear oil (0.209 $\mathrm{mmol}, 69.7 \%$ yield).

${ }^{1} \mathrm{H}$ NMR $\left(400 \mathrm{MHz}, \mathrm{CD}_{3} \mathrm{CN}\right) \delta 5.04(\mathrm{dd}, \mathrm{J}=4.3,0.6 \mathrm{~Hz}, 1 \mathrm{H}), 4.36$ (ddd, J = 8.4, 4.3, $1.6 \mathrm{~Hz}, 1 \mathrm{H}$ ), 4.22 (ddd, J $=9.7,5.3,1.6 \mathrm{~Hz}, 1 \mathrm{H}), 3.79$ (ddd, J = 12.2, 5.5, $2.3 \mathrm{~Hz}, 1 \mathrm{H}), 3.66-3.78(\mathrm{~m}, 2 \mathrm{H}), 3.58(\mathrm{~d}, \mathrm{~J}=8.4 \mathrm{~Hz}, 1 \mathrm{H}), 3.54$ (dddd, J = 9.7, 4.5, 2.3, 0.6 Hz, $1 \mathrm{H}), 3.34(\mathrm{~s}, 3 \mathrm{H}), 3.02(\mathrm{dd}, \mathrm{J}=6.0$ )

${ }^{13} \mathrm{C}$ NMR $\left(101 \mathrm{MHz}, \mathrm{CD}_{3} \mathrm{CN}\right) \delta 207.28,103.36,76.55,75.82,73.09,62.21,55.78$

1H NMR (400 MHz, DMSO-d 6 ) $\delta 5.40(d, J=6.3 \mathrm{~Hz}, 1 \mathrm{H}), 5.27$ (d, J = 7.5 Hz, 1H), $4.94(\mathrm{~d}, \mathrm{~J}=4.2 \mathrm{~Hz}, 1 \mathrm{H})$, $4.85(t, J=6.0 \mathrm{~Hz}, 1 \mathrm{H}), 4.28$ (ddd, J = 7.5, 4.2, $1.6 \mathrm{~Hz}, 1 \mathrm{H}), 4.07(\mathrm{dd}, \mathrm{J}=9.8,6.0 \mathrm{~Hz}, 1 \mathrm{H}), 3.74-3.45(\mathrm{~m}$, $3 \mathrm{H}), 3.26(\mathrm{~s}, 3 \mathrm{H})$.

${ }^{13} \mathrm{C}$ NMR $\left(101 \mathrm{MHz}, \mathrm{DMSO}-\mathrm{d}_{6}\right) \delta 206.26,102.22,75.43,74.68,71.97,60.75,54.52$.

Spectral values are consistent with literature ${ }^{4}$.

Oxidation of methyl- $\alpha$-L-fucopyranoside (8) to $8 \mathrm{c}$ in 2,2,2-trifluoroethanol: $300 \mathrm{mg}$ of 8 (1.7 mmol), $230 \mathrm{mg}$ of 1,4-benzoquinone, and $26.3 \mathrm{mg}$ [(neocuproine) $\mathrm{Pd}(\mathrm{OAc})]_{2}(\mathrm{OTf})_{2}(0.05 \mathrm{mmol})$ were added to 15 $\mathrm{mL}$ of 2,2,2-trifluoroethanol. The solution was stirred for 14 hours at $50^{\circ} \mathrm{C}$, and then evaporated. The crude mixture was resuspended in acetonitrile and was sonicated for 30 minutes, and was eluted through a silica gel column with a gradient from 1:1 hexanes:ethyl acetate to 1:3 hexanes:ethyl acetate. Evaporation of the relevant fractions gave $187.3 \mathrm{mg} 8 \mathrm{c}$ as a crystalline solid ( $63 \%$ yield).

1H NMR (500 MHz, CD 3 CN) $\delta 4.98(d, J=4.4 \mathrm{~Hz}, 1 \mathrm{H}), 4.37$ (ddd, J = 8.5, 4.4, $1.6 \mathrm{~Hz}, 1 \mathrm{H}$ ), 3.86 (ddd, J = 9.4, 5.2, 1.6 Hz, 1H), $3.66(d, J=5.2 \mathrm{~Hz}, 1 \mathrm{H}), 3.61(\mathrm{dq}, \mathrm{J}=9.4,6.21 \mathrm{H}), 3.54(\mathrm{~d}, \mathrm{~J}=8.5 \mathrm{~Hz}, 1 \mathrm{H}), 3.33(\mathrm{~s}, 3 \mathrm{H})$, $1.36(\mathrm{~d}, \mathrm{~J}=6.2 \mathrm{~Hz}, 4 \mathrm{H})$.

${ }^{13} \mathrm{C}$ NMR $\left(126 \mathrm{MHz}, \mathrm{CD}_{3} \mathrm{CN}\right) \delta 206.73,103.16,78.53,75.91,72.03,55.76,18.97$.

1H NMR (400 MHz, CD 30 D) $\delta 4.97(d, J=4.4 \mathrm{~Hz}, 1 \mathrm{H}), 4.40$ (dd, J = 4.3, $1.5 \mathrm{~Hz}, 1 \mathrm{H}), 3.87$ (dd, J = 9.4, 1.5 $\mathrm{Hz}, 1 \mathrm{H}), 3.70(\mathrm{dq}, \mathrm{J}=9.4,6.1 \mathrm{~Hz}, 1 \mathrm{H}), 3.37(\mathrm{~d}, \mathrm{~J}=1.3 \mathrm{~Hz}, 2 \mathrm{H}), 3.37(\mathrm{~s}, 3 \mathrm{H}), 1.38(\mathrm{~d}, \mathrm{~J}=6.1 \mathrm{~Hz}, 2 \mathrm{H})$.

${ }^{13} \mathrm{C}$ NMR $\left(101 \mathrm{MHz}, \mathrm{CD}_{3} \mathrm{OD}\right) \delta 206.96,104.11,79.35,76.62,72.52,56.17,19.43$.

Spectral values are consistent with literature. ${ }^{3}$

Hydroxylamine addition to methyl 3-keto-6-deoxy- $\alpha$-L-glucopyranoside (8c): $41.7 \mathrm{mg}$ (0.6 mmol) hydroxylamine hydrochloride and $49.2 \mathrm{mg}(0.6 \mathrm{mmol})$ of sodium acetate in $1 \mathrm{~mL}$ water was heated to 50 ${ }^{\circ} \mathrm{C}$. $35.2 \mathrm{mg}$ of methyl 3-keto-6-deoxy- $\alpha$-L-glucopyranoside (8c) $(0.2 \mathrm{mmol})$, dissolved in $1 \mathrm{~mL}$ of ethanol, was then added. The mixture was then stirred and heated for $2 \mathrm{hr}$ at $80^{\circ} \mathrm{C}$, and was then stirred at room 
temperature overnight. The solvent was evaporated and $2 \mathrm{~mL}$ of acetonitrile was added to the resulting solid residue. The resulting cloudy solution was then filtered, and the filtrate was evaporated and eluted through a silica gel column deactivated by trimethylamine with 1:3 hexanes:ethyl acetate. Evaporation of the relevant fractions gave $30.5 \mathrm{mg}(0.159 \mathrm{mmol}, 79.8 \%$ yield) $\mathbf{8 d}$ as a clear oil.

${ }^{1} \mathrm{H}-\mathrm{NMR}\left(600 \mathrm{MHz}, \mathrm{CD}_{3} \mathrm{CN}\right) \delta 4.69(\mathrm{~d}, \mathrm{~J}=3.7 \mathrm{~Hz}, 1 \mathrm{H}), 4.15(\mathrm{~d}, \mathrm{~J}=3.7 \mathrm{~Hz}, 1 \mathrm{H}), 4.14(\mathrm{~d}, \mathrm{~J}=8.7 \mathrm{~Hz}, 0.74 \mathrm{H})$, $3.88(\mathrm{dq}, \mathrm{J}=8.6,6.3 \mathrm{~Hz}, 1 \mathrm{H}), 3.40(\mathrm{~s}, 3 \mathrm{H}), 1.21(\mathrm{~d}, \mathrm{~J}=6.3 \mathrm{~Hz}, 3 \mathrm{H})$.

$4.66(d, J=3.6 \mathrm{~Hz}, 0.74 \mathrm{H}), 4.52(\mathrm{~d}, \mathrm{~J}=3.6 \mathrm{~Hz}, 0.74 \mathrm{H}), 3.65(\mathrm{~d}, \mathrm{~J}=8.7 \mathrm{~Hz}, 0.74 \mathrm{H}), 3.57(\mathrm{dq}, \mathrm{J}=8.8,6.2 \mathrm{~Hz}$, $0.74 \mathrm{H}), 3.38(\mathrm{~s}, 2.2 \mathrm{H}), 1.24(\mathrm{~d}, \mathrm{~J}=6.2 \mathrm{~Hz}, 2.2 \mathrm{H})$

${ }^{13} \mathrm{C}$ NMR $\left(101 \mathrm{MHz}, \mathrm{CD}_{3} \mathrm{CN}\right) \delta$ 154.85, 153.73, 101.27, 100.05, 74.34, 73.50, 73.30, 72.13, 70.68, 70.60, $55.68,55.66,18.44,18.14,17.93$

HRMS calc'd for $\left[\mathrm{C}_{7} \mathrm{H}_{12} \mathrm{O}_{5}+\mathrm{Na}\right]^{+} 214.0686$. Found $214.0690(\mathrm{ESI}+)$.

Methoxyamine addition to methyl 3-keto-6-deoxy- $\alpha$-L-glucopyranoside (8c). $35.2 \mathrm{mg}$ of methyl 3-keto6-deoxy- $\alpha$-L-glucopyranoside $(0.2 \mathrm{mmol}), 25.0 \mathrm{mg}(0.300 \mathrm{mmol})$ hydroxylamine hydrochloride, and 25.0 $\mathrm{mg}(0.297 \mathrm{mmol})$ of sodium bicarbonate were dissolved in $1.52 \mathrm{~mL}$ of methanol. The mixture was then stirred and heated for $2 \mathrm{hr}$ at $70^{\circ} \mathrm{C}$. The mixture was then filtered. Evaporation of the filtrate gave a solid residue, to which $2 \mathrm{~mL}$ of hot ethyl acetate was added. The cloudy ethyl acetate solution was filtered. After another trituration, the ethyl acetate fractions were evaporated and eluted through a silica gel column deactivated by trimethylamine with 1:2 hexanes:ethyl acetate. Evaporation of the relevant fractions gave $34.4 \mathrm{mg}(0.168 \mathrm{mmol}, 83.9 \%)$ yield $8 \mathrm{e}$ as a clear oil.

Spectra of the $E / Z$ mixture of isomers are provided.

HRMS calc'd for $\left[\mathrm{C}_{7} \mathrm{H}_{12} \mathrm{O}_{5}+\mathrm{Na}\right]^{+} 228.0842$. Found $228.0842(\mathrm{ESI}+)$.

Hydrogenation of E/Z-methyl-3-O-methyloxime-6-deoxy- $\alpha$-L-glucopyranoside (8e): $30 \mathrm{mg}$ of E/Zmethyl-3-O-methyloxime-6-deoxy- $\alpha$-L-glucopyranoside $(0.148 \mathrm{mmol})$, and $3.39 \mathrm{mg}$ of $\mathrm{PtO}_{2}$ was dissolved in $1 \mathrm{~mL}$ acetic acid. The solution was stirred and hydrogenated for $25 \mathrm{hr}$ at 5 bar. The solution was diluted with approximately $1 \mathrm{~mL}$ of ethyl acetate, and was eluted through a short celite column (the celite was pre-washed with 2 portions of $1 \mathrm{~mL}$ 1:1 acetic acid:ethyl acetate). Evaporation of the ethyl acetate solution yielded $34.0 \mathrm{mg}(0.143 \mathrm{mmol}, 98.3 \%$ yield) $8 \mathrm{f}$ as a clear oil.

1H NMR (600 MHz, CD $\left.{ }_{3} \mathrm{CN}\right) \delta 4.66(\mathrm{~d}, \mathrm{~J}=3.5 \mathrm{~Hz}, 1 \mathrm{H}), 3.83(\mathrm{t}, \mathrm{J}=3.9 \mathrm{~Hz}, 1 \mathrm{H}), 3.62(\mathrm{~m}, 2 \mathrm{H}), 3.49(\mathrm{~d}, \mathrm{~J}=4.0$ $\mathrm{Hz}, 1 \mathrm{H}), 3.47(\mathrm{~s}, 3 \mathrm{H}), 3.35(\mathrm{~s}, 3 \mathrm{H}), 1.84(\mathrm{~s}, 3 \mathrm{H}), 1.22(\mathrm{~d}, \mathrm{~J}=6.1 \mathrm{~Hz}, 3 \mathrm{H})$

${ }^{13} \mathrm{C} \mathrm{NMR}\left(101 \mathrm{MHz}, \mathrm{CD}_{3} \mathrm{CN}\right) \delta 177.82,100.61,70.31,67.05,63.85,56.02,55.80,23.50,18.17$.

HRMS calc'd for $\left[\mathrm{C}_{7} \mathrm{H}_{15} \mathrm{NO}_{4}+\mathrm{H}\right]^{+}$178.1074. Found 178.1069 
Peracetylation of methyl-3-amino-6-deoxy- $\alpha$-L-glucopyranoside (8f): $34.0 \mathrm{mg}(0.135 \mathrm{mmol})$ of methyl3-amino-6-deoxy- $\alpha$-L-glucopyranoside was dissolved in $325 \mu \mathrm{L}$ of pyridine. $100 \mu \mathrm{L}$ of acetic anhydride was added, and the solution was stirred at room temperature for 8 hours. $1 \mathrm{~mL}$ of toluene was added and the mixture was evaporated. The residue was redissolved in $1 \mathrm{~mL}$ 1:3 hexanes:ethyl acetate and eluted through a silica gel column with a gradient from 1:3 hexanes:ethyl acetate to neat ethyl acetate. Evaporation of the relevant fractions gave $35.9 \mathrm{mg}(0.118 \mathrm{mmol}, 82.5 \%$ yield, $70.2 \%$ from methoxyamine) $8 \mathrm{~g}$ as a clear oil.

1H NMR (500 MHz, CD $\left.{ }_{3} \mathrm{CN}\right) \delta 6.87$ (d, J =9.5 Hz), 4.86 (dd, J = 4.6, 3.6 Hz, 2H), $4.84-4.77(\mathrm{~m}, 2 \mathrm{H}), 4.53$ (dd, J = 10.4, 4.0, 1H), $3.97(\mathrm{dq}, \mathrm{J}=10.4,6.3 \mathrm{~Hz}, 1 \mathrm{H}), 3.46(\mathrm{~s}, 3 \mathrm{H}), 2.04(\mathrm{~s}, 3 \mathrm{H}), 1.96(\mathrm{~s}, 3 \mathrm{H}), 1.95(\mathrm{~s}, 3 \mathrm{H})$, $1.21(\mathrm{~d}, \mathrm{~J}=6.3 \mathrm{~Hz}, 3 \mathrm{H})$.

${ }^{13} \mathrm{C} \mathrm{NMR}\left(126 \mathrm{MHz}, \mathrm{CD}_{3} \mathrm{CN}\right) \delta 171.45,170.75,170.65,98.39,72.80,68.19,62.25,55.94,47.88,23.39$, 21.05, 21.01, 17.34.

HRMS for $\left[\mathrm{C}_{13} \mathrm{H}_{21} \mathrm{NO}_{7}+\mathrm{Na}\right]$ 326.1210 Found 326.1216

Oxidation of 2-acetamido-2-deoxy- $\alpha$-D-glucopyranose (16) to 16a in 2,2,2-trifluoroethanol: $70.5 \mathrm{mg} 2$ acetamido-2-deoxy- $\alpha$-D-glucopyranose $16(0.3 \mathrm{mmol}), 48.8 \mathrm{mg}$ benzoquinone $(0.258 \mathrm{mmol})$, and $4.7 \mathrm{mg}$ [(neocuproine) $\mathrm{Pd}(\mathrm{OAc})]_{2}(\mathrm{OTf})_{2}(0.09 \mathrm{mmol})$ were added to $3 \mathrm{~mL}$ of 2,2,2-trifluorothanol. The solution was stirred for 3.5 hours at $60^{\circ} \mathrm{C}$, and then evaporated. The crude mixture was resuspended in acetonitrile and 10:1 ethyl acetate:ethanol, and was eluted through a silica gel column with 10:1 ethyl acetate:ethanol. Evaporation of the relevant fractions gave $44.2 \mathrm{mg}(0.190 \mathrm{mmol}, 63.2 \%) 16 \mathrm{a}$ as white flakes.

${ }^{1} \mathrm{H}-\mathrm{NMR}\left(400 \mathrm{MHz}\right.$, DMSO-d $\left.\mathrm{d}_{6}\right) 8.06(\mathrm{~d}, \mathrm{~J}=8.2 \mathrm{~Hz}, 1 \mathrm{H}), 5.53(\mathrm{~s}, 1 \mathrm{H}), 4.97(\mathrm{~d}, \mathrm{~J}=4.0 \mathrm{~Hz}, 1 \mathrm{H}), 4.76$ (ddd, J = 8.2, 4.0, $1.3 \mathrm{~Hz}, 1 \mathrm{H}), 4.17(\mathrm{~d}, \mathrm{~J}=9.7 \mathrm{~Hz}, 1 \mathrm{H}), 3.77-3.49(\mathrm{~m}, 3 \mathrm{H}), 3.26(\mathrm{~s}, 3 \mathrm{H}), 1.91(\mathrm{~s}, 3 \mathrm{H})$.

${ }^{13} \mathrm{C}$ NMR (126 MHz, DMSO) $\delta$ 203.10, 169.76, 100.58, 75.65, 72.27, 60.69, 58.60, 54.53, 22.30.

Spectra are consistent with literature. ${ }^{4}$

Oxidation of 2-acetamido-2-deoxy- $\boldsymbol{\beta}$-D-glucopyranose (17) to 17a in 2,2,2-trifluoroethanol: $70.5 \mathrm{mg}$ of 2-acetamido-2-deoxy- $\beta$-D-glucopyranose $17(0.3 \mathrm{mmol}), 48.8 \mathrm{mg}$ benzoquinone $(0.45 \mathrm{mmol})$, and $7.1 \mathrm{mg}$ [(neocuproine $) \mathrm{Pd}(\mathrm{OAc})]_{2}(\mathrm{OTf})_{2}(0.014 \mathrm{mmol})$ were added to $3 \mathrm{~mL}$ of 2,2,2-trifluorothanol. The solution was stirred for 5.5 hours at $60^{\circ} \mathrm{C}$, and then evaporated. The crude mixture was resuspended in acetonitrile, and was eluted through a silica gel column with 10:1 ethyl acetate:ethanol. Evaporation of the relevant fractions gave $48.8 \mathrm{mg}(0.209 \mathrm{mmol}, 69.3 \%) 17$ a as an oil that gradually solidified to white flakes. 
Note: while this compound is stable in acetonitrile solution, it converts to a solid only sparingly insoluble in acetonitrile upon standing for an extended period of time. However, if the product can be dissolved in acetonitrile quickly after evaporation of silica gel chromatography fractions, quite pure product can be obtained.

${ }^{1} \mathrm{H}$ NMR $\left(600 \mathrm{MHz}, \mathrm{CD}_{3} \mathrm{CN}\right) \delta 6.66(\mathrm{~d}, J=8.5 \mathrm{~Hz}, 1 \mathrm{H}), 4.51(\mathrm{td}, J=8.4,1.4 \mathrm{~Hz}, 1 \mathrm{H}), 4.45(\mathrm{~d}, J=8.4 \mathrm{~Hz}, 1 \mathrm{H})$, 4.18 (ddd, $J=10.2,4.5,1.4 \mathrm{~Hz}, 1 \mathrm{H}$ ), 3.85 (ddd, $J=12.2,6.2,2.4 \mathrm{~Hz}, 1 \mathrm{H}$ ), 3.72 (ddd, $J=12.0,6.7,5.0 \mathrm{~Hz}$, $1 \mathrm{H}), 3.66(\mathrm{~d}, J=4.6 \mathrm{~Hz}, 1 \mathrm{H}$ ), $3.49(\mathrm{~s}, 3 \mathrm{H}$ ), 3.32 (ddd, $J=10.2,5.0,2.3 \mathrm{~Hz}, 1 \mathrm{H}), 3.00(\mathrm{t}, J=6.5 \mathrm{~Hz}, 1 \mathrm{H})$. The acetate methyl singlet is likely overlapped by the $\mathrm{CD}_{3} \mathrm{CN}$ solvent peak - the methyl signal shows up quite clearly in the ${ }^{13} \mathrm{C} N M R$.

${ }^{13} \mathrm{C}$ NMR $\left(126 \mathrm{MHz}, \mathrm{CD}_{3} \mathrm{CN}\right) \delta$ 204.19, 170.82, 104.11, 77.46, 73.73, 62.41, 61.52, 57.09, 22.86.

HRMS calc'd for $\left[\mathrm{C}_{9} \mathrm{H}_{15} \mathrm{NO}_{6}+\mathrm{Na}\right]^{+}$256.0792. Found $256.0794(\mathrm{ESI}+)$.

Peracetylation of 3-keto-2-acetamido-2-deoxy- $\beta$-D-glucopyranose (17): $70.5 \mathrm{mg}$ of 2-acetamido-2deoxy- $\beta$-D-glucopyranose $17(0.3 \mathrm{mmol}), 48.8 \mathrm{mg}$ benzoquinone $(0.45 \mathrm{mmol})$, and $7.1 \mathrm{mg}$ [(neocuproine $) \mathrm{Pd}(\mathrm{OAc})]_{2}(\mathrm{OTf})_{2}(0.014 \mathrm{mmol})$ were added to $3 \mathrm{~mL}$ of 2,2,2-trifluorothanol. The solution was stirred for 12 hours at $60^{\circ} \mathrm{C}$, after which $3 \mathrm{~mL}$ of pyridine was added. The solvent was then evaporated partially in vacuo to remove the 2,2,2-trifluoroethanol. During the evaporation, the vial was agitated periodically so that solid would not deposit on the sides of the vial. $1 \mathrm{~mL}$ of acetic anhydride was then added and the reaction mixture was stirred for two hours, after which $3 \mathrm{~mL}$ of toluene was added. The solvent was evaporated, and the resulting material was redissolved in ethyl acetate and eluted through a silica gel column twice, first with a gradient from neat ethyl acetate to 10:1 ethyl acetate:ethanol, then with 20:1 ethyl acetate:ethanol. Evaporation of the relevant fractions gave 35.2 $\mathrm{mg}(0.124 \mathrm{mmol}, 36.7 \%$ yield $)$ of a clear oil that gradually solidified to a grey solid.

${ }^{1} \mathrm{H}$ NMR (400 MHz, CD $\mathrm{CN}$ ) $\delta 6.72(\mathrm{~d}, \mathrm{~J}=8.3 \mathrm{~Hz}, 1 \mathrm{H}), 5.25(\mathrm{dd}, \mathrm{J}=10.6,1.1 \mathrm{~Hz}, 1 \mathrm{H}), 4.58(\mathrm{~d}, \mathrm{~J}=8.3 \mathrm{~Hz}$, $1 \mathrm{H}), 4.49(\mathrm{td}, \mathrm{J}=8.3,1.1 \mathrm{~Hz}, 1 \mathrm{H}), 4.37-4.26(\mathrm{~m}, 2 \mathrm{H}), 3.92(\mathrm{ddd}, \mathrm{J}=10.6,4.4,2.5 \mathrm{~Hz}, 1 \mathrm{H}), 3.48(\mathrm{~s}, 3 \mathrm{H})$, $2.09(\mathrm{~s}, 3 \mathrm{H}), 2.04(\mathrm{~s}, 3 \mathrm{H}), 1.93(\mathrm{~s}, 3 \mathrm{H})$.

${ }^{13} \mathrm{C}$ NMR $\left(100 \mathrm{MHz}, \mathrm{CD}_{3} \mathrm{CN}\right) \delta$ 197.73, 171.39, 171.01, 170.12, 103.70, 73.75, 72.14, 63.13, 62.23, 57.39, $22.83,20.93,20.65$.

HRMS calc'd for $\left[\mathrm{C}_{13} \mathrm{H}_{19} \mathrm{NO}_{8}+\mathrm{Na}\right]^{+}$340.1003. Found $340.1002(\mathrm{ESI}+)$.

Oxidation of 2-deoxy-2-acetamido- $\beta$-D-glucopyranosyl azide (18) to 18a: $49.2 \mathrm{mg}$ of 2-deoxy-2acetamido- $\beta$-D-glucopyranosyl azide $18(0.2 \mathrm{mmol}), 32.4 \mathrm{mg}$ benzoquinone $(0.3 \mathrm{mmol})$, and $5.22 \mathrm{mg}$ [(neocuproine $) \mathrm{Pd}(\mathrm{OAc})]_{2}(\mathrm{OTf})_{2}(0.01 \mathrm{mmol})$ was added to $2 \mathrm{~mL}$ trifluoroethanol. The solution was stirred for $2.5 \mathrm{hr}$ at $50{ }^{\circ} \mathrm{C}$. The solvent was then evaporated, redissolved in acetonitrile, and eluted through a silica gel column using 10:1 ethyl acetate:ethanol. Evaporation of the relevant fractions gave $24.5 \mathrm{mg}$ ( $0.1 \mathrm{mmol}, 50.0 \%$ yield) $18 \mathrm{a}$ as a white solid. By NMR, the product is $88 \%$ pure, with the remainder characterized as the azide elimination product. Fractions containing pure elimination product $\mathbf{1 8 b}$ were also obtained and evaporated, and spectra are provided. 
Oxidation product (18a)

${ }^{1} \mathrm{H} N M R\left(400 \mathrm{MHz}, \mathrm{CD}_{3} \mathrm{CN}\right) \delta 6.84(\mathrm{~d}, \mathrm{~J}=8.5 \mathrm{~Hz}, 1 \mathrm{H}), 4.72(\mathrm{~d}, \mathrm{~J}=9.1 \mathrm{~Hz}, 1 \mathrm{H}), 4.63(\mathrm{td}, \mathrm{J}=8.9,1.4 \mathrm{~Hz}, 1 \mathrm{H})$, 4.29 (dd, J = 10.5, 3.0 Hz, 1H), $3.98-3.65(\mathrm{~m}, 4 \mathrm{H}), 3.51$ (ddd, J = 10.2, 4.7, $2.2 \mathrm{~Hz}, 1 \mathrm{H}), 3.19(\mathrm{~s}, 1 \mathrm{H}), 1.99$ (s, 3H).

${ }^{13} \mathrm{C}$ NMR $\left(101 \mathrm{MHz}, \mathrm{CD}_{3} \mathrm{CN}\right) \delta$ 203.32, 171.21, 91.08, 80.29, 73.47, 62.25, 60.58, 22.93.

HRMS calc'd for $\left[\mathrm{C}_{8} \mathrm{H}_{12} \mathrm{~N}_{4} \mathrm{O}_{5}+\mathrm{Na}\right]^{+}$267.0700. Found 267.0702 (ESI+).

Elimination product (18b)

${ }^{1} \mathrm{H}$ NMR $\left(400 \mathrm{MHz}, \mathrm{CD}_{3} \mathrm{CN}\right) \delta 8.39(\mathrm{~s}, 1 \mathrm{H}), 7.52(\mathrm{~s}, 1 \mathrm{H}), 4.39(\mathrm{dd}, \mathrm{J}=13.3,3.3 \mathrm{~Hz}, 1 \mathrm{H}), 4.13$ (ddd, J = 13.2, 4.2, $2.1 \mathrm{~Hz}, 1 \mathrm{H}), 3.97-3.76(\mathrm{~m}, 3 \mathrm{H}), 3.15(\mathrm{t}, \mathrm{J}=6.1 \mathrm{~Hz}, 1 \mathrm{H}), 2.03(\mathrm{~d}, \mathrm{~J}=0.7 \mathrm{~Hz}, 3 \mathrm{H})$

${ }^{13} \mathrm{C}$ NMR $\left(101 \mathrm{MHz}, \mathrm{CD}_{3} \mathrm{CN}\right) \delta 191.04,169.77,156.35,95.47,83.95,68.31,61.37,23.57$.

HRMS calc'd for $\left[\mathrm{C}_{8} \mathrm{H}_{11} \mathrm{NO}_{5}+\mathrm{Na}\right]^{+}$224.0529. Found $224.0532(\mathrm{ESI}+)$.

Oxidation of methyl $\beta$-D-arabinopyranoside (13) to 13a in 1,1,1,3,3,3-hexafluoroisopropanol: $49.2 \mathrm{mg}$ of $13(0.3 \mathrm{mmol}), 48.6 \mathrm{mg}$ of 1,4-benzoquinone, and $1.57 \mathrm{mg}$ [(neocuproine) $\mathrm{Pd}(\mathrm{OAc})]_{2}(\mathrm{OTf})_{2}(0.003$ $\mathrm{mmol}$ ) were added to $1 \mathrm{~mL}$ of 1,1,1,3,3,3-hexafluoroisopropanol. The solution was stirred at 30 hours at $50{ }^{\circ} \mathrm{C}$ and then evaporated. The reaction mixture was then concentrated to a viscous oil, re-dissolved in a small portion of 1:1 hexanes:ethyl acetate. The solution was then eluted through a silica gel column with 1:1 hexanes:ethyl acetate. Evaporation of the relevant fractions yielded $27.4 \mathrm{mg} 13 \mathrm{a}$ ( $56 \%$ yield) as a clear oil.

${ }^{13} \mathrm{C}$ NMR $\left(126 \mathrm{MHz}, \mathrm{CD}_{3} \mathrm{CN}\right): \delta \mathrm{ppm} 207.0,118.5,104.1,76.2,73.1,65.3,55.9$

${ }^{1} \mathrm{H}-\mathrm{NMR}\left(500 \mathrm{MHz}, \mathrm{CD}_{3} \mathrm{CN}\right.$ ) $\delta$ ppm 3.34 (br. s., $\left.3 \mathrm{H}\right) 3.47$ (t, J=10.38 Hz, $\left.1 \mathrm{H}\right) 3.52$ (dd, J=8.53 Hz, $1 \mathrm{H}$ ) 3.61 (d, J=5.72, 1 H) 4.02 (dd, J=8.05, 10.2, 1 H) 4.34 (m, 2 H) 5.00 (d, J=4.22, 1 H)

HRMS calc'd for $\left[\mathrm{C}_{6} \mathrm{H}_{10} \mathrm{O}_{5}+\mathrm{Na}\right]^{+}$185.0420. Found 185.0429 (ESI+).

Oxidation of methyl- $\alpha$-L-rhamnopyranoside (9) to $8 \mathrm{c}$ in 1,1,1,3,3,3-hexafluoroisopropanol: $53.4 \mathrm{mg}$ of 9 (0.3 mmol), $48.6 \mathrm{mg}$ of 1,4-benzoquinone, and $4.7 \mathrm{mg}$ [(neocuproine) $\mathrm{Pd}(\mathrm{OAc})]_{2}(\mathrm{OTf})_{2}(0.09 \mathrm{mmol})$ were added to $3 \mathrm{~mL}$ of 1,1,1,2,2,2-hexafluoroisopropanol. The solution was stirred for 16 hours at $50{ }^{\circ} \mathrm{C}$, and then evaporated. The crude mixture was resuspended in 1:1 hexanes:ethyl acetate and was sonicated for 30 minutes. The resulting slurry was then eluted through a silica gel column with gradient of 3:1 hexanes:ethyl acetate to 1:1 hexanes:ethyl acetate. Evaporation of the relevant fractions gave $23.2 \mathrm{mg}(0.131 \mathrm{mmol}, 44.8 \%$ yield) $8 \mathrm{c}$ as white flecks.

${ }^{1} \mathrm{H}-\mathrm{NMR}\left(400 \mathrm{MHz}, \mathrm{CD}_{3} \mathrm{CN}\right) \delta 4.98(\mathrm{~d}, \mathrm{~J}=4.4 \mathrm{~Hz}, 1 \mathrm{H}), 4.37$ (ddd, J = 8.5, 4.4, $\left.1.6 \mathrm{~Hz}, 1 \mathrm{H}\right), 3.86$ (ddd, J = 9.4, $5.3,1.6 \mathrm{~Hz}, 1 \mathrm{H}), 3.70-3.57(\mathrm{~m}, 2 \mathrm{H}), 3.53(\mathrm{~d}, \mathrm{~J}=8.5 \mathrm{~Hz}, 1 \mathrm{H}), 3.33(\mathrm{~s}, 3 \mathrm{H}), 1.36(\mathrm{~d}, \mathrm{~J}=6.2 \mathrm{~Hz}, 3 \mathrm{H})$. 
${ }^{13} \mathrm{C}$ NMR NMR $\left(101 \mathrm{MHz}, \mathrm{CD}_{3} \mathrm{CN}\right) \delta 206.73,103.16,78.54,75.91,72.04,55.76,18.97$.

HRMS calc'd for $\left[\mathrm{C}_{7} \mathrm{H}_{12} \mathrm{O}_{5}+\mathrm{Na}\right]^{+}$199.0577. Found $199.0575(\mathrm{ESI}+)$.

Oxidation of benzyl 2,3-O-isopropylidene- $\alpha$-D-mannofuranoside (20) to 20a: $31.0 \mathrm{mg}$ of benzyl 2,3-Oisopropylidene- $\alpha$-D-mannofuranoside 20 (0.1 mmol), $16.2 \mathrm{mg}$ benzoquinone $(0.15 \mathrm{mmol})$, and $1.57 \mathrm{mg}$ [(neocuproine) $\mathrm{Pd}(\mathrm{OAc})]_{2}(\mathrm{OTf})_{2}(0.003 \mathrm{mmol})$ was added to $1 \mathrm{~mL}$ 2,2,2-trifluoroethanol. The solution was stirred for $2.5 \mathrm{hr}$ at $50^{\circ} \mathrm{C}$. The reaction mixture was evaporated, redissolved in 3:1 hexanes:ethyl acetate, and sonicated for about 30 minutes. The solution was then eluted through a silica gel column with a gradient from 3:1 hexanes:ethyl acetate to 2:1 hexanes:ethyl acetate. Evaporation of the relevant fractions gave $22.6 \mathrm{mg}(0.0732 \mathrm{mmol}, 73.0 \%$ yield) $20 \mathrm{a}$ as a clear oil.

${ }^{1} \mathrm{H}$ NMR $\left(500 \mathrm{MHz}, \mathrm{CD}_{3} \mathrm{CN}\right) \delta 7.41-7.27(\mathrm{~m}, 5 \mathrm{H}), 5.17(\mathrm{~s}, 1 \mathrm{H}), 5.06(\mathrm{dd}, \mathrm{J}=5.8,4.1 \mathrm{~Hz}, 1 \mathrm{H}), 4.66(\mathrm{dd}, \mathrm{J}=$ 7.9, $3.7 \mathrm{~Hz}, 2 \mathrm{H}), 4.62(\mathrm{~d}, \mathrm{~J}=5.8 \mathrm{~Hz}, 1 \mathrm{H}), 4.49(\mathrm{~d}, \mathrm{~J}=11.5 \mathrm{~Hz}, 1 \mathrm{H}), 4.43-4.27(\mathrm{~m}, 2 \mathrm{H}), 3.18(\mathrm{t}, \mathrm{J}=5.7 \mathrm{~Hz}$, $1 \mathrm{H}), 1.35(\mathrm{~d}, \mathrm{~J}=0.7 \mathrm{~Hz}, 4 \mathrm{H}), 1.25(\mathrm{~d}, \mathrm{~J}=0.7 \mathrm{~Hz}, 4 \mathrm{H})$.

${ }^{13} \mathrm{C}$ NMR $\left(126 \mathrm{MHz}, \mathrm{CD}_{3} \mathrm{CN}\right) \delta 206.67,138.62,129.42,129.13,128.82,113.61,106.69,85.21,84.65$, $81.81,69.89,68.14,26.09,24.63$.

HRMS calc'd for $\left[\mathrm{C}_{16} \mathrm{H}_{20} \mathrm{O}_{6}+\mathrm{Na}\right]^{+}$331.1152. Found $331.1149(\mathrm{ESI}+)$.

Oxidation of octyl- $\beta$-D-galactofuranoside (21) to 21a: $29.2 \mathrm{mg}$ of octyl- $\beta$-D-galactofuranoside 21 (0.1 $\mathrm{mmol}), 16.2 \mathrm{mg}$ benzoquinone $(0.15 \mathrm{mmol})$ and $2.6 \mathrm{mg}$ [(neocuproine) $\mathrm{Pd}(\mathrm{OAc})]_{2}(\mathrm{OTf})_{2}(0.005 \mathrm{mmol})$ were added to $1 \mathrm{~mL}$ of 2,2,2-trifluoroethanol. The solution was stirred for $1.5 \mathrm{hr}$ at $50{ }^{\circ} \mathrm{C}$. The reaction mixture was evaporated, and redissolved in acetonitrile. The solution was then eluted through a silica gel column with 1:3 hexanes:ethyl acetate. Evaporation of the relevant fractions gave $23.9 \mathrm{mg} \mathbf{2 1 a}$ ( $0.0824 \mathrm{mmol}, 82.4 \%$ yield) as a clear oil.

Note: while this compound is stable in acetonitrile solution, it appears to form dimers upon standing for an extended period of time. However, the dimer seems to gradually break apart in solution, and heating can accelerate this process. Dimers can also be broken up nearly instantaneously with addition of catalytic trifluoromethanesulfonic acid, but addition of acid results in product decomposition over time, possibly due to cleavage of the n-octyloxy group.

1H NMR (400 MHz, CD $\left.\mathrm{CD}_{3} \mathrm{CN}\right) \delta 4.99(\mathrm{~s}, 1 \mathrm{H}), 4.51-4.30(\mathrm{~m}, 3 \mathrm{H}), 3.99(\mathrm{dt}, \mathrm{J}=8.2,2.5 \mathrm{~Hz}, 1 \mathrm{H}), 3.91(\mathrm{dd}, \mathrm{J}=$ 3.8, 1.7 Hz, $1 \mathrm{H}), 3.68(\mathrm{dt}, \mathrm{J}=9.7,6.7 \mathrm{~Hz}, 1 \mathrm{H}), 3.52-3.47(\mathrm{~m}, 2 \mathrm{H}), 3.43(\mathrm{dt}, \mathrm{J}=9.7,6.6 \mathrm{~Hz}, 1 \mathrm{H}), 3.07(\mathrm{t}, \mathrm{J}=$ $5.5 \mathrm{~Hz}, 1 \mathrm{H}), 1.54(\mathrm{~m}, 2 \mathrm{H}), 1.40-1.16(\mathrm{~m}, 10 \mathrm{H}), 0.93-0.81(\mathrm{~m}, 3 \mathrm{H})$.

13C NMR $\left(126 \mathrm{MHz}, \mathrm{CD}_{3} \mathrm{CN}\right) \delta 210.23,109.75,90.04,81.19,80.41,68.83,66.93,32.61,30.24,30.08$, $30.04,26.84,23.42,14.43$.

HRMS calc'd for $\left[\mathrm{C}_{14} \mathrm{H}_{26} \mathrm{O}_{6}+\mathrm{Na}\right]^{+}$313.1622. Found 313.1621 (ESI+). 
Oxidation of $\mathrm{N}$-acetylneuraminic acid methyl ester (22) to 22a: $32.3 \mathrm{mg}$ of $\mathrm{N}$-acetylneuraminic acid methyl ester $22(0.1 \mathrm{mmol}), 27.9 \mathrm{mg}$ benzoquinone $(0.15 \mathrm{mmol})$, and $2.61 \mathrm{mg}$ [(neocuproine $) \mathrm{Pd}(\mathrm{OAc})]_{2}(\mathrm{OTf})_{2}(0.005 \mathrm{mmol})$ were added to $2 \mathrm{~mL}$ of 2,2,2-trifluorothanol. The solution was stirred for 1 hour at $50^{\circ} \mathrm{C}$, and then evaporated. The crude mixture was resuspended in 2,2,2trifluoroethanol and 10:1 ethyl acetate:ethanol, and was eluted through a silica gel column with 10:1 ethyl acetate:ethanol. Evaporation of the relevant fractions gave $15.6 \mathrm{mg}(0.485 \mathrm{mmol}, 48.5 \%) 22 \mathrm{a}$ as a clear oil.

${ }^{1} \mathrm{H}$ NMR $\left(400 \mathrm{MHz}, \mathrm{CD}_{3} \mathrm{CN}\right) \delta 6.74(\mathrm{~d}, \mathrm{~J}=8.5 \mathrm{~Hz}, 1 \mathrm{H}), 4.91(\mathrm{~d}, \mathrm{~J}=5.0 \mathrm{~Hz}, 1 \mathrm{H}), 4.79(\mathrm{~d}, \mathrm{~J}=2.3 \mathrm{~Hz}, 1 \mathrm{H}), 4.47$ $(\mathrm{dd}, \mathrm{J}=19.8,5.0 \mathrm{~Hz}, 1 \mathrm{H}), 4.31-4.18(\mathrm{~m}, 2 \mathrm{H}), 4.01-3.89(\mathrm{~m}, 2 \mathrm{H}), 3.75-3.61(\mathrm{~m}, 4 \mathrm{H}), 3.43(\mathrm{~d}, \mathrm{~J}=5.3 \mathrm{~Hz}$, $1 \mathrm{H}), 3.09(\mathrm{t}, \mathrm{J}=5.4 \mathrm{~Hz}, 1 \mathrm{H}), 2.15-2.06(\mathrm{~m}, 1 \mathrm{H}), 1.97(\mathrm{~s}, 3 \mathrm{H}), 1.83(\mathrm{ddd}, \mathrm{J}=13.3,11.3,2.4 \mathrm{~Hz}, 1 \mathrm{H})$

${ }^{13} \mathrm{C}$ NMR $\left(101 \mathrm{MHz}, \mathrm{CD}_{3} \mathrm{CN}\right) \delta$ 211.49, 174.26, 170.62, 96.29, 75.67, 74.82, 67.88, 66.65, 54.03, 53.63, $40.42,23.09$.

HRMS calc'd for $\left[\mathrm{C}_{12} \mathrm{H}_{19} \mathrm{NO}_{9}+\mathrm{Na}\right]^{+}$344.0952. Found 344.0951 (ESI+).

Oxidation of L-threitol ((2S,3S)-1,2,3,4-butanetetrol) (15) to 15a in 2,2,2-trifluoroethanol: $61 \mathrm{mg}$ of Lthreitol $15(0.5 \mathrm{mmol}), 56.7 \mathrm{mg}$ benzoquinone $(0.75 \mathrm{mmol})$, and $7.8 \mathrm{mg}$ [(neocuproine)Pd(OAc) $]_{2}(\mathrm{OTf})_{2}$ (0.015) were added to $5 \mathrm{~mL}$ of 2,2,2-trifluoroethanol. The solution was stirred for 20 minutes at $50{ }^{\circ} \mathrm{C}$, and then evaporated. The crude mixture was resuspended in acetonitrile and sonicated for 30 minutes. The resulting slurry was then eluted through a silica gel column with 15:1 ethyl acetate:ethanol. Evaporation of the relevant fractions gave $37.7 \mathrm{mg}(0.0314 \mathrm{mmol}, 62.8 \%$ yield) $15 \mathrm{a}$ as a clear oil.

${ }^{1} \mathrm{H}$ NMR $\left(500 \mathrm{MHz}, \mathrm{D}_{2} \mathrm{O}\right) \delta 4.58-4.44(\mathrm{~m}, 1 \mathrm{H}), 4.40(\mathrm{t}, \mathrm{J}=4.1 \mathrm{~Hz}, \mathrm{OH}), 3.87-3.76(\mathrm{~m}, 1 \mathrm{H})$.

${ }^{13} \mathrm{C}$ NMR $\left(126 \mathrm{MHz}, \mathrm{D}_{2} \mathrm{O}\right) \delta 212.74,76.58,66.52,63.59$. Methanol was used as the internal standard.

Spectra are consistent with literature. ${ }^{2}$

The resulting erythrulose was trisacetylated and enantiomeric excess determined according to a literature procedure. ${ }^{5}$ Retention times were compared against a racemic sample of erythrulose trisacetate, the preparation of which is described in said previous literature procedure. ${ }^{5}$ From the chromatograms (see Figure S91), the enantiomeric ratio is $21: 79$, corresponding to an enantiomeric excess of $58 \%$. 
NMR spectra of isolated products

Aerobic oxidation of erythritol (2a)

$\overbrace{\mathrm{OH}}^{\mathrm{O}} \mathrm{OH}$

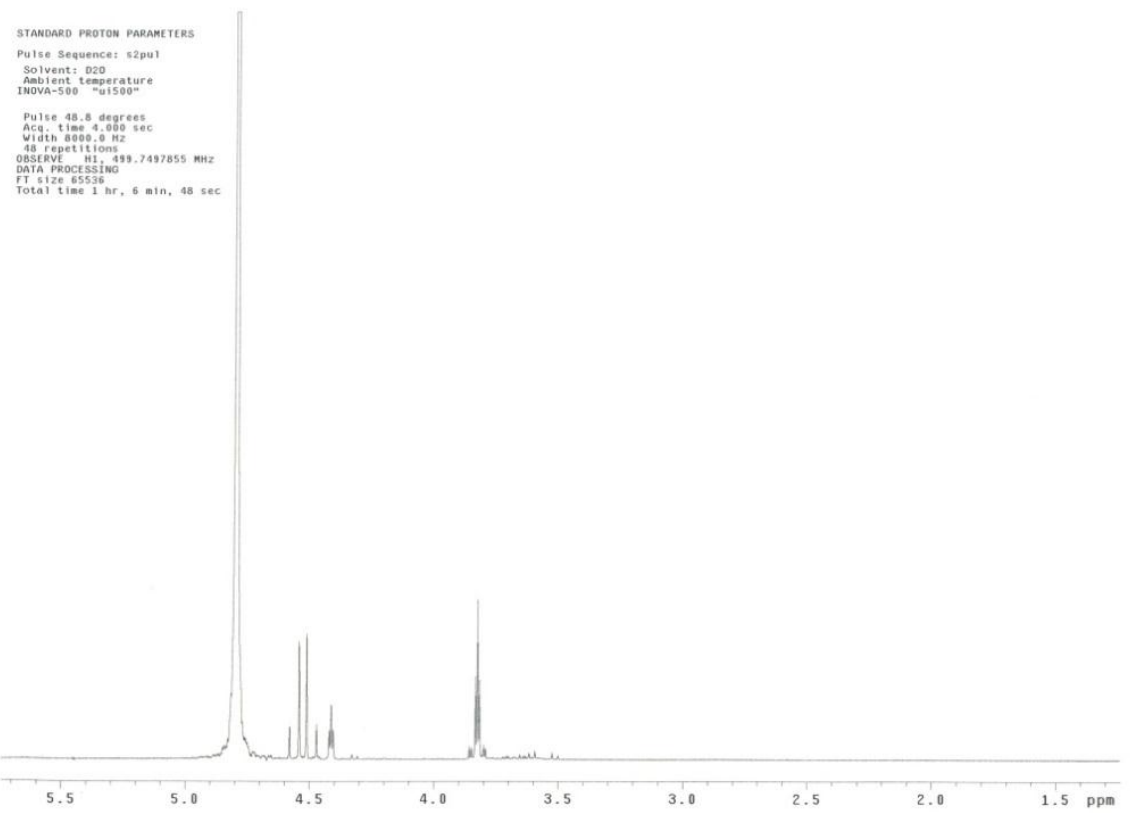

Figure S1. ${ }^{1} \mathrm{H}$ NMR spectrum of $2 \mathrm{a}$ 


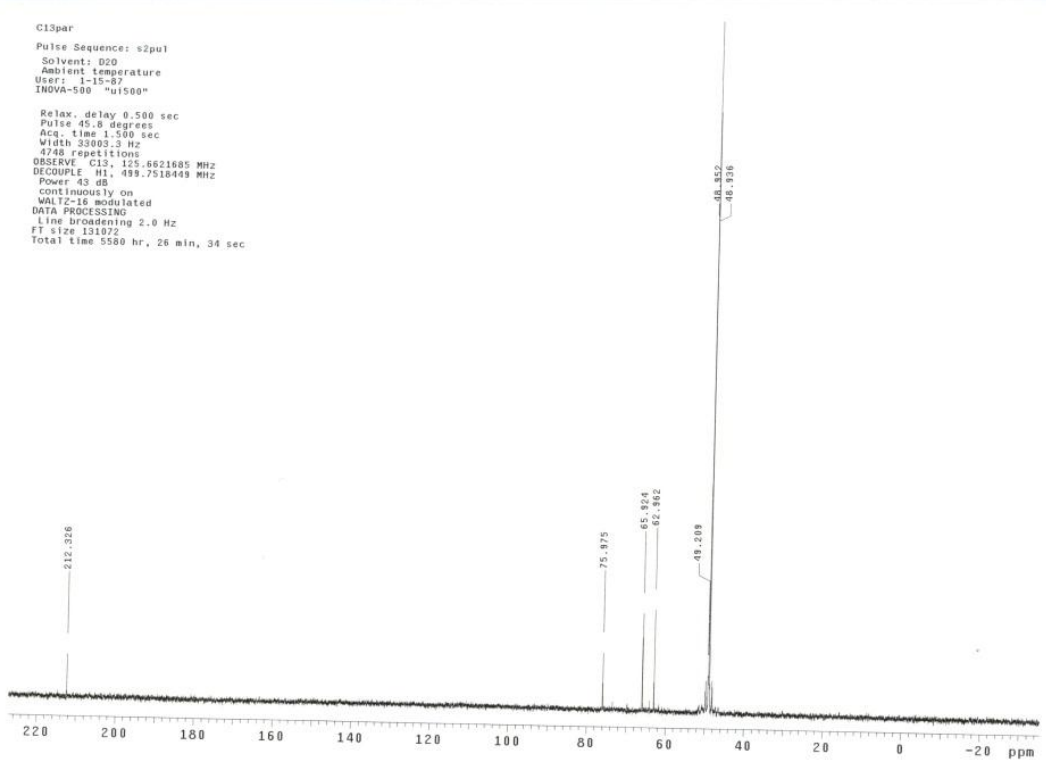

Figure S2. ${ }^{13} \mathrm{C}$ NMR spectrum of $2 a$

Aerobic oxidation of octyl- $\beta$-D-glucopyranoside (3a)
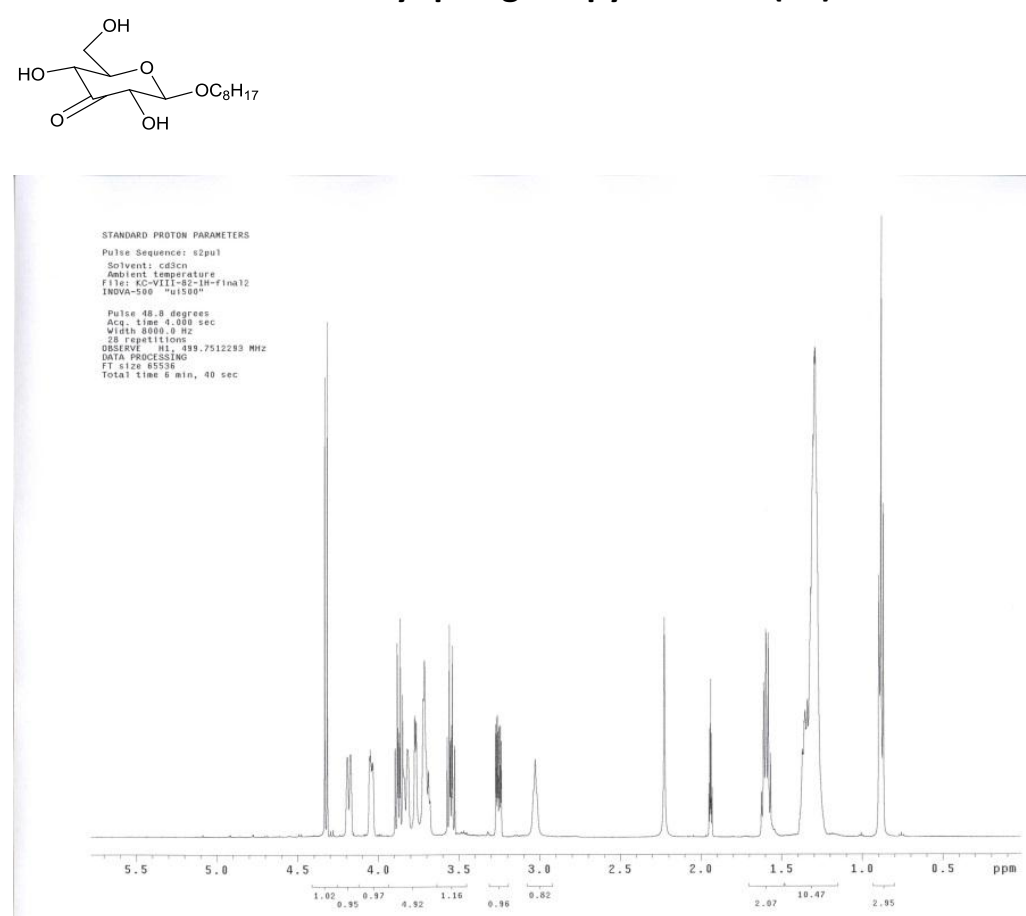

Figure S3. ${ }^{1} \mathrm{H}$ NMR of $3 a$ 


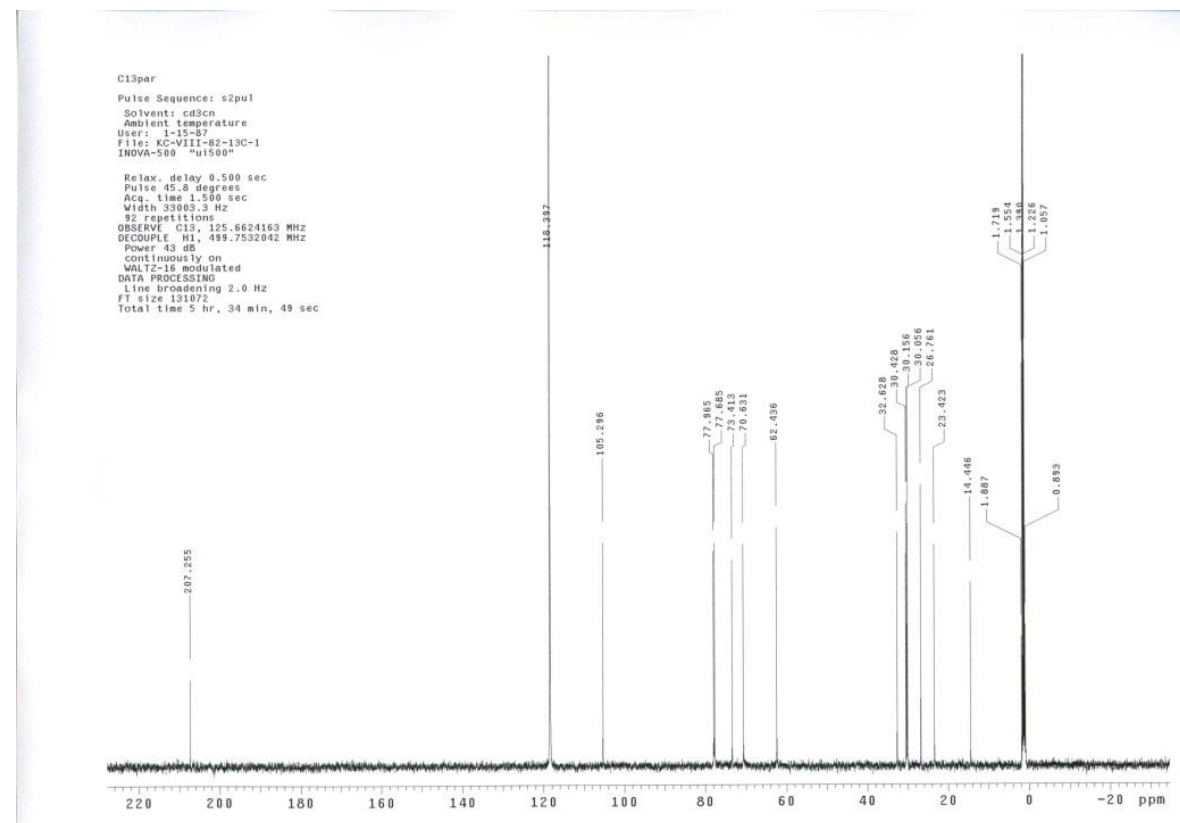

Figure $54 .{ }^{13} \mathrm{C}$ NMR spectrum of $3 a$ 
Aerobic oxidation of 1-deoxy-1-azido- $\beta$-D-glucopyranoside (4a)
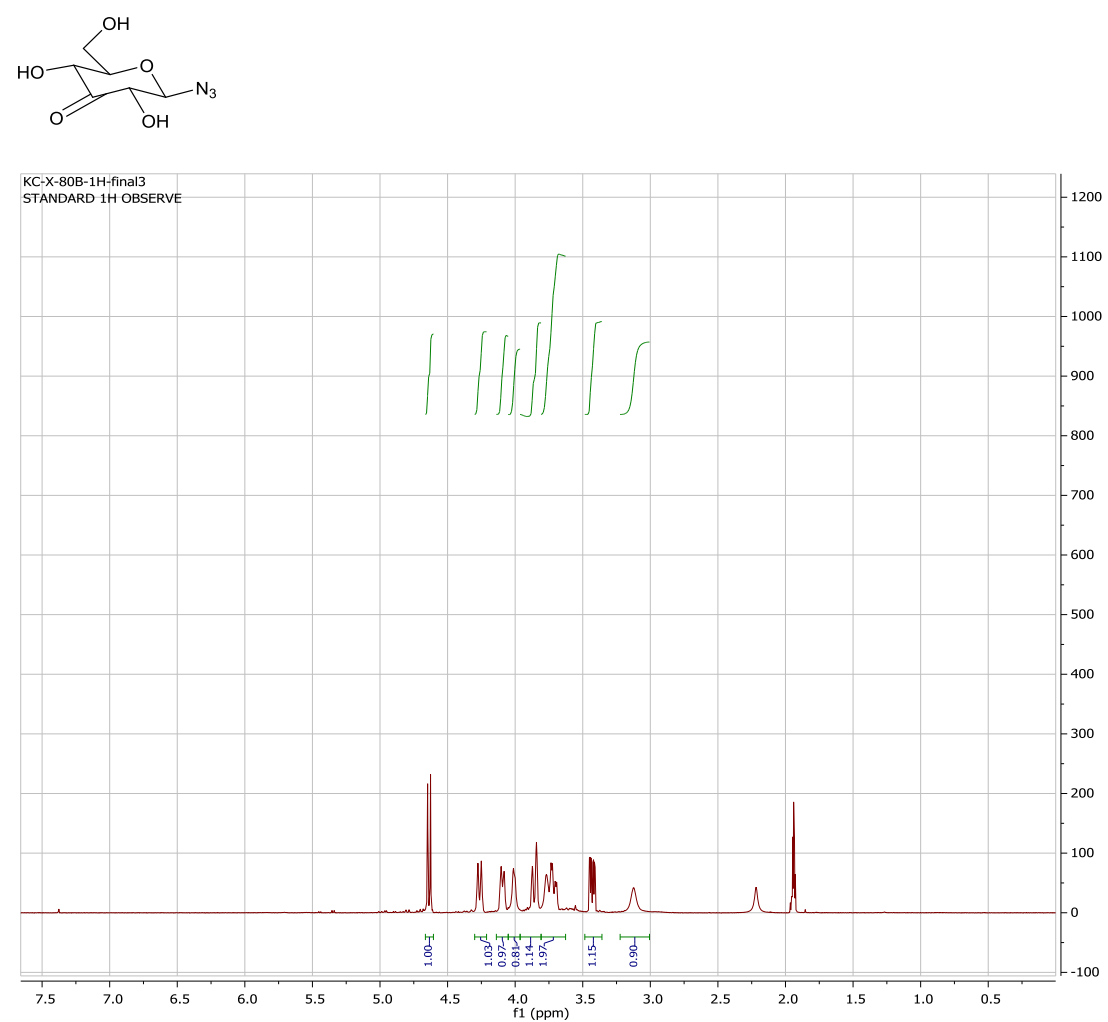

Figure S5. ${ }^{1} \mathrm{H}$ NMR spectrum of $4 \mathrm{a}$

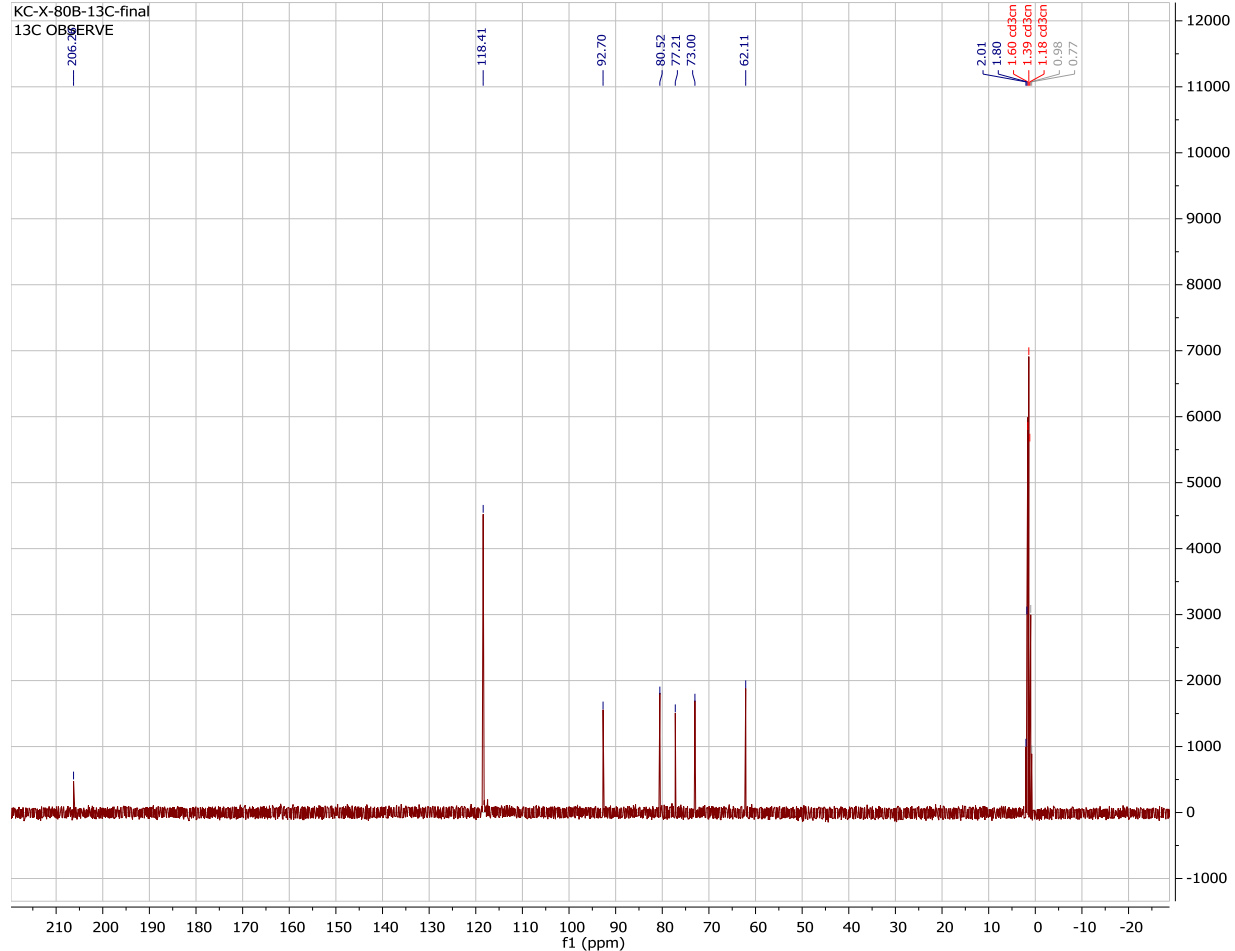

Figure $56 .{ }^{13} \mathrm{C}$ NMR spectrum of $4 a$ 
Aerobic oxidation of 1-deoxy-1-azido- $\beta$-D-glucopyranoside (elimination product $4 \mathrm{~b}$ )

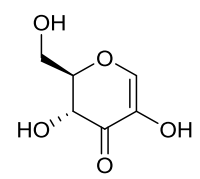

KC-X-80A-1H-crude STANDARD PROTON PARAMETERS
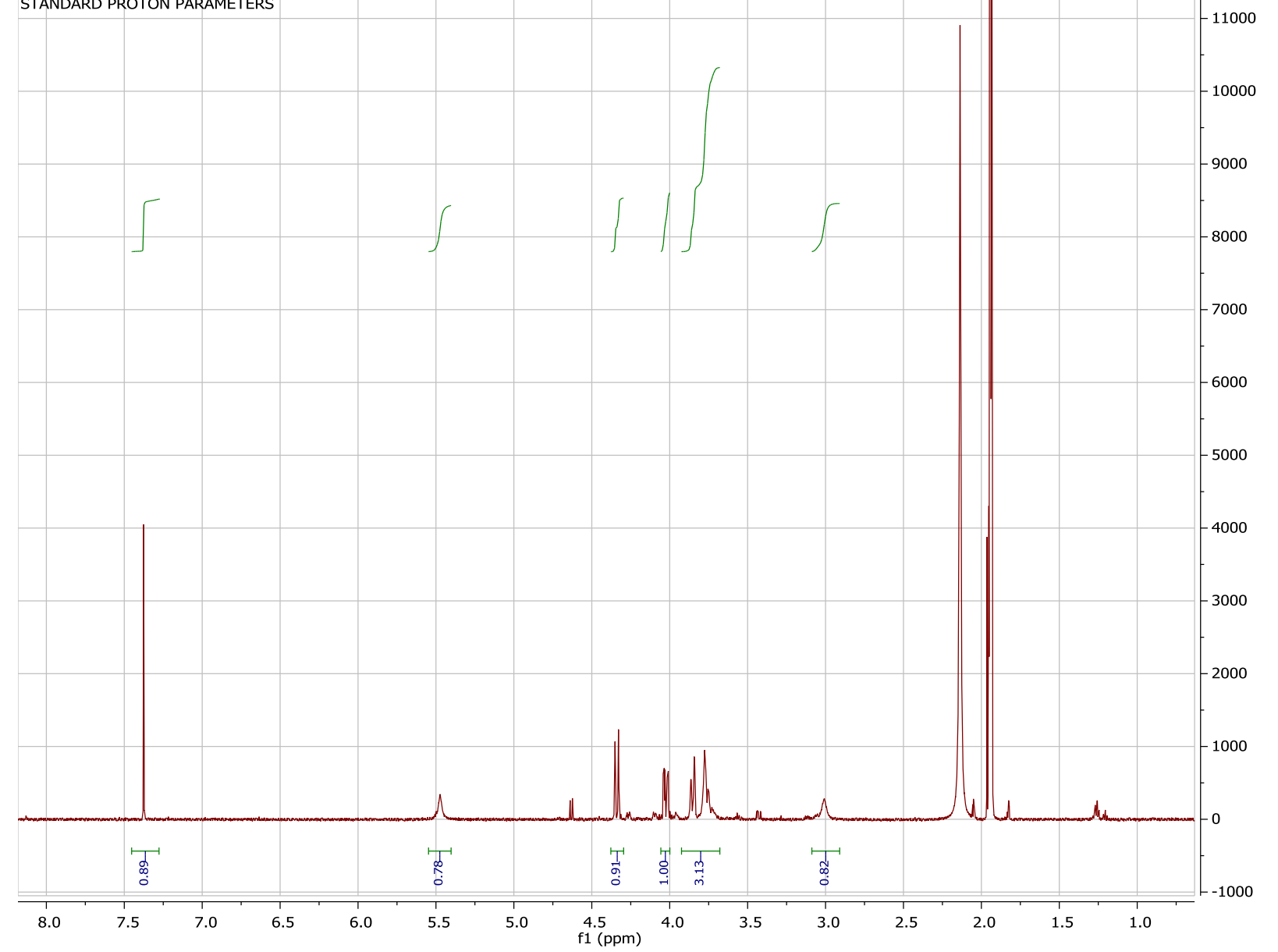

Figure S7. ${ }^{1} \mathrm{H}$ NMR spectrum of $4 \mathrm{~b}$ 
Aerobic oxidation of 4-methoxyphenyl- $\beta$-D glucopyranoside ( $5 \mathrm{a}$ )
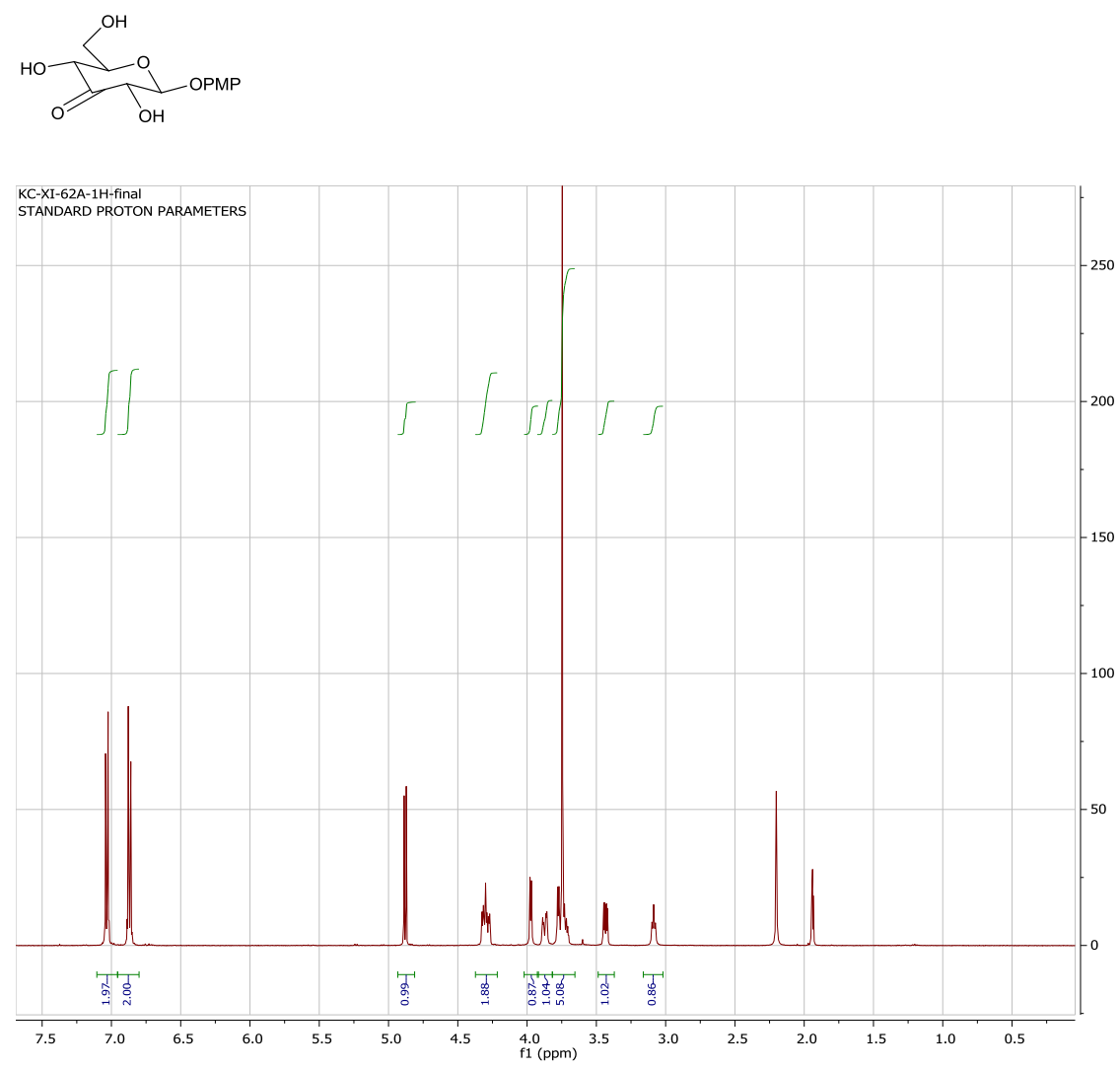

Figure $58 .{ }^{1} \mathrm{H}$ NMR spectrum of 5 a

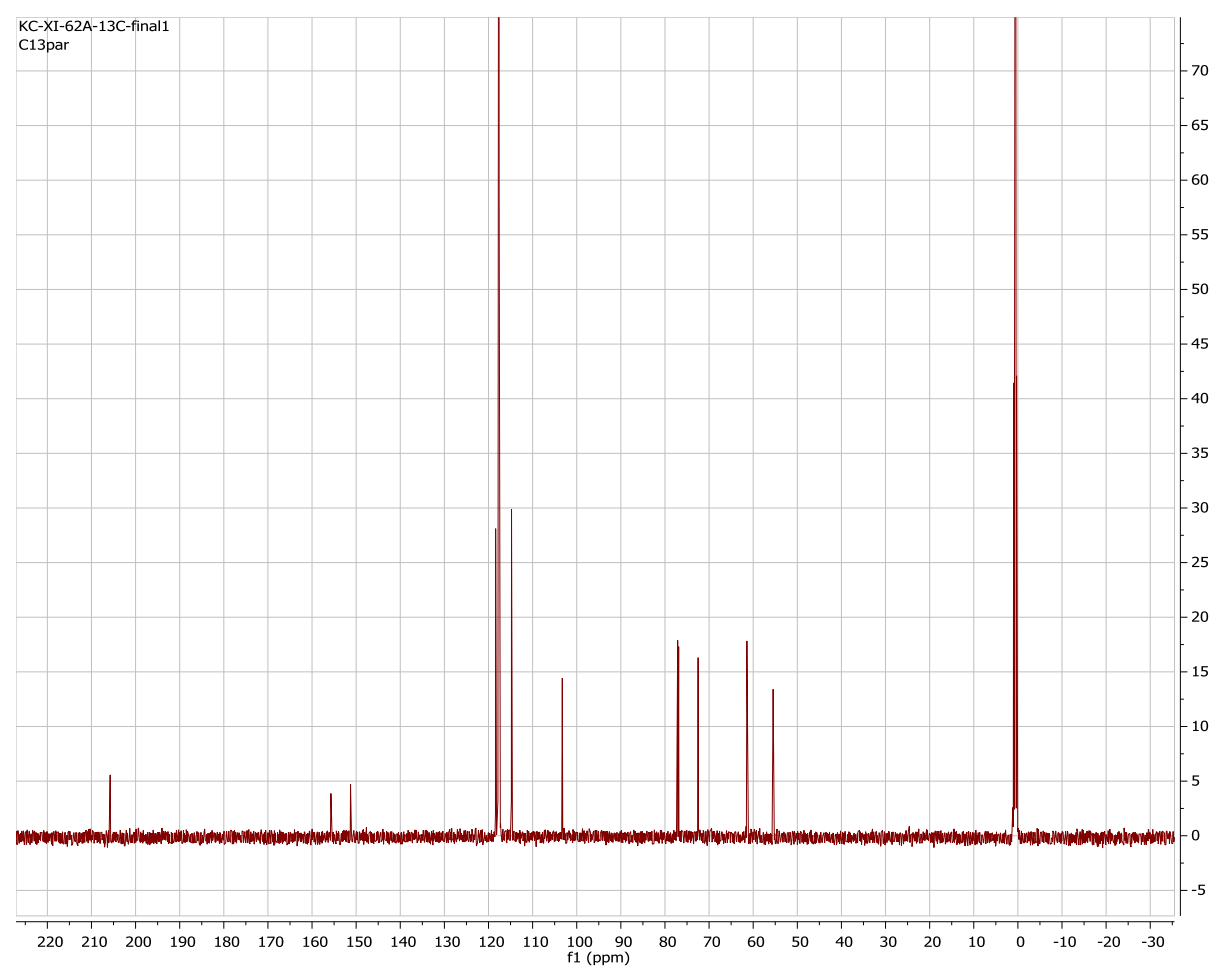

Figure S9. ${ }^{1} \mathrm{H}$ NMR spectrum of 5 a 


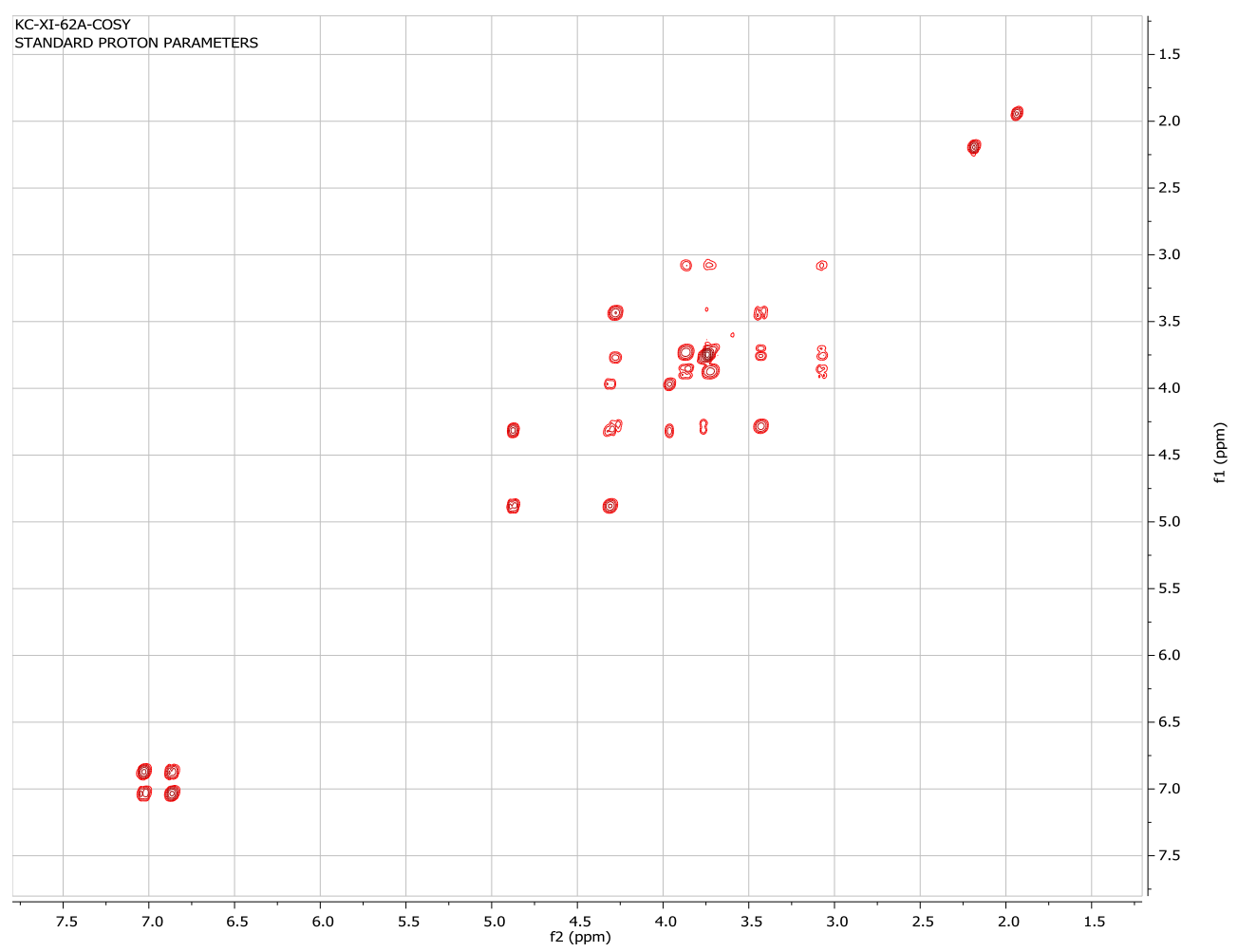

Figure S10. COSY NMR spectrum of 2a

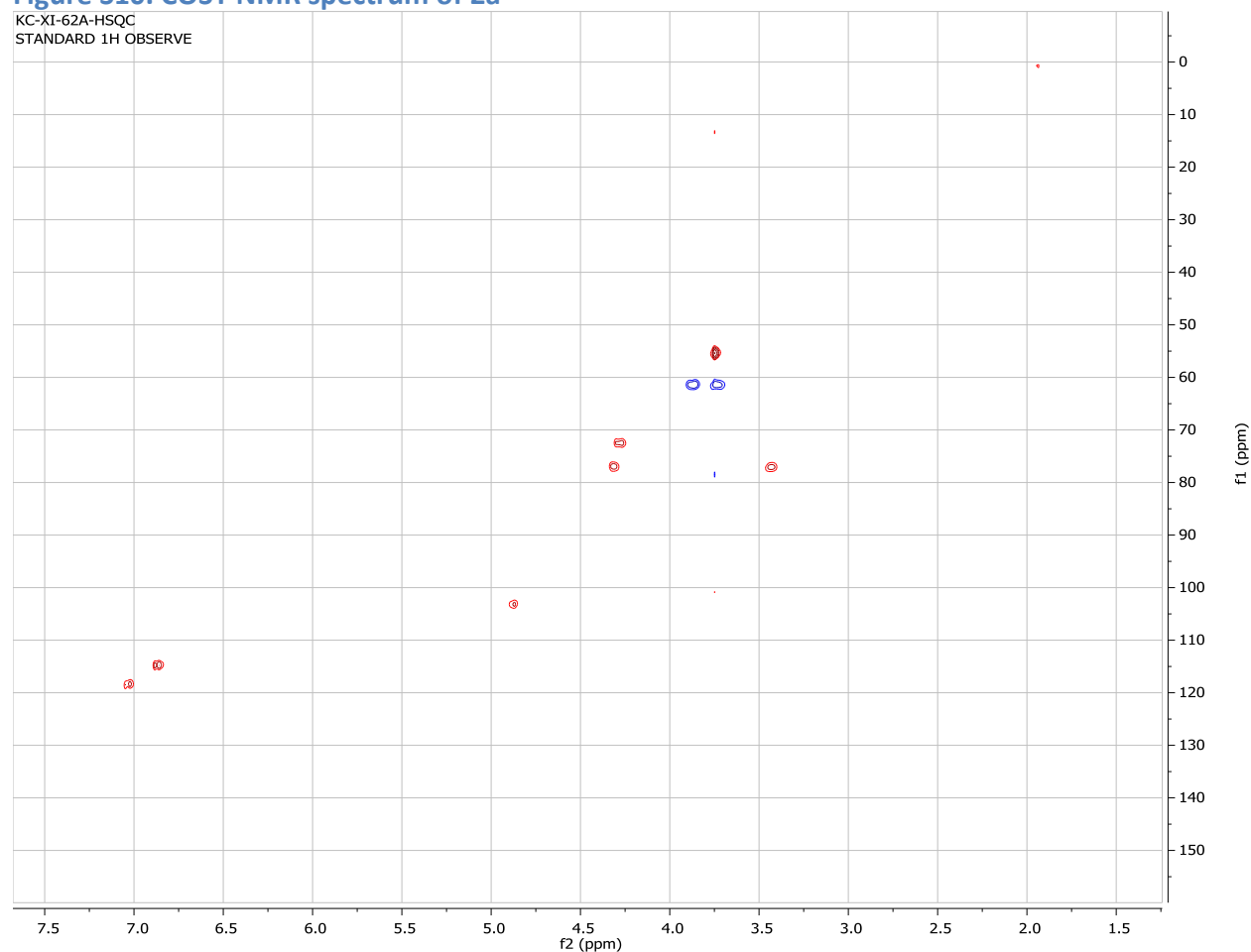

Figure S11. HSQC NMR spectrum of 2a 


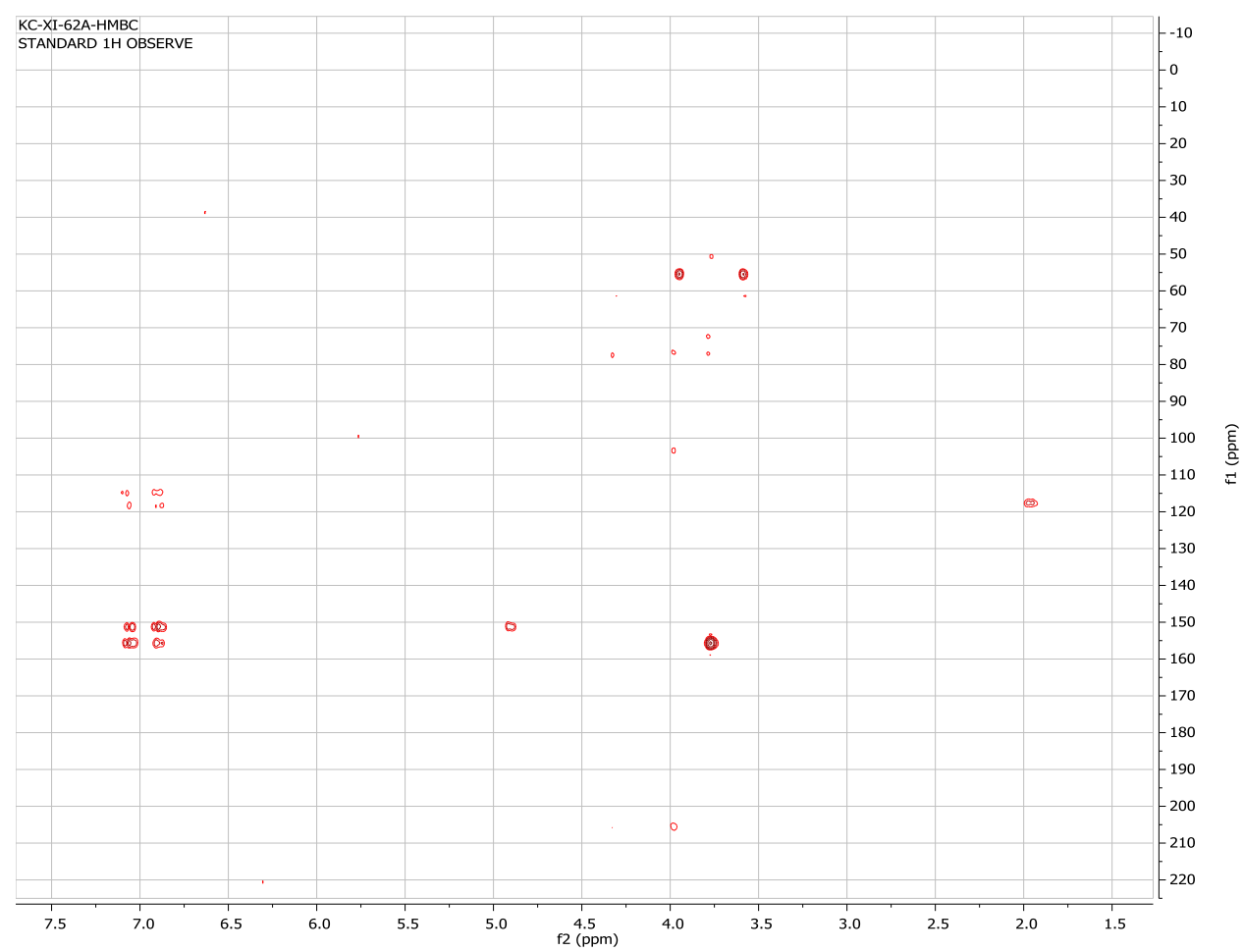

Figure S12. HMBC NMR spectrum of 2a 
Aerobic oxidation of methyl-6-deoxy- $\alpha$-D-glucopyranoside (6a)



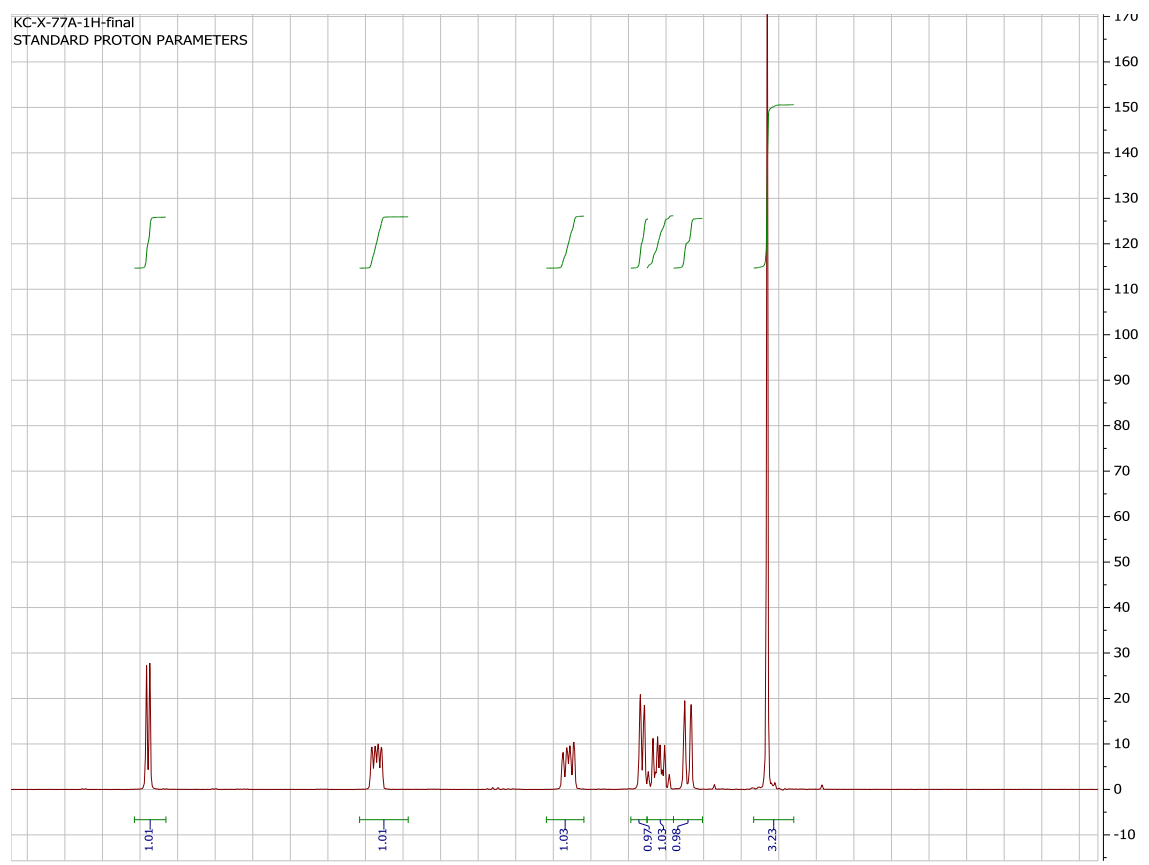

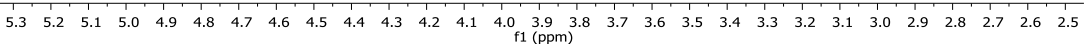

Figure S13. ${ }^{1} \mathrm{H}$ NMR spectrum of $6 \mathrm{a}$

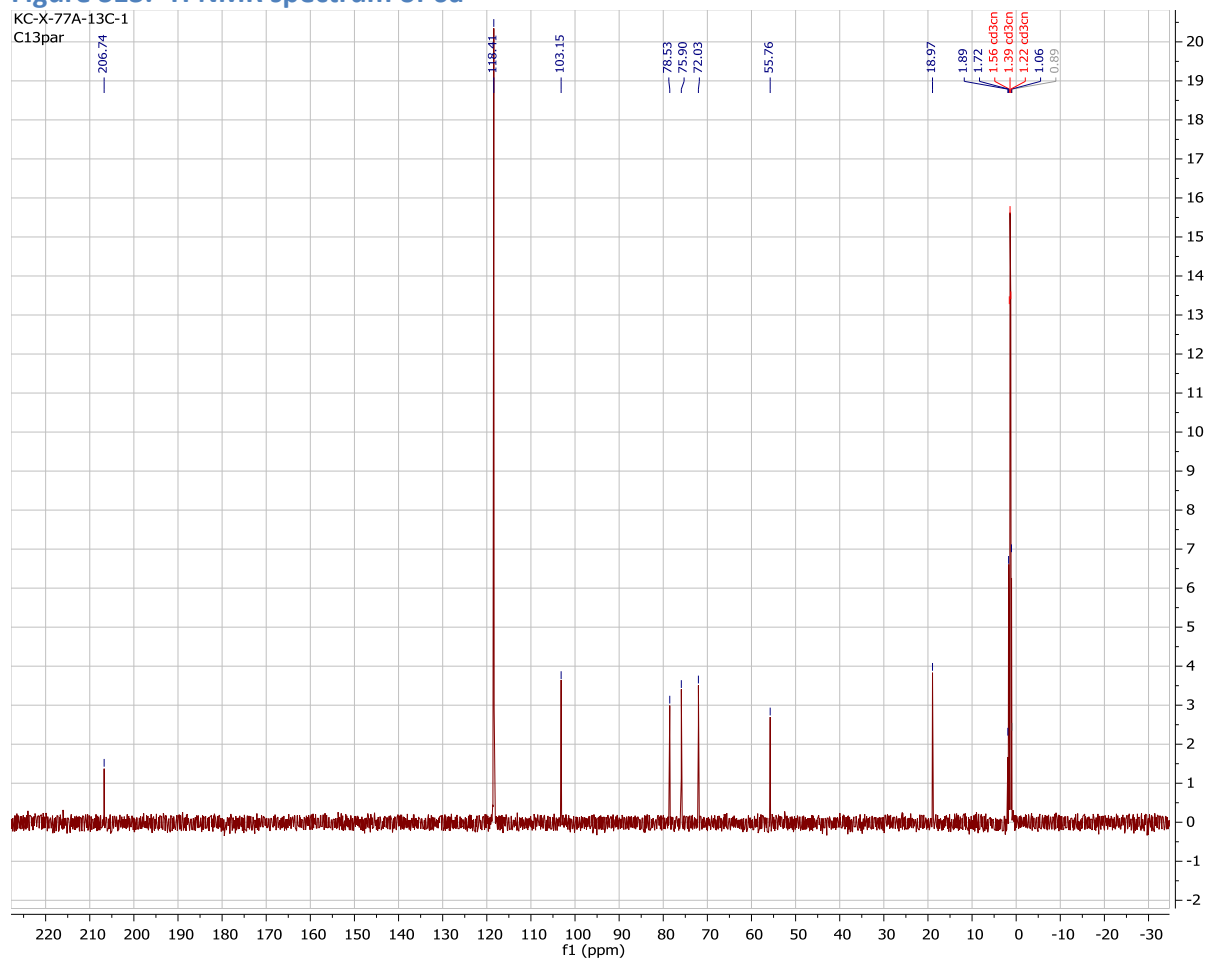

Figure S14. ${ }^{13} \mathrm{C}$ NMR spectrum of $6 a$ 
Aerobic oxidation of methyl- $\alpha$-D-xylopyranoside (7a)

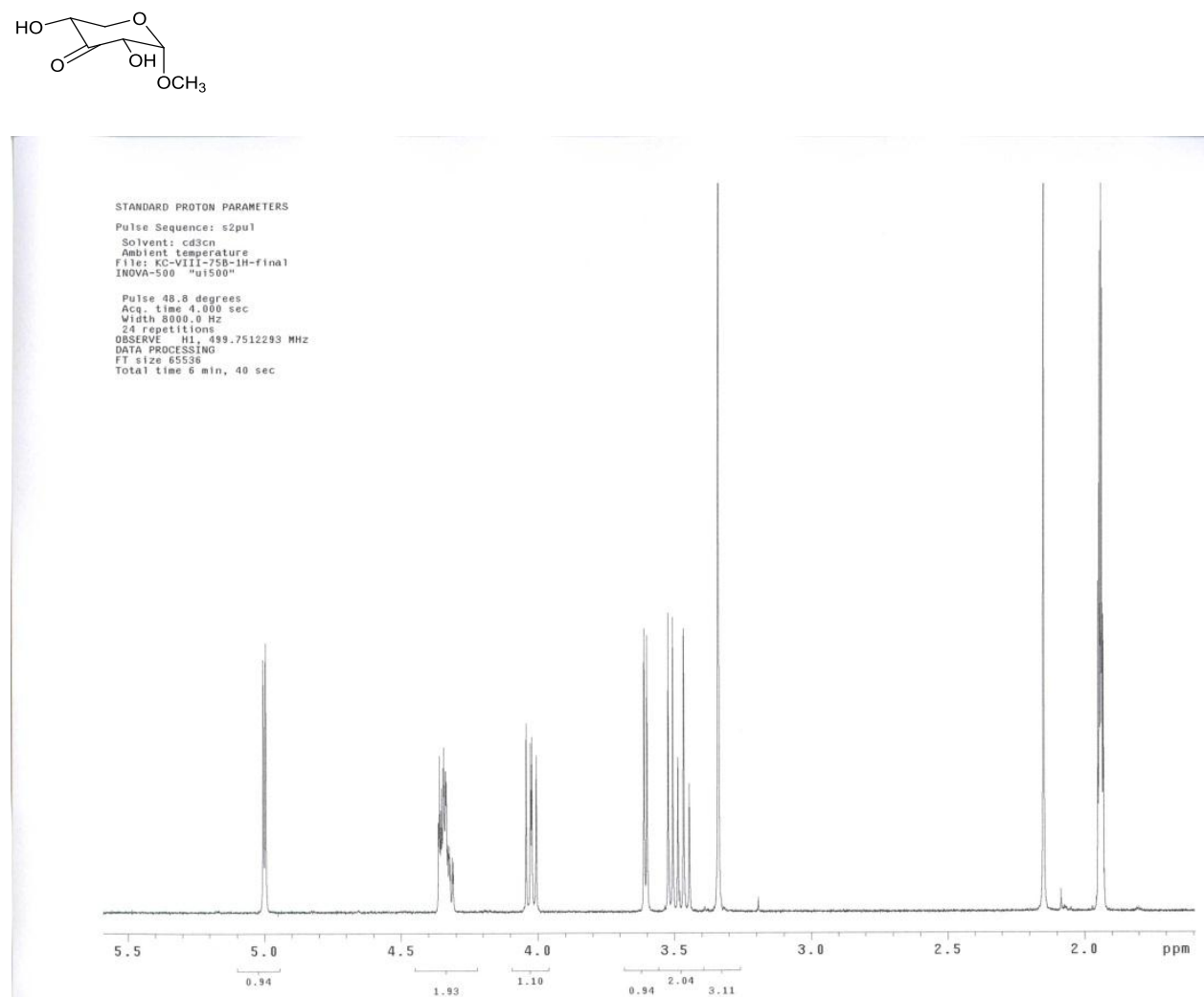

Figure S15. ${ }^{1} \mathrm{H}$ NMR spectrum of 7a
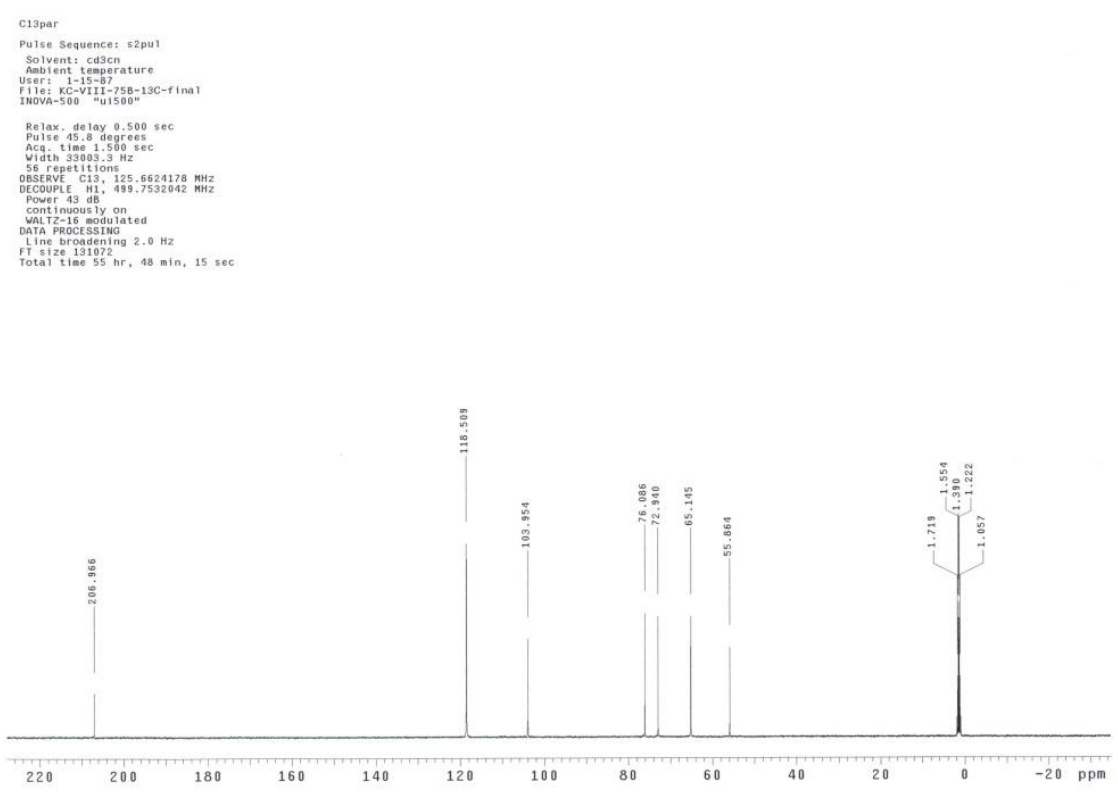

Figure S16. ${ }^{13} \mathrm{C}$ NMR spectrum of $7 a$ 


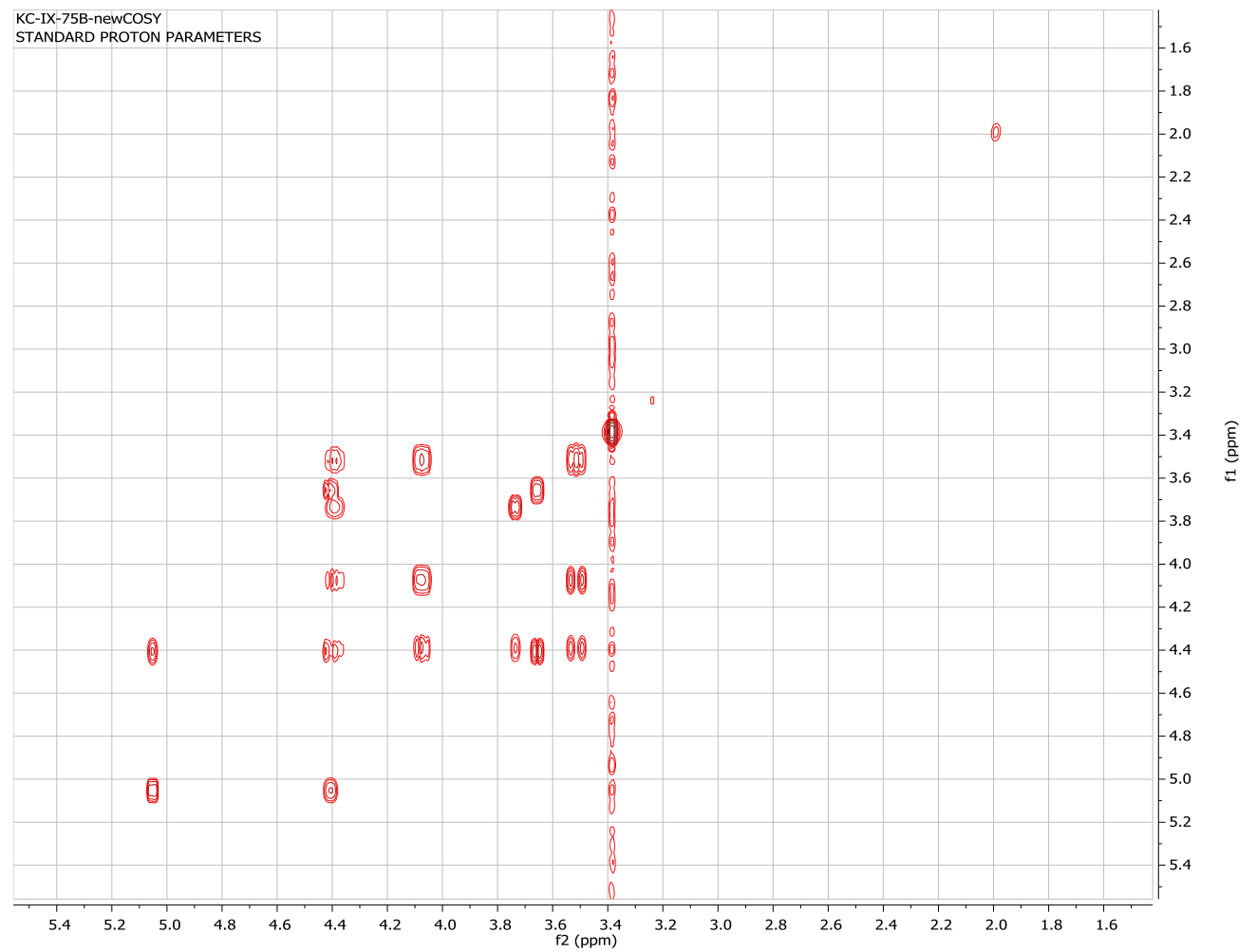

Figure S17. COSY NMR spectrum of 7a

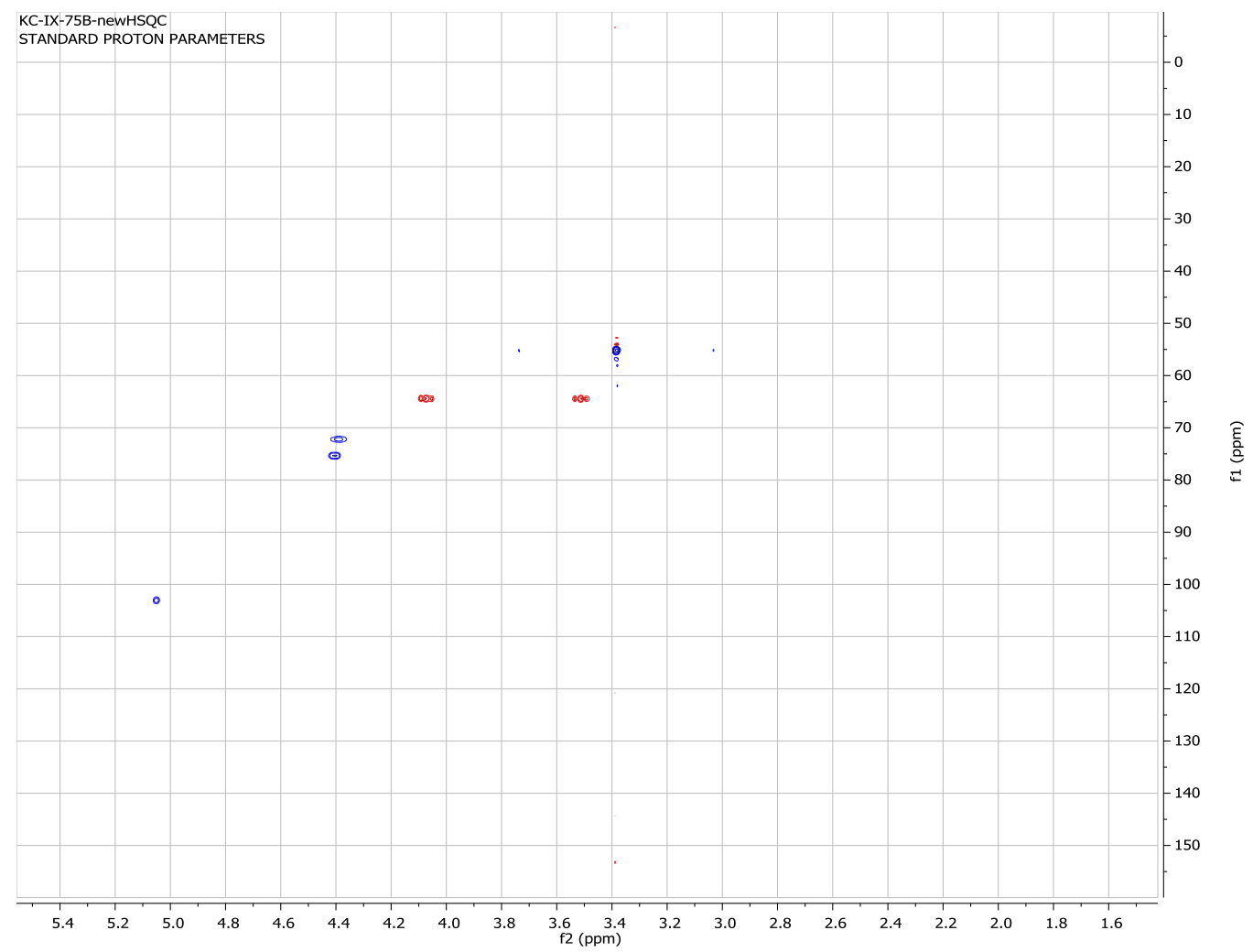

Figure S18. HSQC NMR spectrum of 7a 


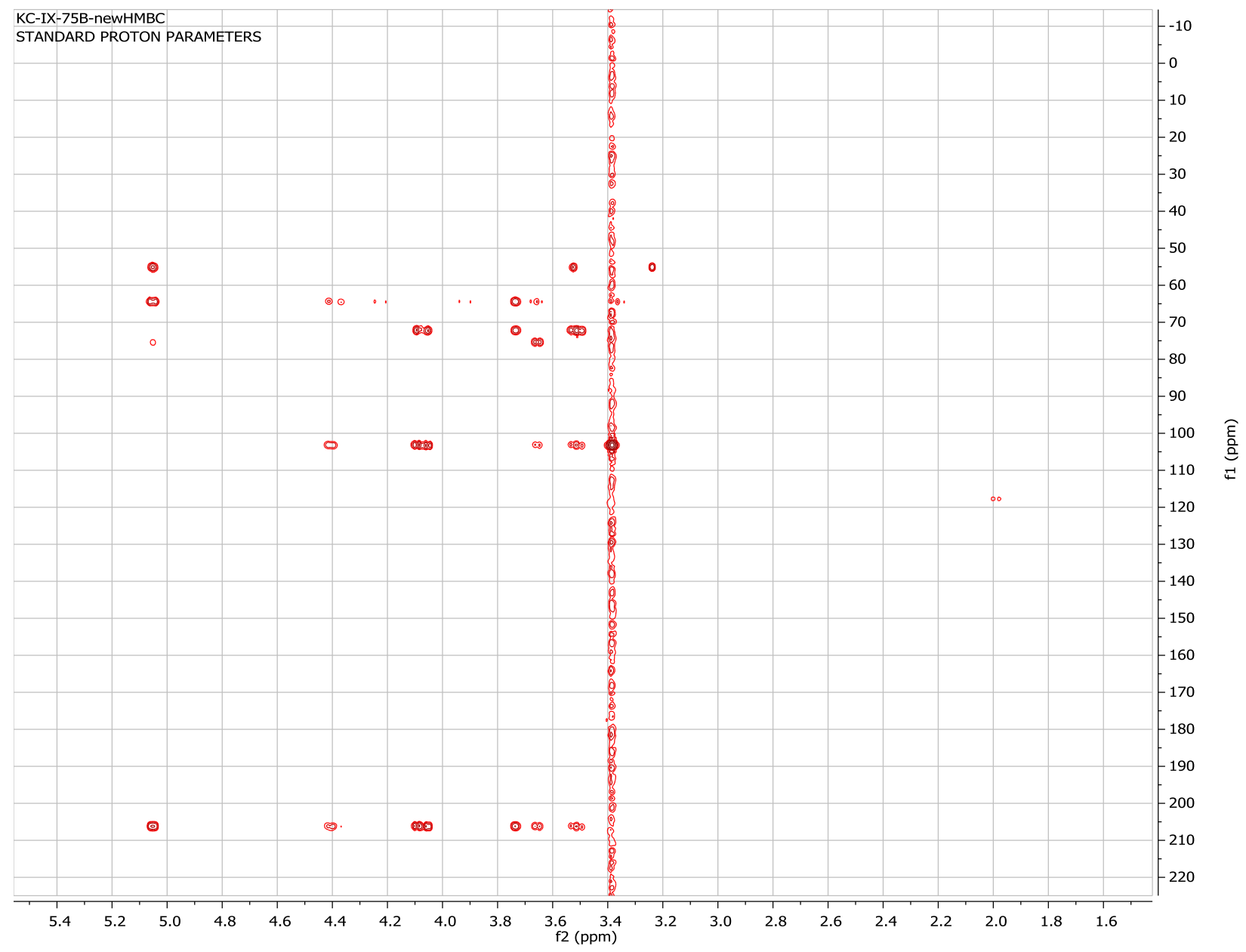

Figure S19. HMBC NMR spectrum of 7a 
Oxidation of methyl- $\alpha$-L-fucopyranoside in acetonitrile (8a)
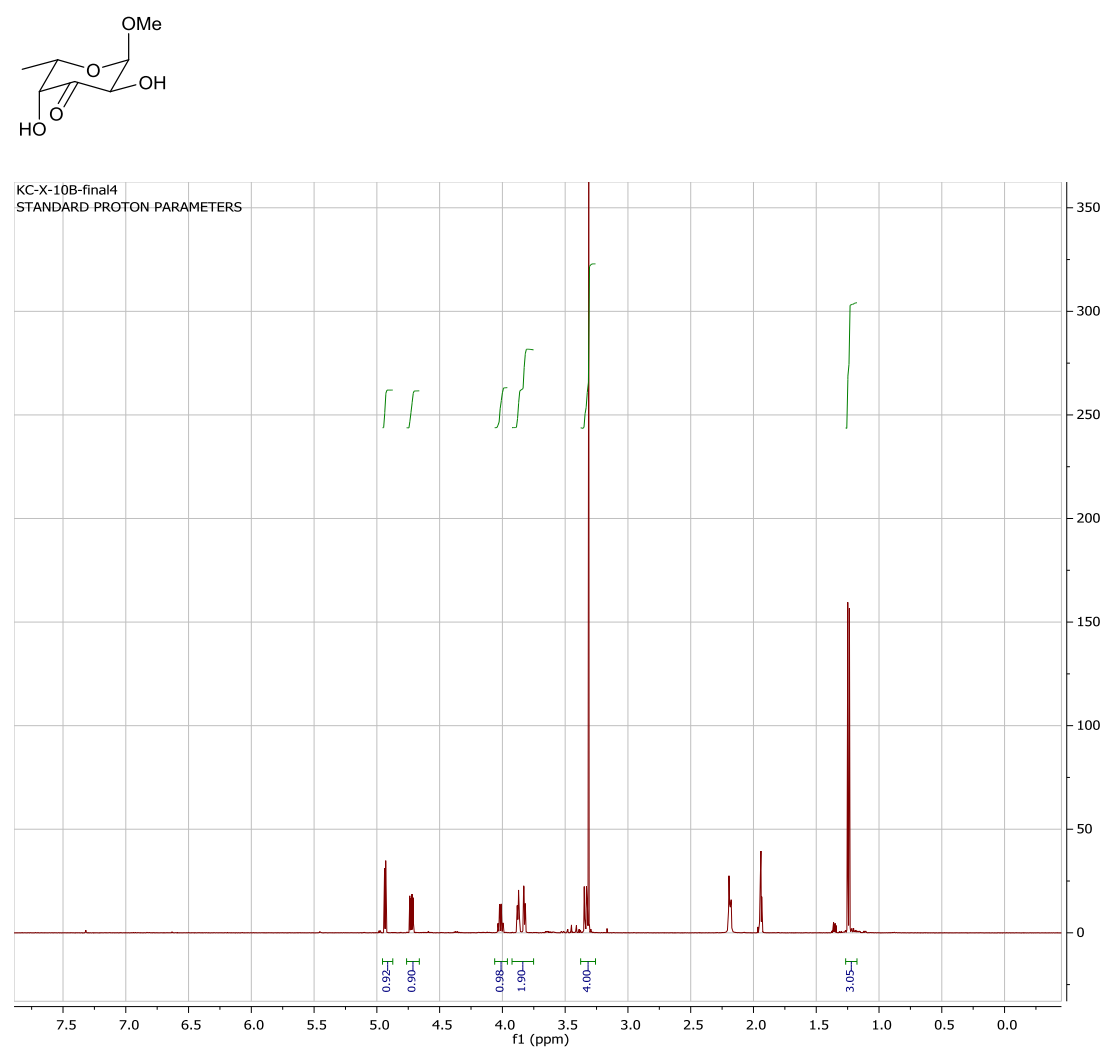

Figure S20. ${ }^{1} \mathrm{H}$ NMR spectrum of $8 \mathrm{a}$

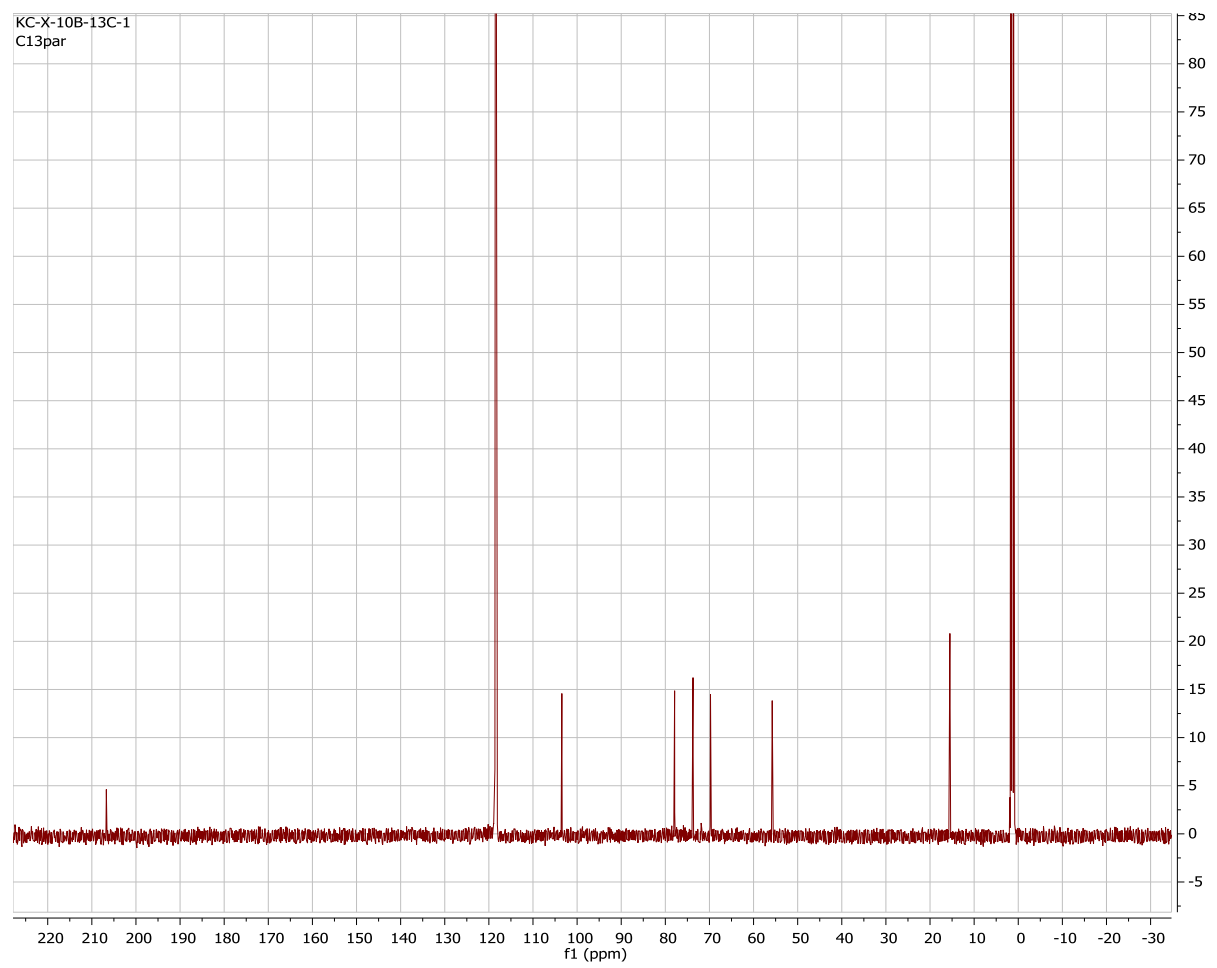

Figure $\mathrm{S} 21 .{ }^{13} \mathrm{C}$ NMR spectrum of 8 a 


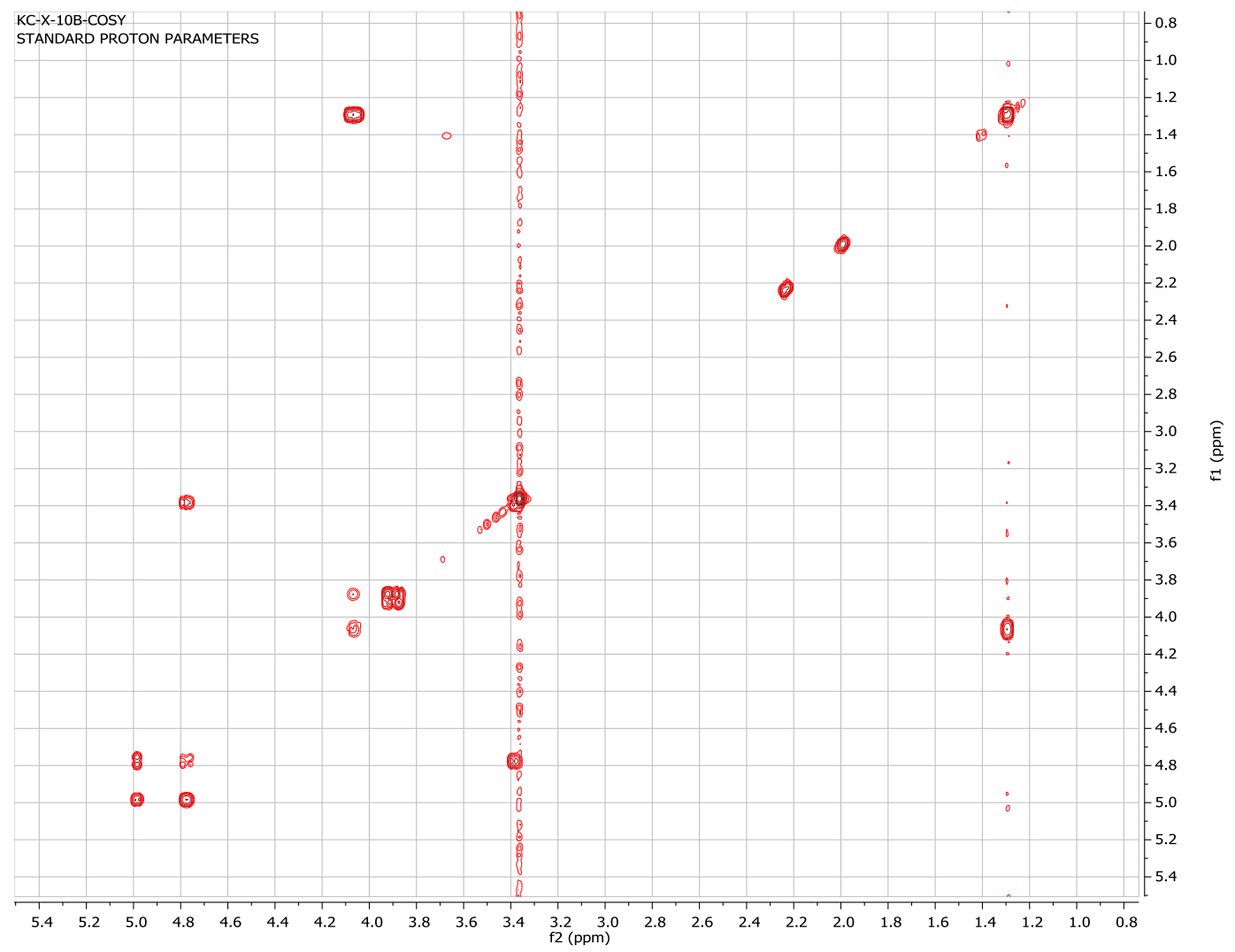

Figure S22. COSY NMR spectrum of 8 a

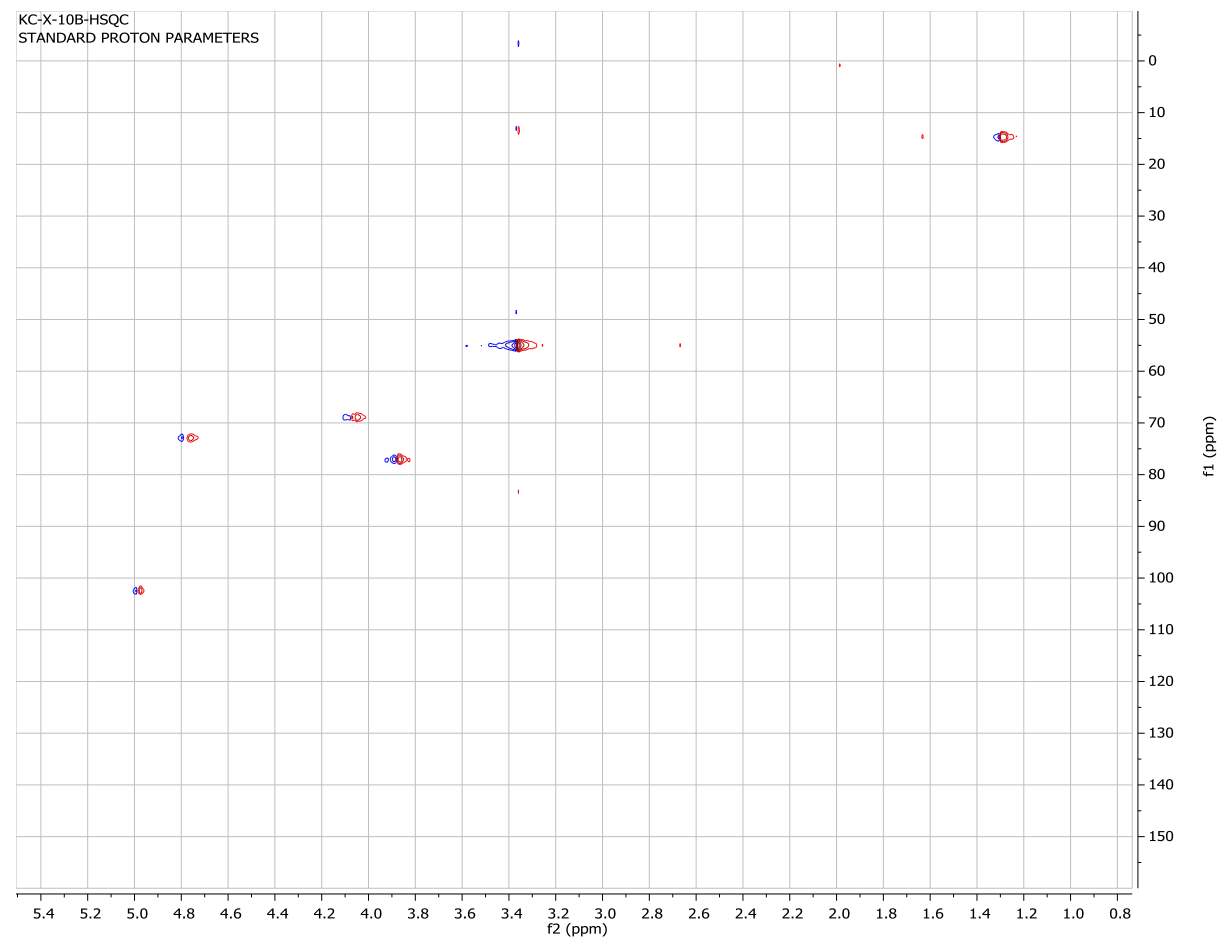

Figure S23. HSQC NMR spectrum of 8 a 


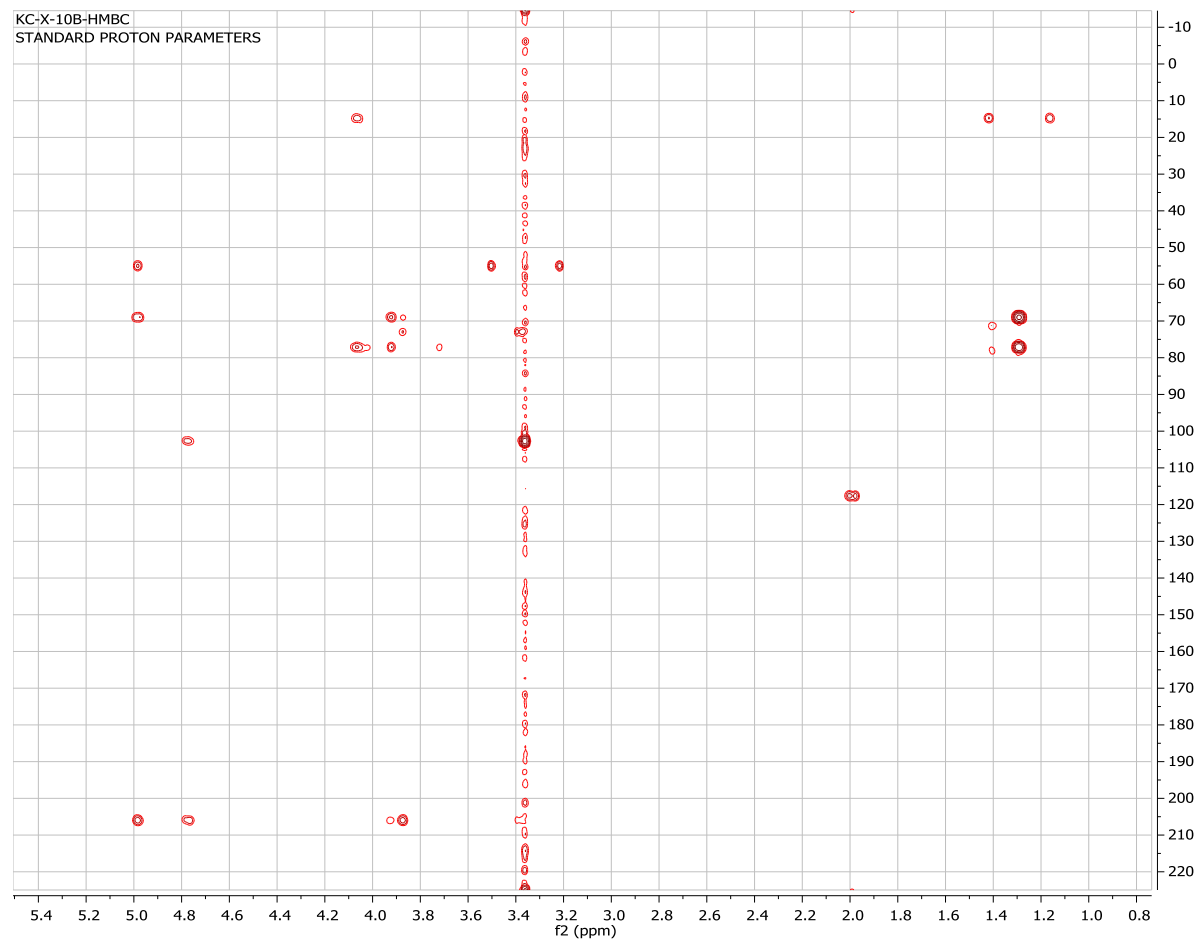

Figure S24. HMBC NMR spectrum of 8a 
Oxidation of methyl $\alpha$-L-rhamnopyranoside in acetonitrile:water (9a)

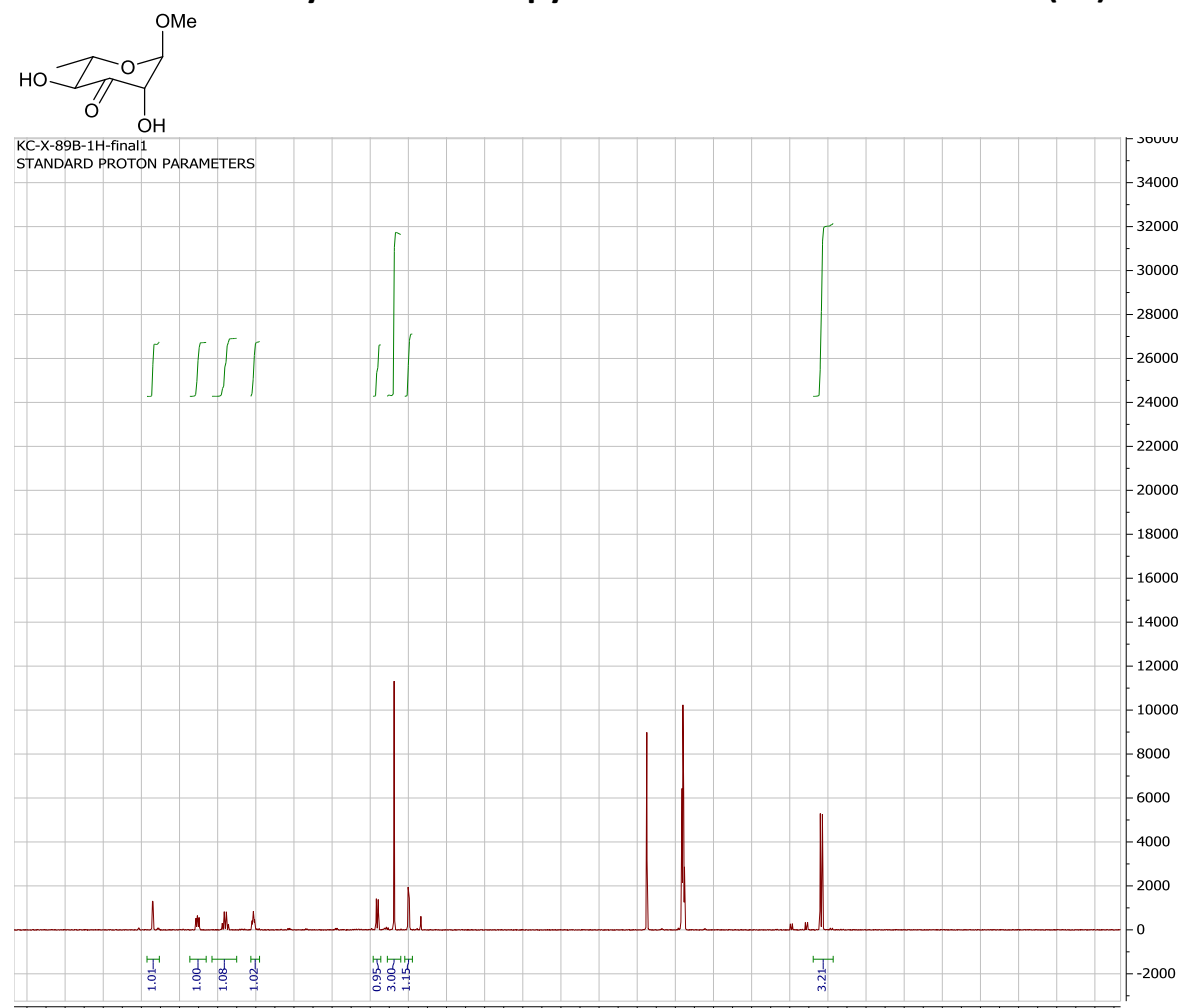

\begin{tabular}{lllllllllllllllllllllllllllllllllllll}
\hline 5.4 & 5.2 & 5.0 & 4.8 & 4.6 & 4.4 & 4.2 & 4.0 & 3.8 & 3.6 & 3.4 & 1.2 & 3.0 & 2.8 & 2 & 2.6 & 1 & 2.4 & 1.2 & 1.0 & 1.8 & 1.6 & 1.4 & 1.2 & 1.0 & 1 & 1 & 1 & 1 & 1 & 1 \\
\hline
\end{tabular}

Figure S25. ${ }^{1} \mathrm{H}$ NMR spectrum of 9 a KC- $x-89 B-13$ - final2

C13par
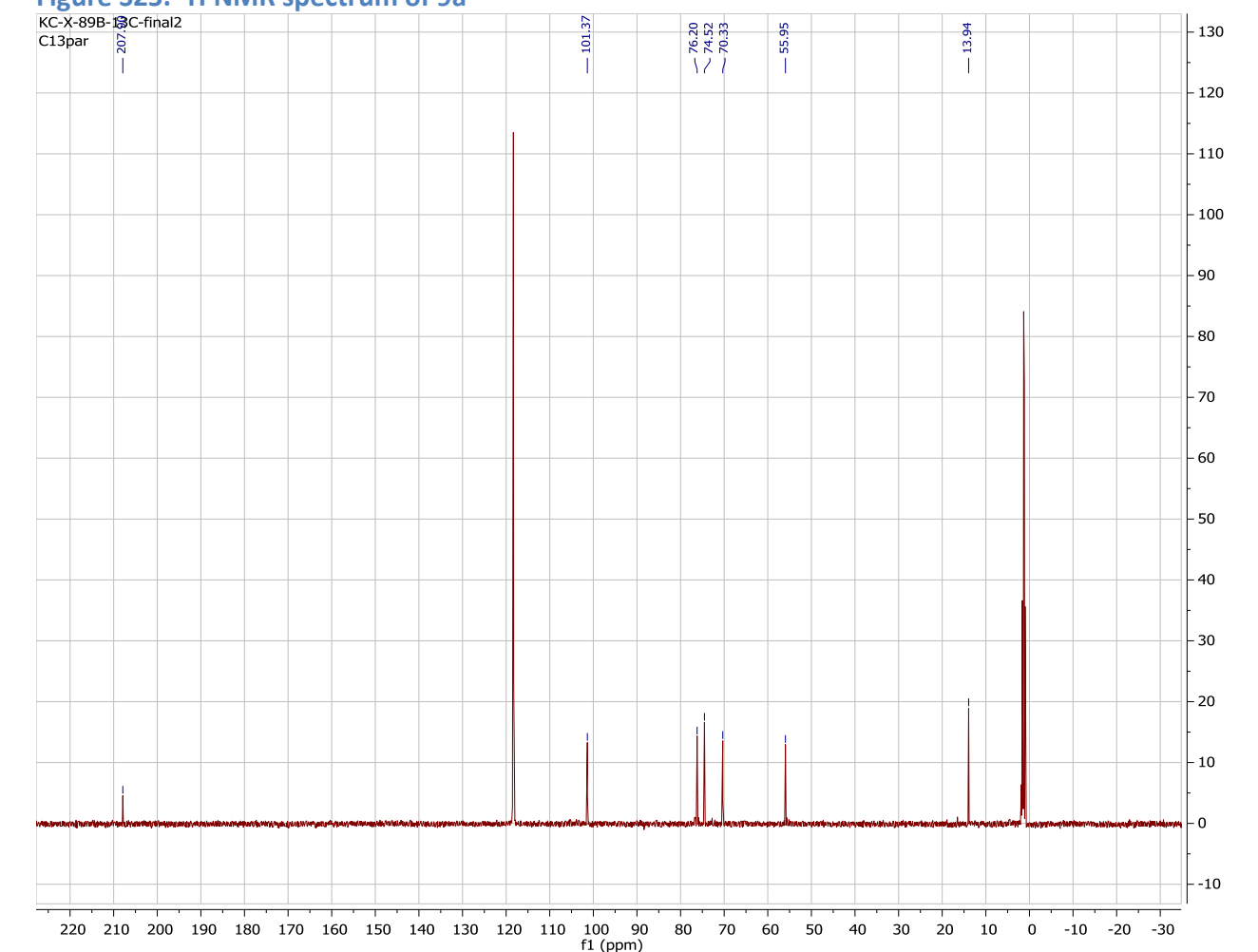

Figure S26. ${ }^{13} \mathrm{C}$ NMR spectrum of $9 a$ 
Oxidation of 1,6-anhydro- $\beta$-D-galactopyranoside in acetonitrile (10a)

$\overbrace{\mathrm{OH}}^{\mathrm{O}}$
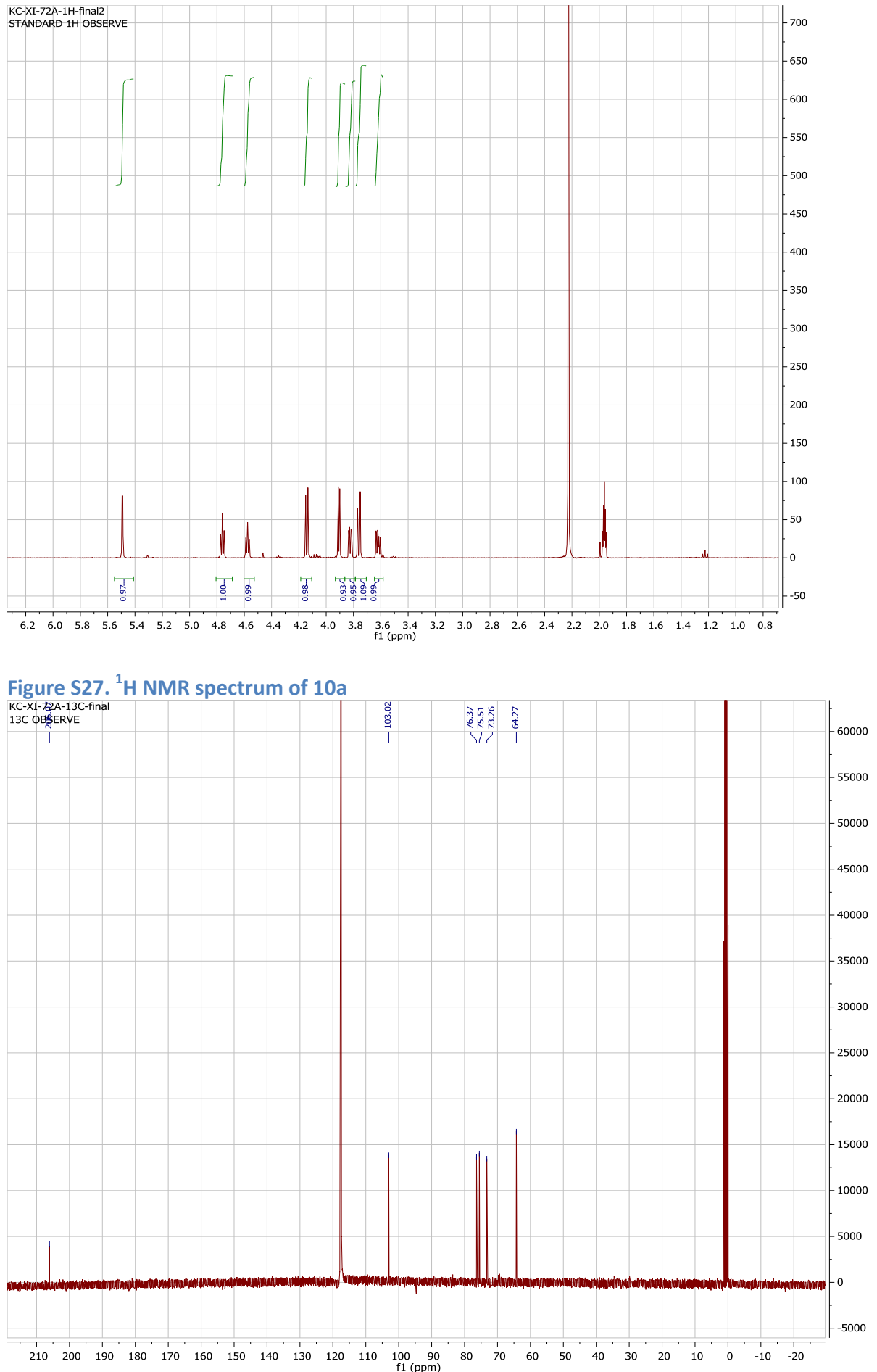

Figure S28. ${ }^{13} \mathrm{C}$ NMR spectrum of $10 \mathrm{a}$ 
Oxidation of 1,6-anhydro- $\beta$-D-mannopyranoside in acetonitrile (11a)

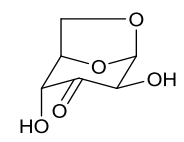

Monomer form (in $\mathrm{CD}_{3} \mathrm{CN}$ )

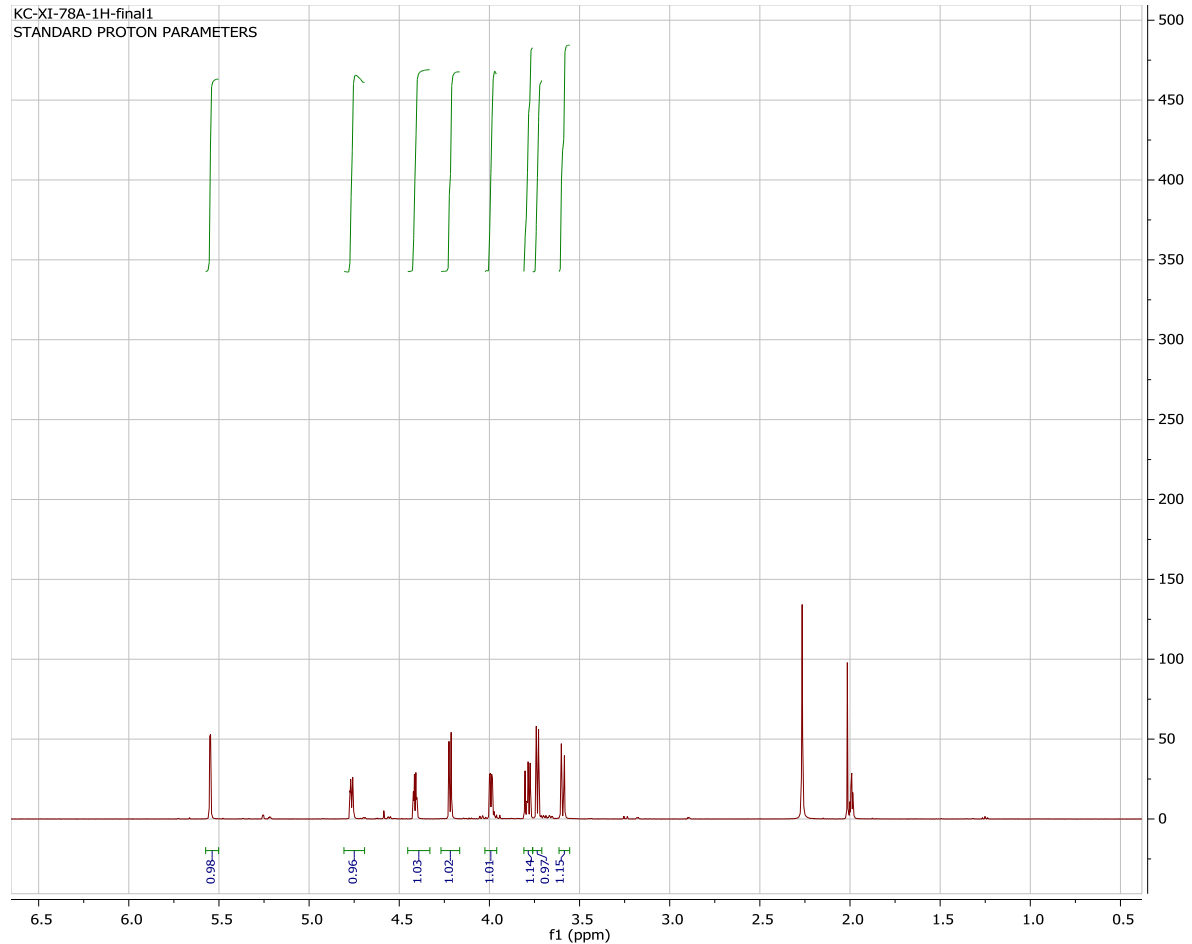

Figure S29. ${ }^{1} \mathrm{H}$ NMR spectrum of monomeric 11a acquired in $\mathrm{CD}_{3} \mathrm{CN}$ 


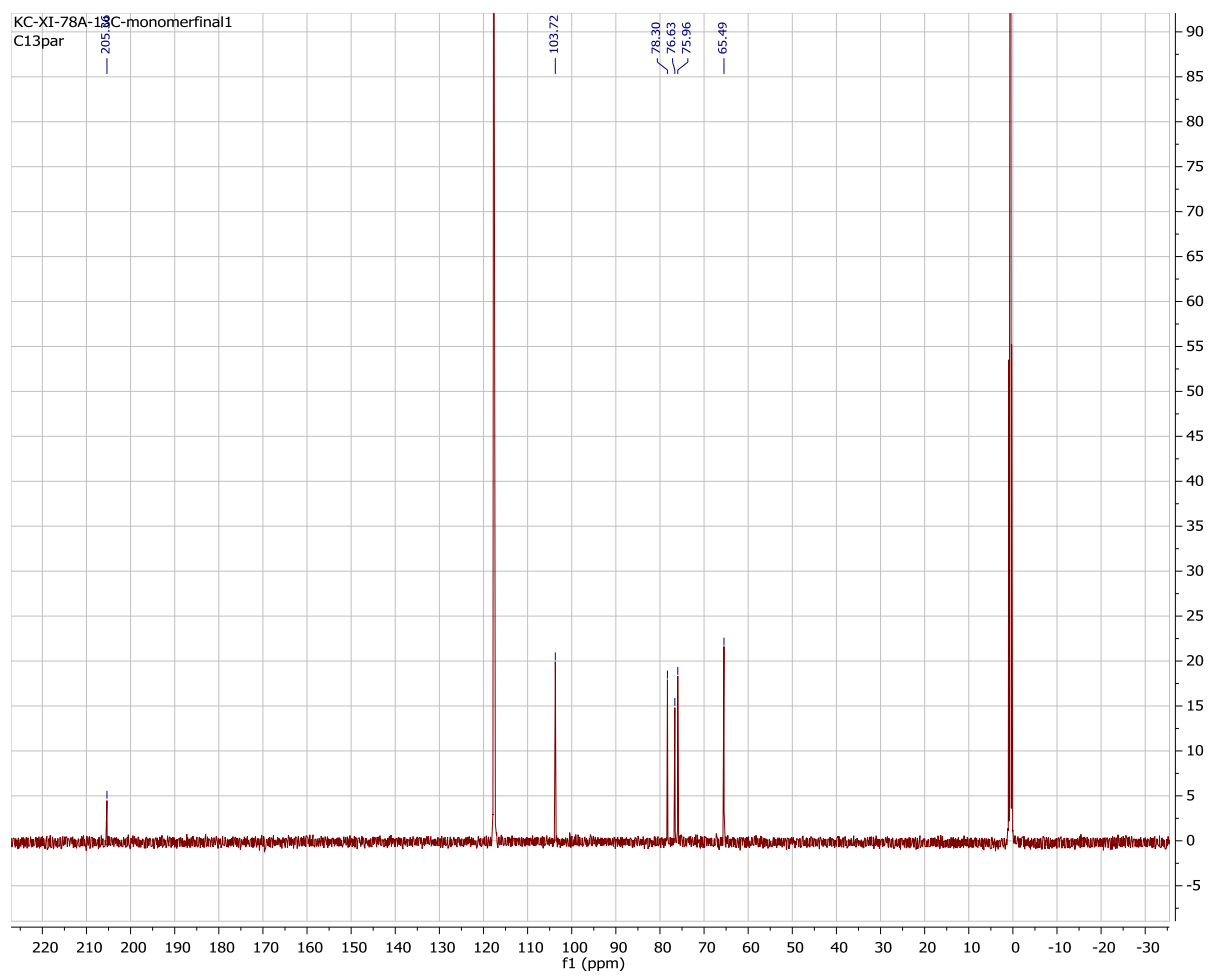

Figure S30. ${ }^{13} \mathrm{C}$ NMR spectrum of monomeric 10 a acquired in $\mathrm{CD}_{3} \mathrm{CN}$. 
Monomer/dimer mixture (in CD3CN)

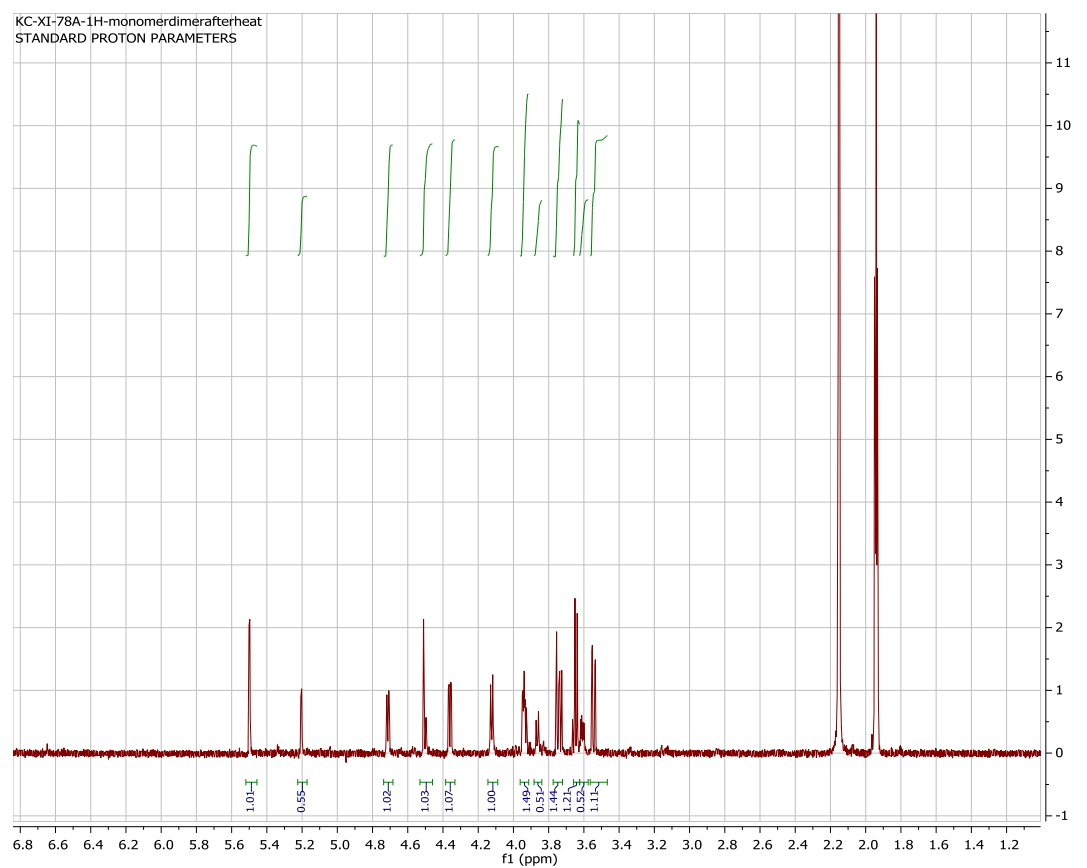

Figure S31. ${ }^{1}$ H NMR spectrum of monomeric/dimeric 11a.

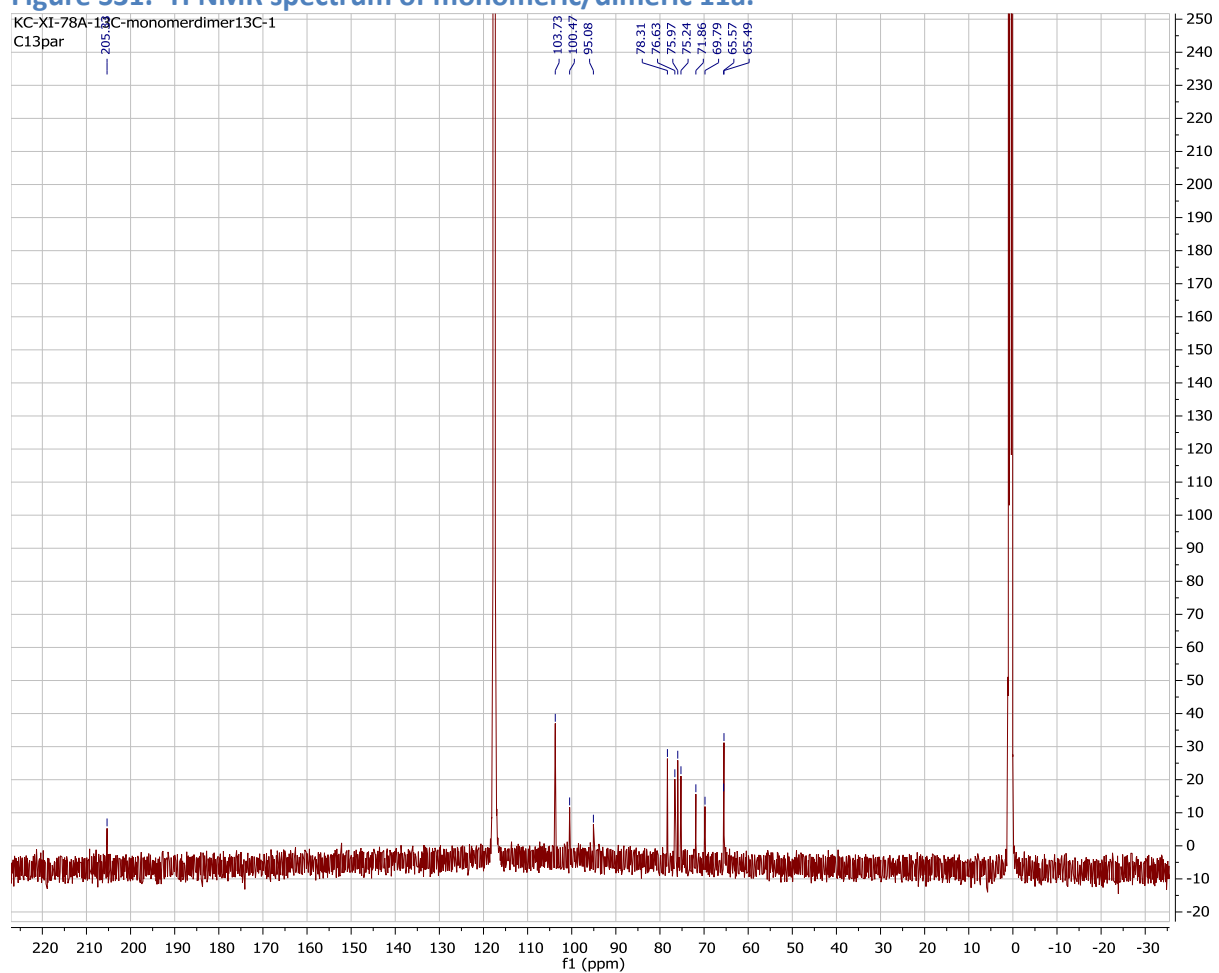

Figure S32. ${ }^{13} \mathrm{C}$ NMR spectrum of monomeric/dimeric 11a. 


\section{Monomer form (in $\mathrm{d}_{6}$-DMSO)}

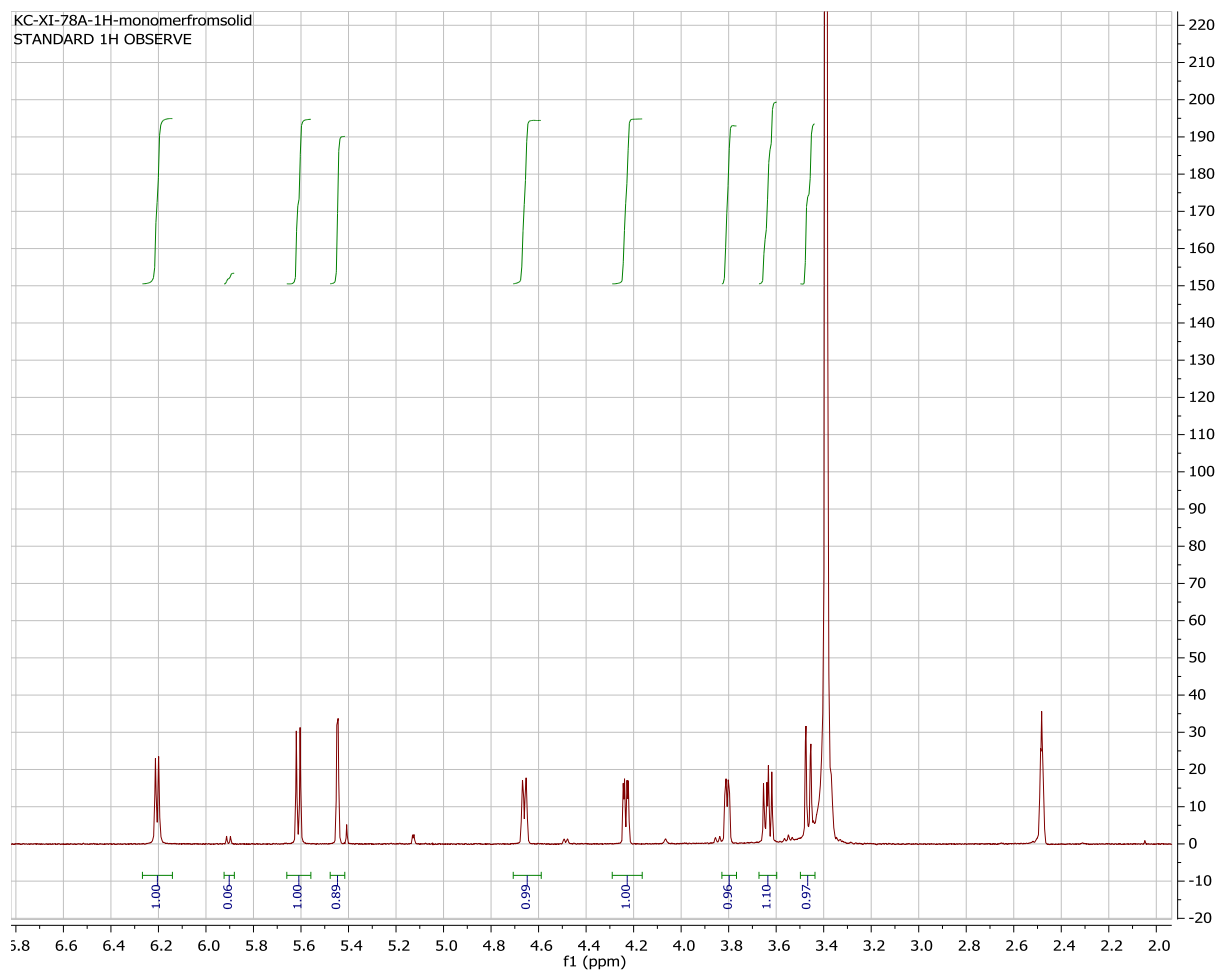

Figure S33. ${ }^{1} \mathrm{H}$ NMR spectrum of monomeric 11 a in $\mathrm{d}_{6}$-DMSO

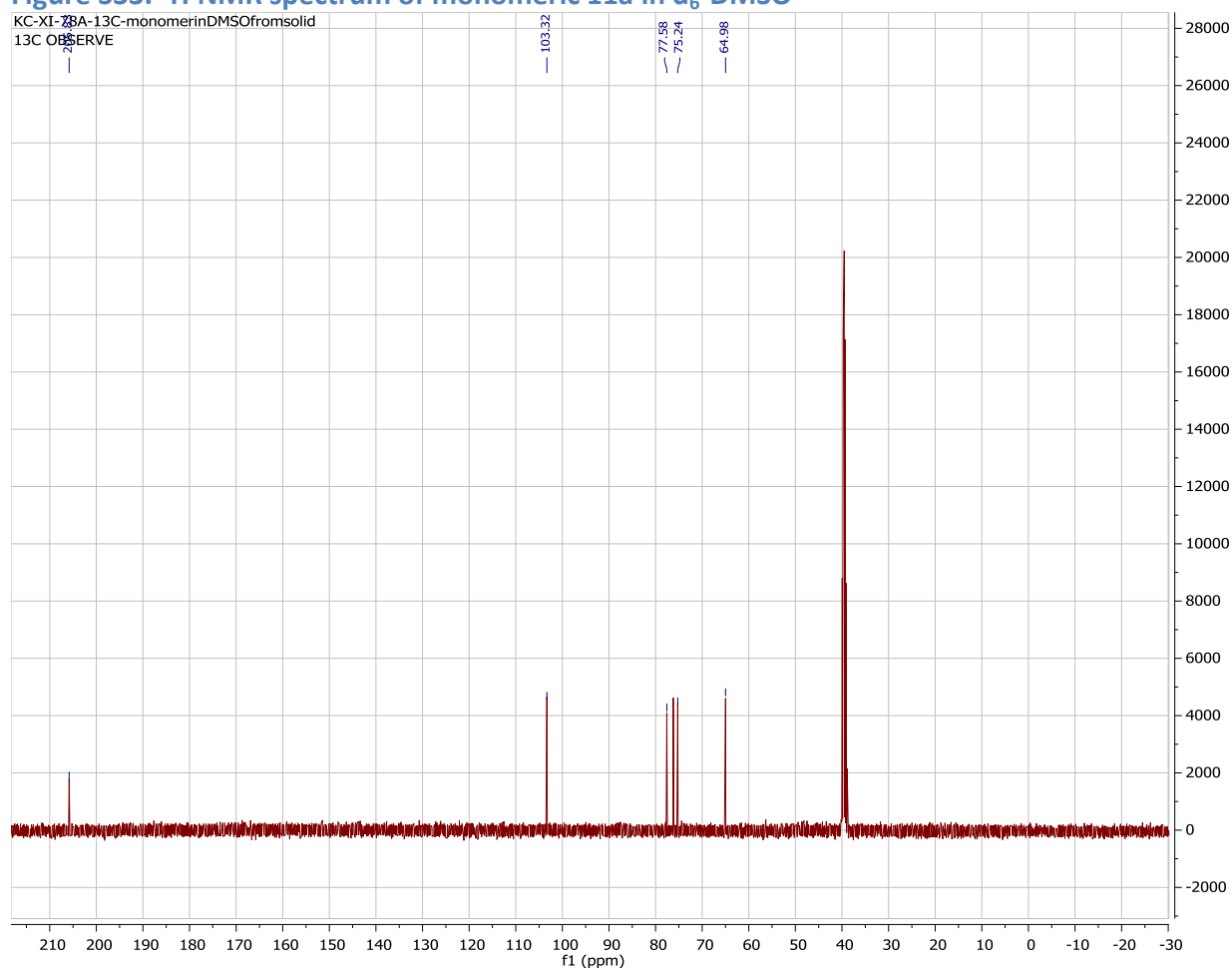

Figure S34. ${ }^{13} \mathrm{C}$ NMR spectrum of monomeric 11 in in $\mathrm{d}_{6}$-DMSO 
Oxidation of methyl-6-deoxy- $\alpha$-D-glucopyranoside in 2,2,2-trifluoroethanol (6a)
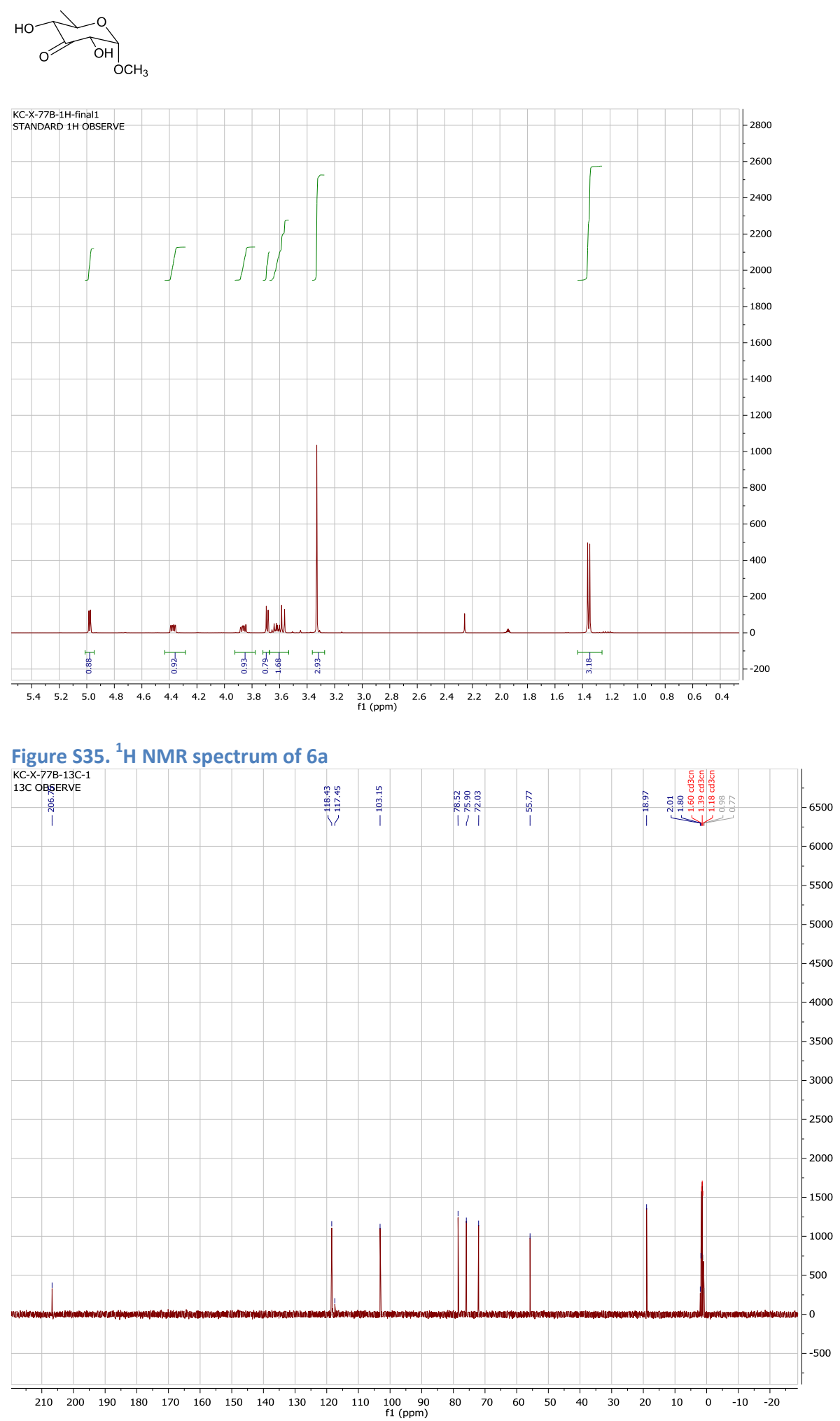

Figure S36. ${ }^{13} \mathrm{C}$ NMR spectrum of $6 a$ 
Oxidation of methyl- $\alpha$-D-galactopyranoside in 2,2,2-trifluoroethanol (12a)

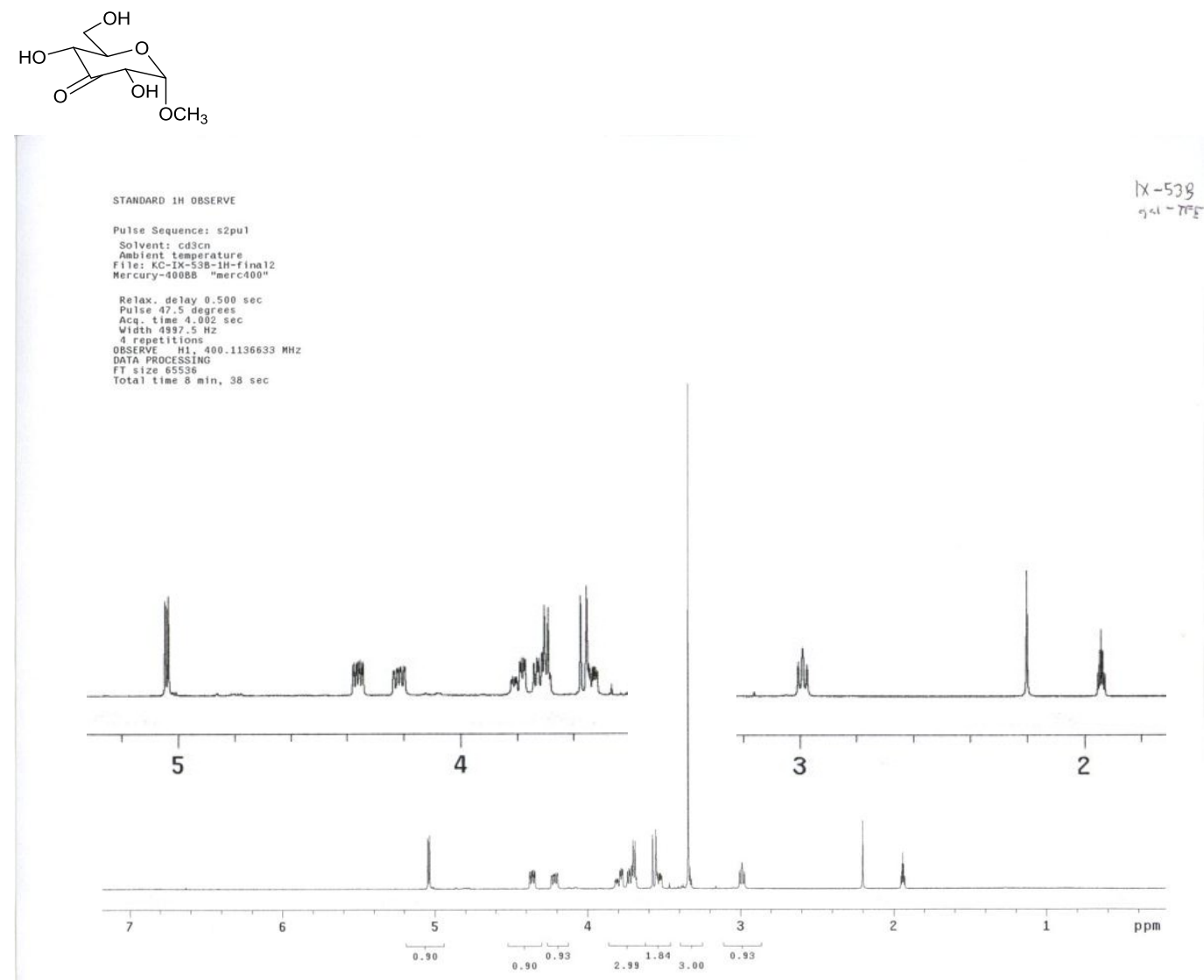

Figure S37. ${ }^{1} \mathrm{H}$ NMR spectrum of $12 \mathrm{a}$ acquired in $\mathrm{CD}_{3} \mathrm{CN}$ 


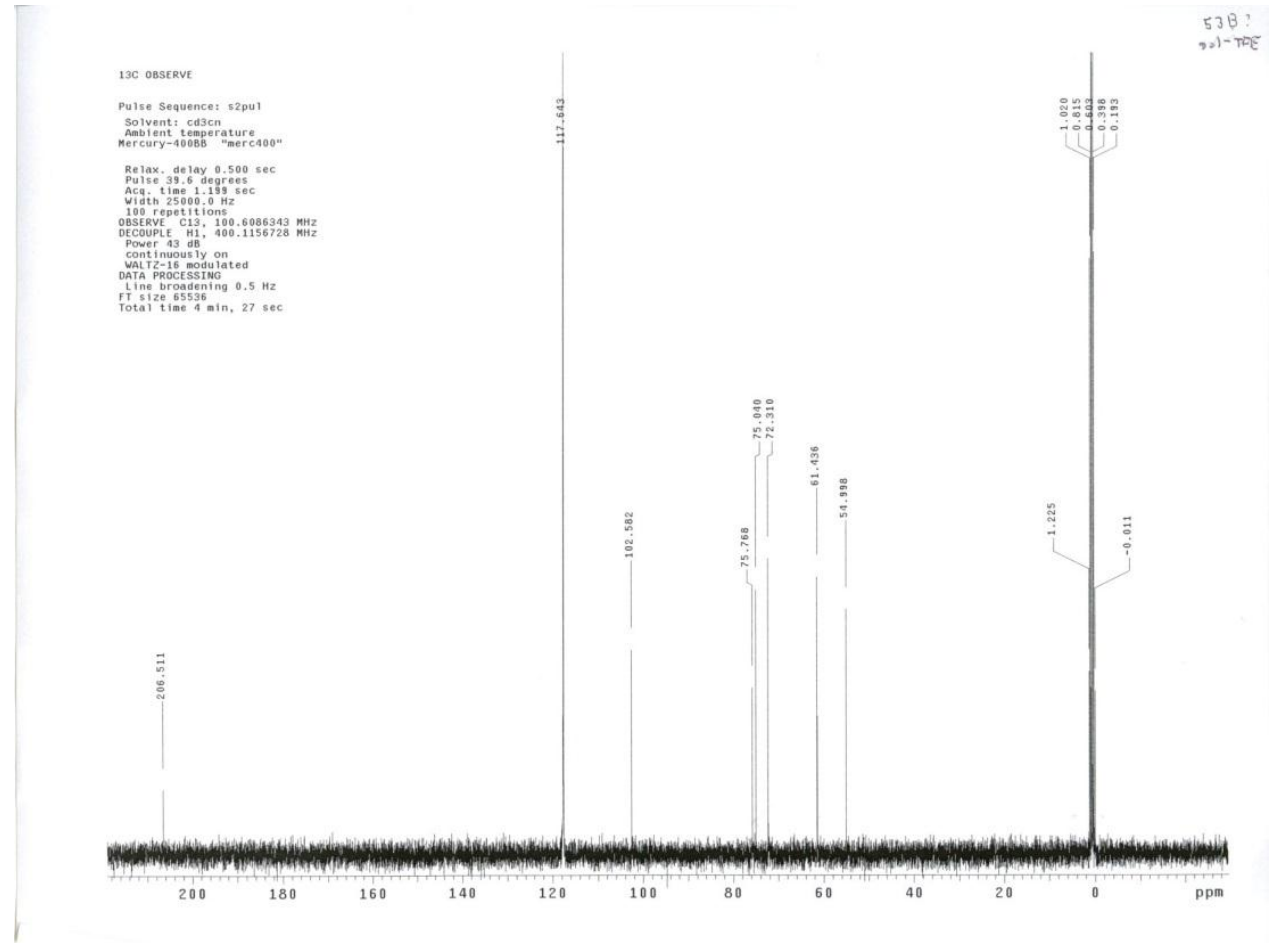

Figure S38. ${ }^{13} \mathrm{C}$ NMR spectrum of $12 \mathrm{a}$ acquired in $\mathrm{CD}_{3} \mathrm{CN}$ 


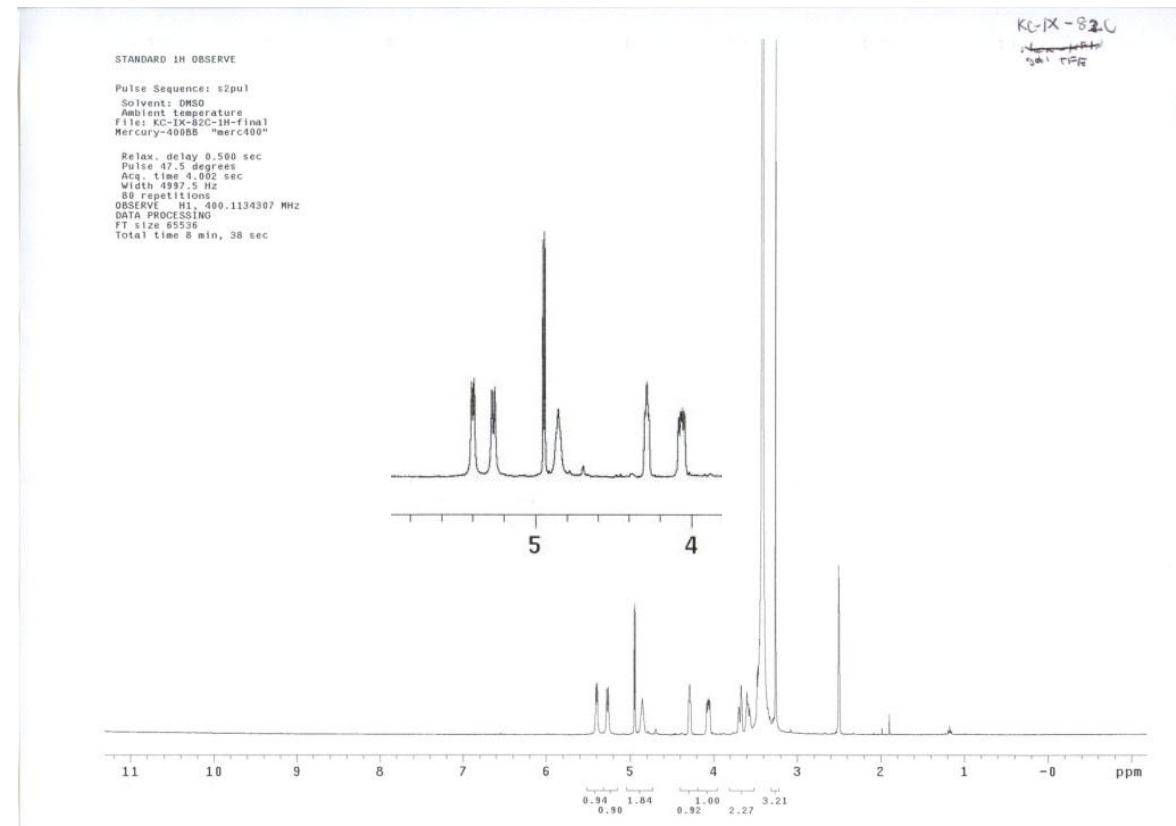

Figure S39. ${ }^{1} \mathrm{H}$ NMR spectrum of 12 a acquired in $\mathrm{d}_{6}$-DMSO

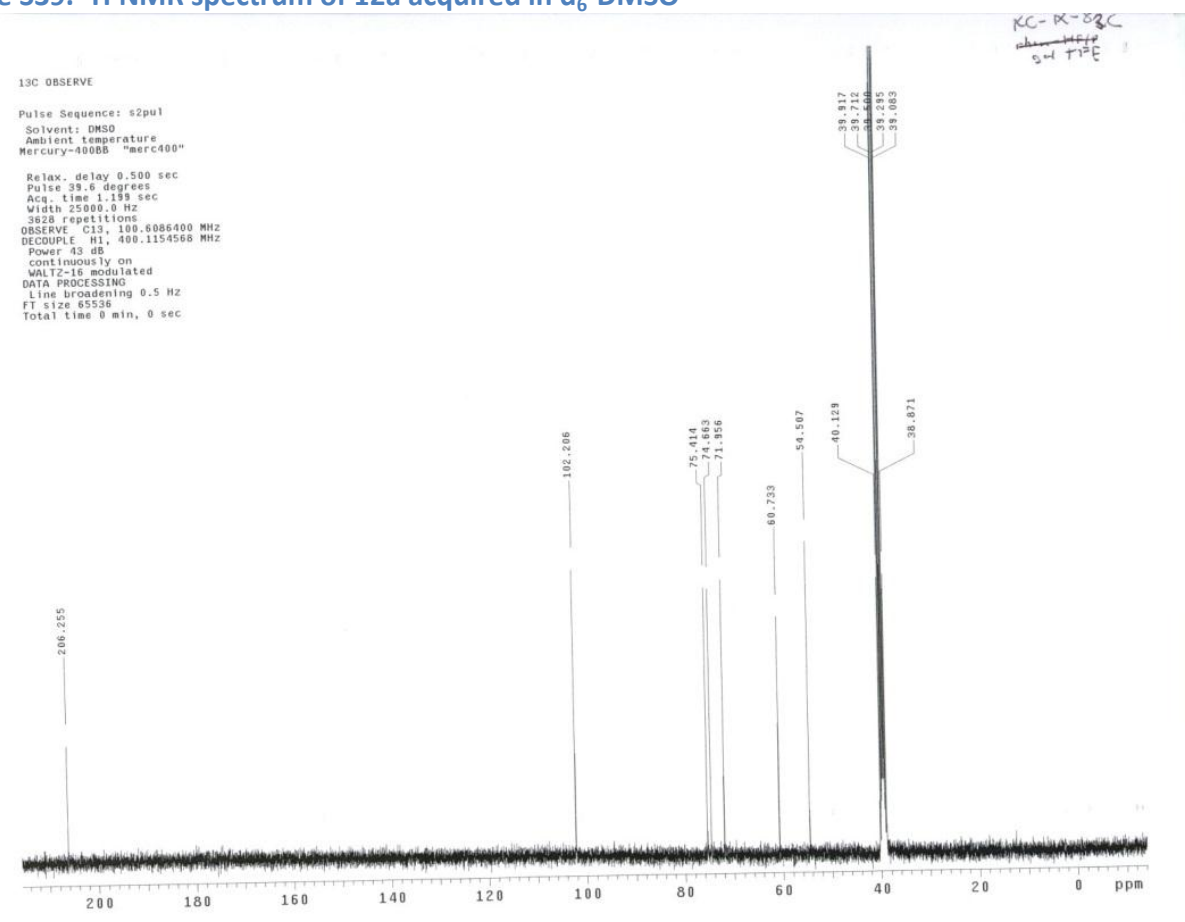

Figure $S 40 .{ }^{13} \mathrm{C}$ NMR spectrum of $12 \mathrm{a}$ acquired in $\mathrm{d}_{6}$-DMSO 
Oxidation of methyl- $\alpha$-L-fucopyranoside in 2,2,2-trifluoroethanol (8c)

Ho $\pi_{0}^{\circ} Z_{\mathrm{OH}}^{\mathrm{Me}}$

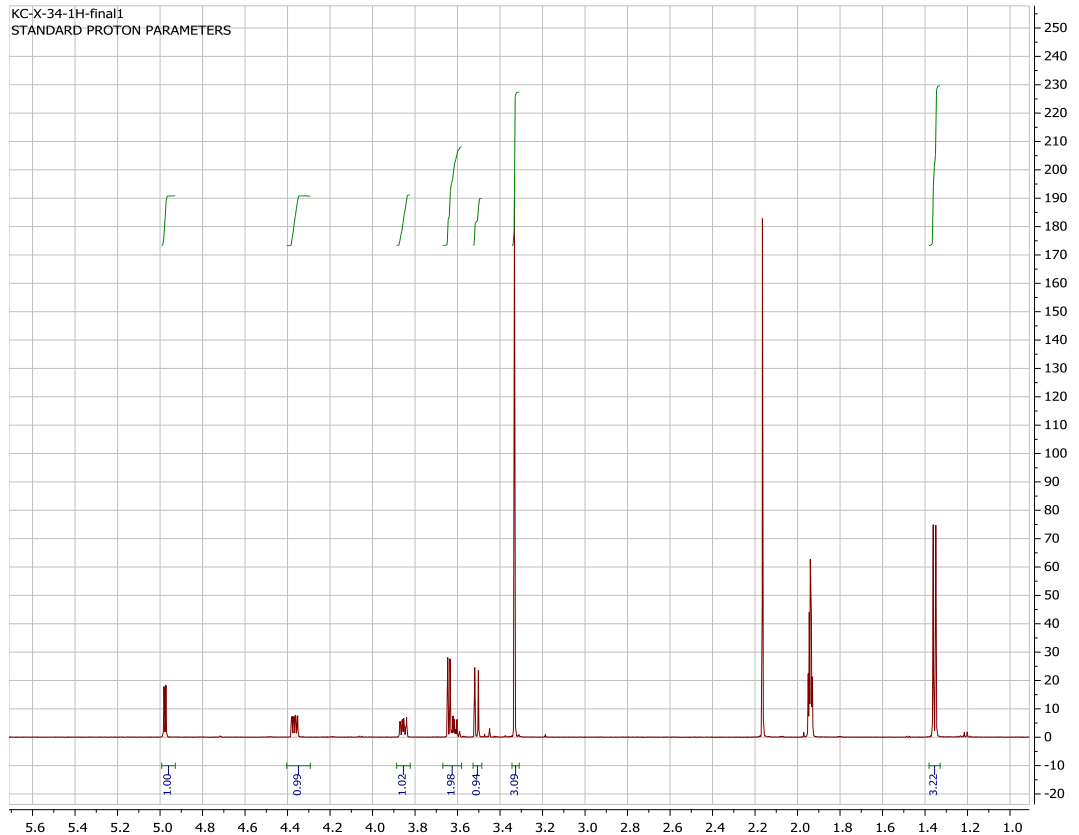

Figure $\mathrm{S} 41 .{ }^{1} \mathrm{H}$ NMR spectrum of $8 \mathrm{c}$ acquired in $\mathrm{CD}_{3} \mathrm{CN}$

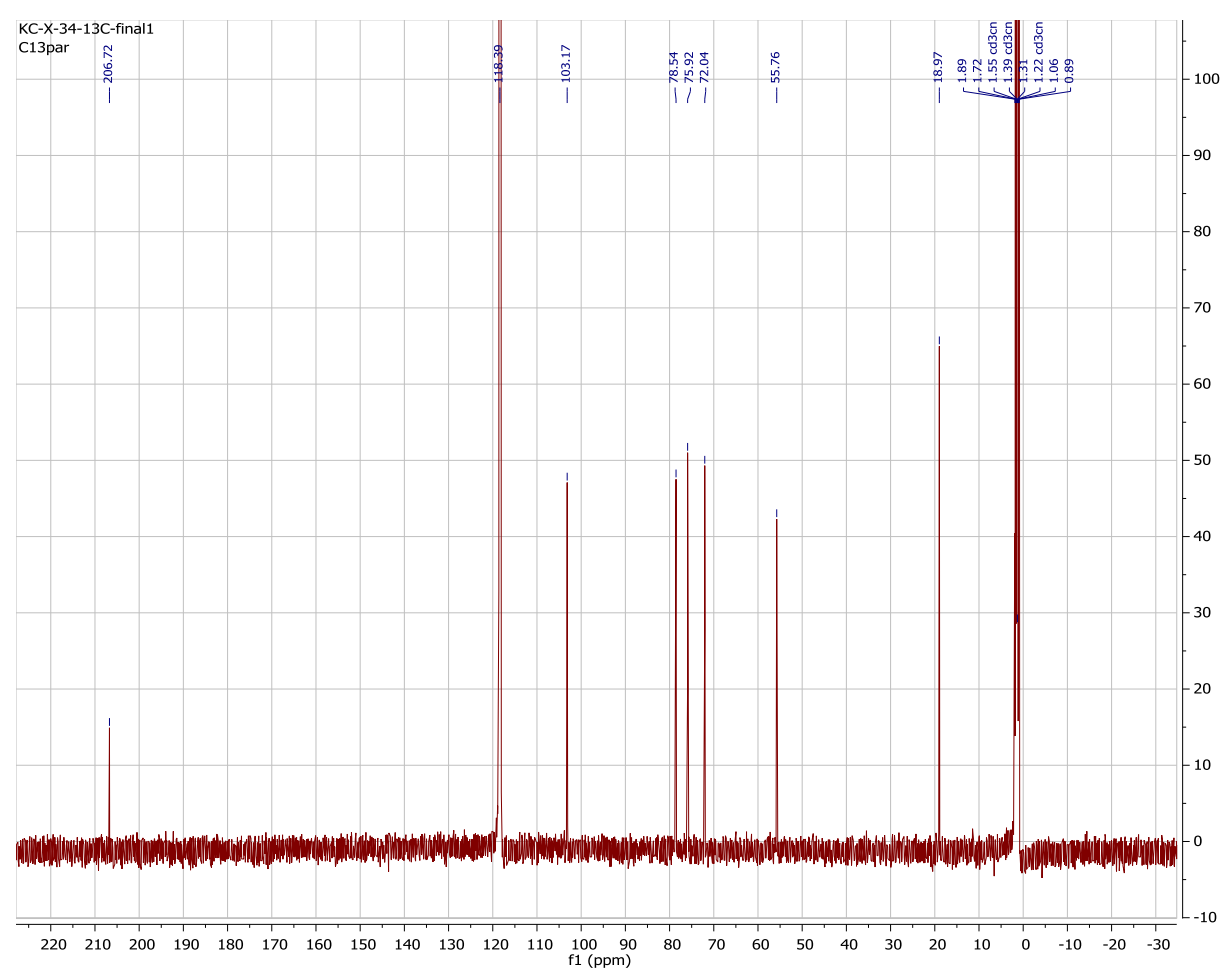

Figure $\mathrm{S} 42 .{ }^{13} \mathrm{C}$ NMR spectrum of $8 \mathrm{c}$ acquired in $\mathrm{CD}_{3} \mathrm{CN}$ 


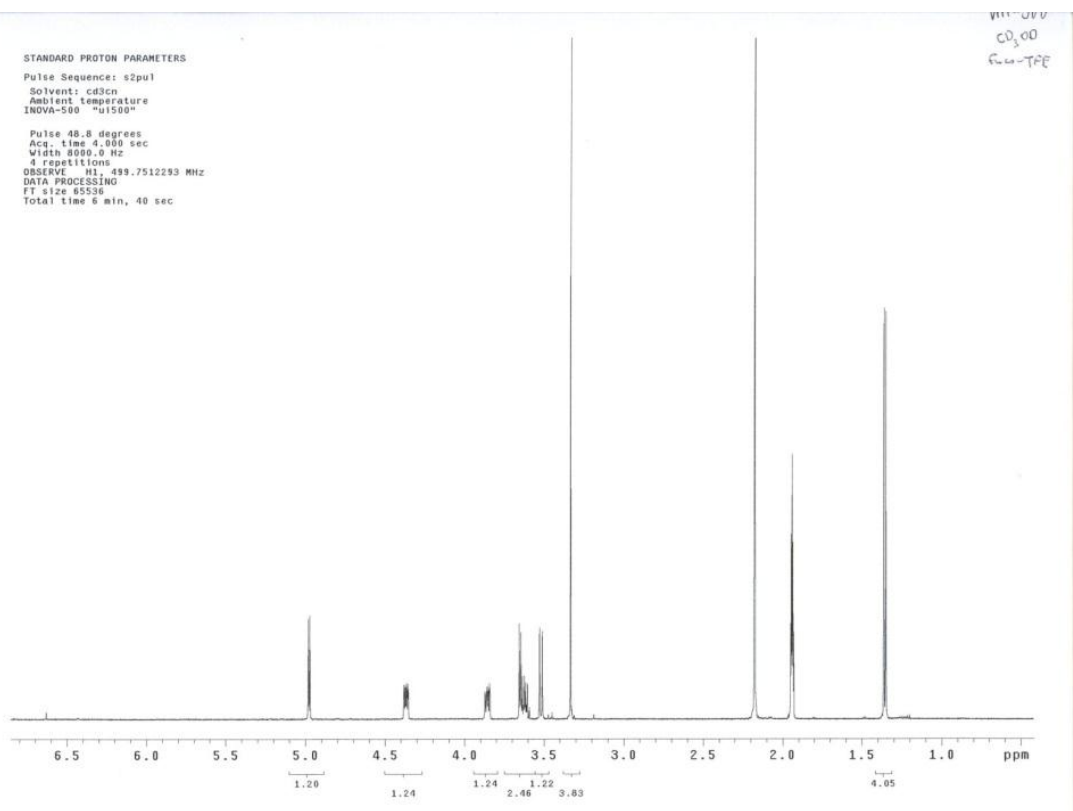

Figure S43. ${ }^{1} \mathrm{H}$ NMR spectrum of $8 \mathrm{c}$ acquired in $\mathrm{CD}_{3} \mathrm{OD}$

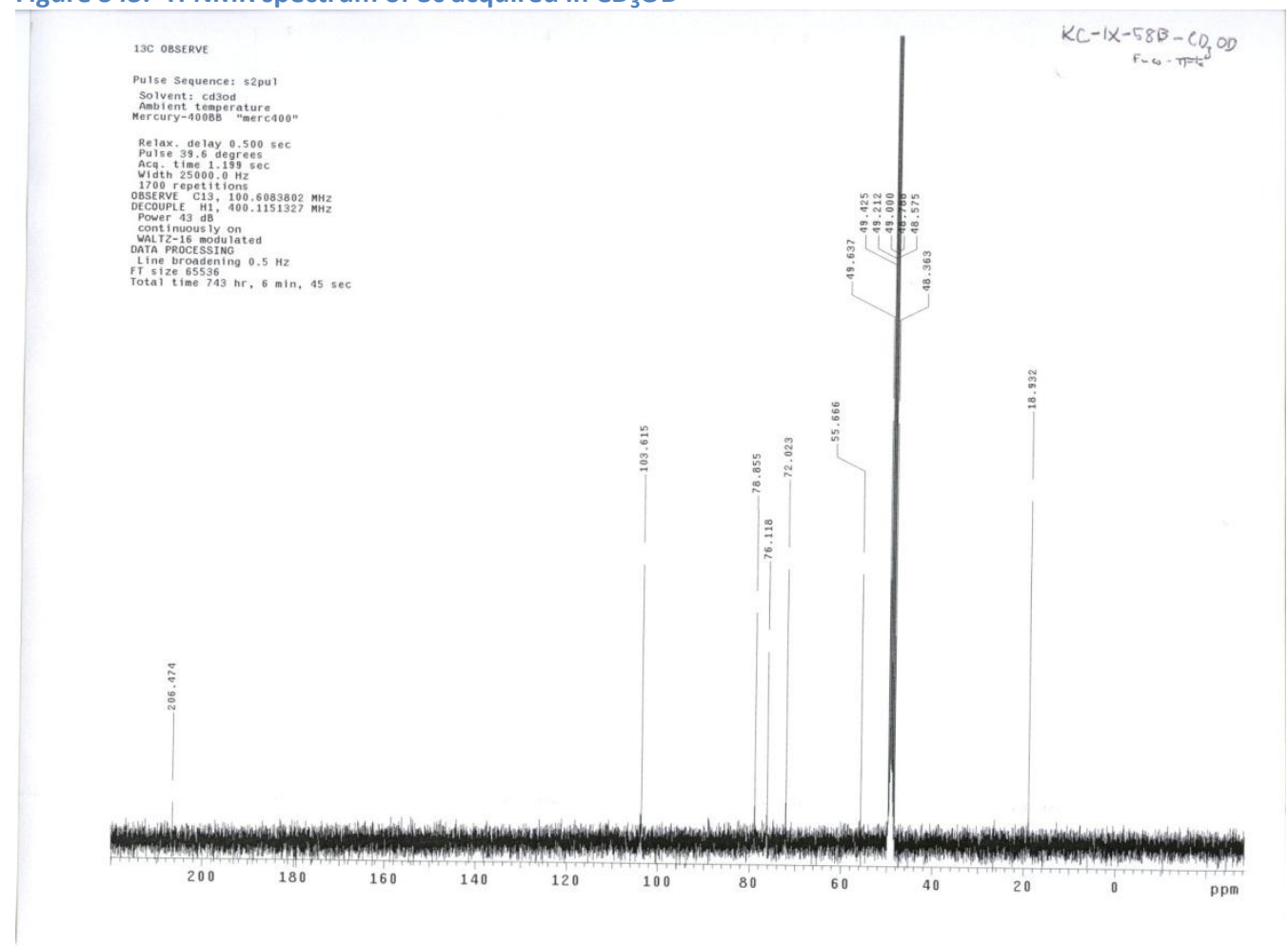

Figure $544 .{ }^{13} \mathrm{C}$ NMR spectrum of $8 \mathrm{c}$ acquired in $\mathrm{CD}_{3} \mathrm{OD}$ 
Hydroxylamine addition to methyl 3-keto-6-deoxy- $\alpha$-L-glucopyranoside (8d)

$\mathrm{N}_{\mathrm{NOMe}}^{\mathrm{OMe}}$

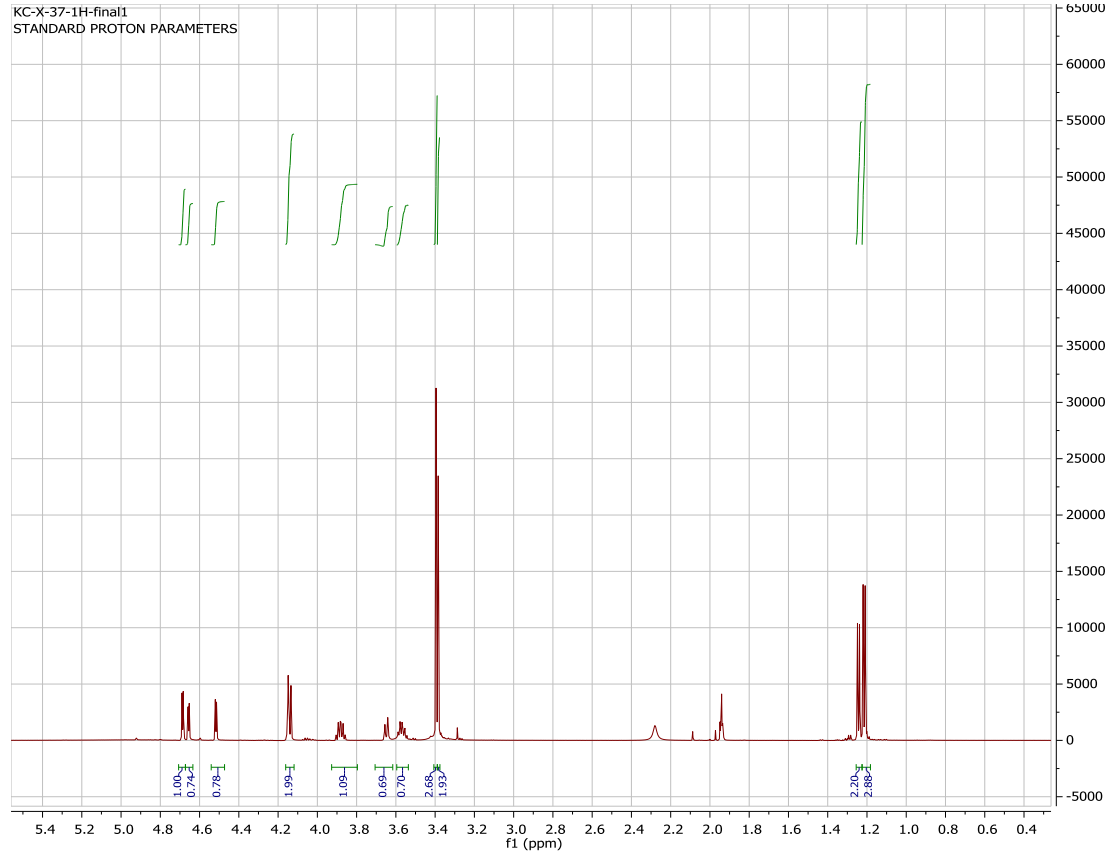

Figure $\mathbf{S 4 5} .{ }^{1} \mathrm{H}$ spectrum of $8 \mathrm{~d}$

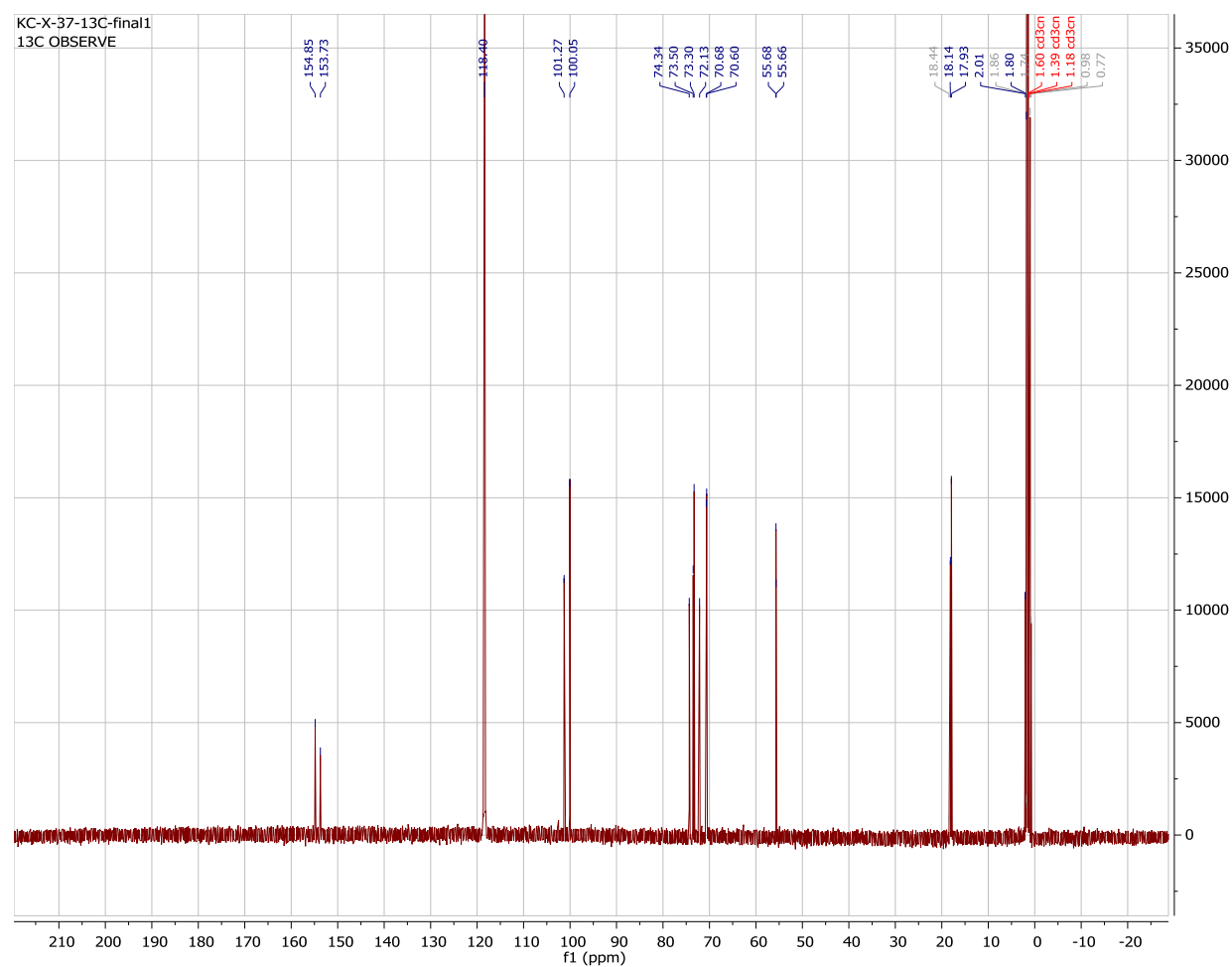

Figure S46. ${ }^{13} \mathrm{C}$ spectrum of $8 d$ 


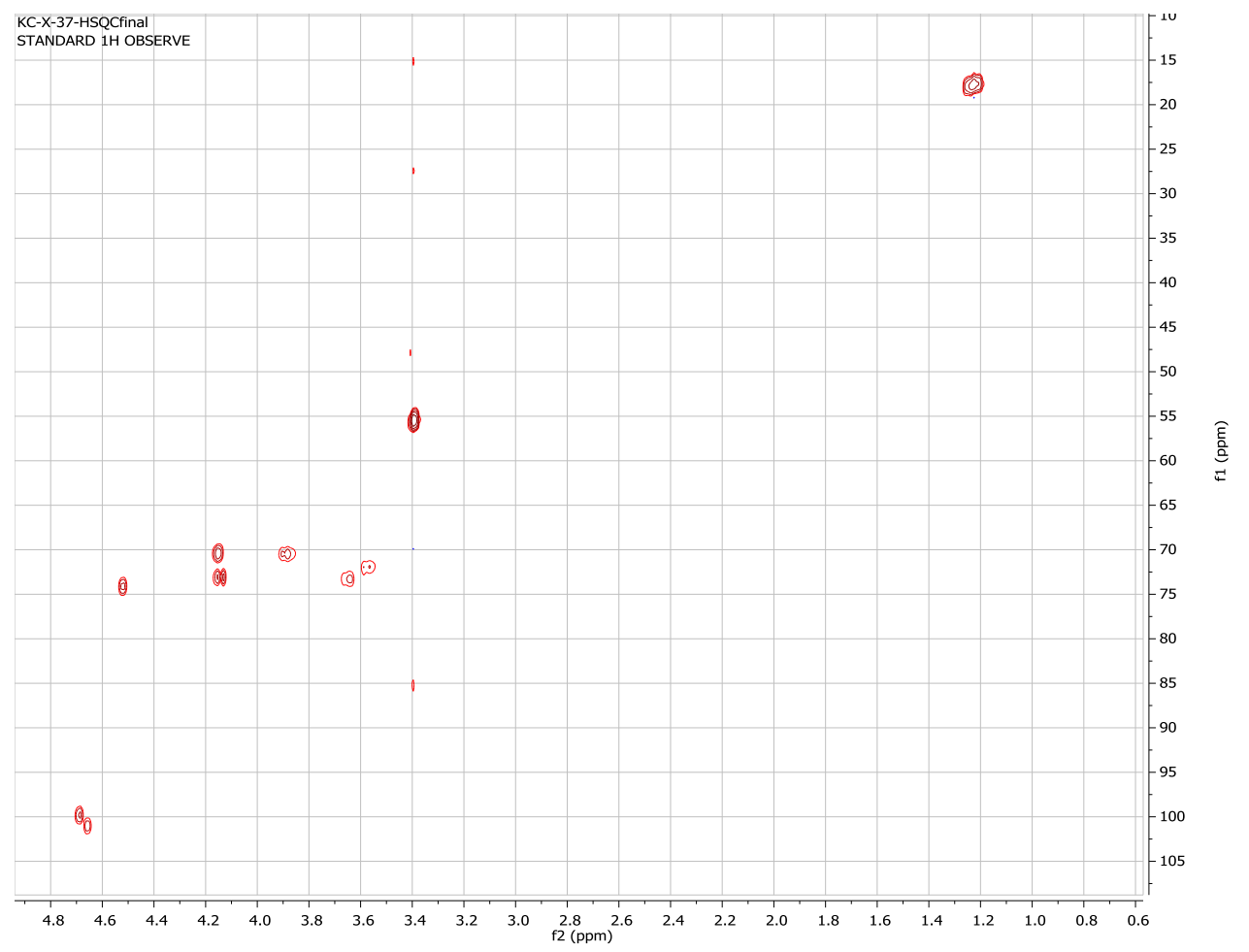

Figure S47. HSQC spectrum of $8 d$

KC-X-37-COSY
STANDARD PROTON PARAMETERS

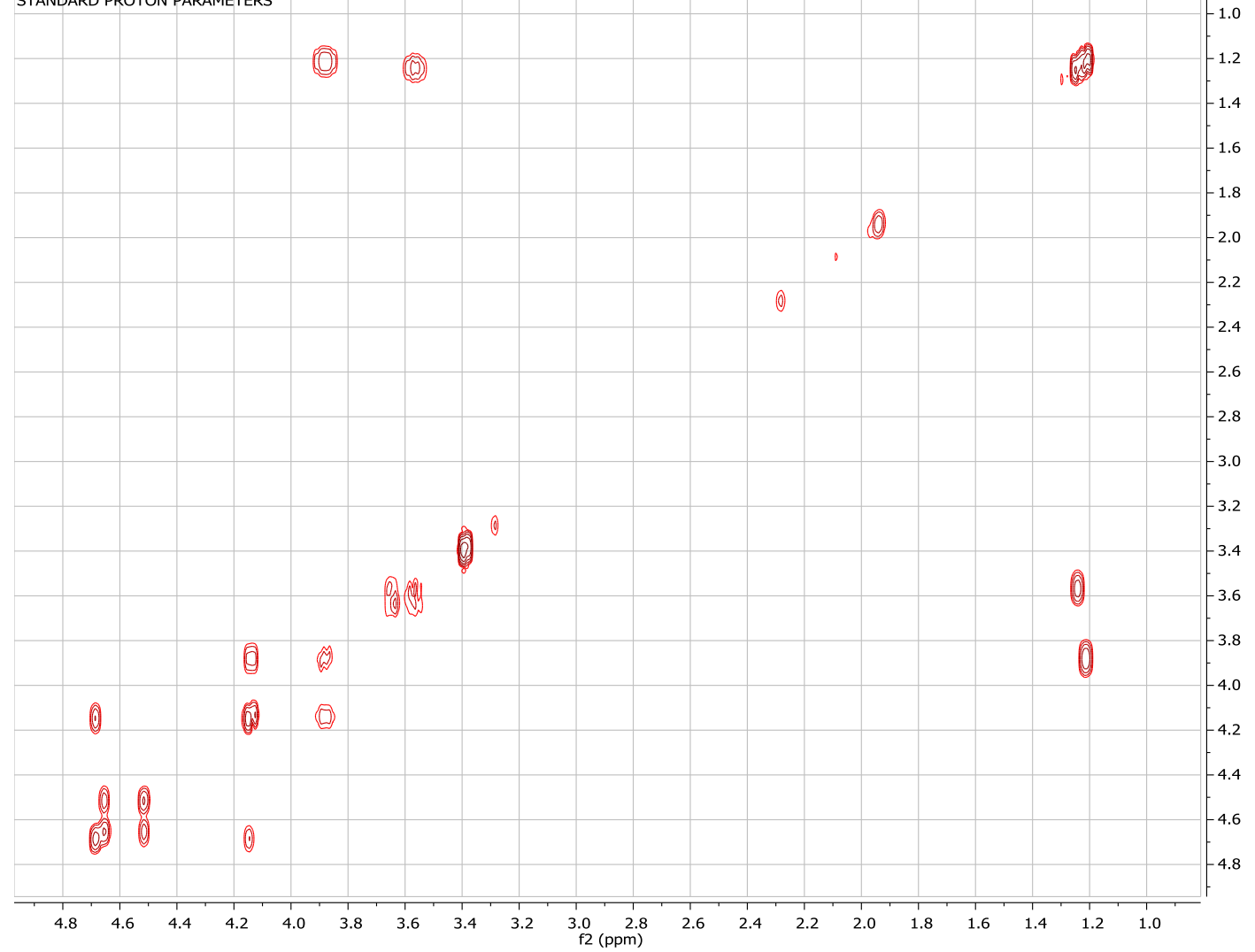

Figure S48. COSY spectrum of $8 d$ 


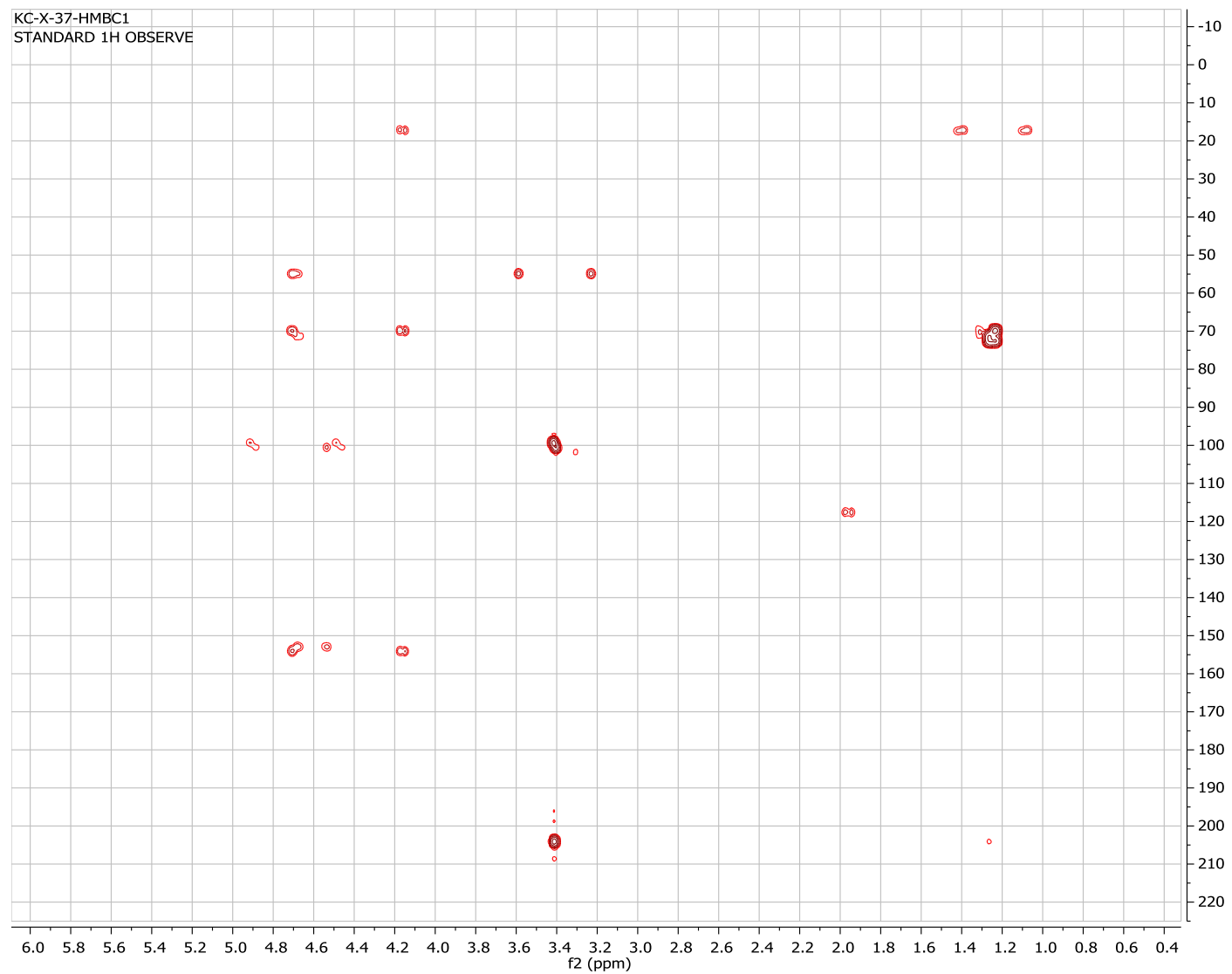

Figure S49. HMBC spectrum of $8 d$ 
Methoxyamine addition to methyl 3-keto-6-deoxy- $\alpha$-L-glucopyranoside (8e)

$\mathrm{T}_{\mathrm{N}_{\mathrm{OMMe}}}^{\mathrm{OMe}}$

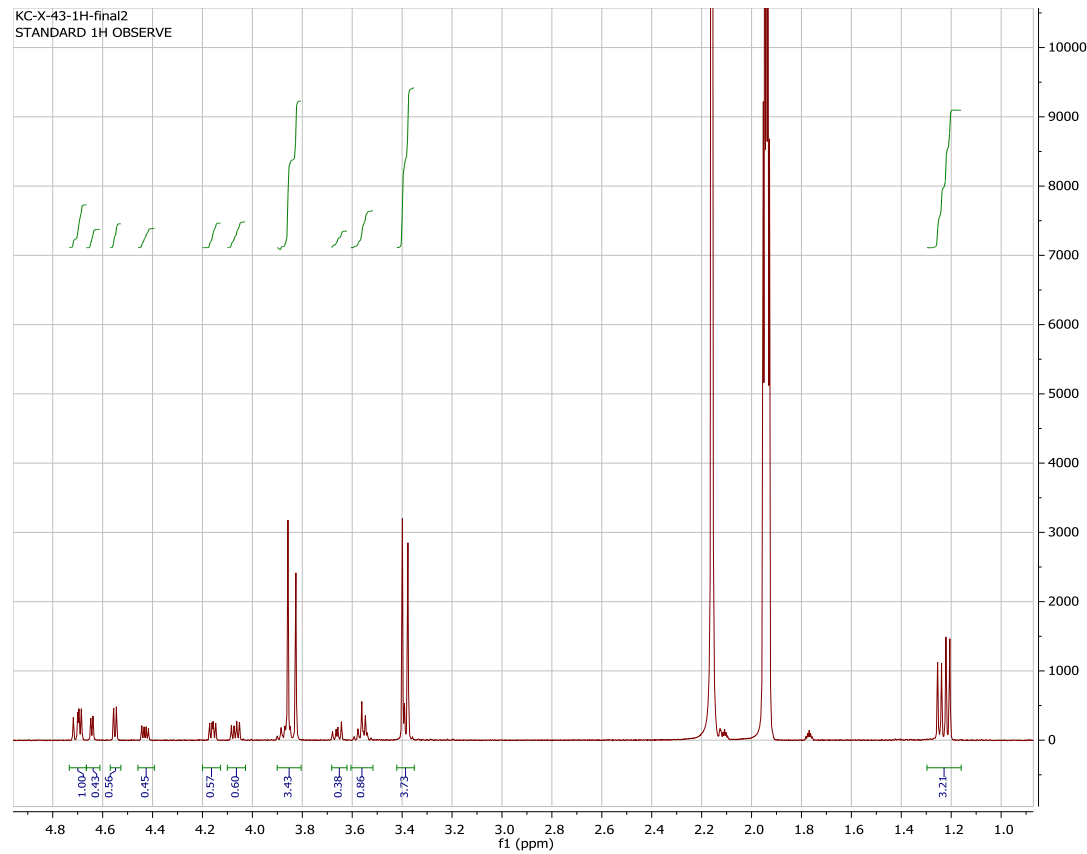

Figure $550 .{ }^{1} \mathrm{H}$ spectrum of $8 \mathrm{e}$

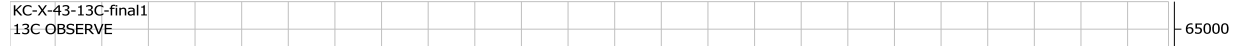
13C OBSERVE

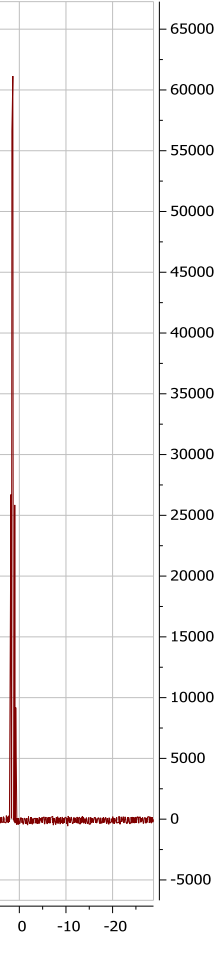

Figure S51. ${ }^{13} \mathrm{C}$ spectrum of $8 \mathrm{e}$ 
Hydrogenation of E/Z-methyl-3-O-methyloxime-6-deoxy- $\alpha$-L-glucopyranoside (8f)

HO $-\operatorname{to}^{\mathrm{NH}} \overbrace{\mathrm{OH}}^{\mathrm{MMe}}$

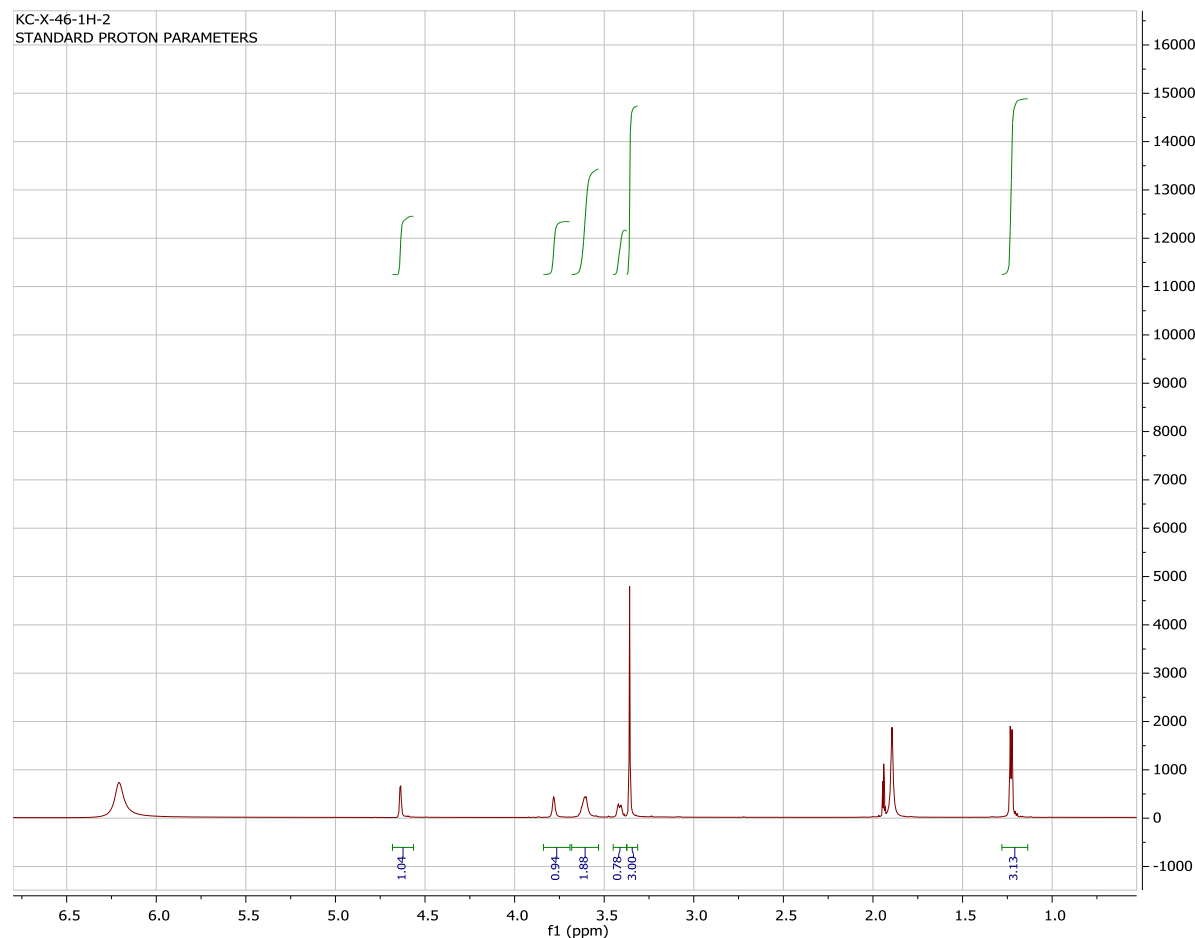

Figure $552 .{ }^{1} \mathrm{H}$ spectrum of $8 \mathrm{f}$

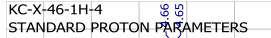
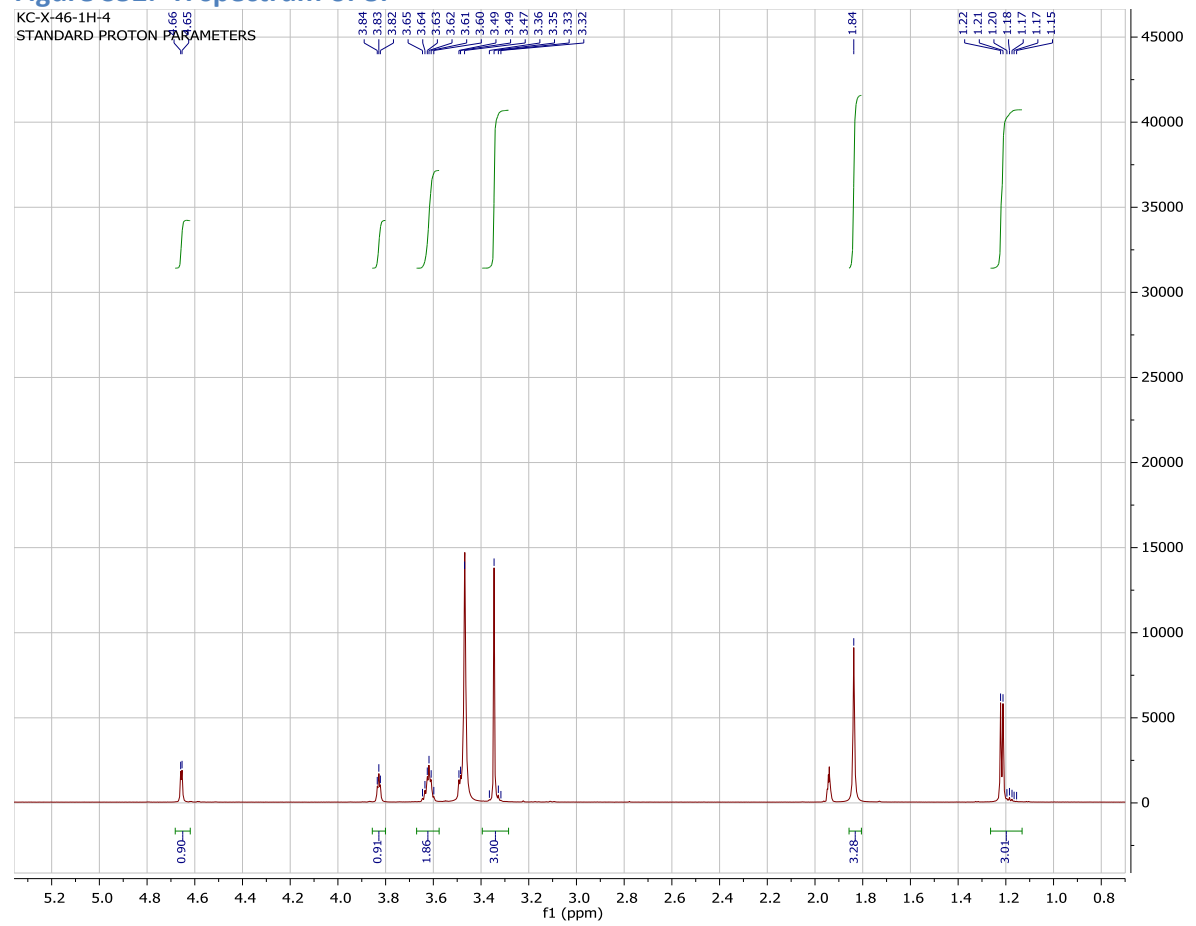

Figure S53. ${ }^{1} \mathrm{H}$ spectrum of $8 \mathrm{f}$ after addition of $\mathrm{D}_{2} \mathrm{O}$ 


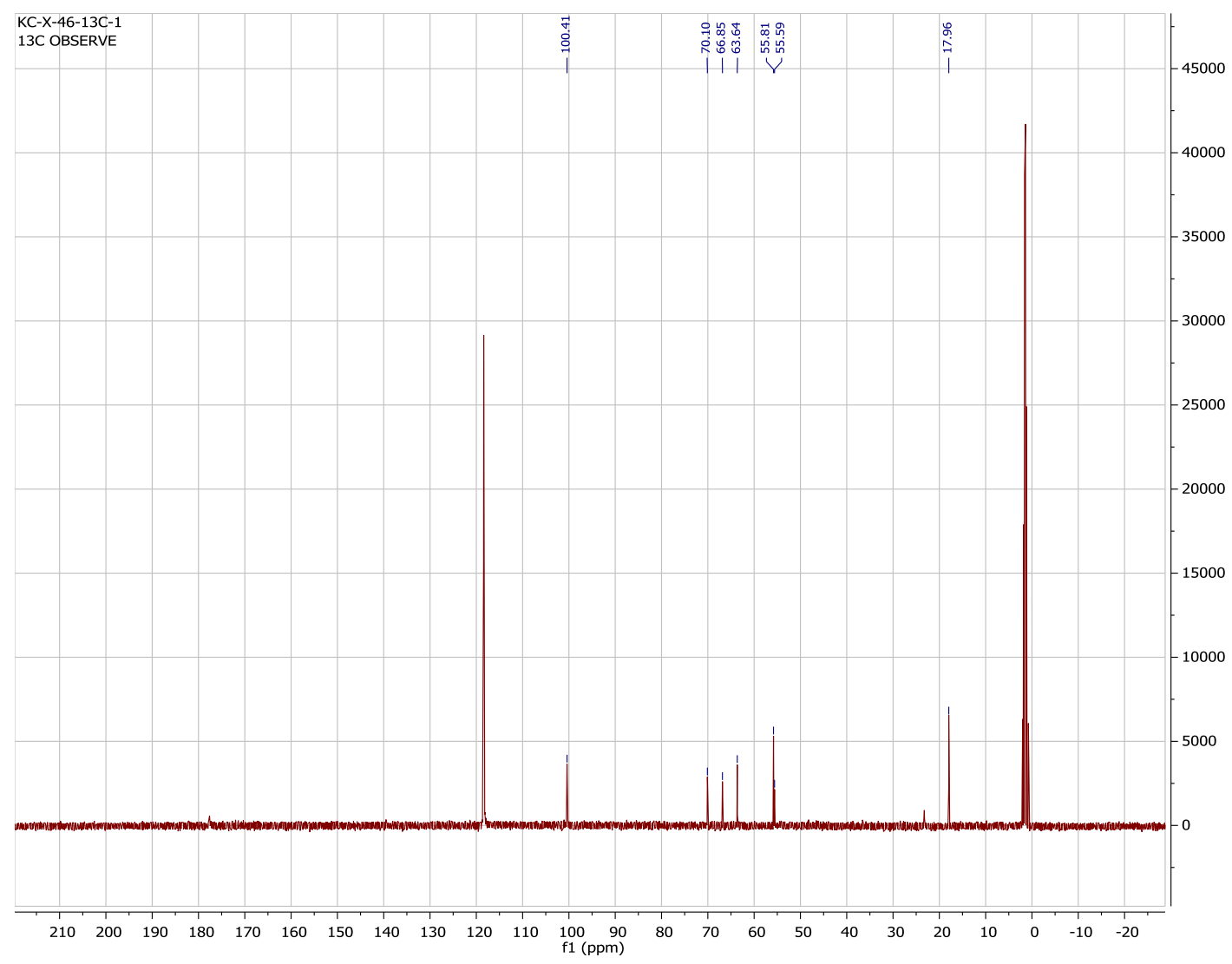

Figure $554 .{ }^{13} \mathrm{C}$ spectrum of $8 f$ 
Peracetylation of methyl-3-amino-6-deoxy- $\alpha$-L-glucopyranoside (8g)
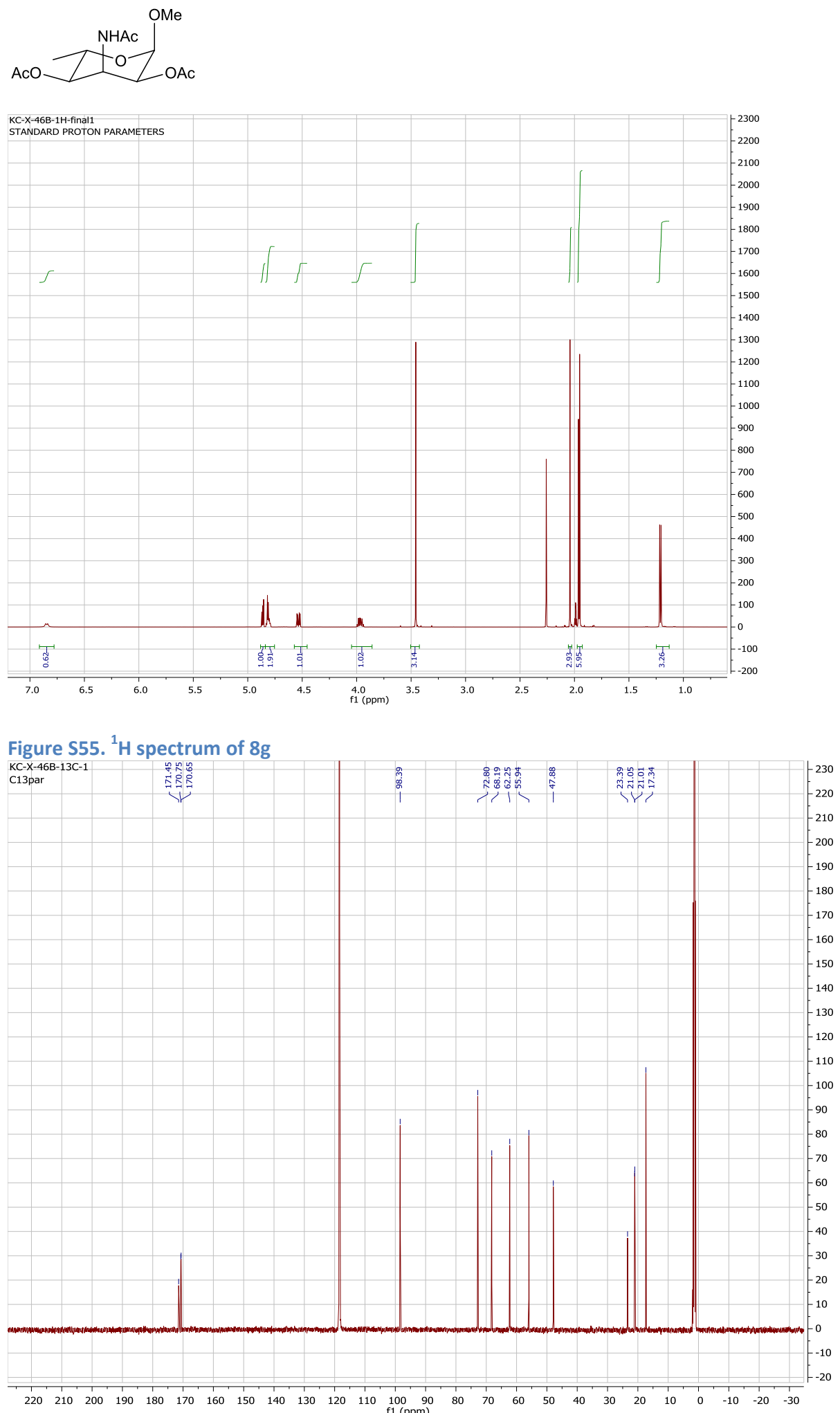

Figure $556 .{ }^{13} \mathrm{C}$ spectrum of $8 \mathrm{~g}$ 
Oxidation of 2-acetamido-2-deoxy- $\alpha$-D-glucopyranose in 2,2,2-trifluoroethanol (16a)

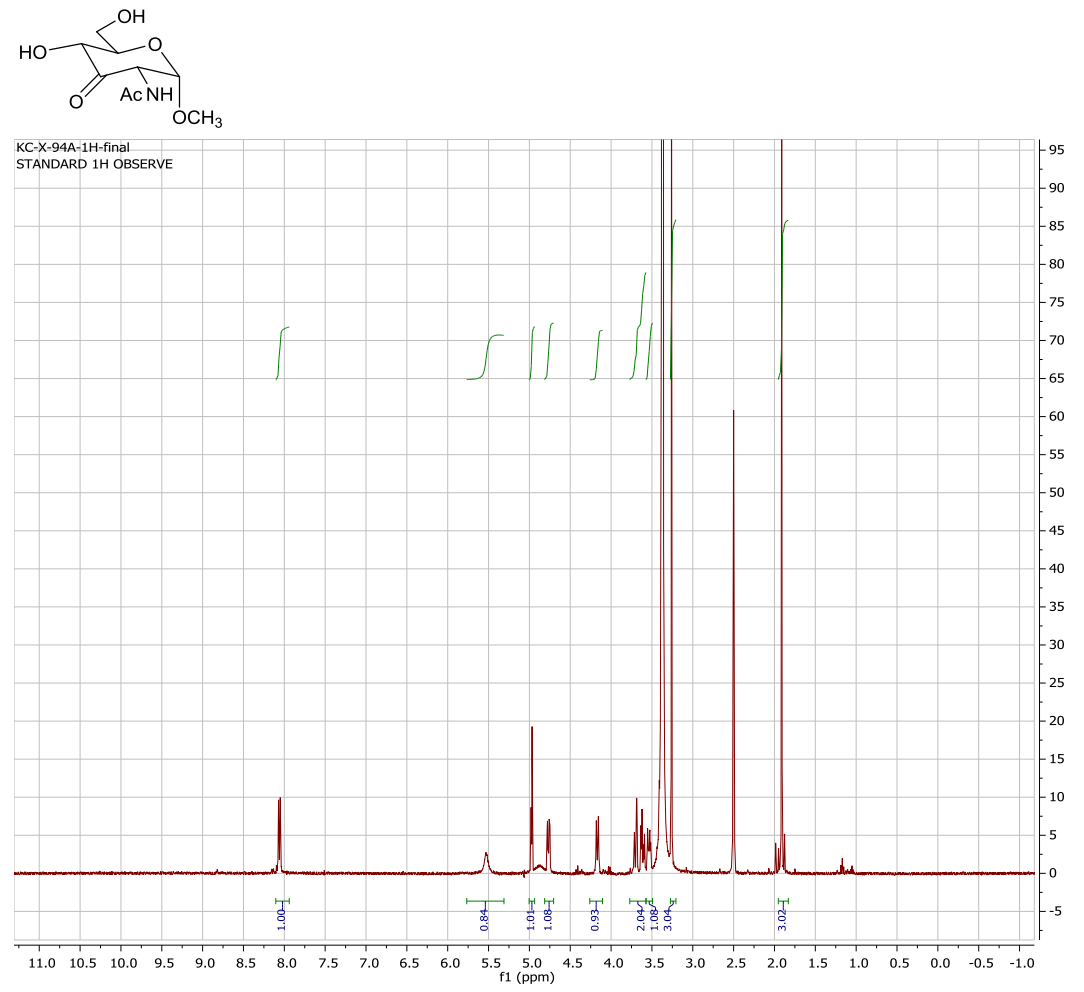

Figure S57. ${ }^{1} \mathrm{H}$ NMR spectrum of 16 a

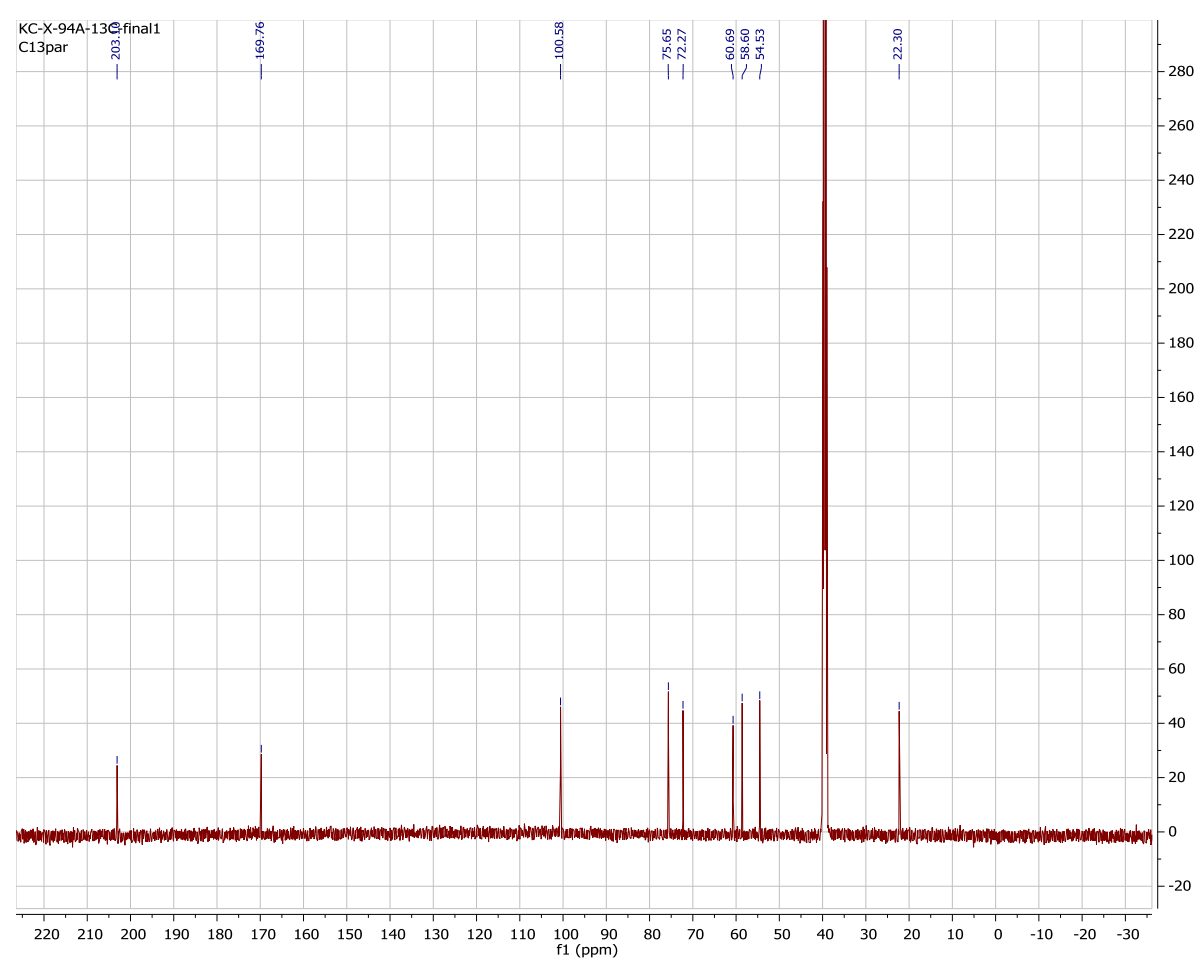

Figure S58. ${ }^{13} \mathrm{C}$ NMR spectrum of $16 a$ 
Oxidation of 2-acetamido-2-deoxy- $\beta$-D-glucopyranose in 2,2,2-trifluoroethanol (17a)

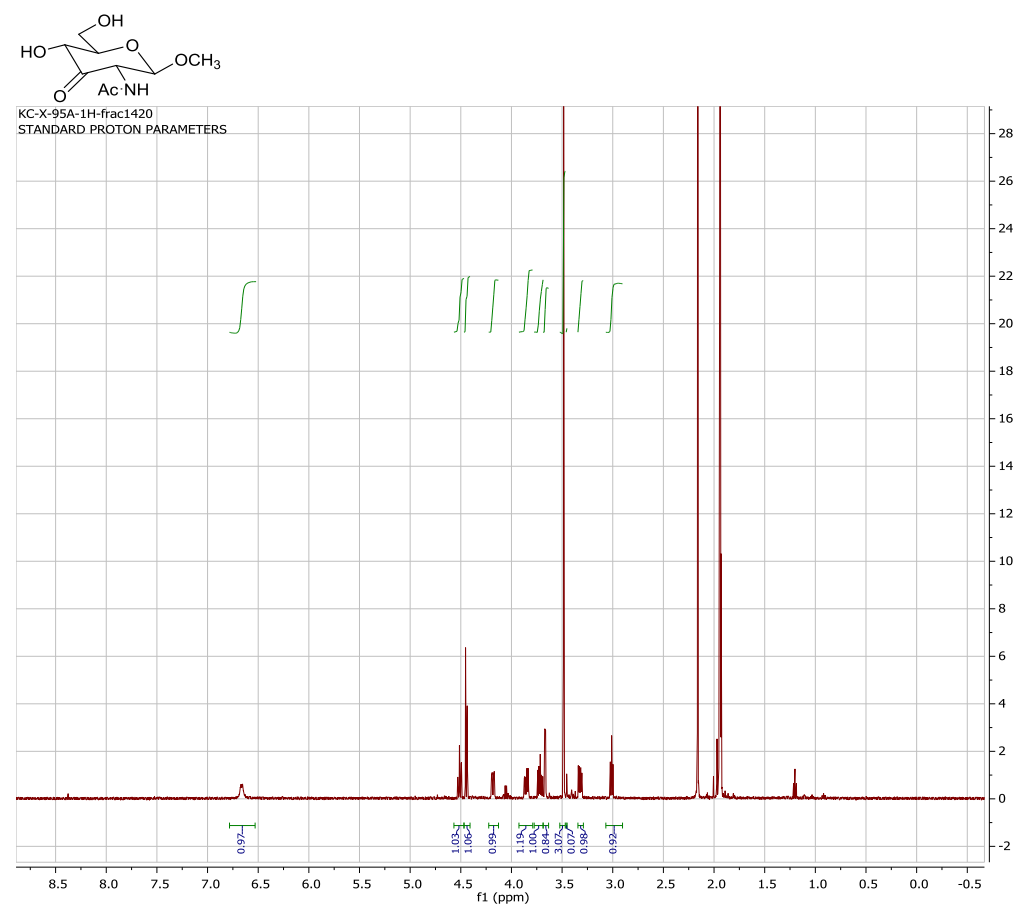

Figure S59. ${ }^{1}$ H NMR spectrum of 17 a (sample prepared rapidly after evaporation) KC-X-95A-Postworkup 2nd-1H-1
STANDARD PROTON PARAMETERS

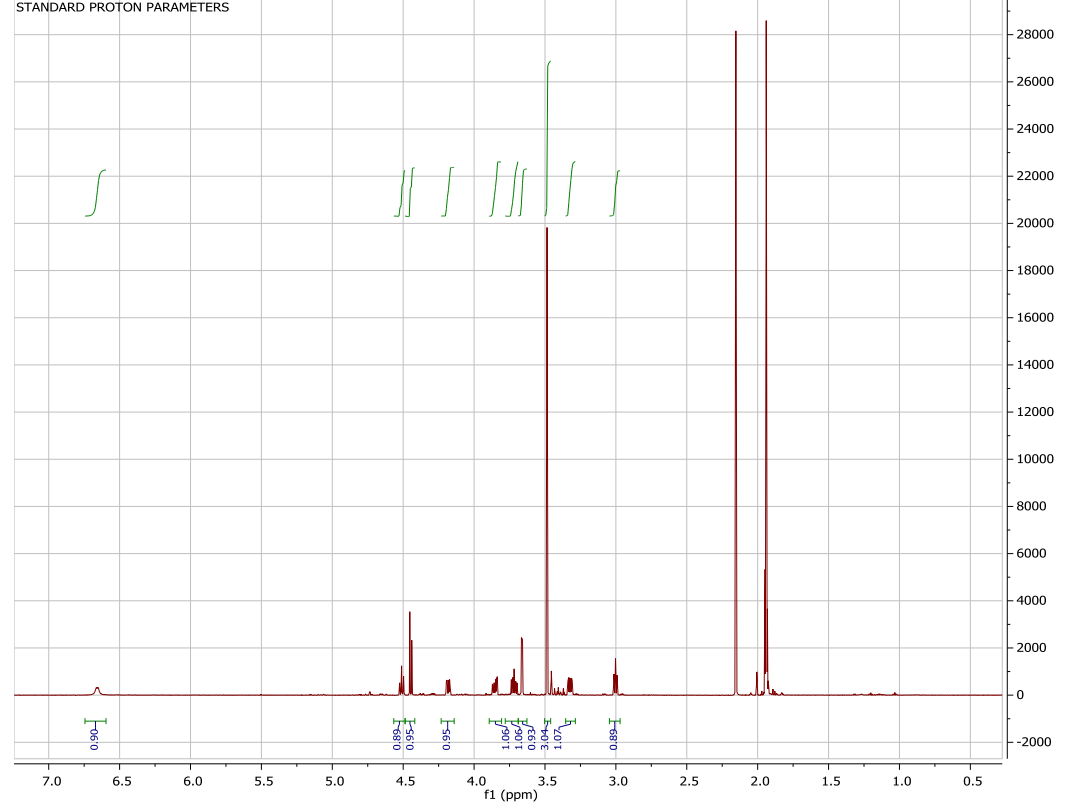

Figure $60 .{ }^{1} \mathrm{H}$ NMR spectrum of 17 a after 1 hour standing 


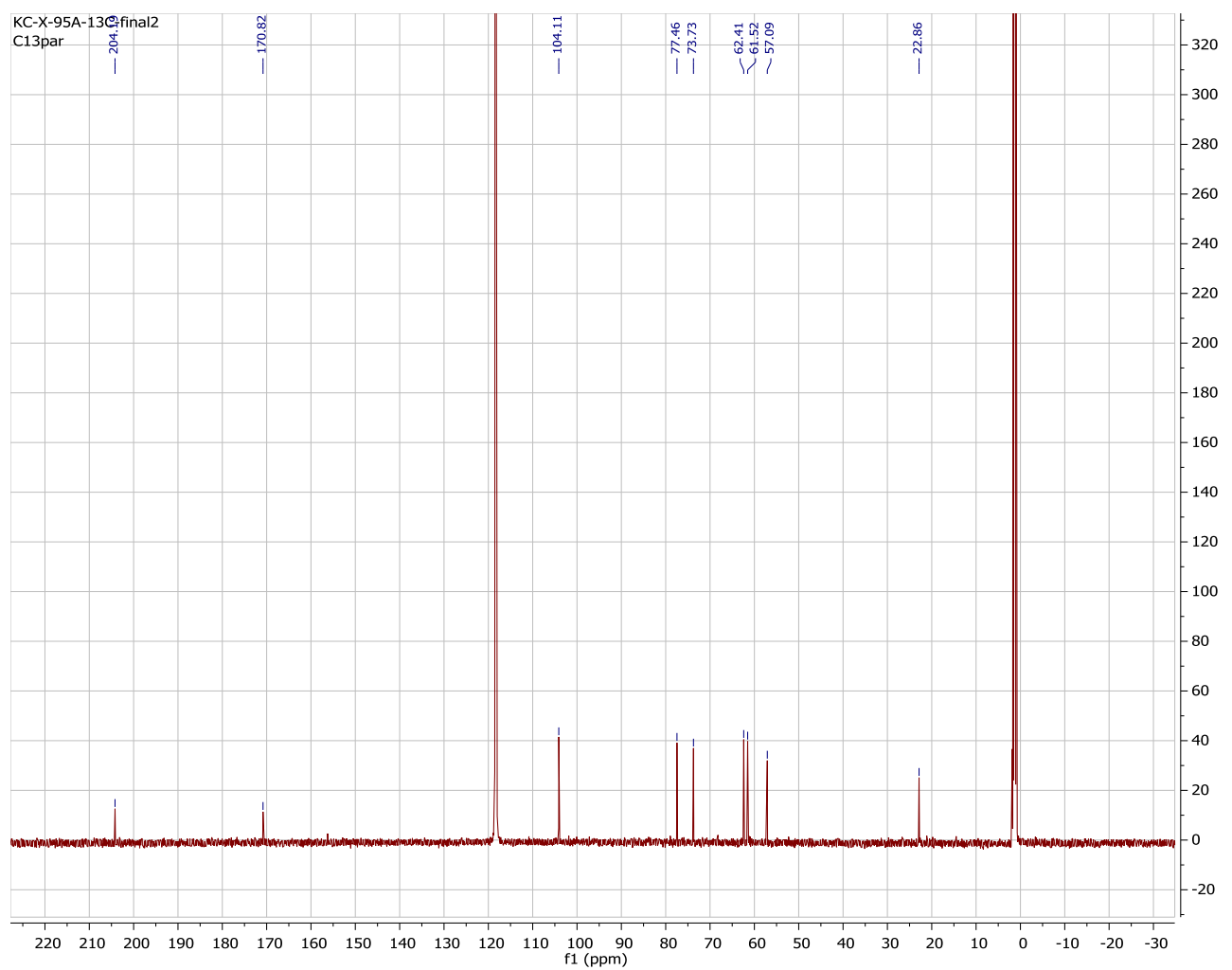

Figure S61. ${ }^{13} \mathrm{C}$ NMR spectrum of 17 a after 1 hour standing 


\section{Peracetylation of 3-keto-2-acetamido-2-deoxy- $\beta$-D-glucopyranose}

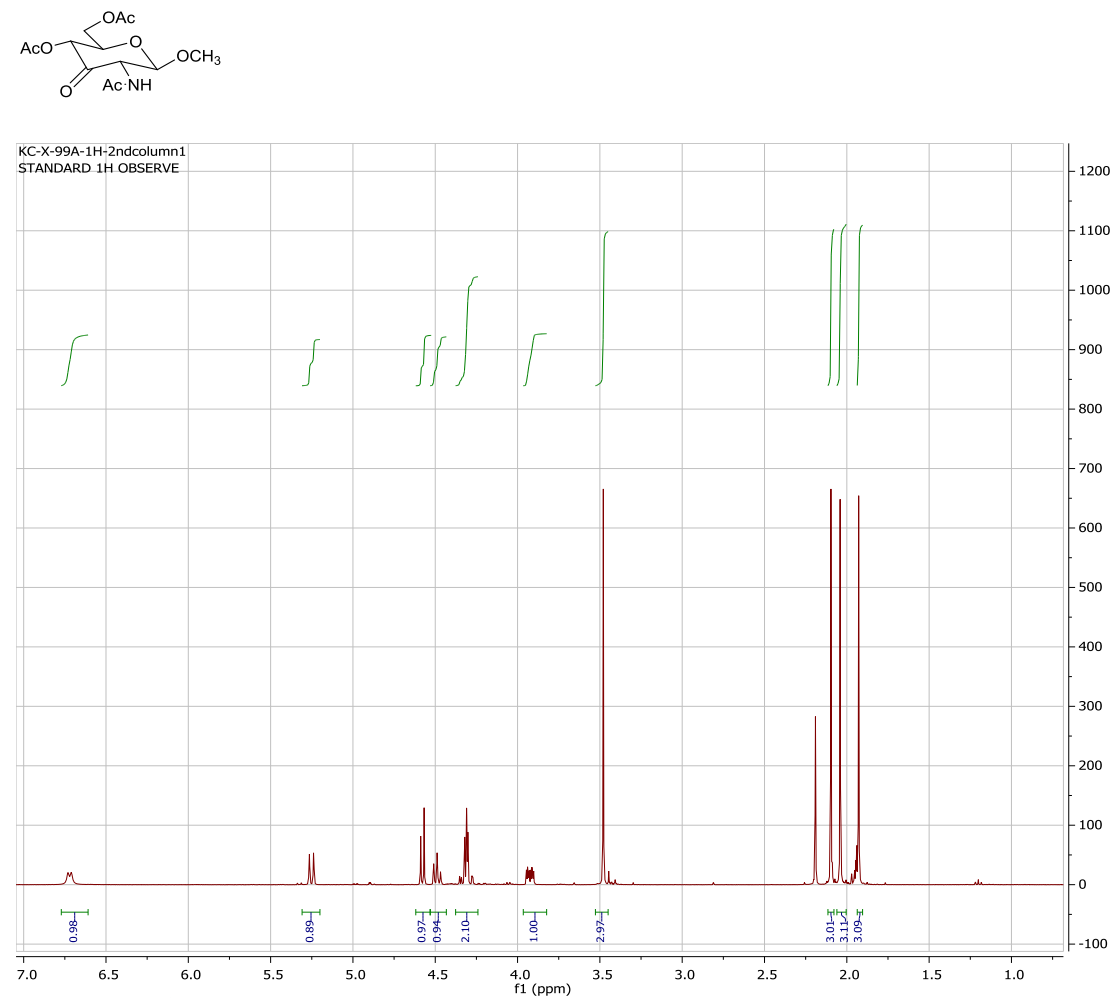

Figure S62. ${ }^{1}$ H NMR spectrum of peracetylated 3-keto-2-acetamido-2-deoxy- $\beta$-D-glucopyranose

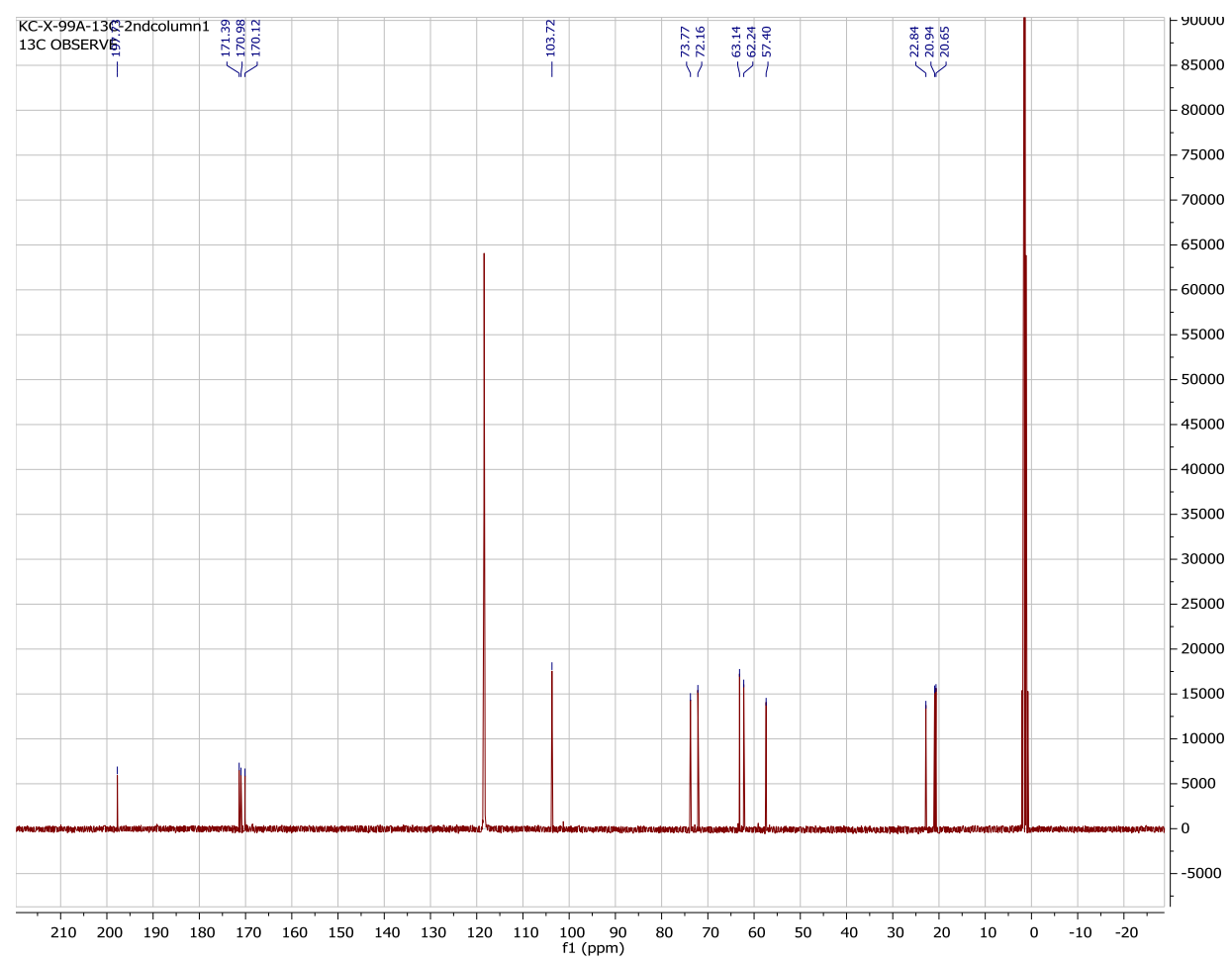

Figure S63. ${ }^{13} \mathrm{C}$ NMR spectrum of peracetylated 3-keto-2-acetamido-2-deoxy- $\beta$-D-glucopyranose 


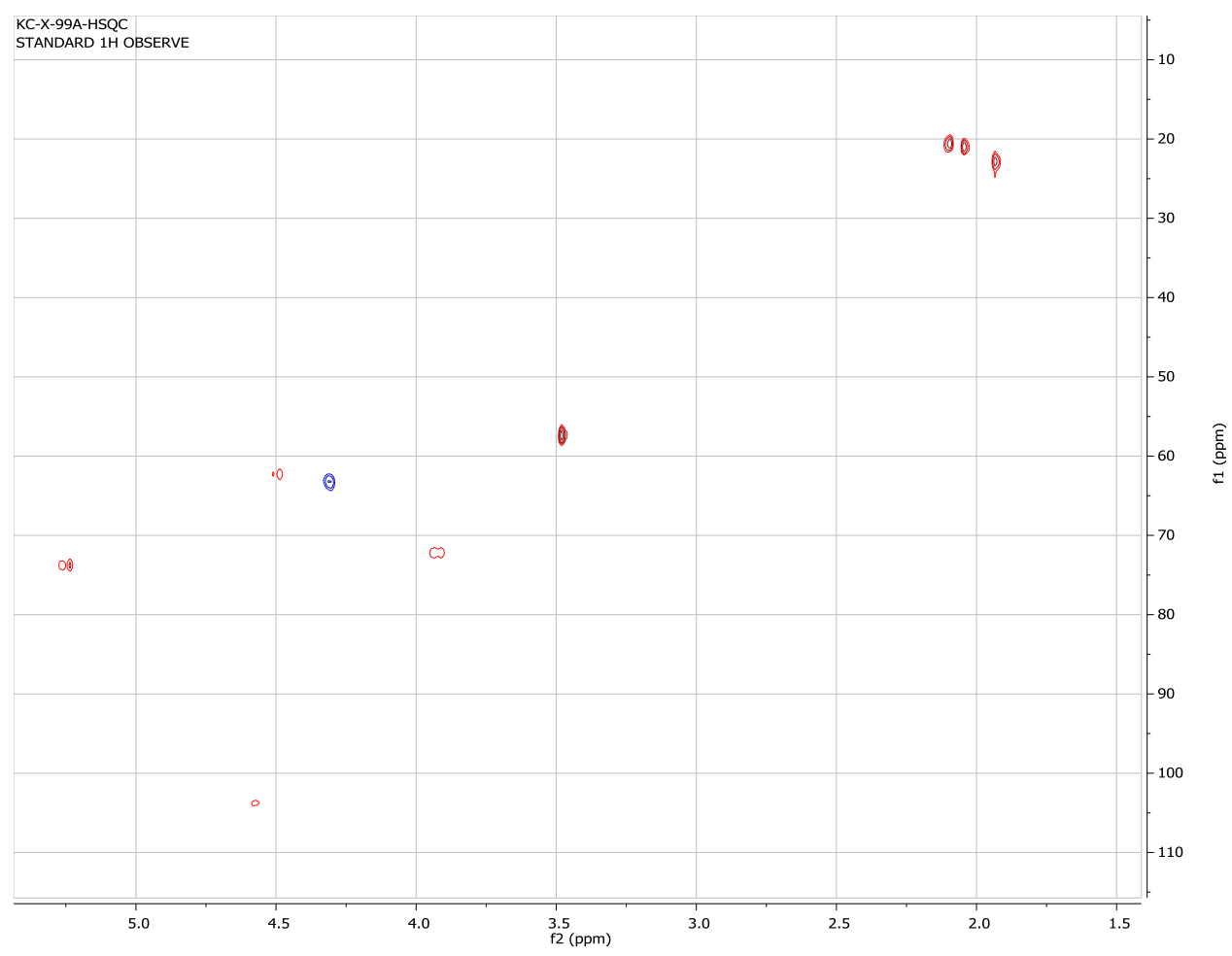

Figure S64. HSQC spectrum of peracetylated 3-keto-2-acetamido-2-deoxy- $\beta$-D-glucopyranose KC-X-99A-HMBC

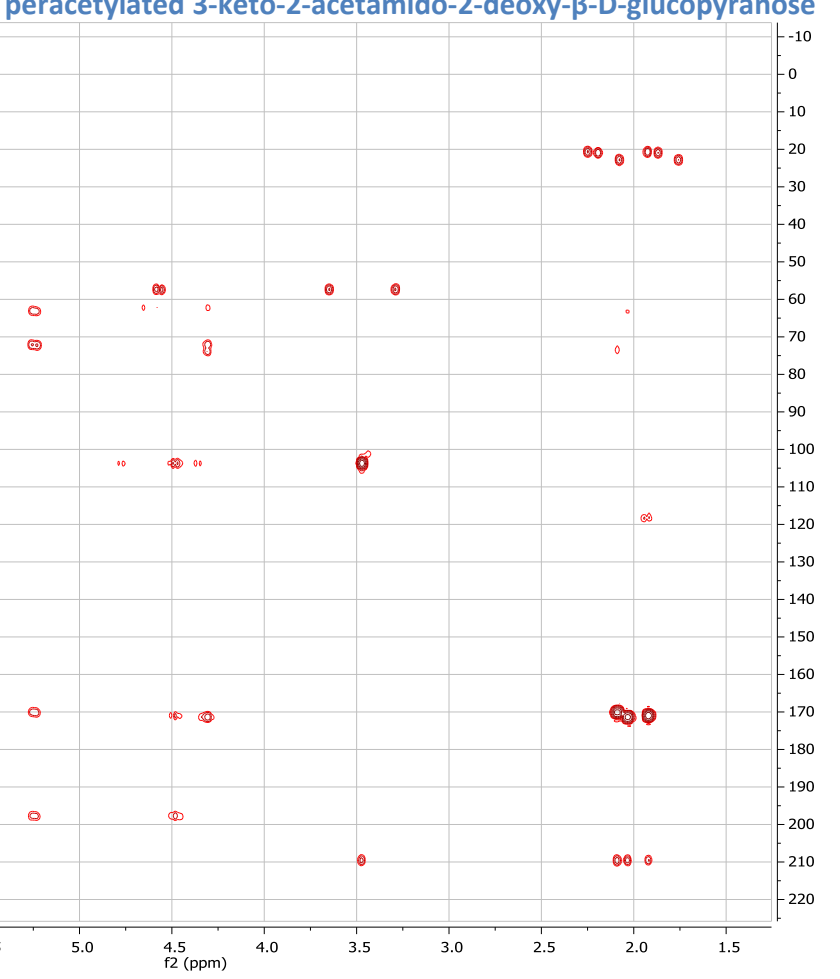

Figure S65. HMBC spectrum of peracetylated 3-keto-2-acetamido-2-deoxy- $\beta$-D-glucopyranose 
Oxidation of 2-deoxy-2-acetamido- $\beta$-D-glucopyranosyl azide (18a)

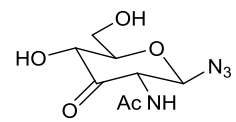

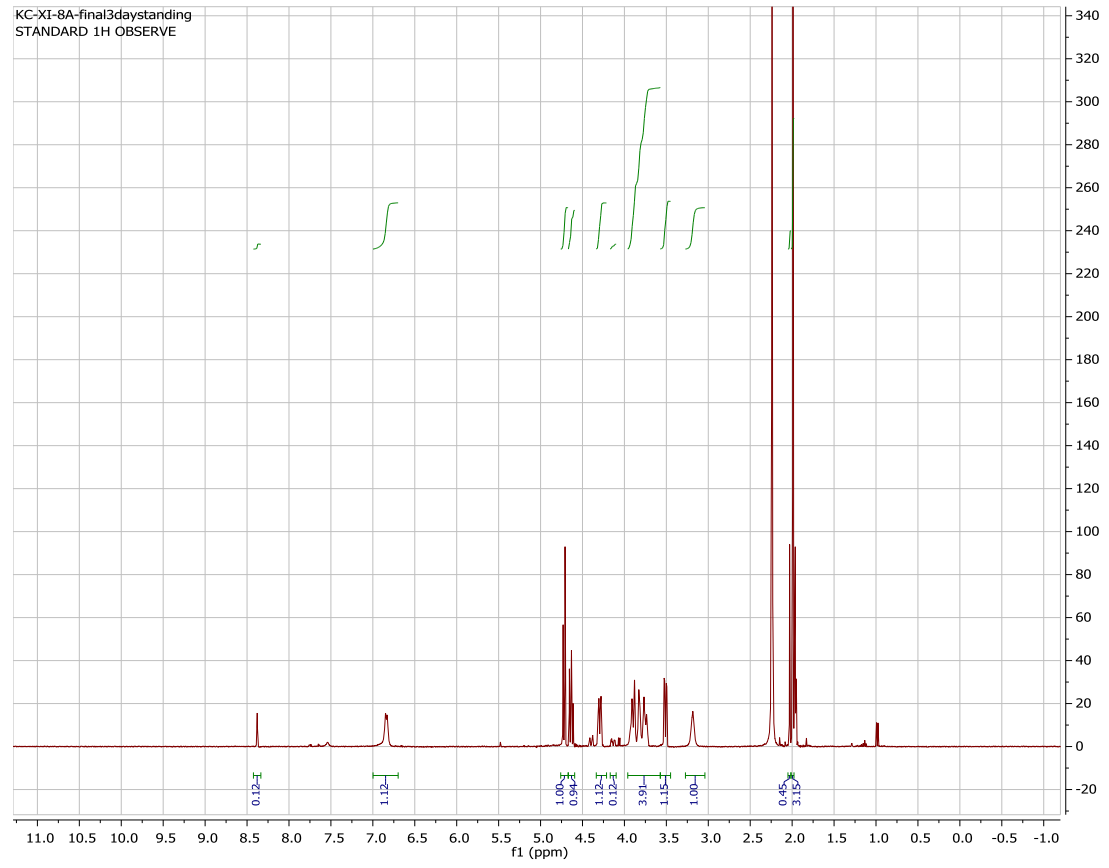

Figure S66. ${ }^{1} \mathrm{H}$ NMR spectrum of $18 \mathrm{a}$.

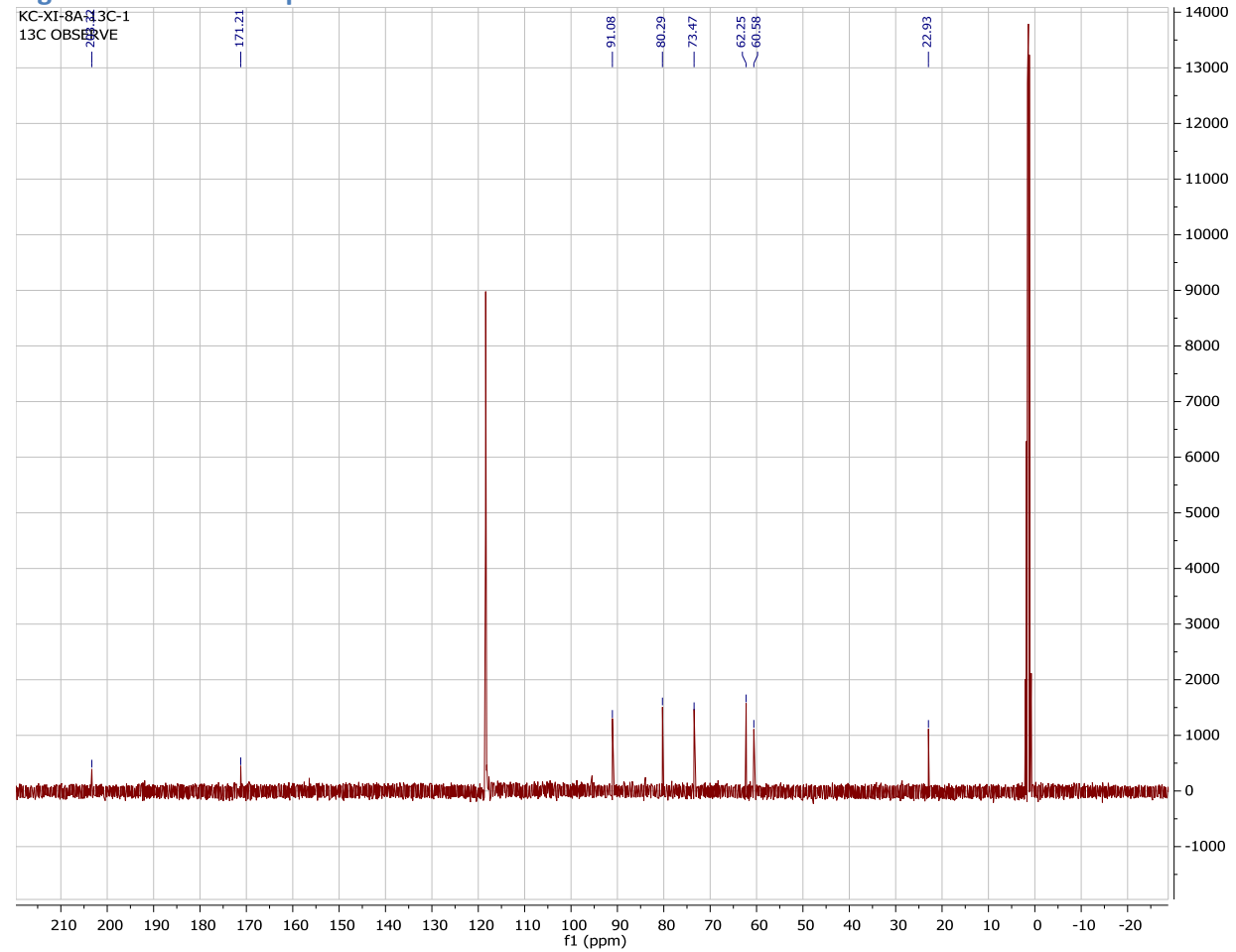

Figure S67. ${ }^{13} \mathrm{C}$ NMR spectrum of $18 \mathrm{a}$. 
Oxidation of 2-deoxy-2-acetamido- $\beta$-D-glucopyranosyl azide (18b)<smiles>O=C1COC(CO)C(O)C1O</smiles>

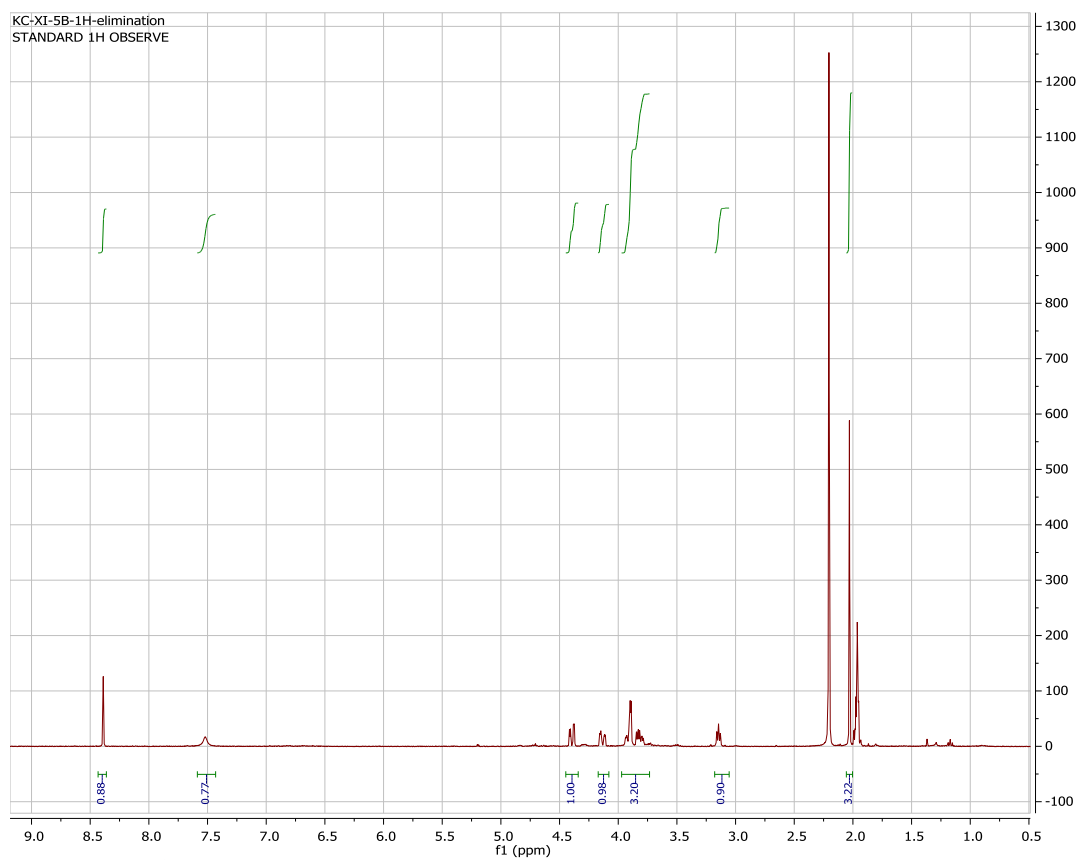

Figure S68. ${ }^{1} \mathrm{H}$ NMR spectrum of $18 \mathrm{~b}$.

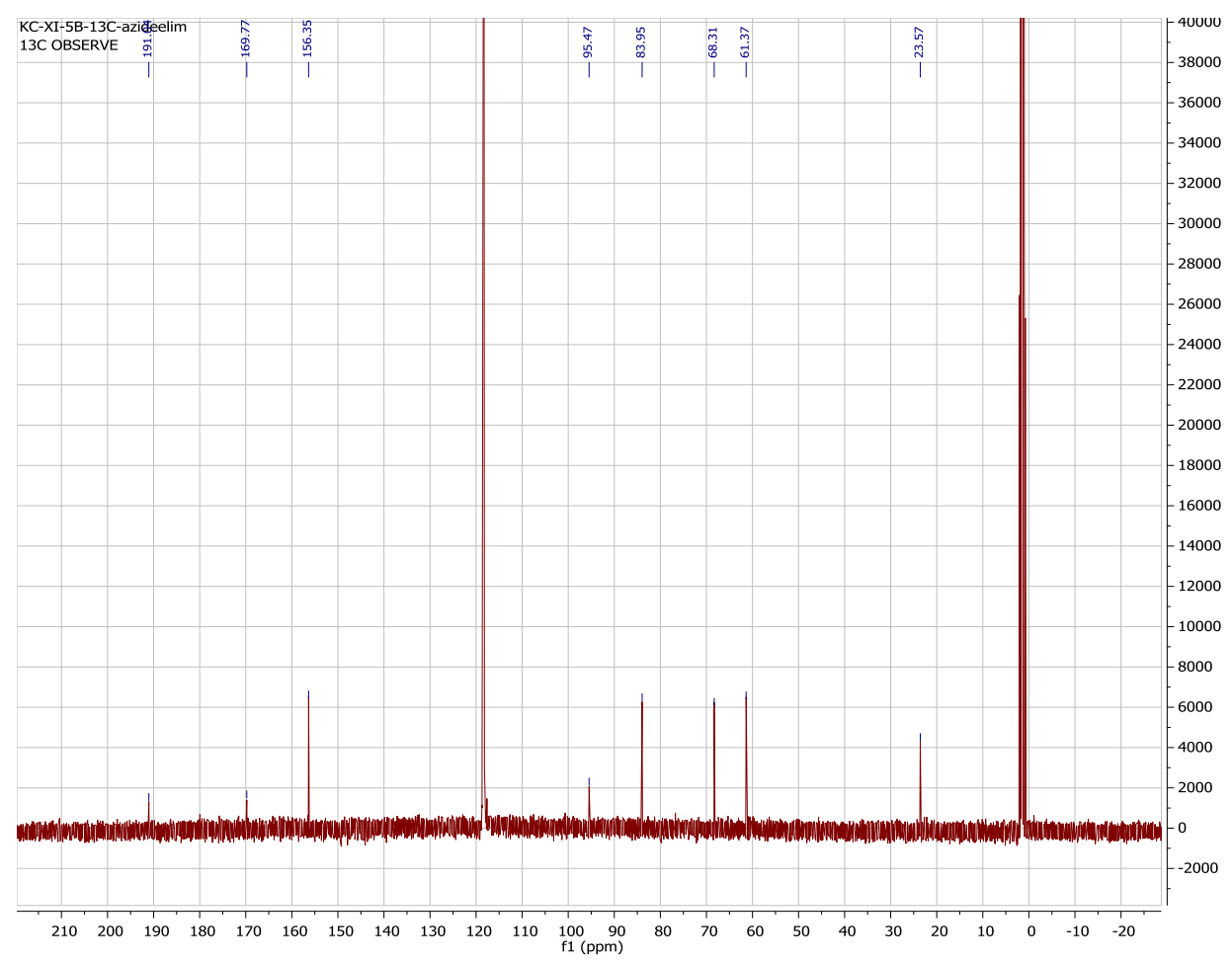

Figure S69. ${ }^{13} \mathrm{C}$ NMR spectrum of $18 \mathrm{~b}$. 
Oxidation of methyl $\beta$-D-arabinopyranoside in 1,1,1,3,3,3-hexafluoroisopropanol (13a)

Ho $\pi_{0}^{\circ} z_{\mathrm{OH}}^{\mathrm{Me}}$

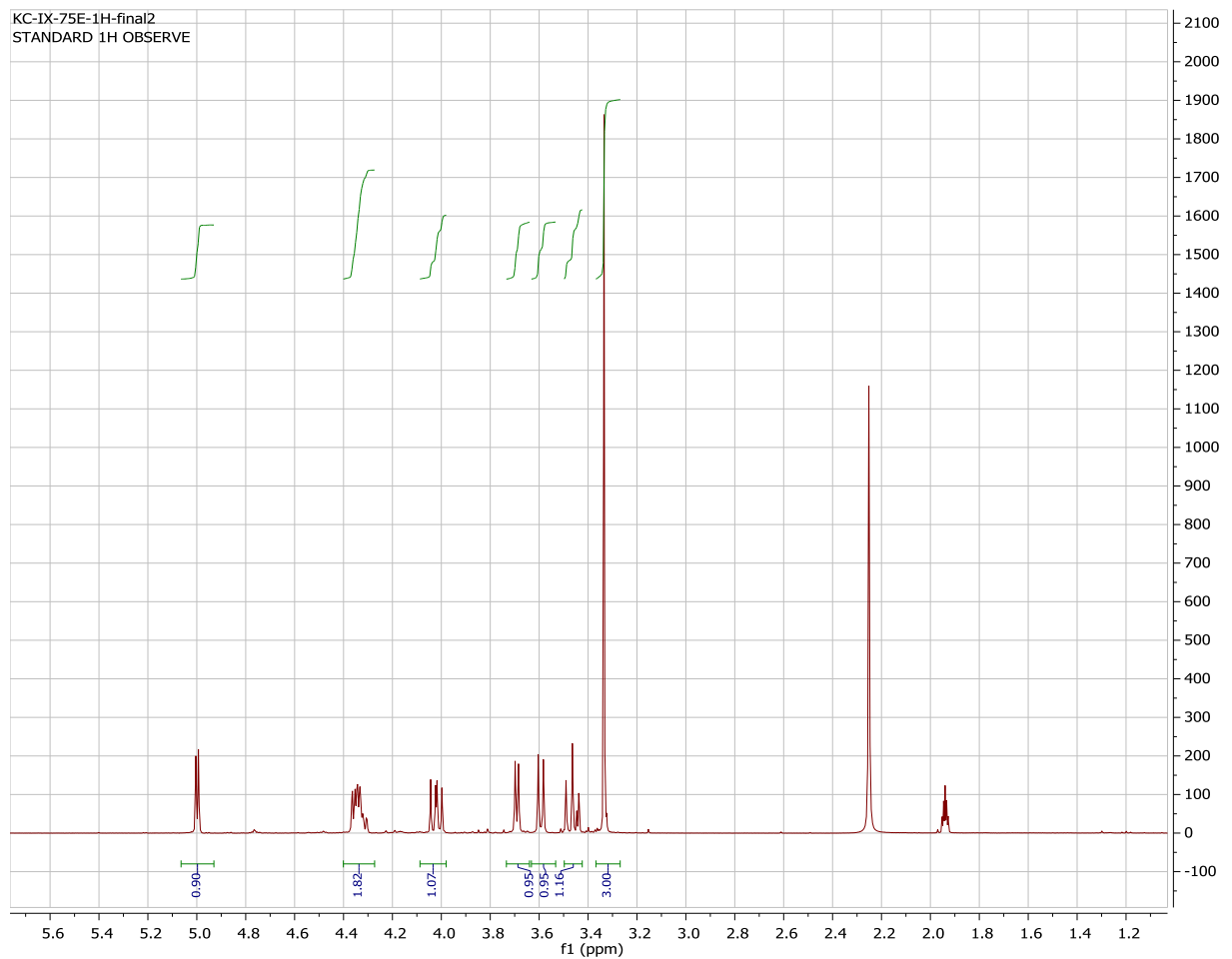

Figure S70. ${ }^{1} \mathrm{H}$ NMR spectrum of 13 a

KC-IX-75E-final-13C2

13C OBSERVE

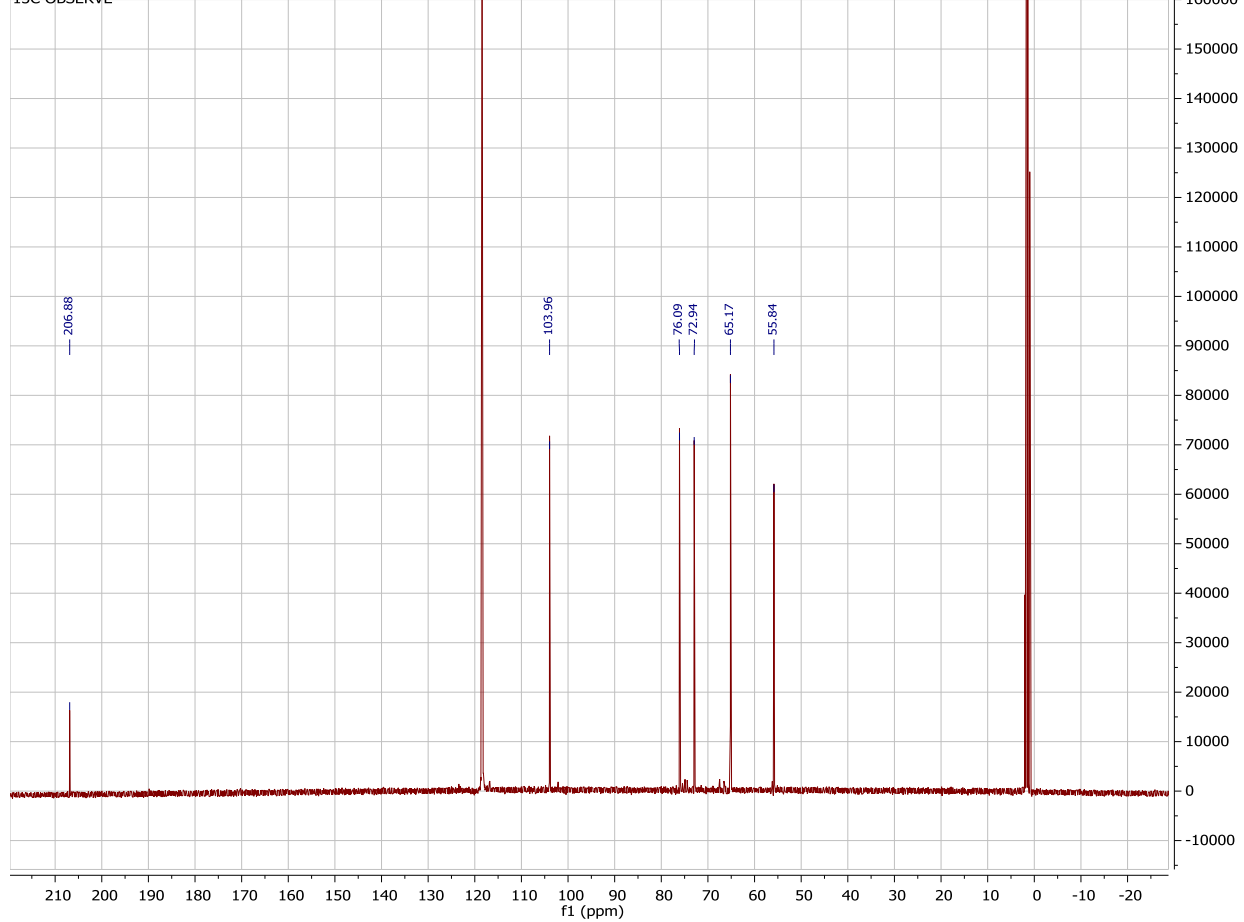

Figure $\mathrm{S} 71 .{ }^{13} \mathrm{C}$ NMR spectrum of 13 a 
Oxidation of methyl- $\alpha$-L-rhamnopyranoside in 1,1,1,3,3,3-hexafluoroisopropanol (8c) To $\pi_{0}^{\circ} \mathcal{Z}_{\mathrm{OH}}^{\mathrm{Me}}$

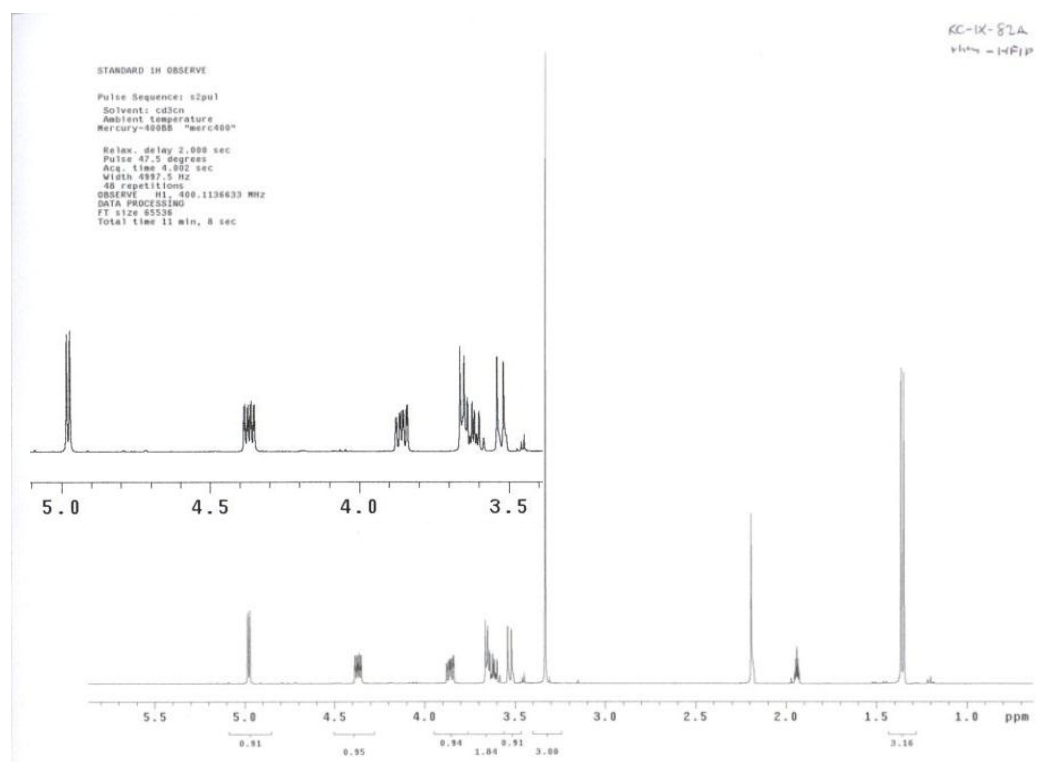

Figure S72. ${ }^{1} \mathrm{H}$ NMR spectrum of $8 \mathrm{c}$

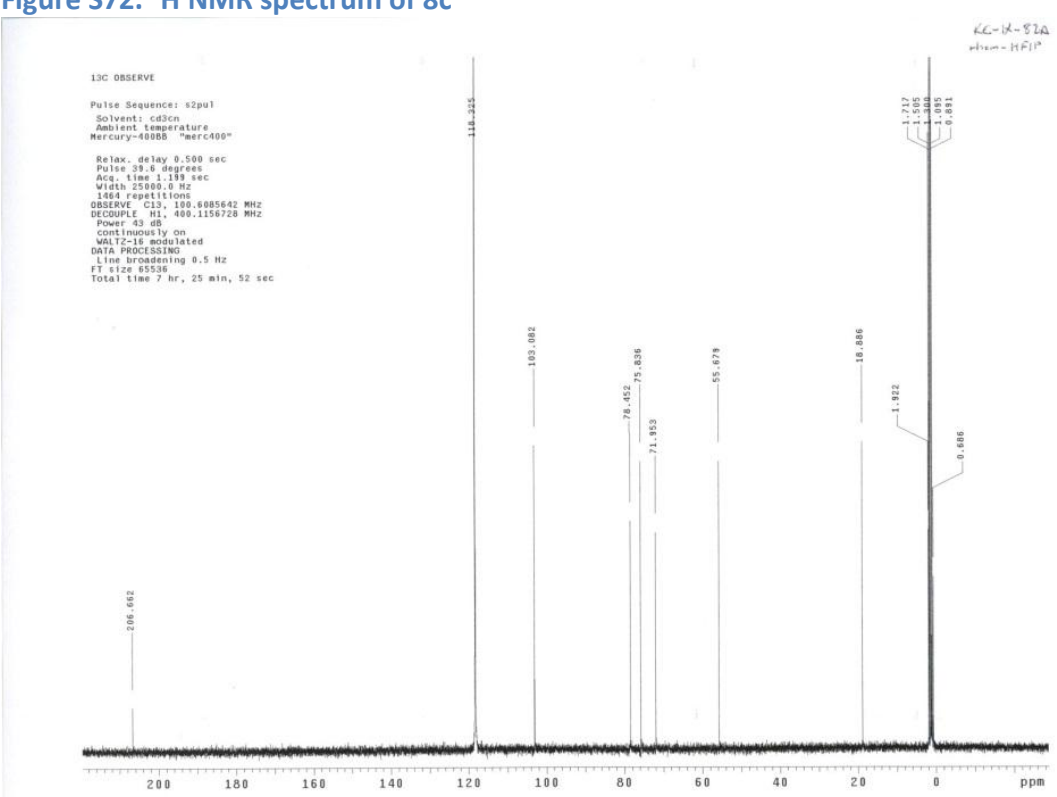

Figure $573 .{ }^{13} \mathrm{C}$ NMR spectrum of $8 \mathrm{c}$ 
Oxidation of benzyl 2,3-0-isopropylidene-alpha-D-mannofuranoside (20a)

(1)

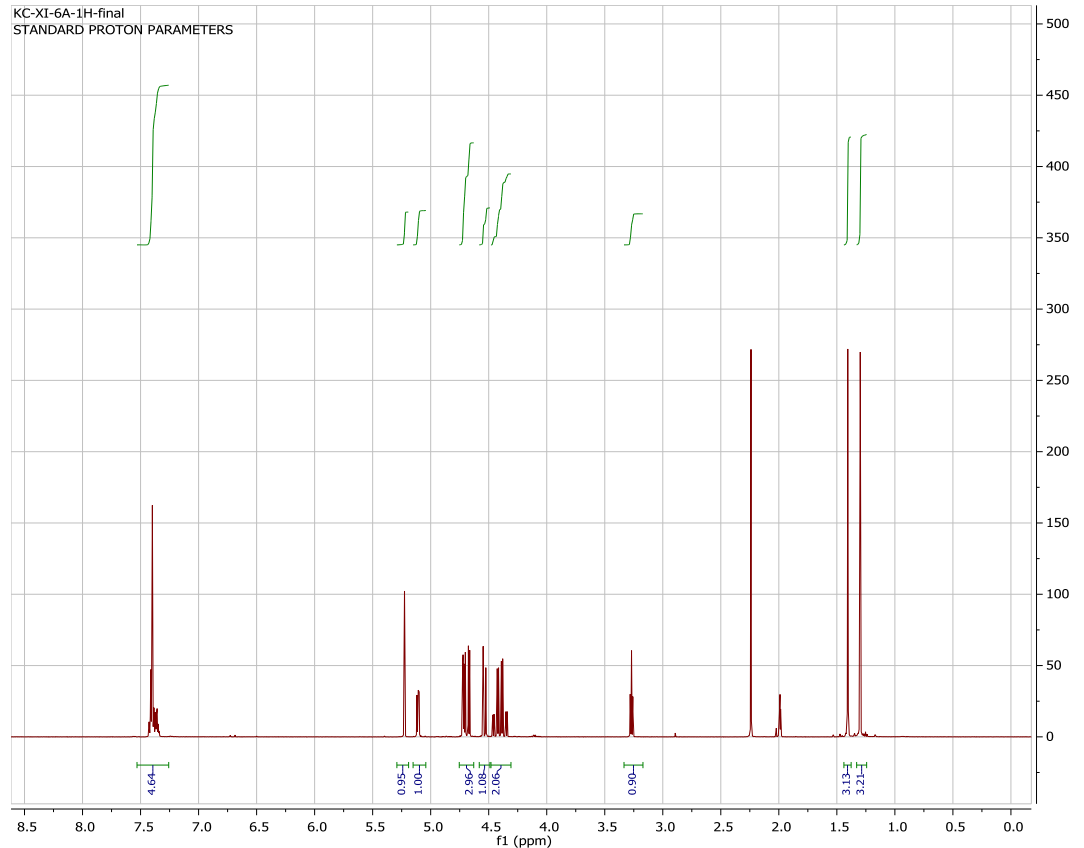

Figure S74. ${ }^{1} \mathrm{H}$ NMR spectrum of $20 \mathrm{a}$

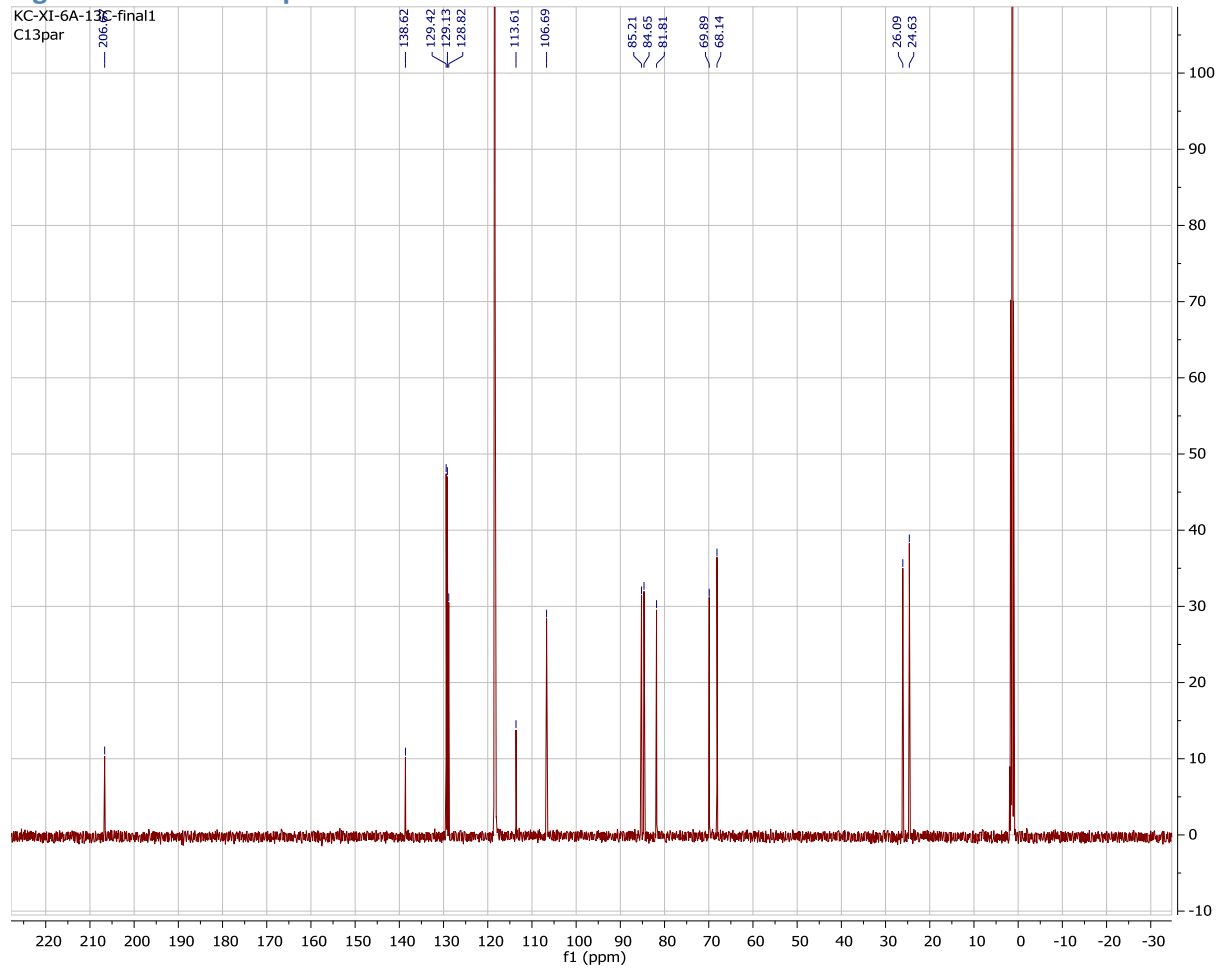

Figure S75. ${ }^{13} \mathrm{C}$ NMR spectrum of $20 \mathrm{a}$ 
Oxidation of octyl- $\beta$-D-galactofuranoside (21a)

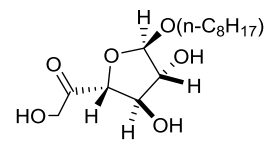

If NMR sample is taken immediately after isolation:

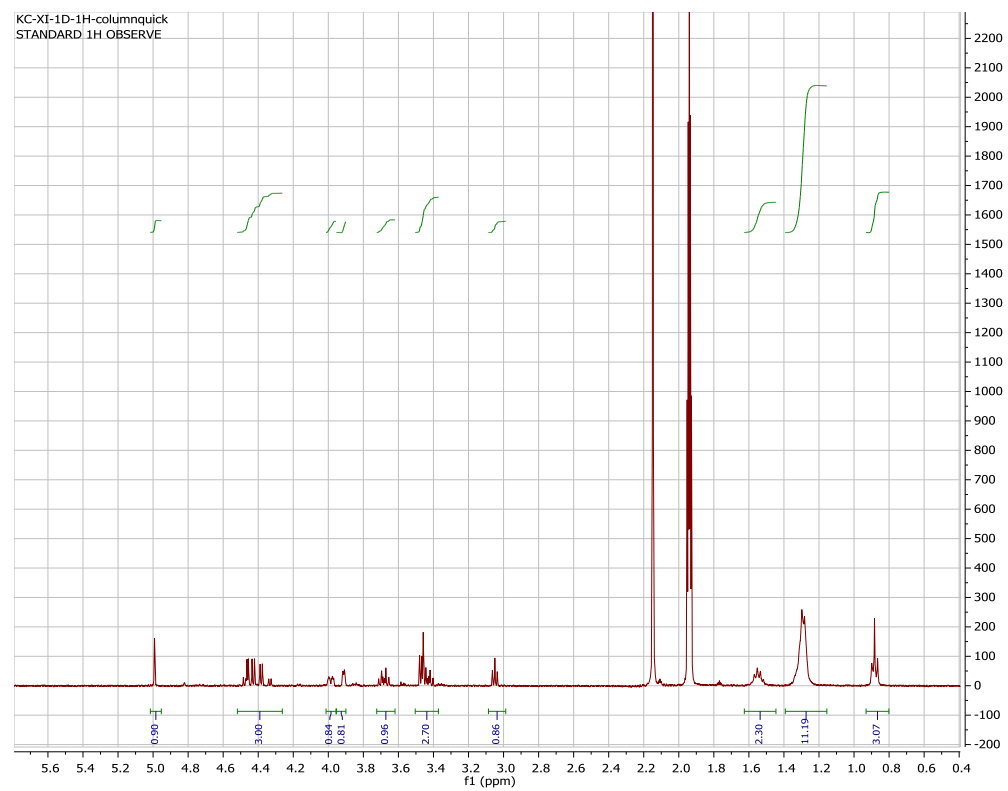

Figure S76. ${ }^{1}$ H NMR spectrum of 21a, with NMR sample prepared immediately after isolation

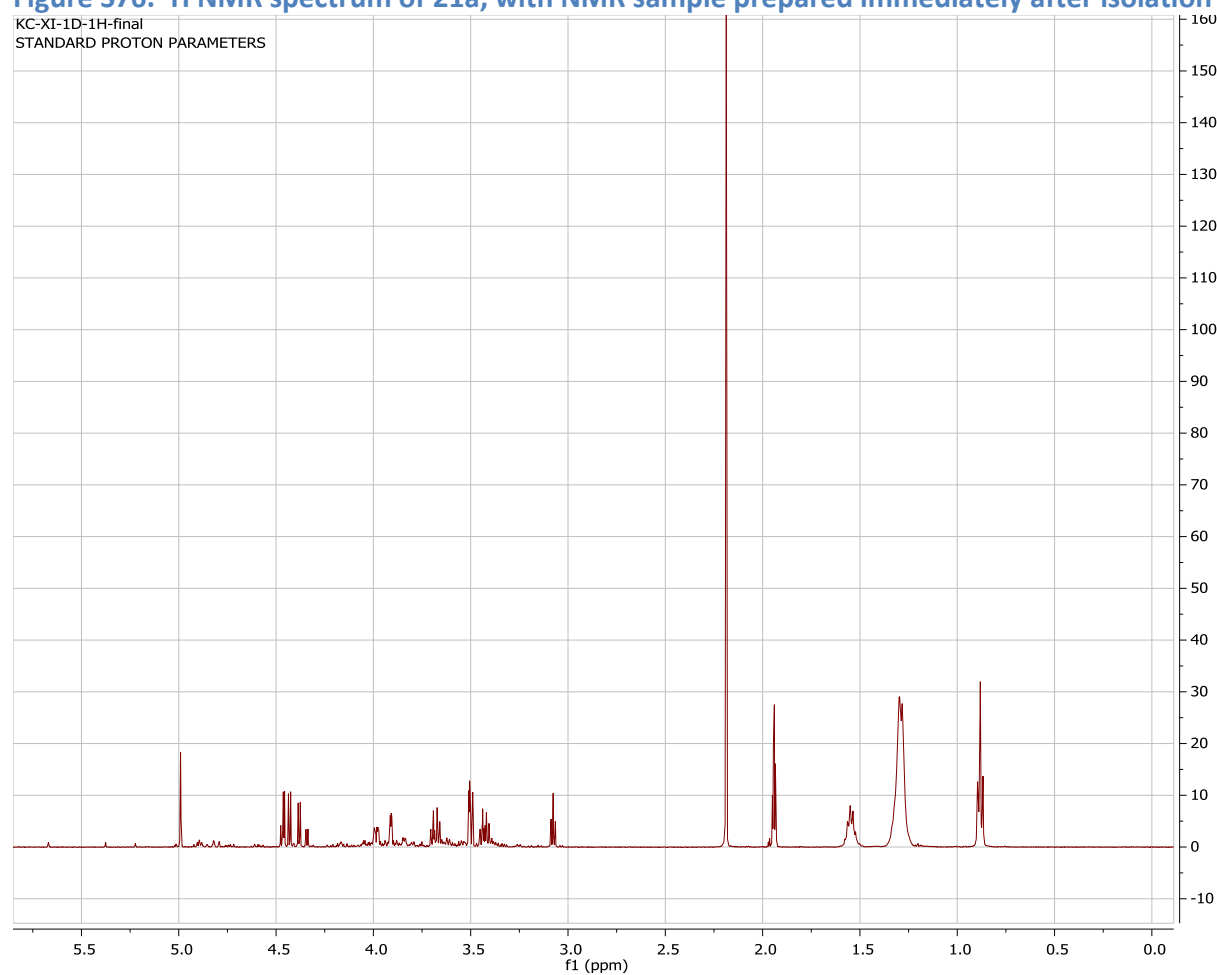

Figure S77. ${ }^{1} \mathrm{H}$ NMR spectrum of $21 \mathrm{a}$, with NMR sample prepared after $\approx 1$ hour of standing Upon standing in solution $\left(\approx 48 \mathrm{hr} @ 35^{\circ} \mathrm{C}\right)$ the presumed dimerization products appears to dissipate: 


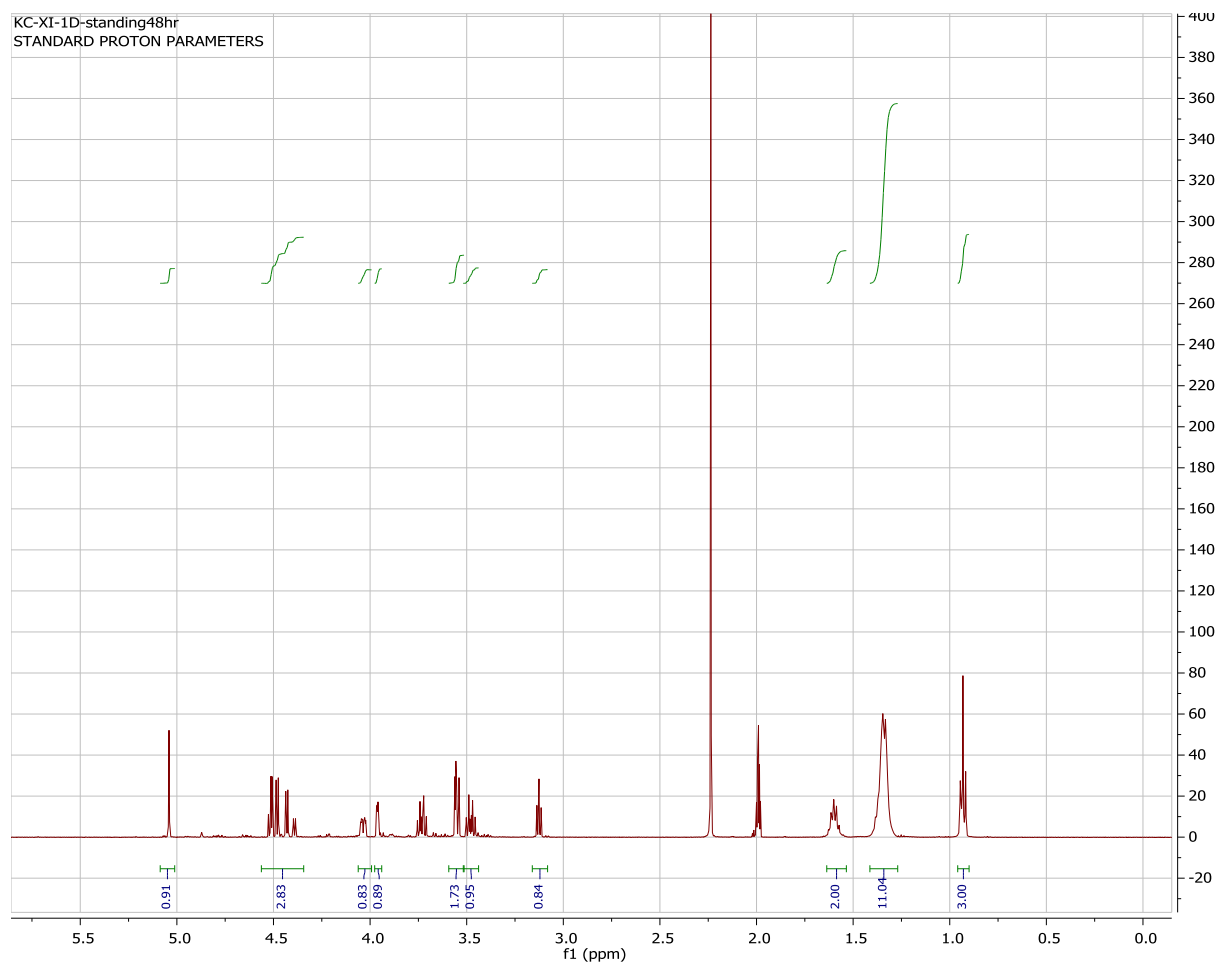

Figure 78. ${ }^{1} \mathrm{H}$ NMR spectrum of 21 a, after heating the sample in solution for 2 days in $\mathrm{CD}_{3} \mathrm{CN}$

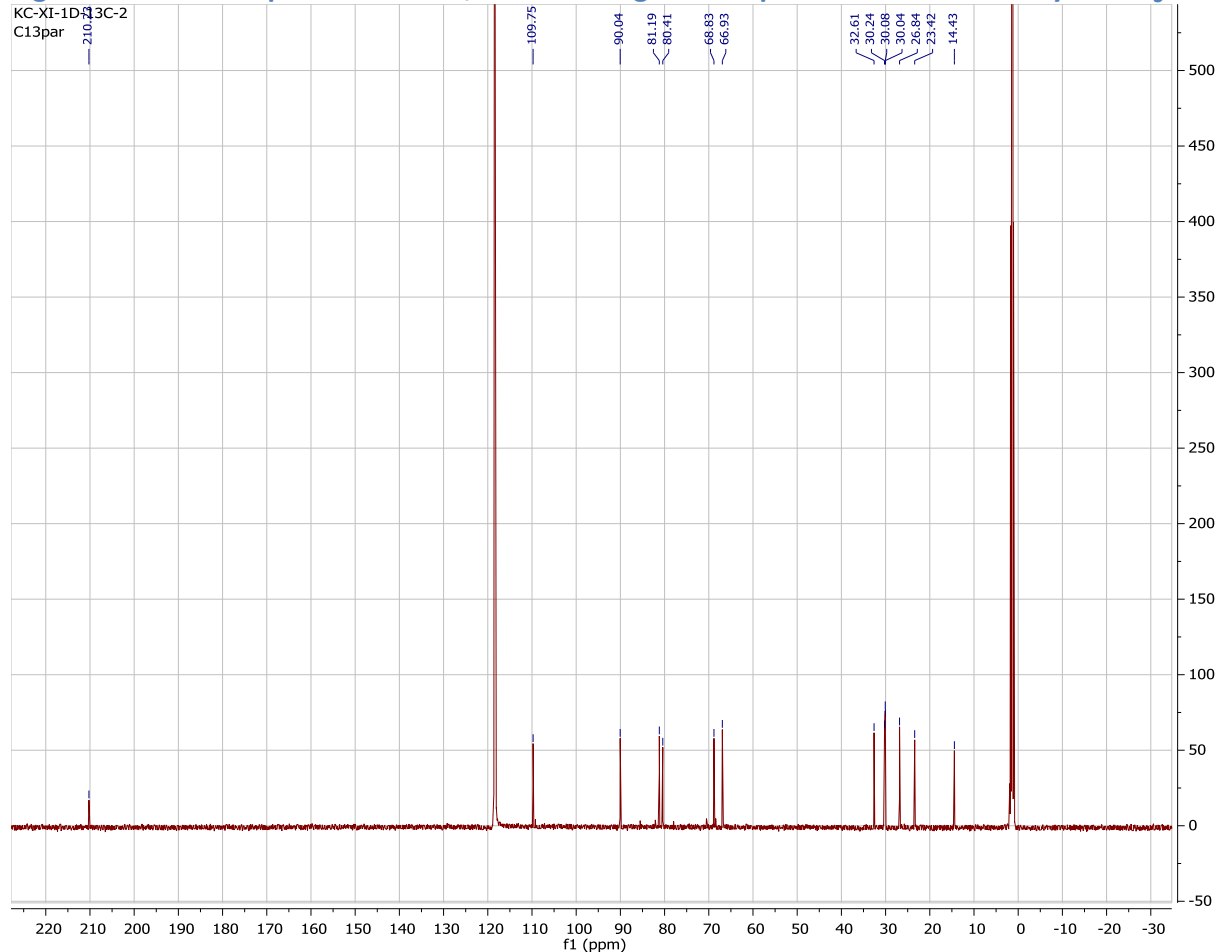

Figure S79. ${ }^{13} \mathrm{C}$ NMR spectrum of 21 a, after heating the sample in solution for 2 days in $\mathrm{CD}_{3} \mathrm{CN}$ 


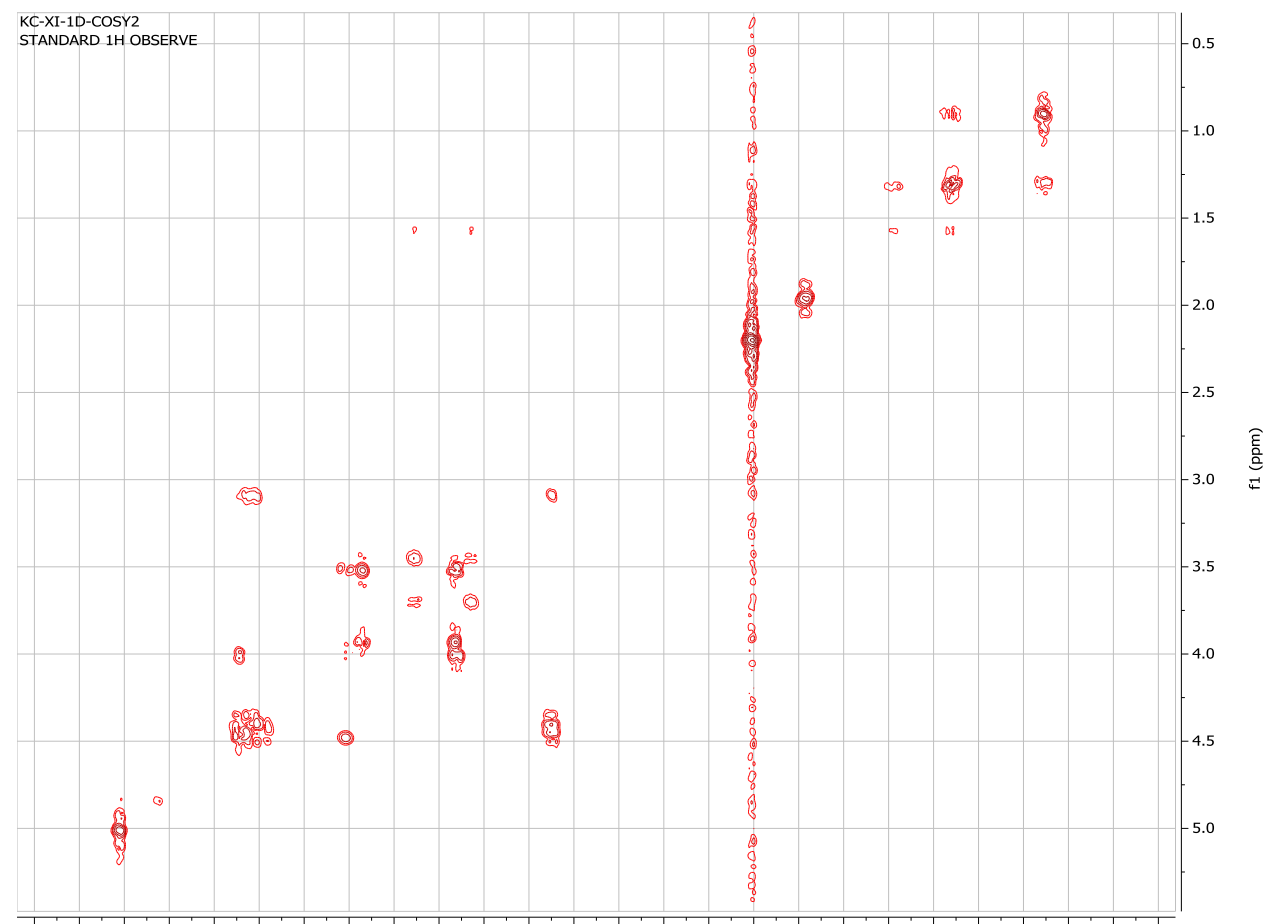

$\begin{array}{lllllllllllllllllllllllllllll}5.4 & 5.2 & 5.0 & 4.8 & 4.6 & 4.4 & 4.2 & 4.0 & 3.8 & 3.6 & 3.4 & 3.2 & \begin{array}{l}3.0 \\ \mathrm{f} 2(\mathrm{ppm})\end{array} & 2.6 & 2.4 & 2.2 & 2.0 & 1.8 & 1.6 & 1.4 & 1.2 & 1.0 & 0.8 & 0.6 & 0.4\end{array}$

Figure S80. COSY NMR spectrum of 21a

KC-XI-1D-HSQC
STANDARD 1 H OBSERVE
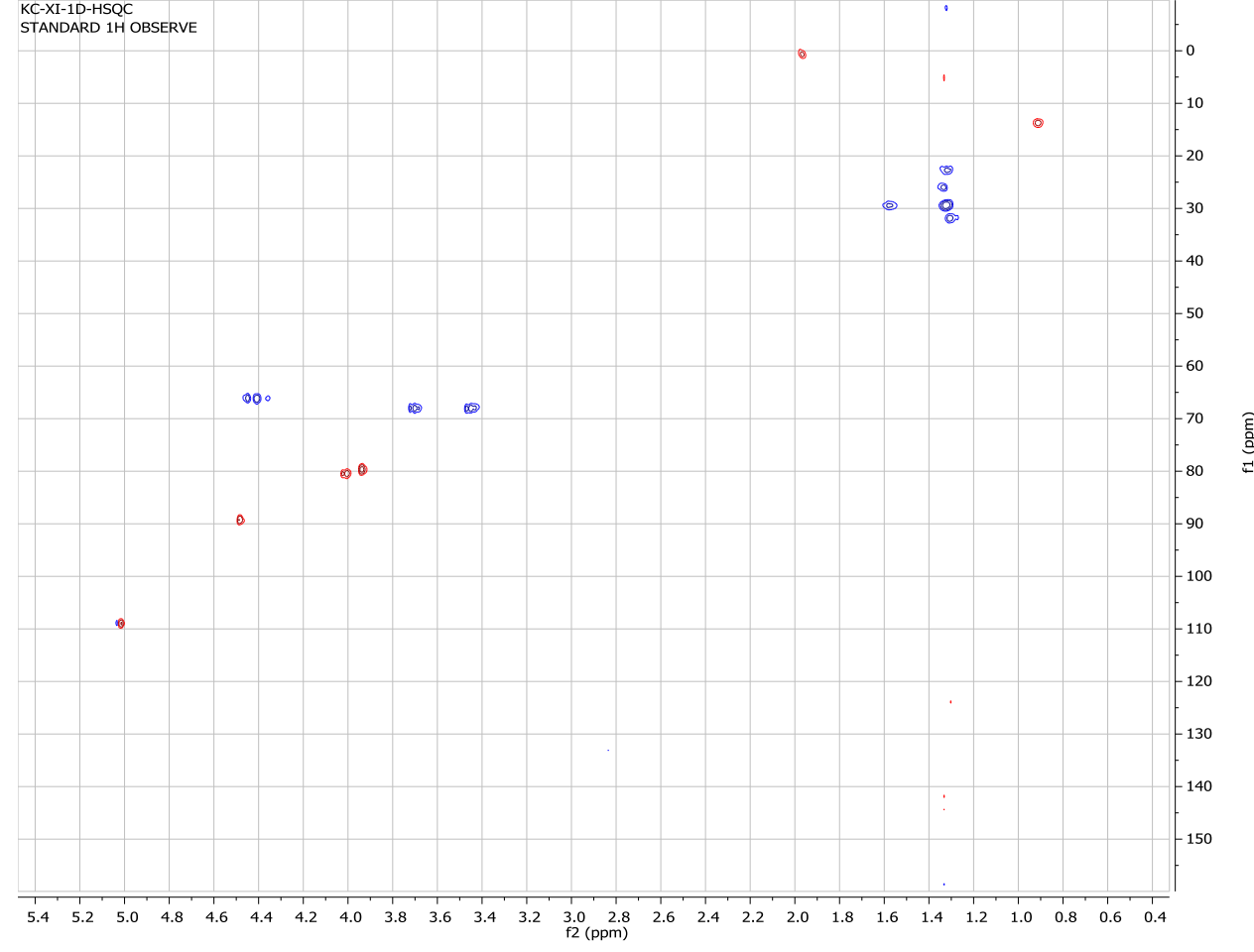

Figure S81. HSQC NMR spectrum of 21a 


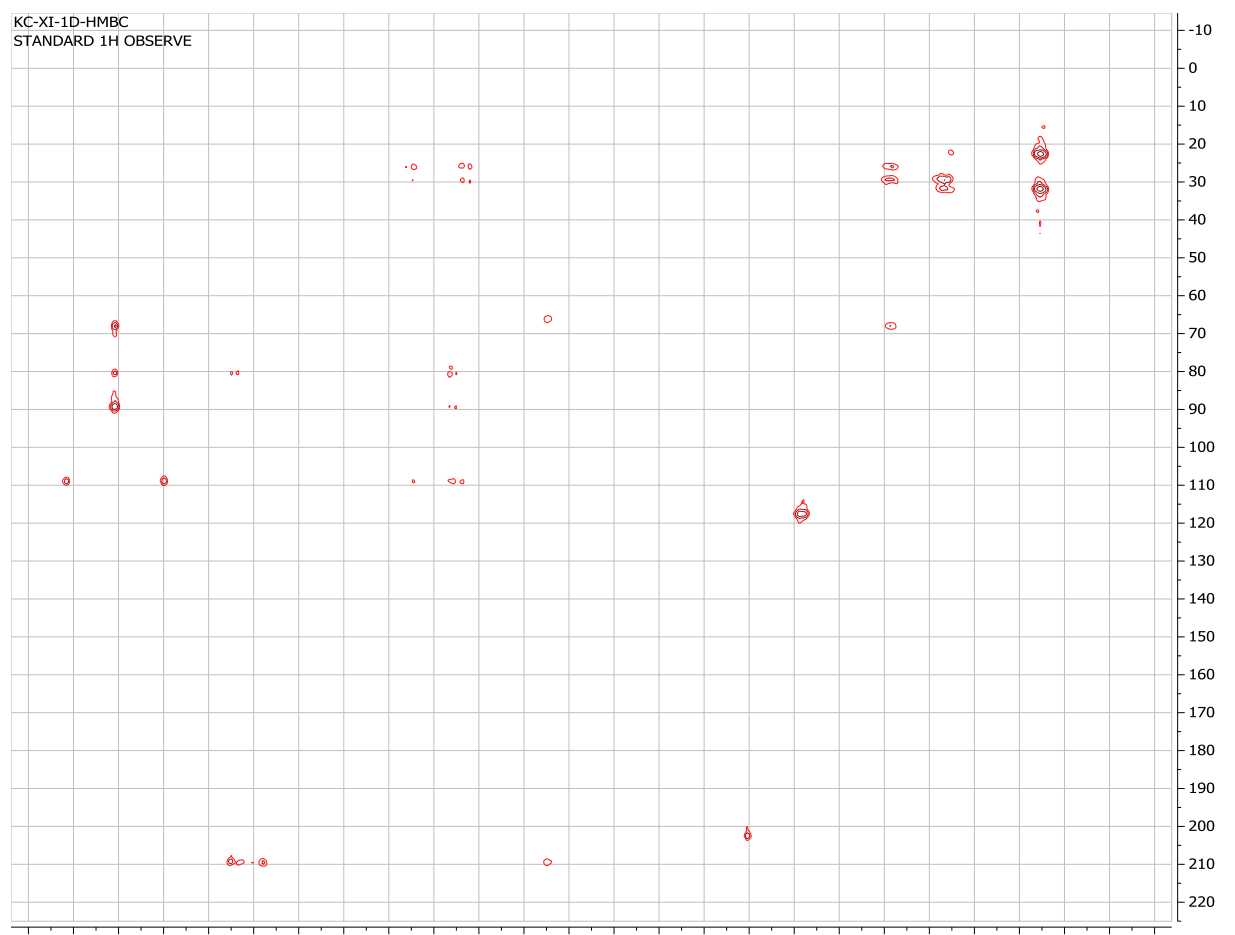

$\begin{array}{llllllllllllllllllllllllll}5.4 & 5.2 & 5.0 & 4.8 & 4.6 & 4.4 & 4.2 & 4.0 & 3.8 & 3.6 & 3.4 & 3.2 & \begin{array}{c}3.0 \\ \mathrm{f} 2(\mathrm{ppm})\end{array} & 2.6 & 2.4 & 2.2 & 2.0 & 1.8 & 1.6 & 1.4 & 1.2 & 1.0 & 0.8 & 0.6 & 0.4\end{array}$

Figure S82. HMBC NMR spectrum of 21a 
Oxidation of $\mathrm{N}$-acetylneuraminic acid methyl ester (22a)

(1)

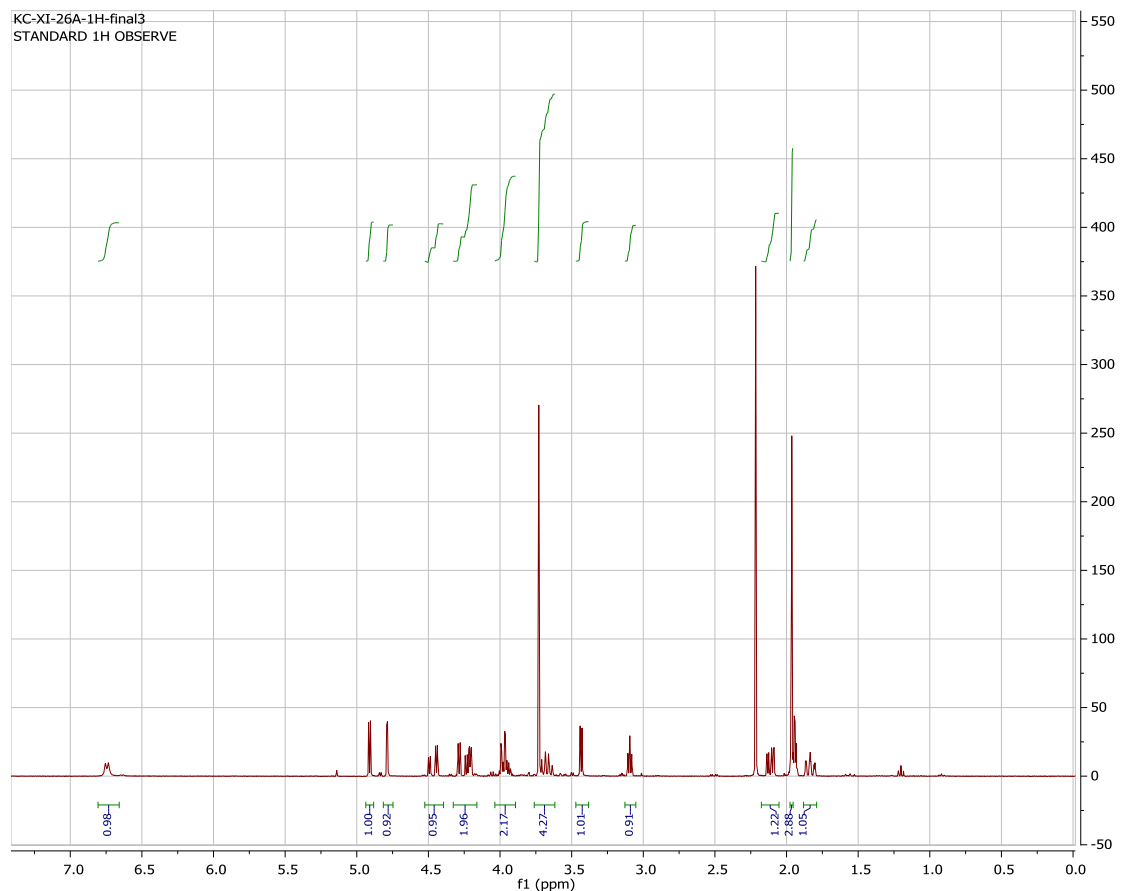

Figure $\mathrm{S} 83 .{ }^{1} \mathrm{H}$ spectrum of $22 \mathrm{a}$

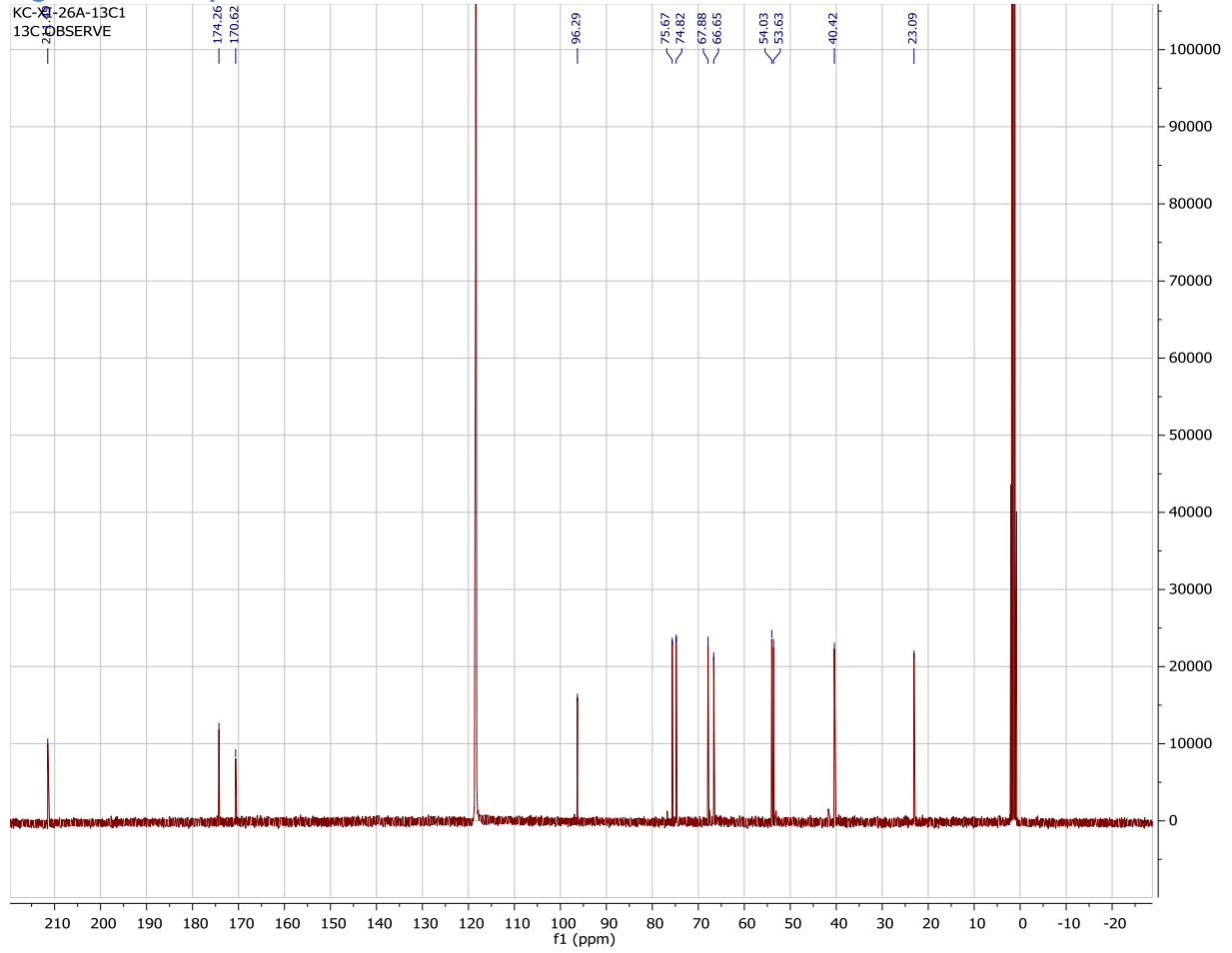

Figure S84. ${ }^{13} \mathrm{C}$ spectrum of $22 \mathrm{a}$ 


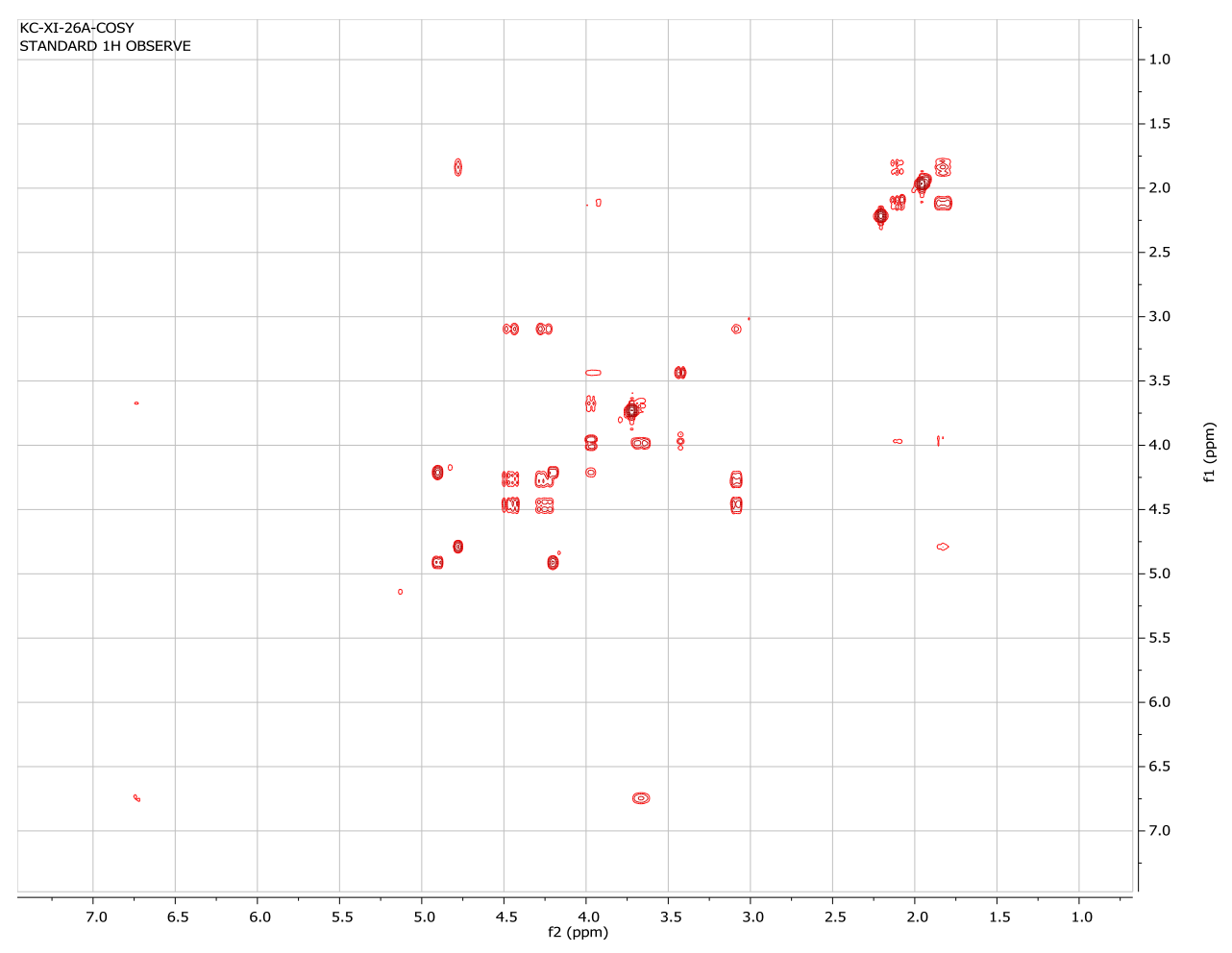

Figure S85. COSY spectrum of 22a KC-XI-26A-HSQC
STANDARD 1H OBSERVE

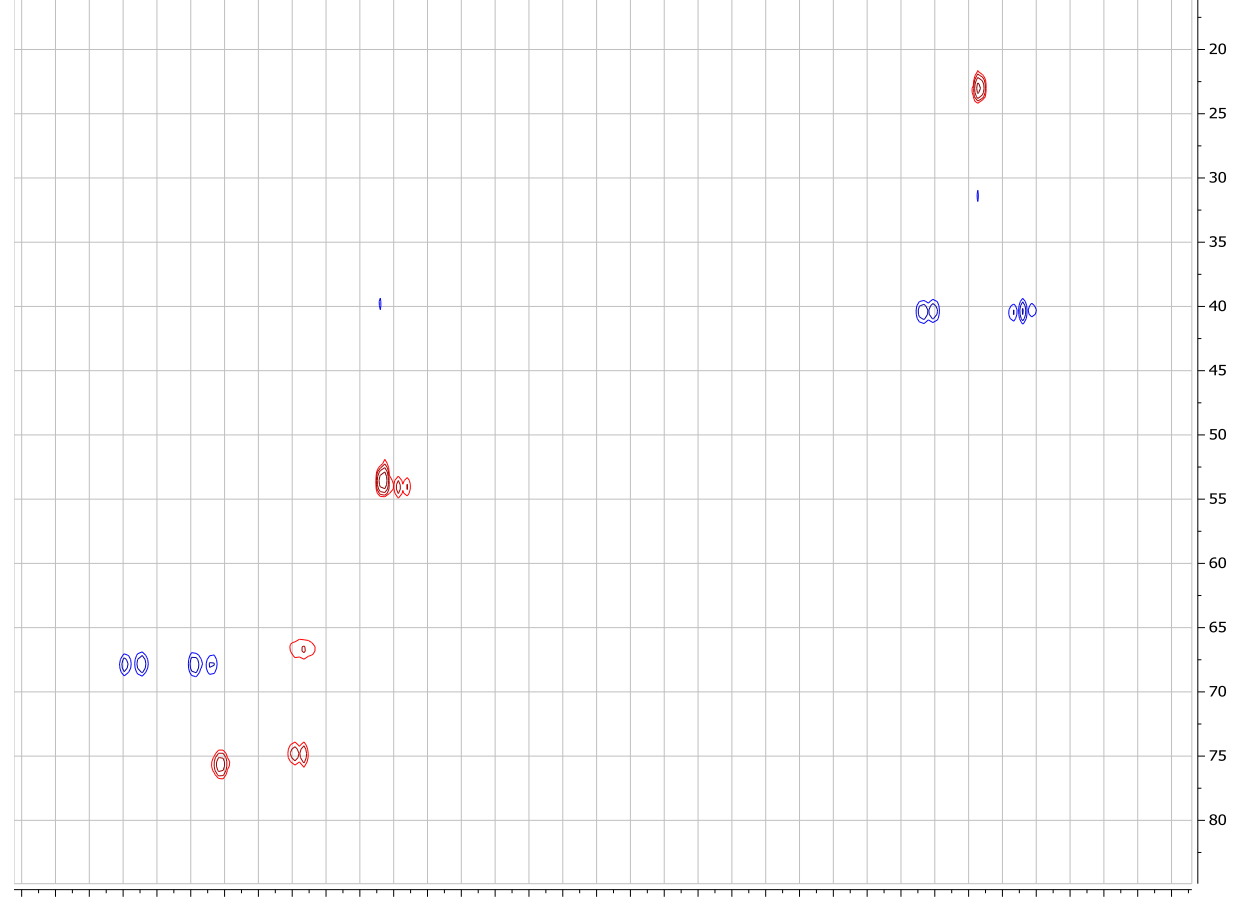

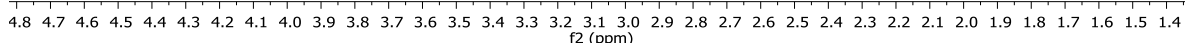

Figure S86. HSQC spectrum of 22a 


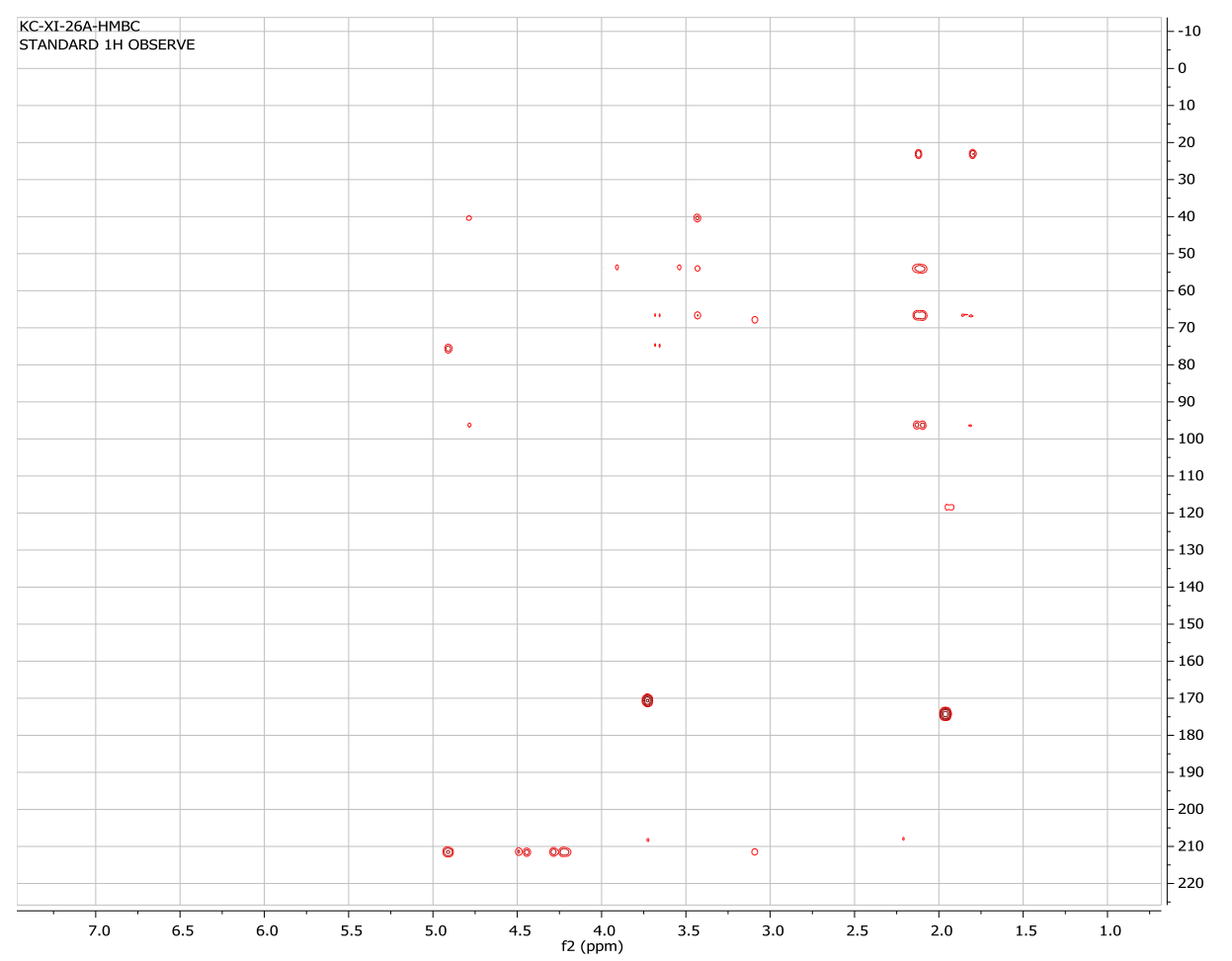

Figure S87. HMBC spectrum of 22a 
Oxidation of L-threitol ((2S,3S)-1,2,3,4-butanetetrol) in 2,2,2-trifluoroethanol (15a)

$\overbrace{\mathrm{OH}}^{\mathrm{O}} \mathrm{OH}$

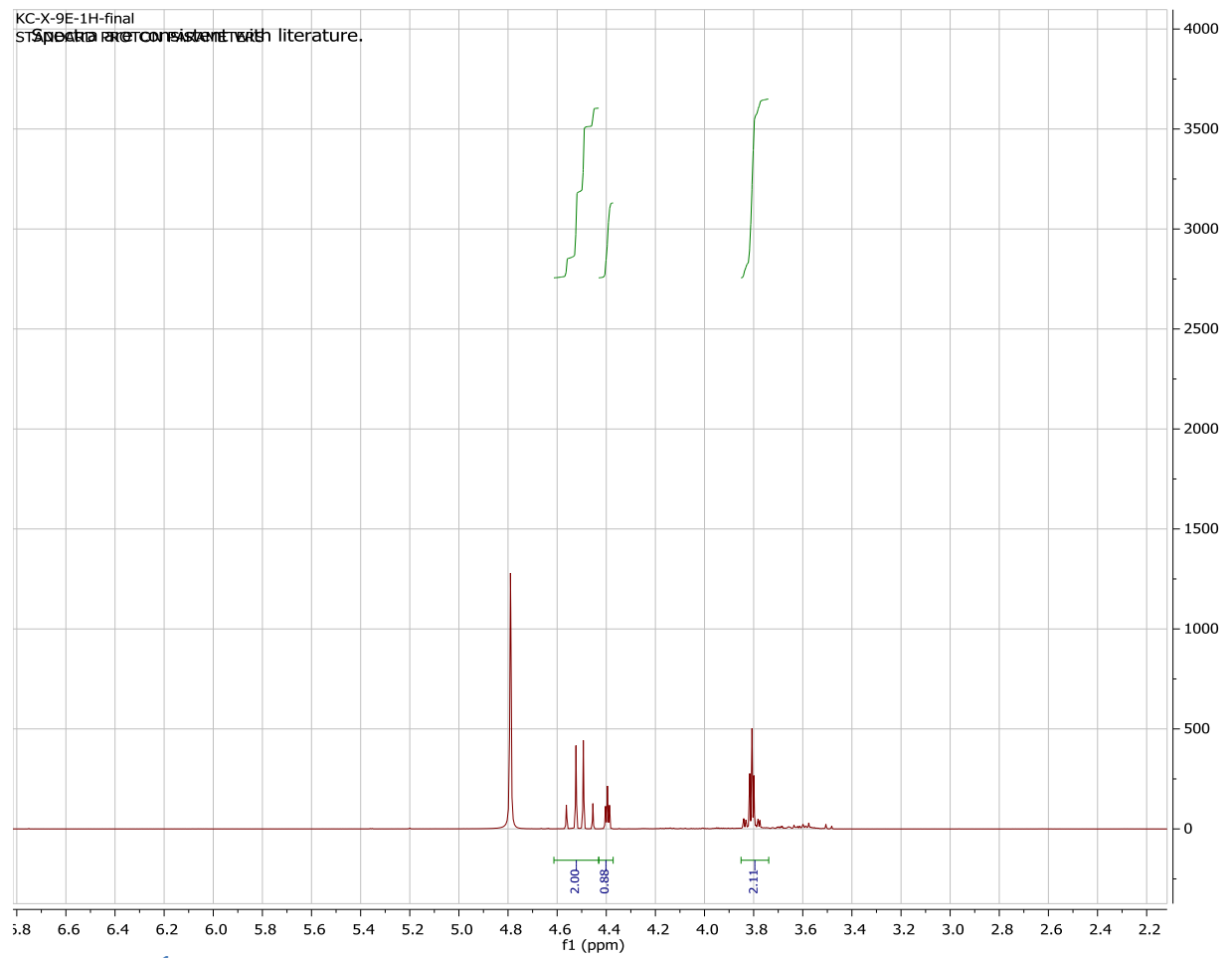

Figure S88. ${ }^{1} \mathrm{H}$ spectrum of $15 \mathrm{a}$

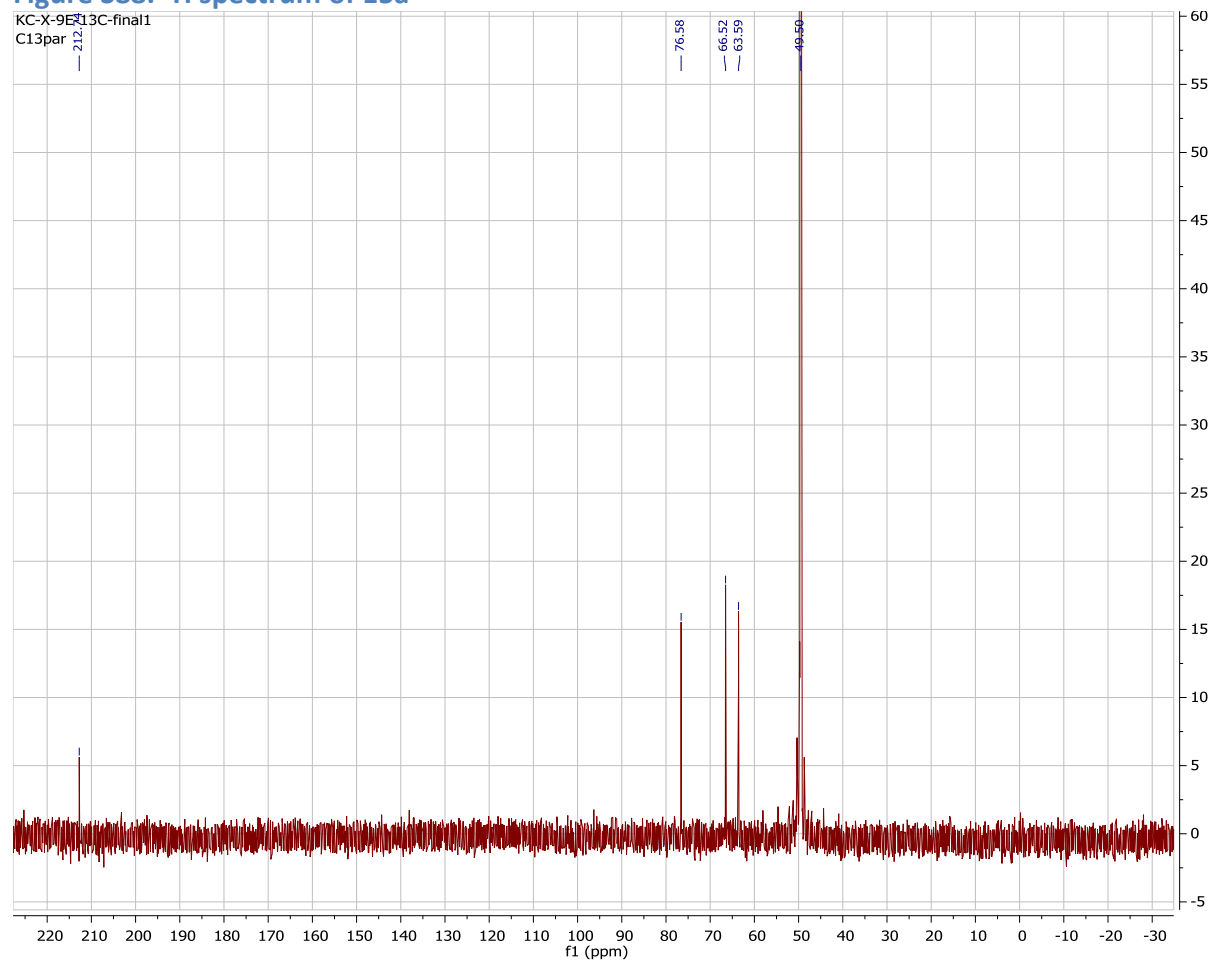

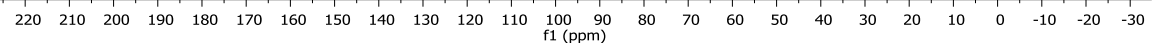

Figure S89. ${ }^{13} \mathrm{C}$ spectrum of 15 a 
Chiral HPLC chromatograms for erythrulose trisacetate

\section{Racemic erythrulose tris-acetate}

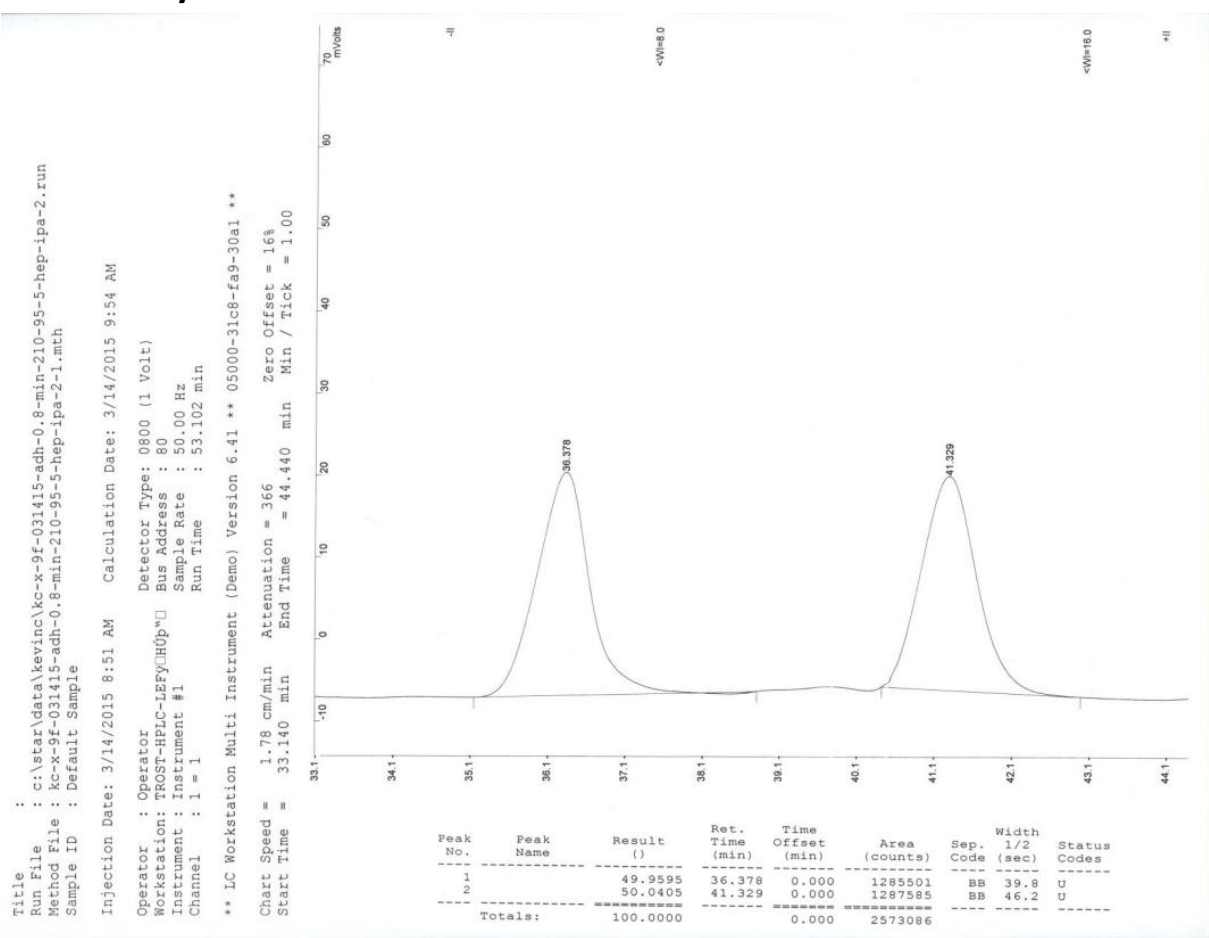

Figure S90. Chiral HPLC trace of racemic erythrulose tris-acetate 
Erythrulose trisacetate from oxidation of L-threitol ((2S,3S)-1,2,3,4-butanetetrol) in 2,2,2trifluoroethanol (15a)

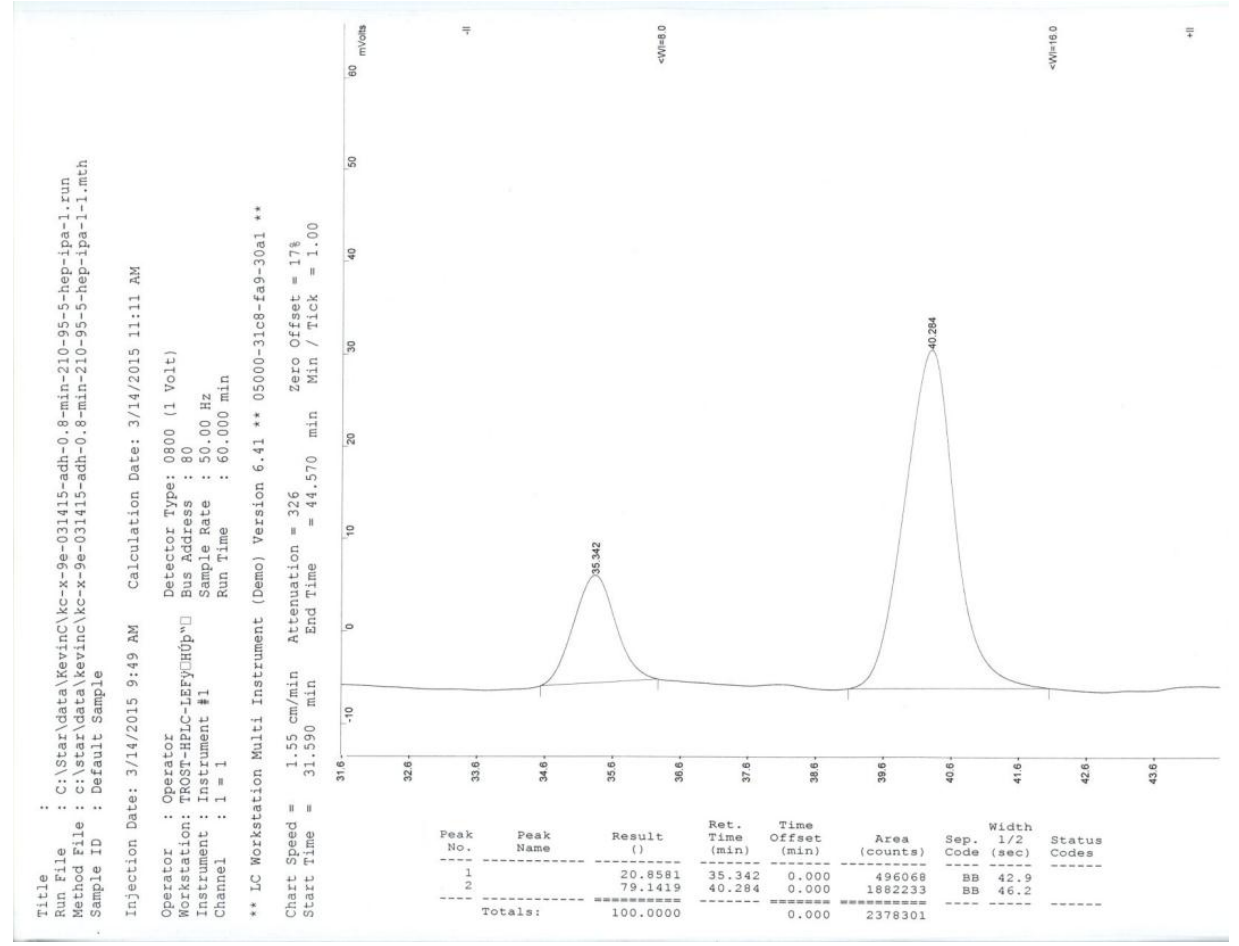

Figure S91. Chiral HPLC trace of erythrulose tris-acetate derived from oxidation of L-threitol in 2,2,2-trifluoroethanol 


\section{Regioselectivity determinations by NMR}

Crude reaction mixture: oxidation of methyl- $\alpha$-D-glucopyranoside (12) in 10:1 acetonitrile:water

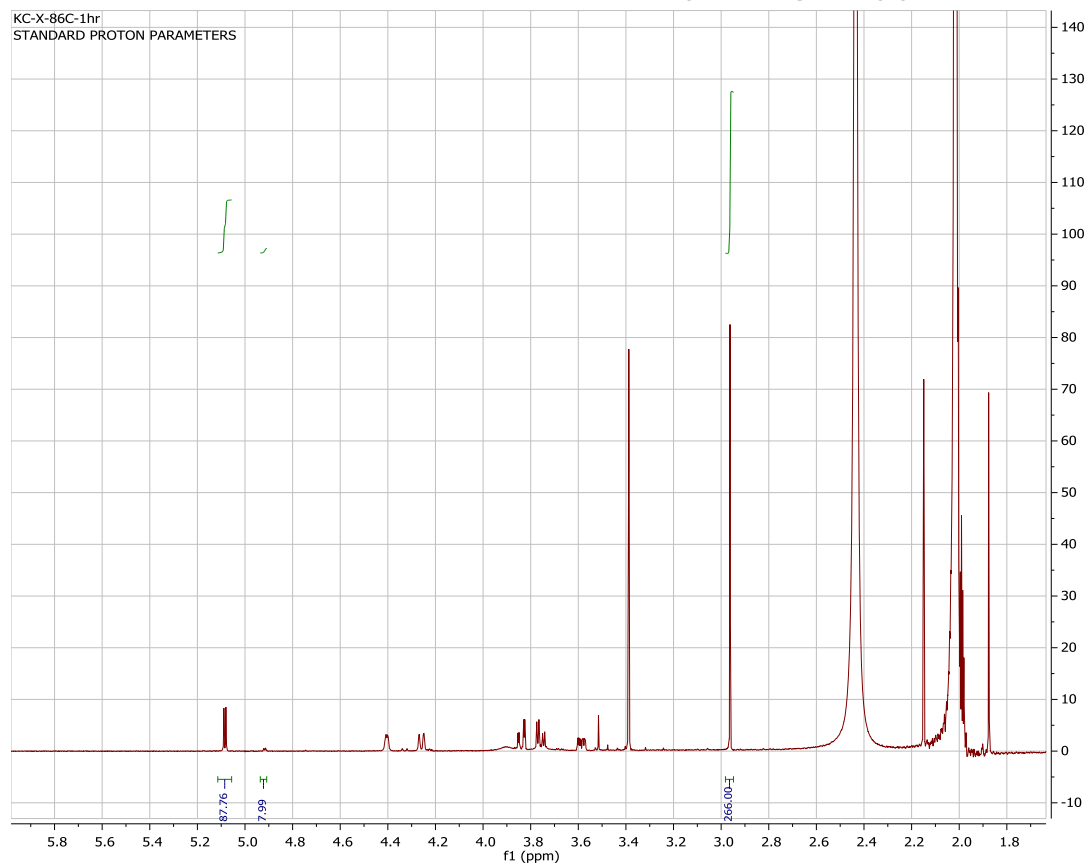

Figure S92. ${ }^{1} \mathrm{H}$ spectrum: oxidation of methyl- $\alpha$-D-glucopyranoside in 10:1 acetonitrile:water

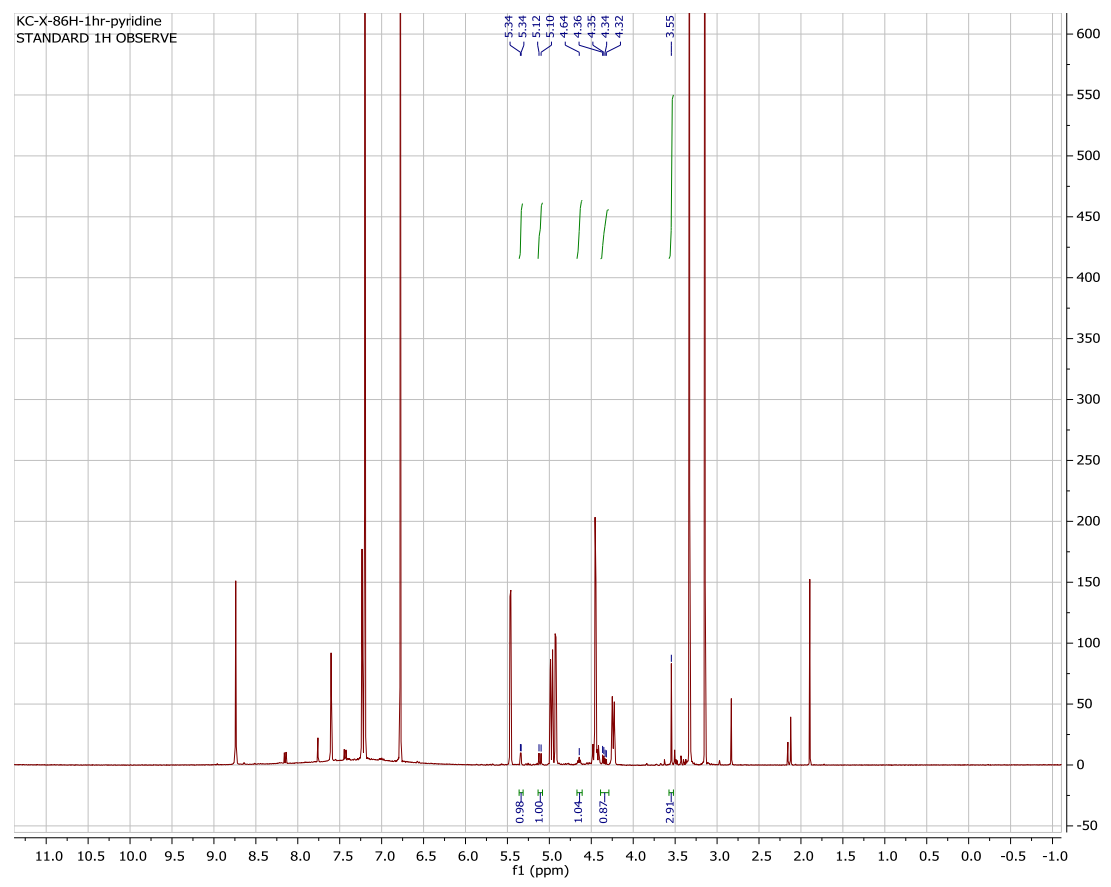

Figure S93. ${ }^{1} \mathrm{H}$ spectrum (acquired in $\mathrm{d}_{5}$-pyridine): oxidation of methyl- $\alpha$-D-glucopyranoside in 10:1 acetonitrile:water 


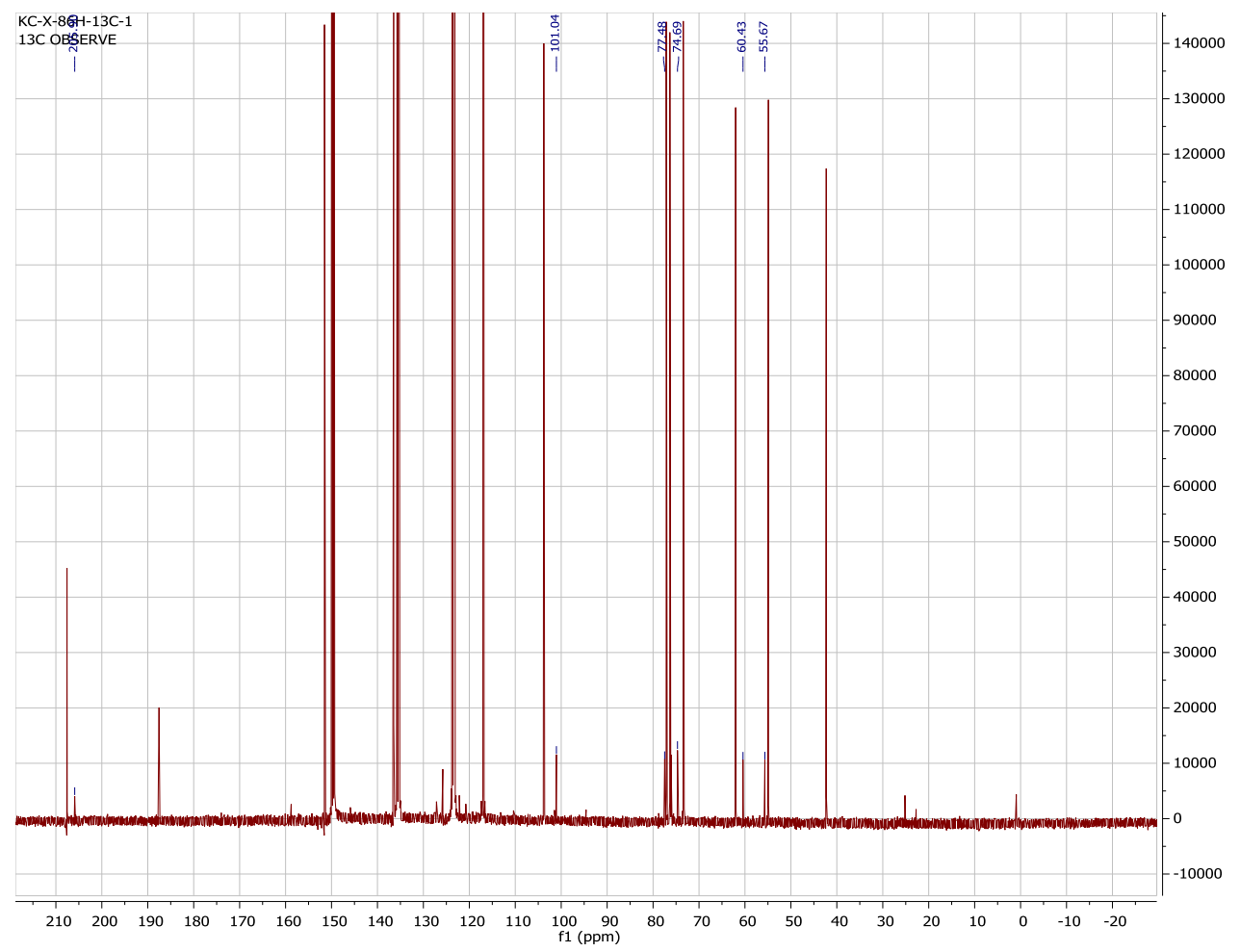

Figure S94. ${ }^{13} \mathrm{C}$ spectrum (acquired in $d_{5}$-pyridine): oxidation of methyl- $\alpha$-D-glucopyranoside in 10:1 acetonitrile:water

The ${ }^{1} \mathrm{H}$ peaks at $\delta 5.34,5.11,4.64,4.34,3.55 \mathrm{ppm}$ and ${ }^{13} \mathrm{C}$ peaks at $\delta 205.90,101.04,77.48,74.69,60.43$, $55.67 \mathrm{ppm}$ in $\mathrm{d}_{5}$-pyridine are in excellent agreement with literature values for the 4-ketoglucoside. ${ }^{6}$ The expected ${ }^{1} \mathrm{H}$ peaks at $\delta 4.42$ and $4.46 \mathrm{ppm}$ are likely overlapped by the peaks for 3-keto- $\alpha$-Dglucopyranoside. 
Crude reaction mixture: oxidation of methyl-6-deoxy- $\alpha$-D-glucopyranoside (6) in 10:1 acetonitrile: $\mathrm{H}_{2} \mathrm{O}$ KC-X-78A-1H-1.5hr
STANDARD $1 \mathrm{H}$ OBSERV

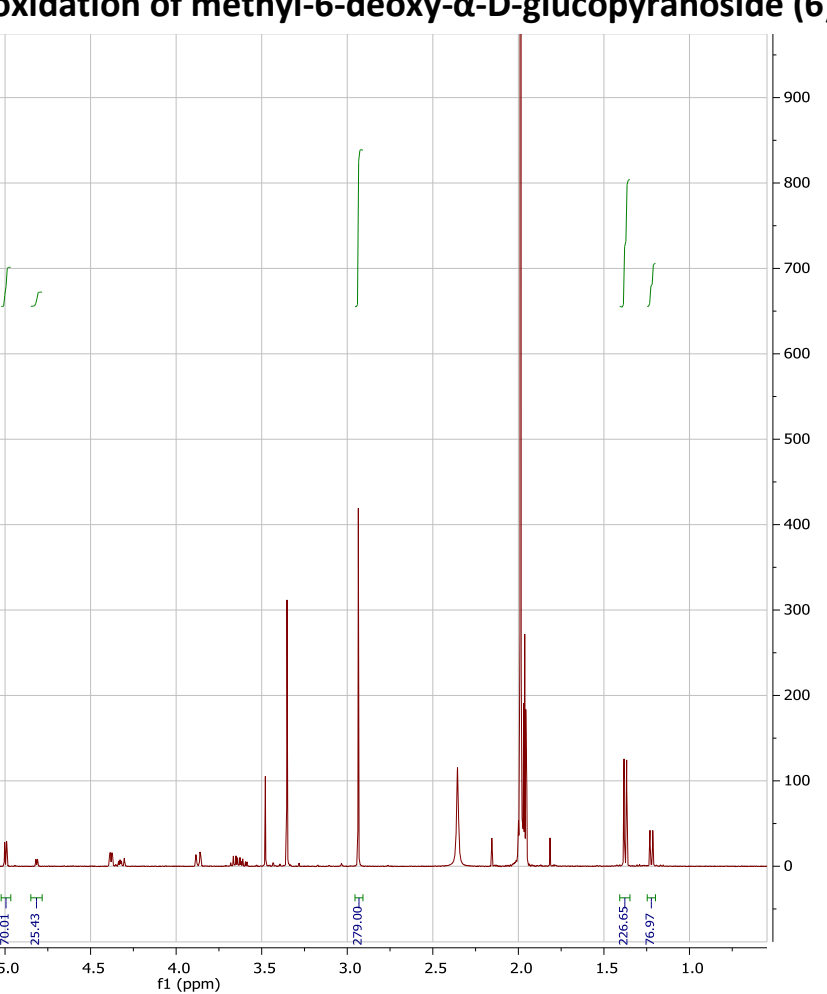

Figure S95. ${ }^{1} \mathrm{H}$ spectrum: oxidation of methyl-6-deoxy- $\alpha$-D-glucopyranoside in 10:1 acetonitrile: $\mathrm{H}_{2} \mathrm{O}$

Crude reaction mixture: oxidation of methyl- $\alpha$-D-xylopyranoside (7) in 10:1 acetonitrile:water KC-X-86E-1H-30min

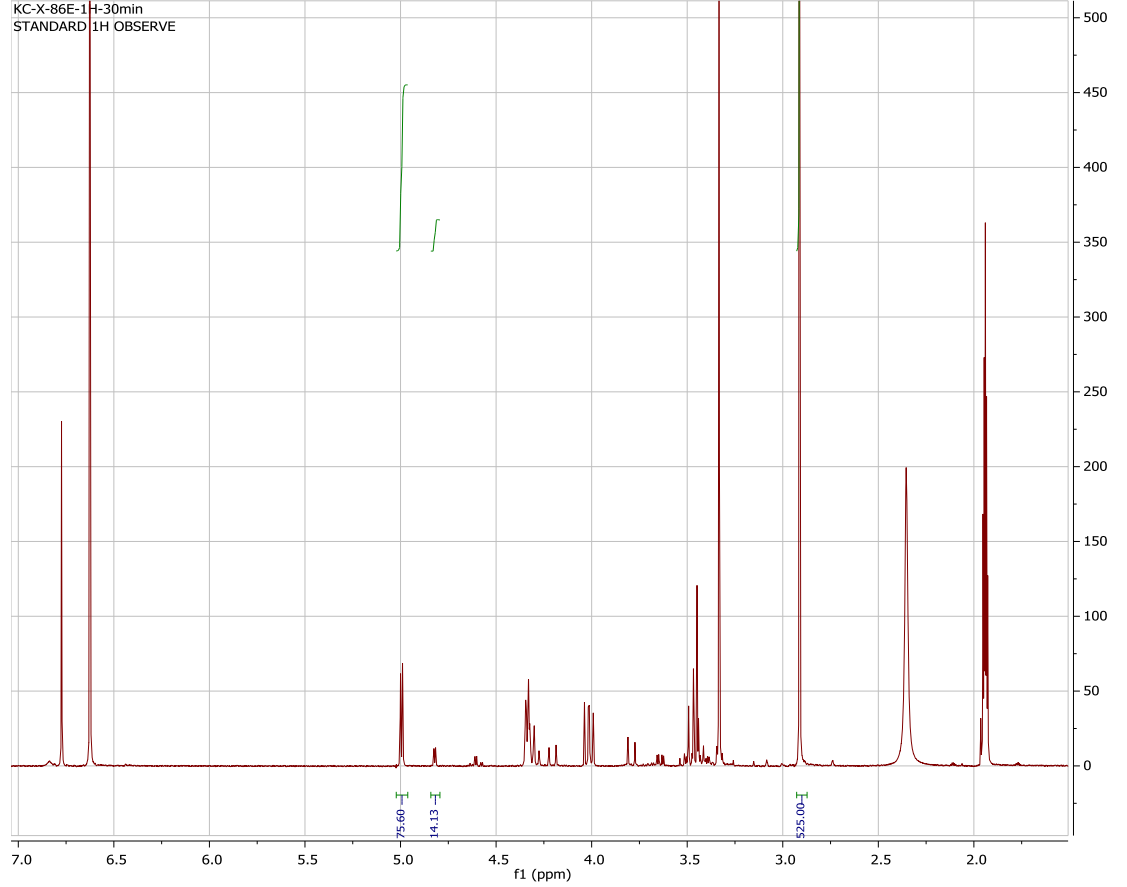

Figure S96. ${ }^{1} \mathrm{H}$ spectrum: oxidation of methyl- $\alpha$-D-xylopyranoside 10:1 acetonitrile:water 


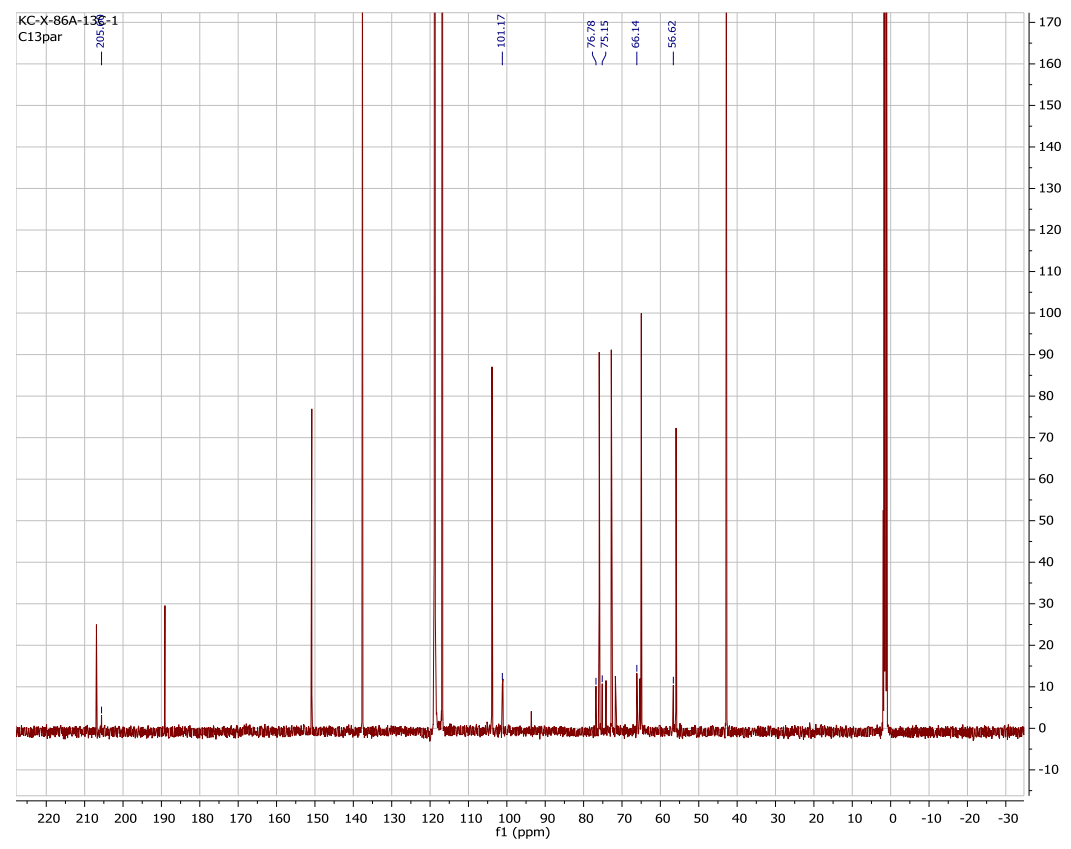

Figure S97. ${ }^{13} \mathrm{C}$ spectrum: oxidation of methyl- $\alpha$-D-xylopyranoside 10:1 acetonitrile:water

The observed ${ }^{1} \mathrm{H}$ shifts at $\delta 4.83,4.30,4.20,3.79,3.64,3.45 \mathrm{ppm}$ and ${ }^{13} \mathrm{C}$ shifts at $\delta 205.60,101.17$, $76.78,75.15,66.14,56.62 \mathrm{ppm}$ are consistent with the minor $\mathrm{C} 4$ oxidation product observed in the oxidation of methyl- $\beta$-D-arabinopyranoside. See "Crude reaction mixture: oxidation of methyl- $\beta-D-$ arabinopyranoside in $10: 1 \mathrm{CD}_{3} \mathrm{CN}: \mathrm{D}_{2} \mathrm{O}^{\prime \prime}$ for a detailed analysis of the 2D NMRs which support this structure. 


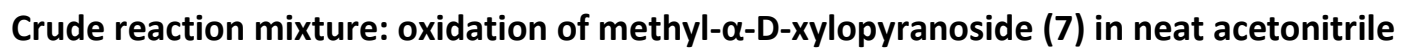

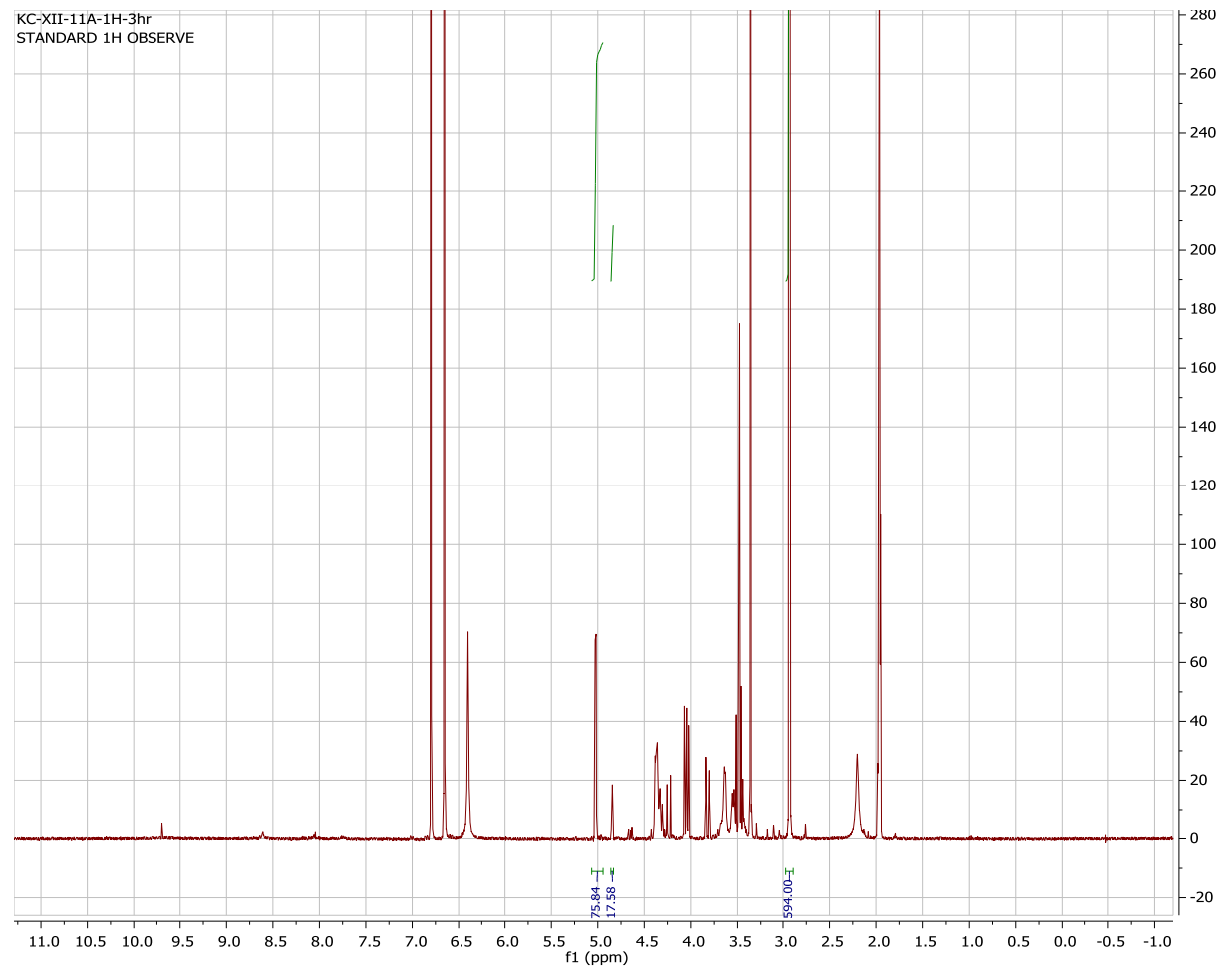

Figure S98. ${ }^{1} \mathrm{H}$ spectrum: oxidation of methyl- $\alpha$-D-xylopyranoside in neat acetonitrile 
Crude reaction mixture: oxidation of methyl- $\alpha$-L-fucopyranoside (8) in 10:1 acetonitrile:water

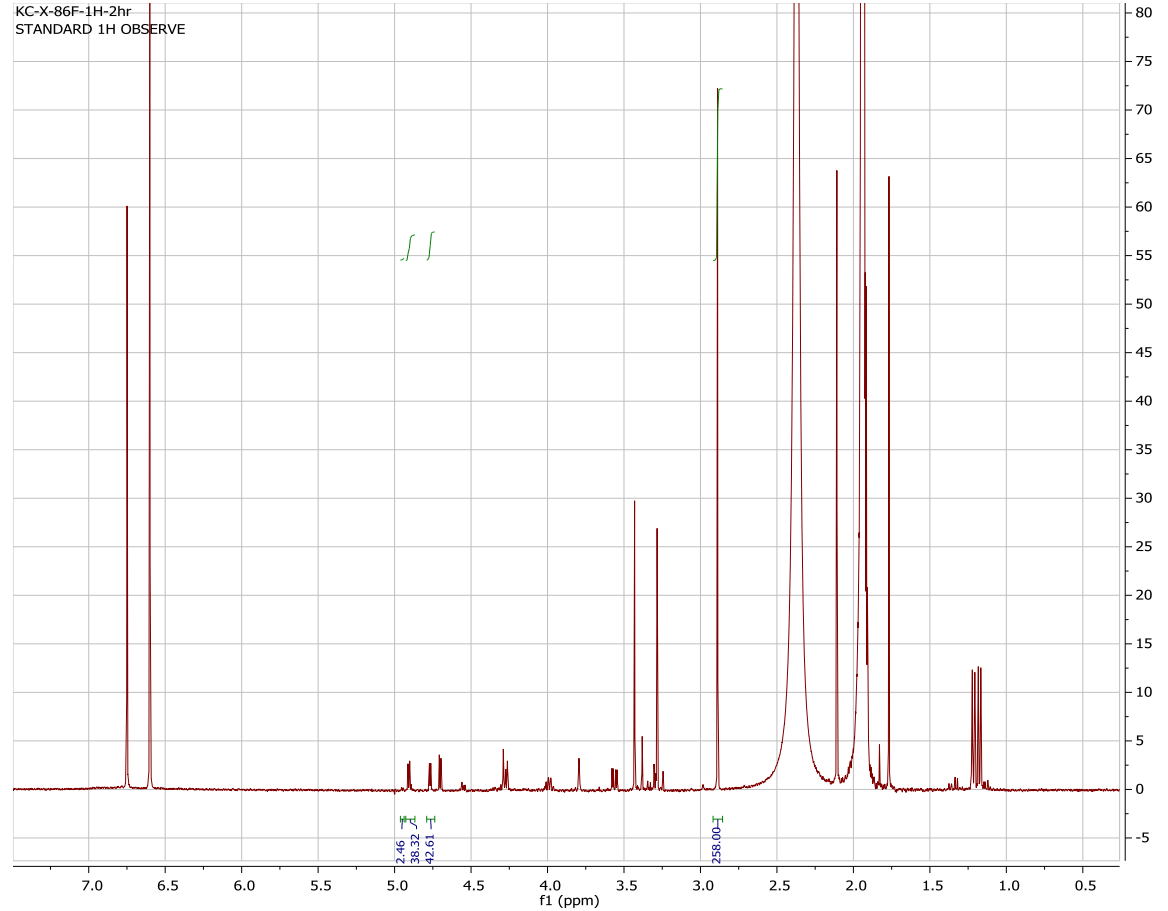

Figure S99. ${ }^{1} \mathrm{H}$ spectrum: oxidation of methyl- $\alpha$-L-fucopyranoside in 10:1 acetonitrile:water

Crude reaction mixture: oxidation of methyl- $\alpha$-L-rhamnopyranoside (9) in 10:1 $C D_{3} C N: D_{2} O$

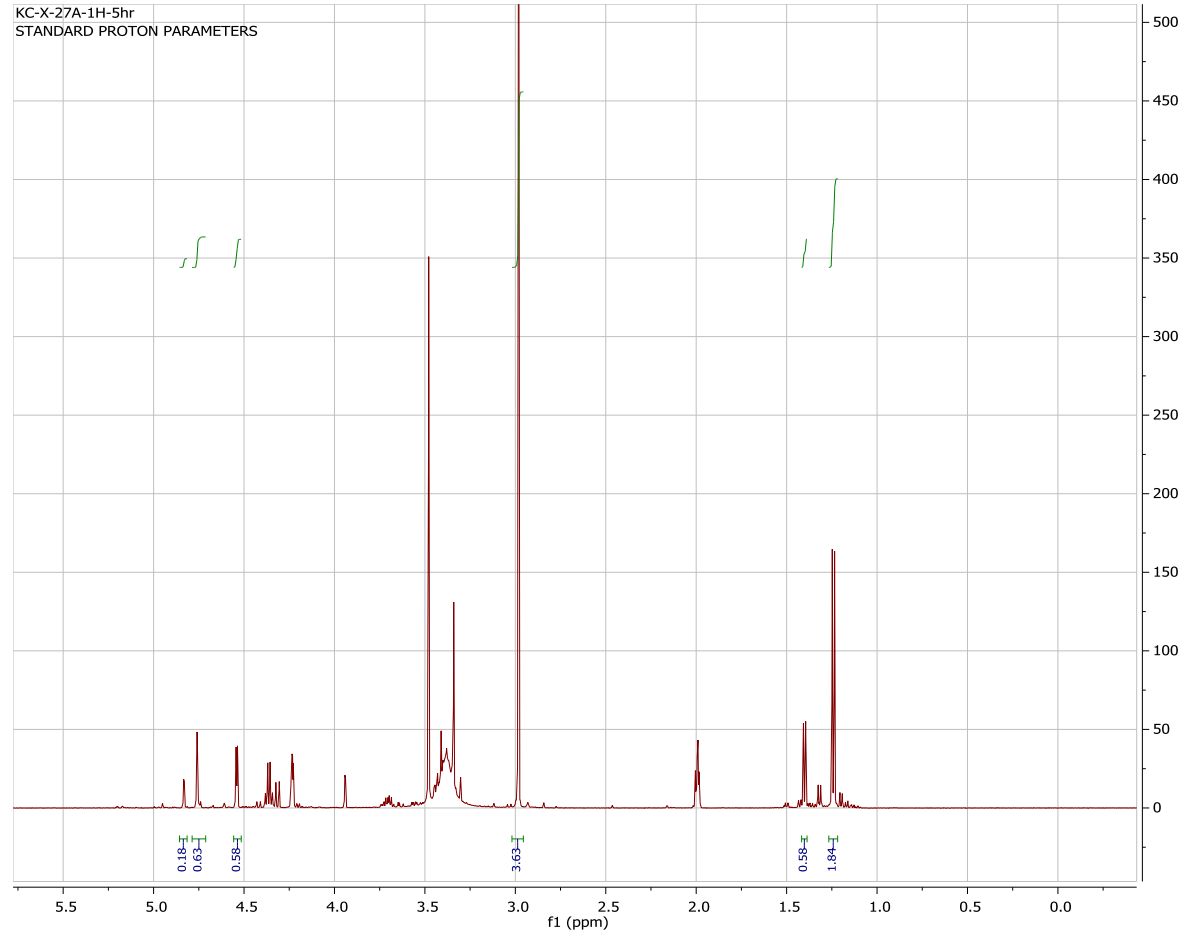

Figure S100. ${ }^{1} \mathrm{H}$ spectrum: oxidation of methyl- $\alpha$-L-rhamnopyranoside in 10:1 $\mathrm{CD}_{3} \mathrm{CN}: \mathrm{D}_{2} \mathrm{O}$ 


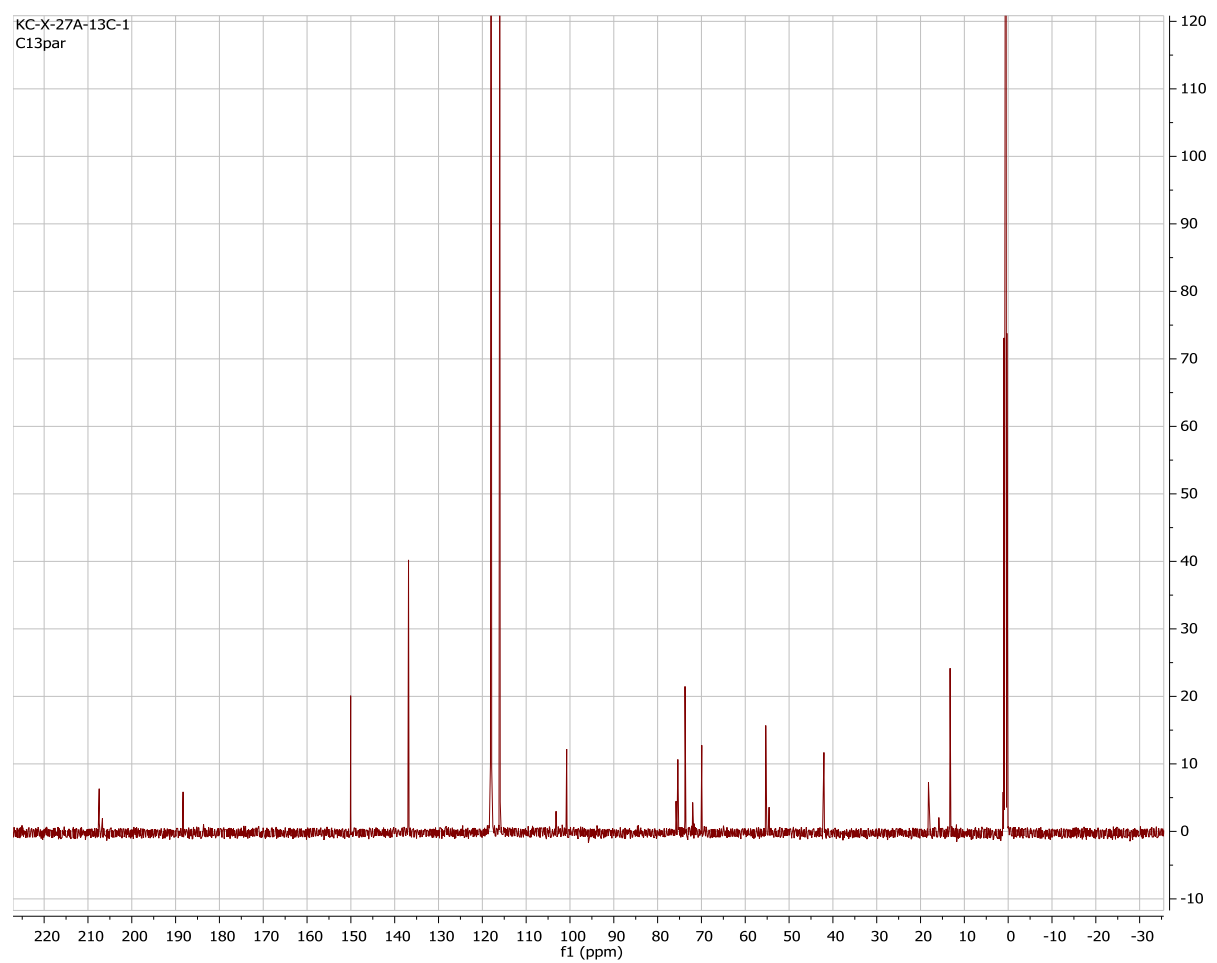

Figure S101. ${ }^{13} \mathrm{C}$ spectrum: oxidation of methyl- $\alpha$-L-rhamnopyranoside in 10:1 $\mathrm{CD}_{3} \mathrm{CN}: \mathrm{D}_{2} \mathrm{O}$

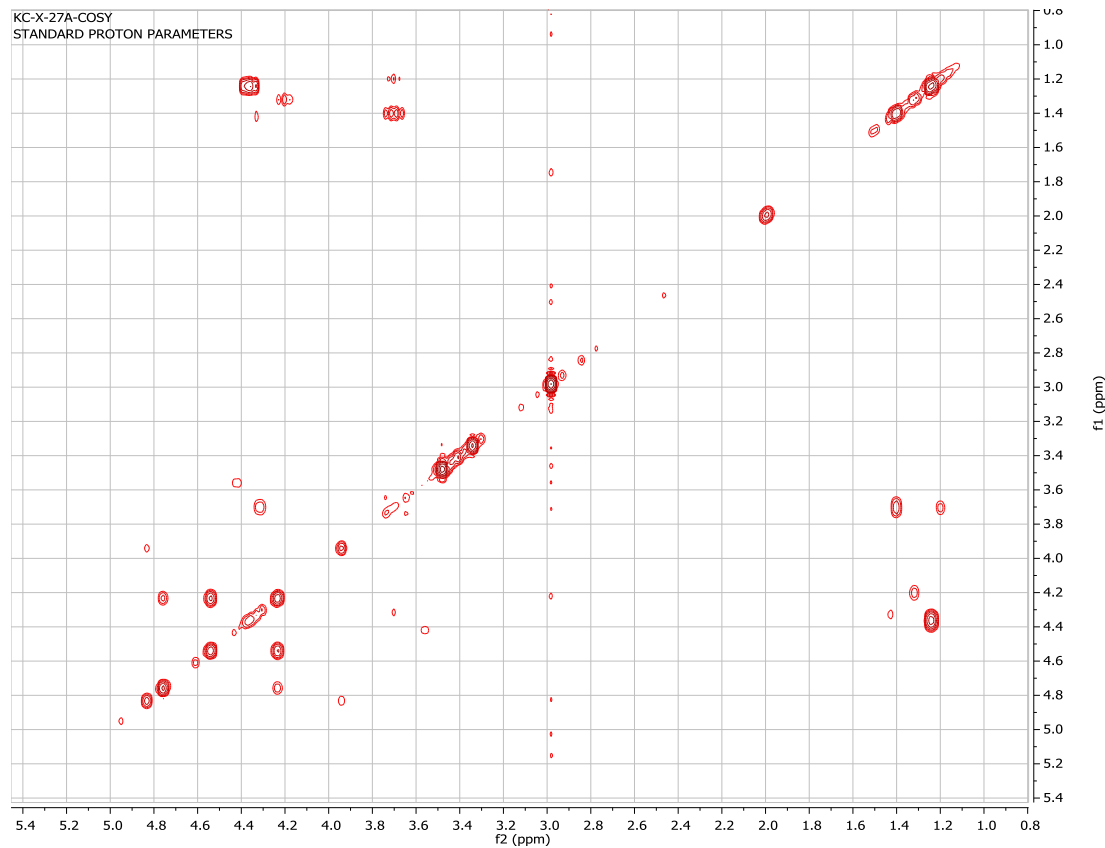

Figure S102. COSY spectrum: oxidation of methyl- $\alpha$-L-rhamnopyranoside in $10: 1 C_{3} C N: D_{2} O$ 


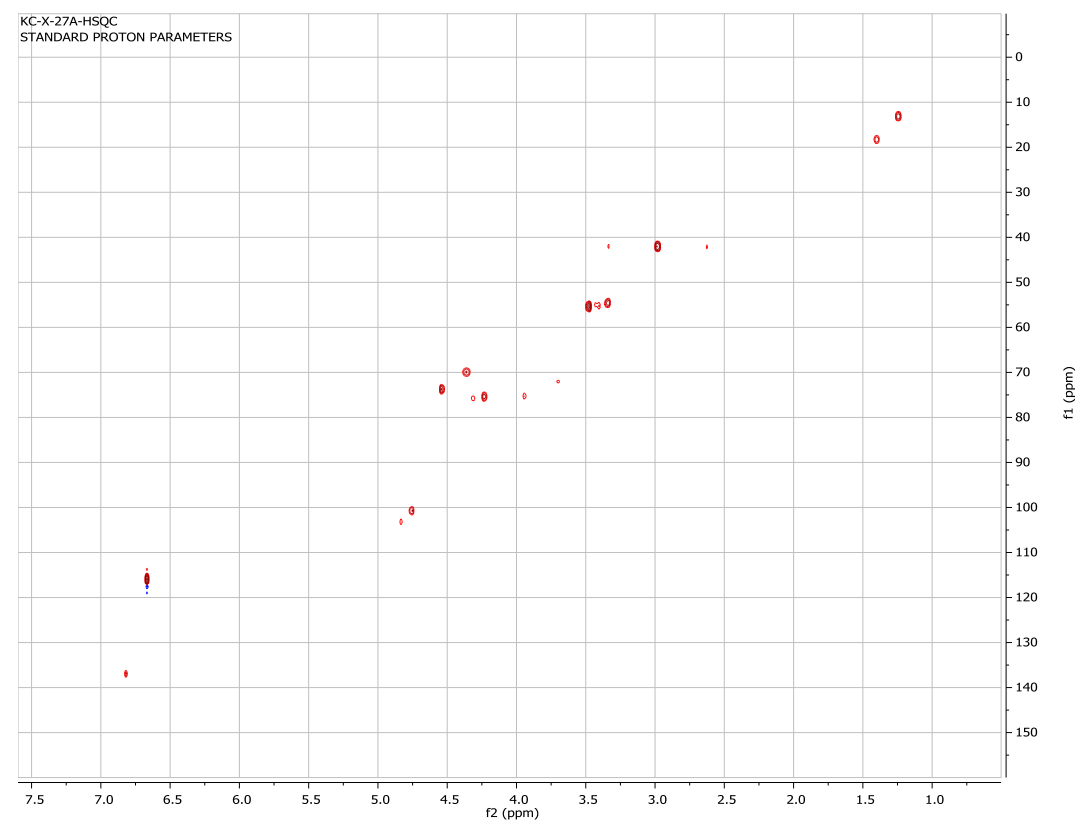

Figure S103. HSQC spectrum: oxidation of methyl- $\alpha$-L-rhamnopyranoside in 10:1 $C D_{3} C N: D_{2} O$

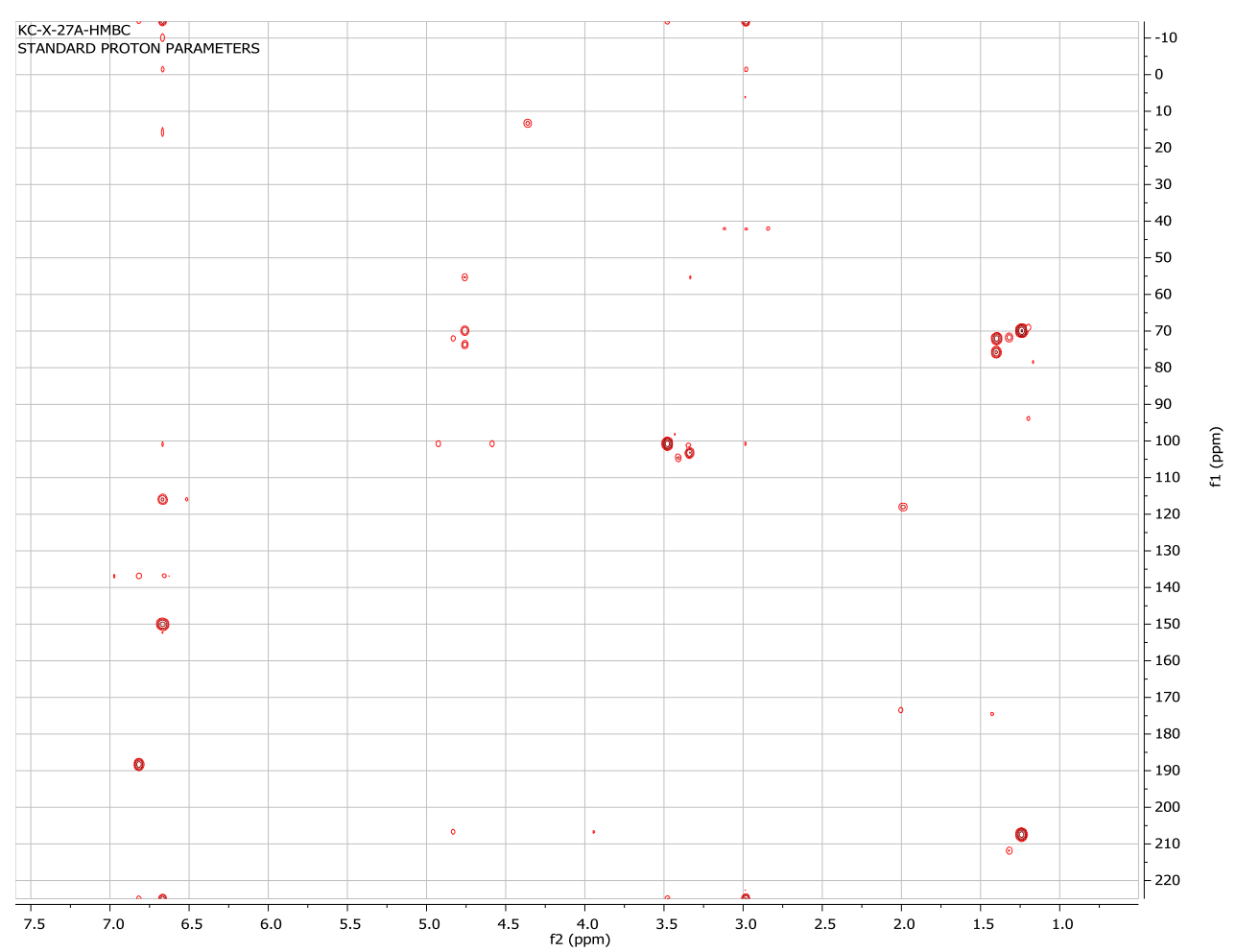

Figure S104. HMBC spectrum: oxidation of methyl- $\alpha$-L-rhamnopyranoside in $10: 1 C_{3} C N: D_{2} O$ 


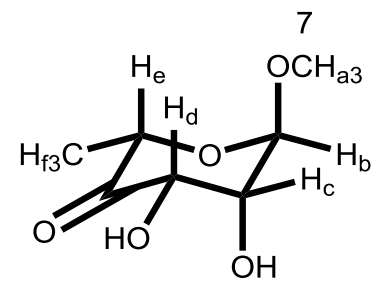

Solvent: $10: 1 \mathrm{CD}_{3} \mathrm{CN}: \mathrm{D}_{2} \mathrm{O}$

\begin{tabular}{|l|r|l|r|}
\hline C1 & 101.8 & $\mathrm{Ha}$ & 3.43 \\
\hline C2 & 76.3 & $\mathrm{Hb}$ & 4.71 \\
\hline C3 & 74.6 & $\mathrm{Hc}$ & 4.18 \\
\hline C4 & 208.1 & $\mathrm{Hd}$ & 4.50 \\
\hline C5 & 70.8 & $\mathrm{He}$ & 4.31 \\
\hline C6 & $13.9(5)$ & $\mathrm{Hf}$ & 1.19 \\
\hline C7 & 56.2 & & \\
\hline
\end{tabular}

$\operatorname{COSY}(\mathrm{S} 102):$

$\mathrm{Hb}(4.71)-\mathrm{Hc}(4.18)$

$\mathrm{Hc}(4.18)-\mathrm{Hd}(4.50)(\mathrm{J}=3.7 \mathrm{~Hz})$

$\mathrm{He}(4.31)-\mathrm{Hf}(1.19)$

The low coupling constant for the Hc-Hd coupling (see COSY spectrum Figure S106) strongly suggests that $\mathrm{Hc}$ is equatorial, as axial-axial couplings tend to be extremely strong $(\approx 10 \mathrm{~Hz})$

HSQC (S103):

$\mathrm{C} 1(101.8)-\mathrm{Hb}(4.71)$

$\mathrm{C} 2(76.3)-\mathrm{Hc}(4.18)$

C3 (74.6) - Hd (4.50)

C5 (70.8) - He (4.31)

C6 (13.95) - Hf (1.19)

C7 (56.2) - Ha (3.43)

HMBC (S104):

$\mathrm{C} 1$ (101.8) - Ha (3.43)

$\mathrm{C} 3$ (74.6) - Hb (4.71)

C4 (208.1) - Hc (4.18), Hd (4.50), He (4.31), Hf (1.19)

C5 (70.8) - Hb (4.71), Hf (1.19)

C6 (13.95) - He (4.31)

C7 (56.2) - Hb (4.71) 


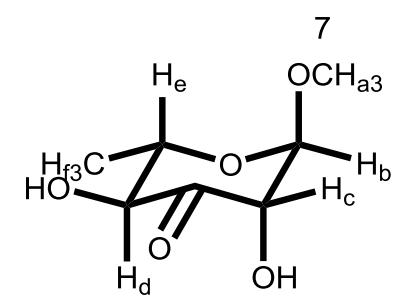

Solvent: $10: 1 \mathrm{CD}_{3} \mathrm{CN}: \mathrm{D}_{2} \mathrm{O}$

\begin{tabular}{|l|l|l|l|}
\hline C1 & 104.0 & $\mathrm{Ha}$ & 3.29 \\
\hline C2 & 76.0 & $\mathrm{Hb}$ & 4.78 \\
\hline C3 & 207.4 & $\mathrm{Hc}$ & 3.89 \\
\hline C4 & 76.5 & $\mathrm{Hd}$ & 4.26 \\
\hline C5 & 72.8 & $\mathrm{He}$ & 3.64 \\
\hline C6 & 19.1 & $\mathrm{Hf}$ & 1.35 \\
\hline C7 & 55.5 & & \\
\hline
\end{tabular}

$\operatorname{COSY}(\mathrm{S} 102):$

$\mathrm{Hb}(4.78)-\mathrm{Hc}(3.89)(\mathrm{J}=1.8 \mathrm{~Hz})$

$\mathrm{Hd}(4.26)-\mathrm{He}(3.64)(\mathrm{J}=9.4 \mathrm{~Hz})$

$\mathrm{He}(3.64)-\mathrm{Hf}(1.35)$

The high coupling constant between $\mathrm{Hd}$ and $\mathrm{He}$ (see COSY spectrum Figure S106) strongly suggests both protons are axial.

HSQC (S103):

$\mathrm{C} 1(104.0)-\mathrm{Hb}(4.78)$

C2 (76.0) - Hc (3.89)

C4 (76.5) - Hd (4.26)

C5 (72.8) - He (3.64)

C6 (19.1) - Hf (1.35)

C7 (55.5) - Ha (3.29)

HMBC (S104):

$\mathrm{C} 1$ (104.0) - Ha (3.29)

C3 (207.4) - Hb (4.78), Hc (3.89)

C4 (76.5) - Hf (1.35)

C5 (72.8)-Hb (4.78), Hf (1.35)

C6 (19.1) - Hd (4.26) 
Crude reaction mixture: oxidation of methyl- $\beta$-D-arabinopyranoside (13) in 10:1 CD3CN:D20 KC-X-27B-1 $1 \mathrm{H}-4 \mathrm{hr}$

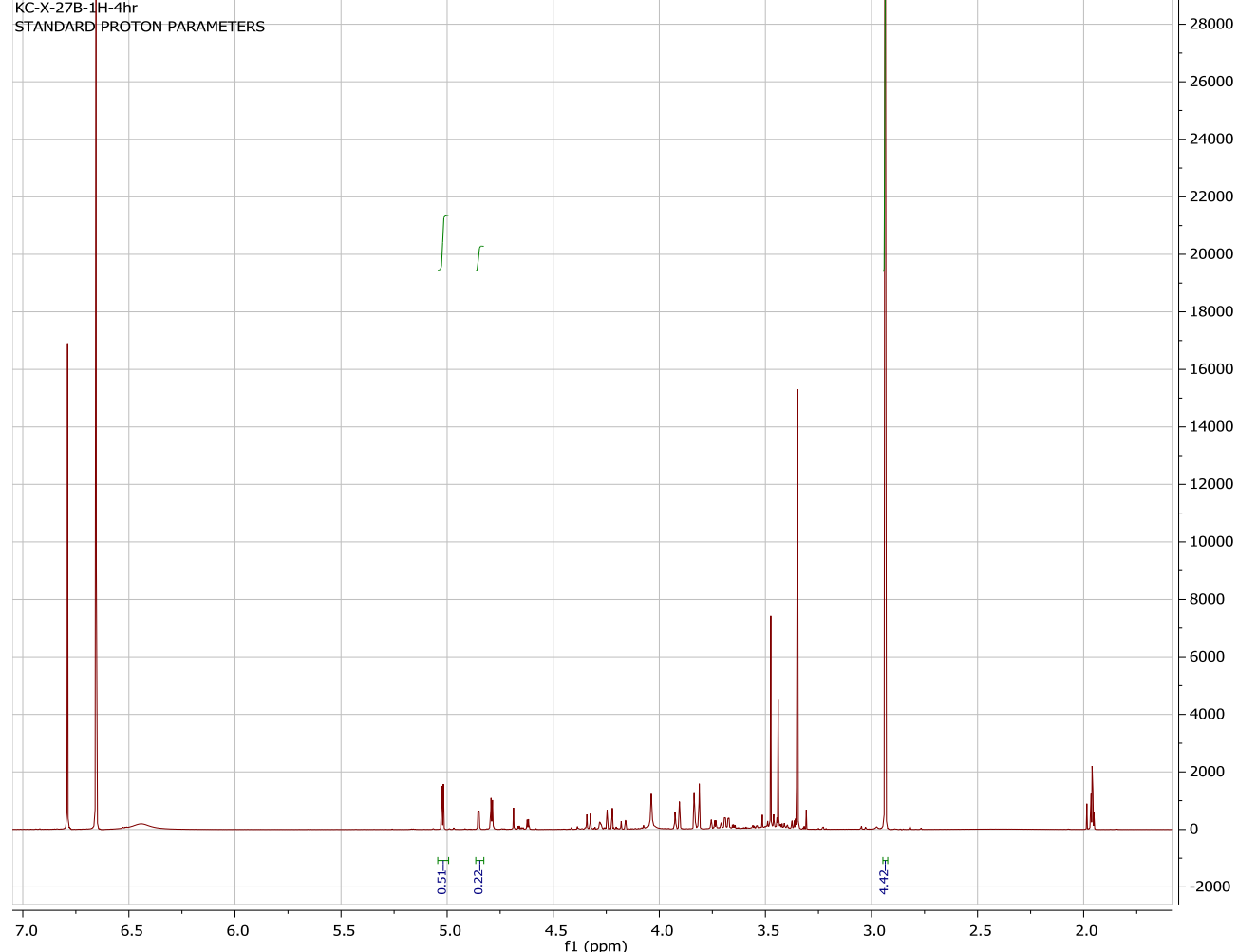

Figure S105. ${ }^{1} \mathrm{H}$ spectrum: oxidation of methyl- $\beta$-D-arabinopyranoside in $10: 1 \mathrm{CD}_{3} \mathrm{CN}: \mathrm{D}_{2} \mathrm{O}$

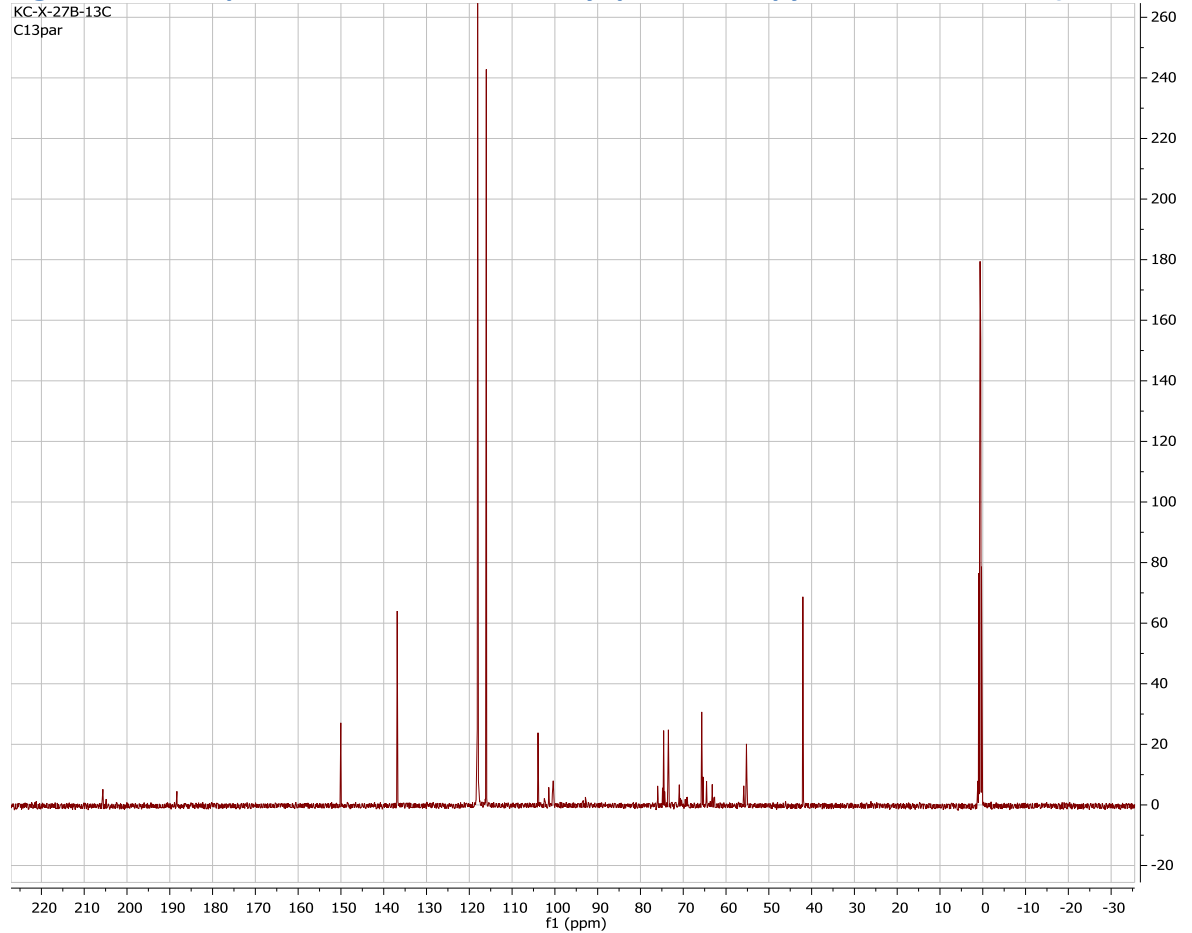

Figure S106. ${ }^{13} \mathrm{C}$ spectrum: oxidation of methyl- $\beta$-D-arabinopyranoside in $10: 1 \mathrm{CD}_{3} C N: \mathrm{D}_{2} \mathrm{O}$ 


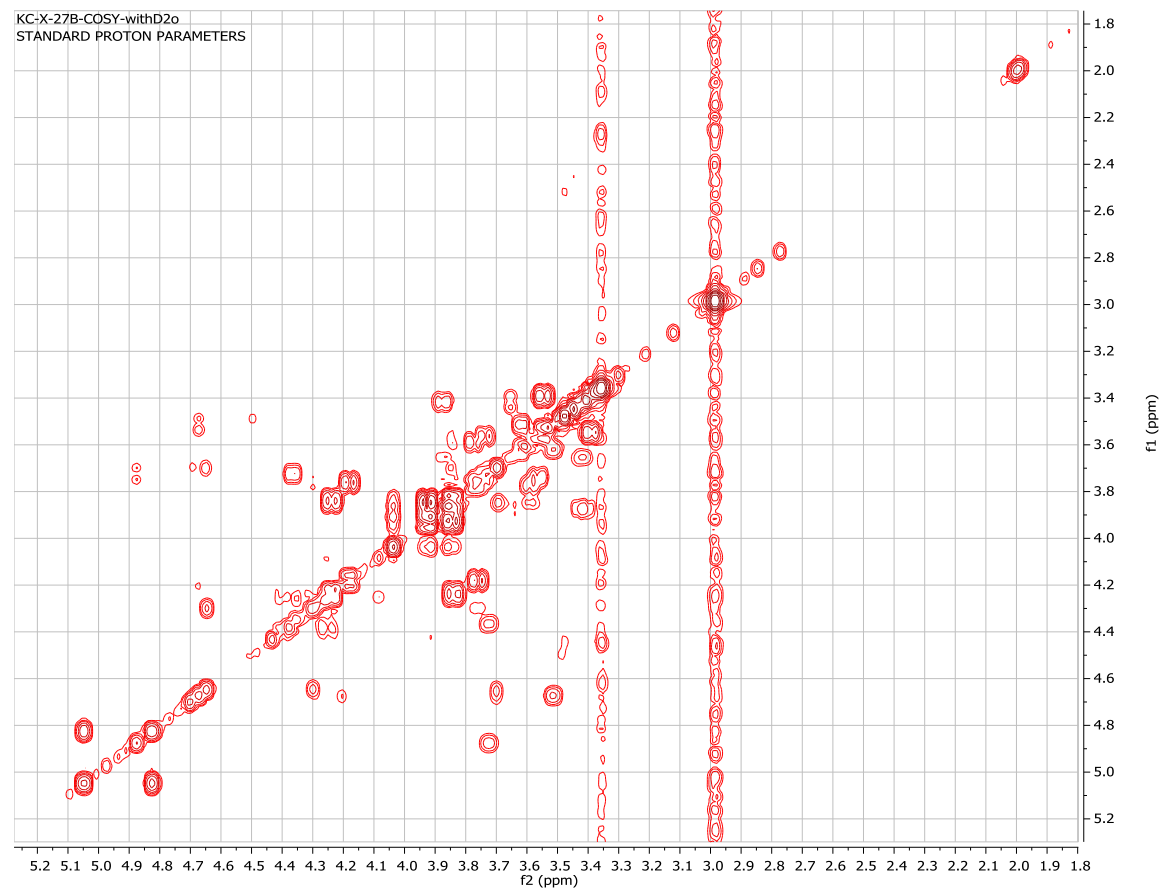

Figure S107. COSY spectrum: oxidation of methyl- $\beta$-D-arabinopyranoside in 10:1 $C_{3} C N: D_{2} O$

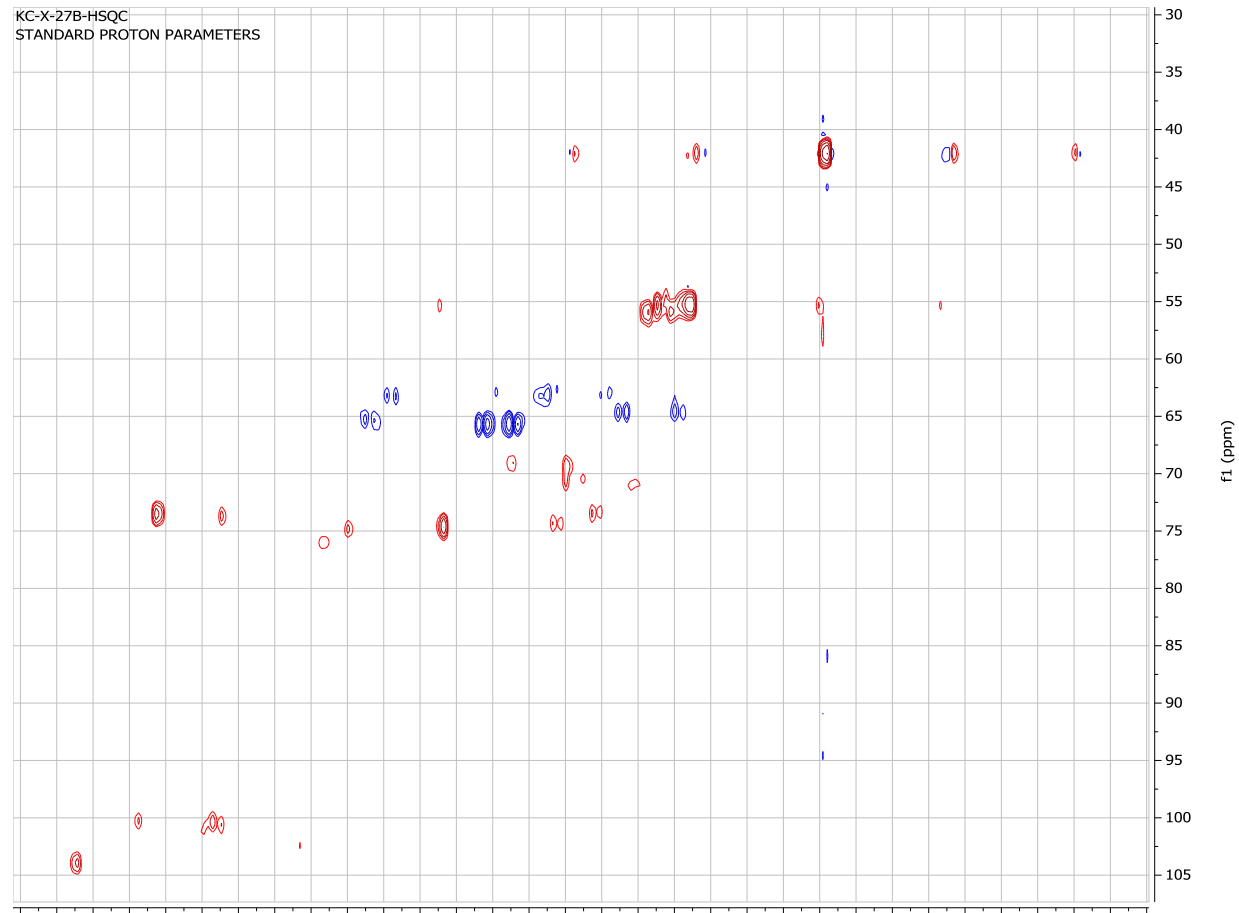

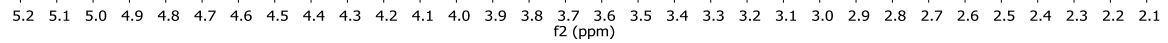

Figure S108. HSQC spectrum: oxidation of methyl- $\beta$-D-arabinopyranoside in $10: 1 \mathrm{CD}_{3} C N: \mathrm{D}_{2} \mathrm{O}$ 


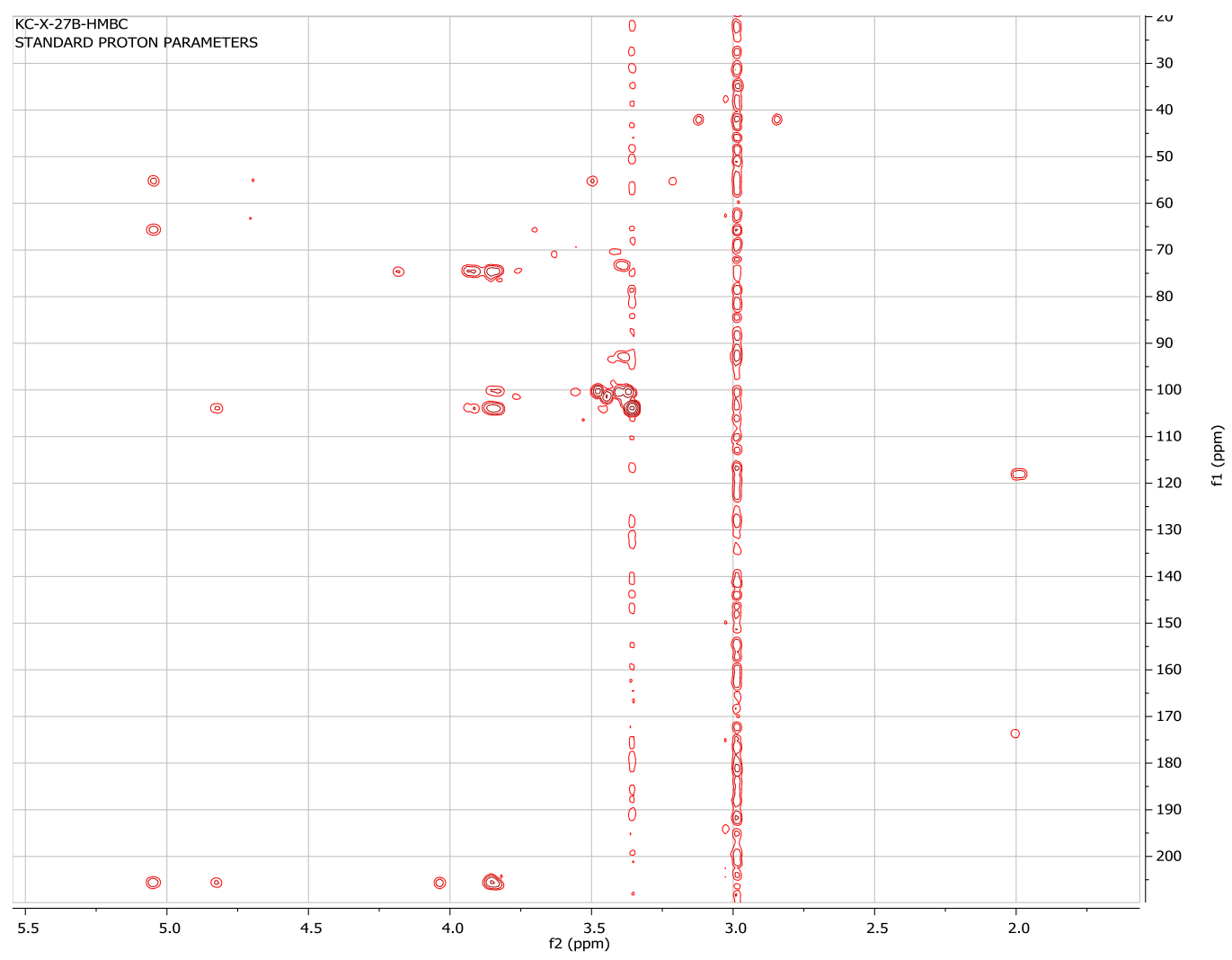

Figure S109. $H M B C$ spectrum: oxidation of methyl- $\beta$-D-arabinopyranoside in $10: 1 C_{3} C N: D_{2} O$ 


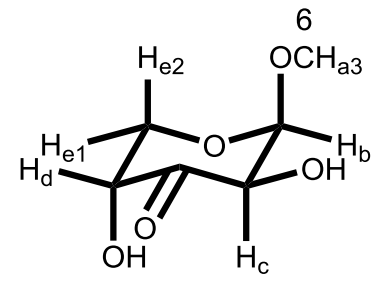

Solvent: $10: 1 \mathrm{CD}_{3} \mathrm{CN}: \mathrm{D}_{2} \mathrm{O}$

\begin{tabular}{|l|l|l|l|}
\hline C1 & 104.8 & $\mathrm{Ha}$ & 3.33 \\
\hline C2 & 74.25 & $\mathrm{Hb}$ & 4.99 \\
\hline C3 & 205.75 & $\mathrm{HC}$ & 4.76 \\
\hline C4 & 75.3 & $\mathrm{Hd}$ & 3.99 \\
\hline C5 & 66.42 & $\mathrm{He}$ & 3.88 \\
\hline C6 & 56.0 & $\mathrm{He} 2$ & 3.80 \\
\hline
\end{tabular}

COSY (Figure S107):

$\mathrm{Hb}(4.99)-\mathrm{Hc}(4.76)$

$\mathrm{Hd}(3.99)-\mathrm{He}(3.80)(\mathrm{J}=0.7 \mathrm{~Hz})$

$\mathrm{Hd}(3.99)-\mathrm{He}(3.88)(\mathrm{J}=1.1 \mathrm{~Hz})$

The low J-values for the $\mathrm{Hd}$-He couplings (see COSY spectrum Figure S111) strongly suggest that $\mathrm{Hd}$ is equatorial, as axial-axial couplings tend to be extremely strong $(\approx 10 \mathrm{~Hz})$

HSQC (Figure S108):

$\mathrm{C} 1$ (104.8) - Hb (4.99)

$\mathrm{C} 2(74.25)-\mathrm{Hc}(4.76)$

C4 (75.3) - Hd (3.99)

C5 $(66.42)-\mathrm{He}, \mathrm{He}(3.80,3.88)$

C6 (56.0) - Ha (3.33)

HMBC (Figure S109):

C1 (104.8) - Ha (3.33), He (3.80)

C3 (205.75) - Hb (4.99), Hc (4.76), Hd (3.99), He (3.80)

C4 (75.3) - He $(3.80,3.88)$ 


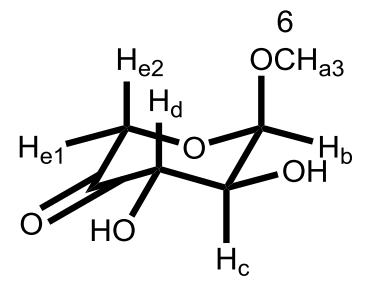

Solvent: $10: 1 \mathrm{CD}_{3} \mathrm{CN}: \mathrm{D}_{2} \mathrm{O}$

\begin{tabular}{|l|l|l|l|}
\hline C1 & 101.2 & $\mathrm{Ha}$ & 3.45 \\
\hline C2 & 75.1 & $\mathrm{Hb}$ & 4.82 \\
\hline C3 & 77.0 & $\mathrm{HC}$ & 3.67 \\
\hline C4 & 205.6 & $\mathrm{Hd}$ & 4.31 \\
\hline C5 & 66.1 & $\mathrm{He}$ & $4.19(?)$ \\
\hline C6 & 56.8 & $\mathrm{He}$ & $3.80(?)$ \\
\hline
\end{tabular}

COSY (Figure S107):

$\mathrm{Hb}(4.82)-\mathrm{Hc}(3.67)$

$\mathrm{Hc}(3.67)-\mathrm{Hd}(4.31)(\mathrm{J}=10.1 \mathrm{~Hz})$

He (3.80) - He (4.19)

The high coupling constant between $\mathrm{Hc}$ and $\mathrm{Hd}$ strongly suggests both protons are axial.

HSQC (Figure S108):

$\mathrm{C} 1(101.2)-\mathrm{Hb}(4.82)$

$\mathrm{C} 2(75.1)-\mathrm{Hc}(3.67)$

C3 (77.0) - Hd (4.31)

C5 (66.1) - He $(3.80,4.19)$

C6 (56.8) - Ha (3.45)

HMBC (Figure S109):

C1 (101.2) - Ha (3.45)

C4 (205.6) - He $(3.79,4.19)$

The assignments for the two $\mathrm{H}_{\mathrm{e}}$ and $\mathrm{C} 5$ are extremely tentative, and are centered on consistent integrations, as well as weak $\mathrm{HMBC}$ correlations between $\mathrm{H}_{\mathrm{e}}$ 4.19/3.77 ppm signals and the $\mathrm{C} 4$ ketone carbonyl at 205.6. That said, the exact identity of these protons and carbons does not strongly affect the overall determination that this product is oxidized at $\mathrm{C} 4$, as strong COSY correlations support the elucidation of the rest of the structure.

Similarly, the connection of $\mathrm{C} 6$ and $\mathrm{H}_{\mathrm{a}}$ to the rest of the structure is dependent on the consistent integrations and $\mathrm{HMBC}$ correlations between the $\mathrm{Ha} 3.45$ ppm signal and $\mathrm{C}$. 
Crude reaction mixture: oxidation of 1,6-anhydro- $\beta$-D-galactopyranoside (10) in $\mathrm{CD}_{3} \mathrm{CN}$

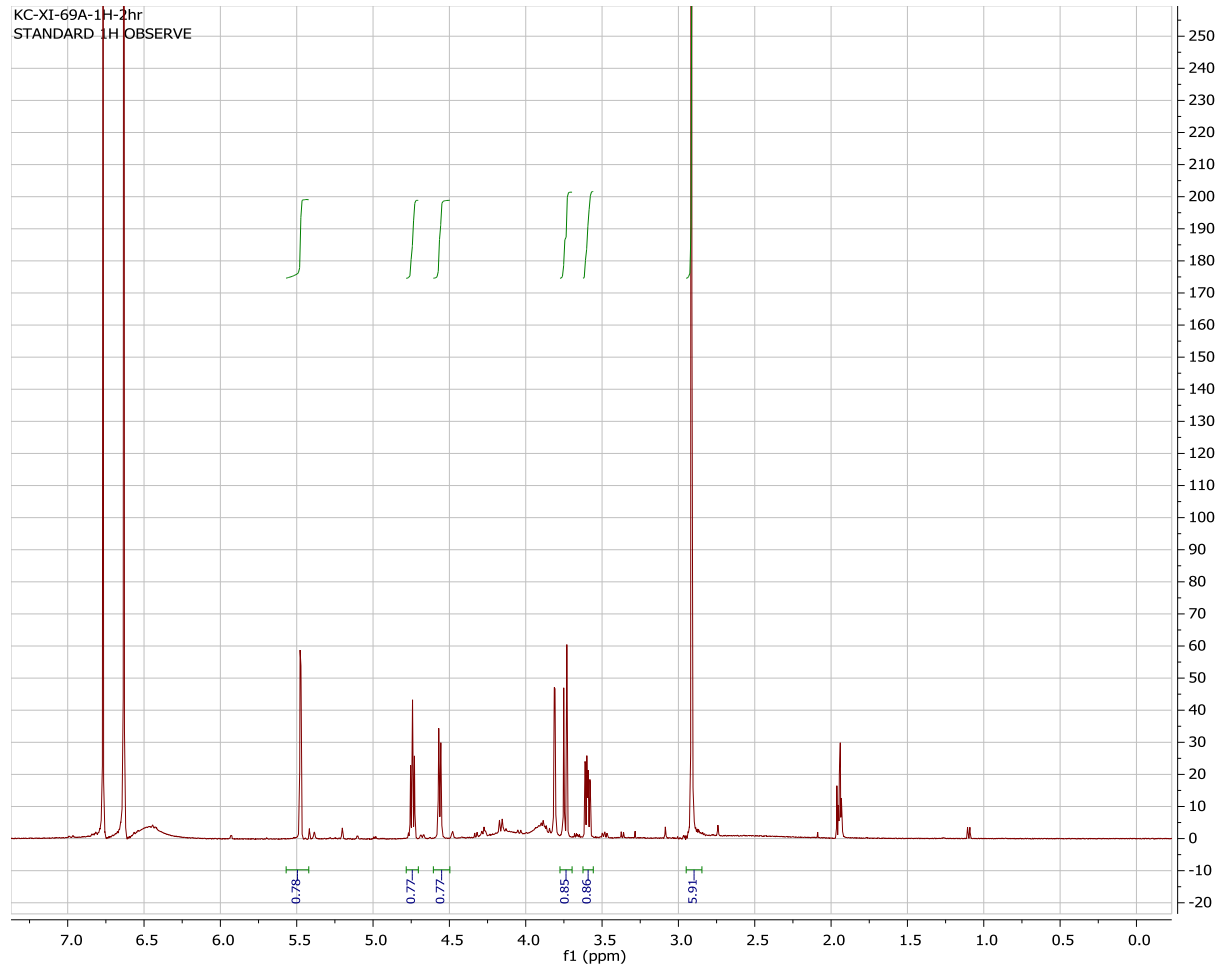

Figure S110. ${ }^{1} \mathrm{H}$ spectrum: oxidation of 1,6-anhydro- $\beta$-D-galactopyranoside in $\mathrm{CD}_{3} \mathrm{CN}$

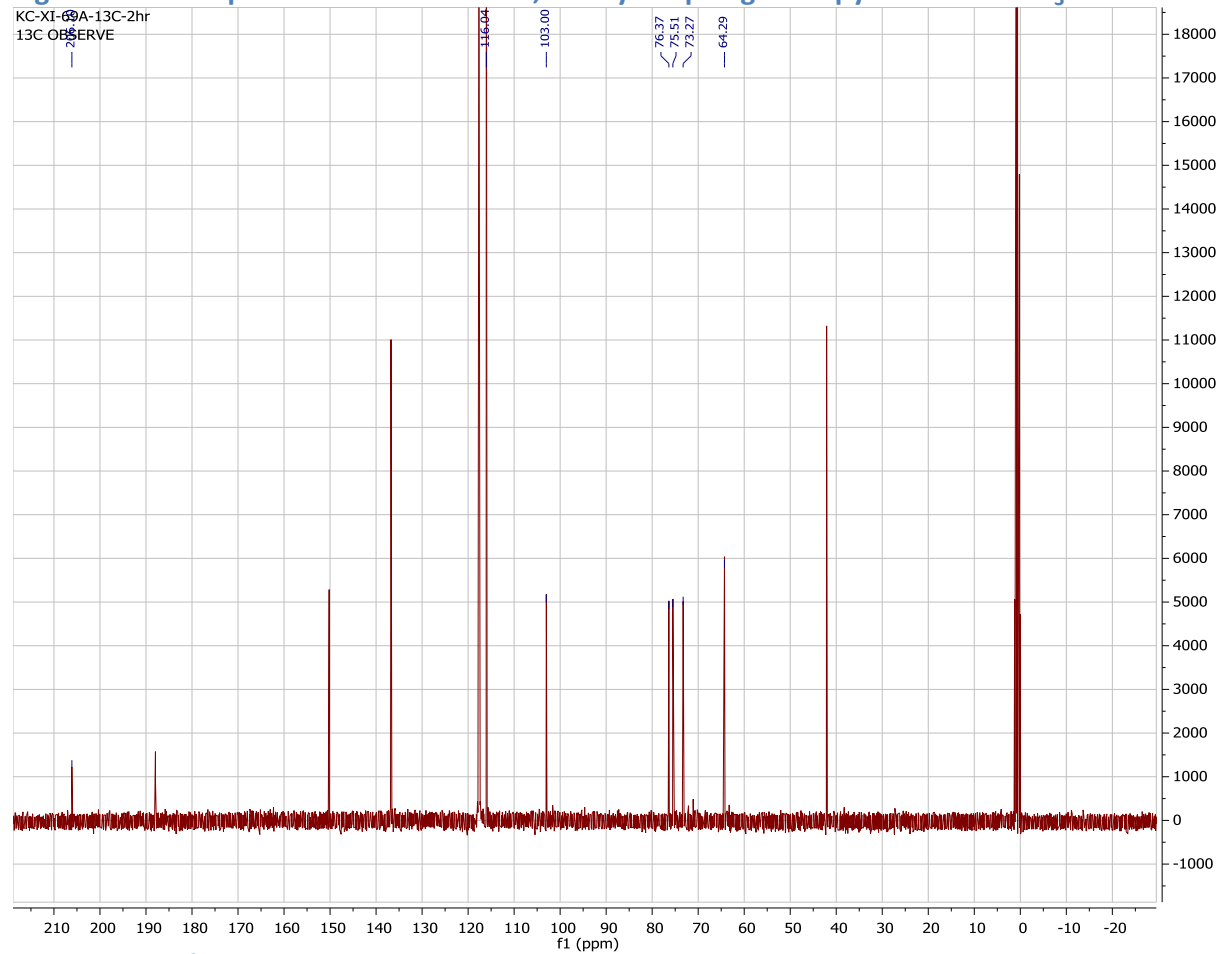

Figure $\mathrm{S} 111 .{ }^{13} \mathrm{C}$ spectrum: oxidation of 1,6 -anhydro- $\beta$-D-galactopyranoside in $\mathrm{CD}_{3} \mathrm{CN}$ 


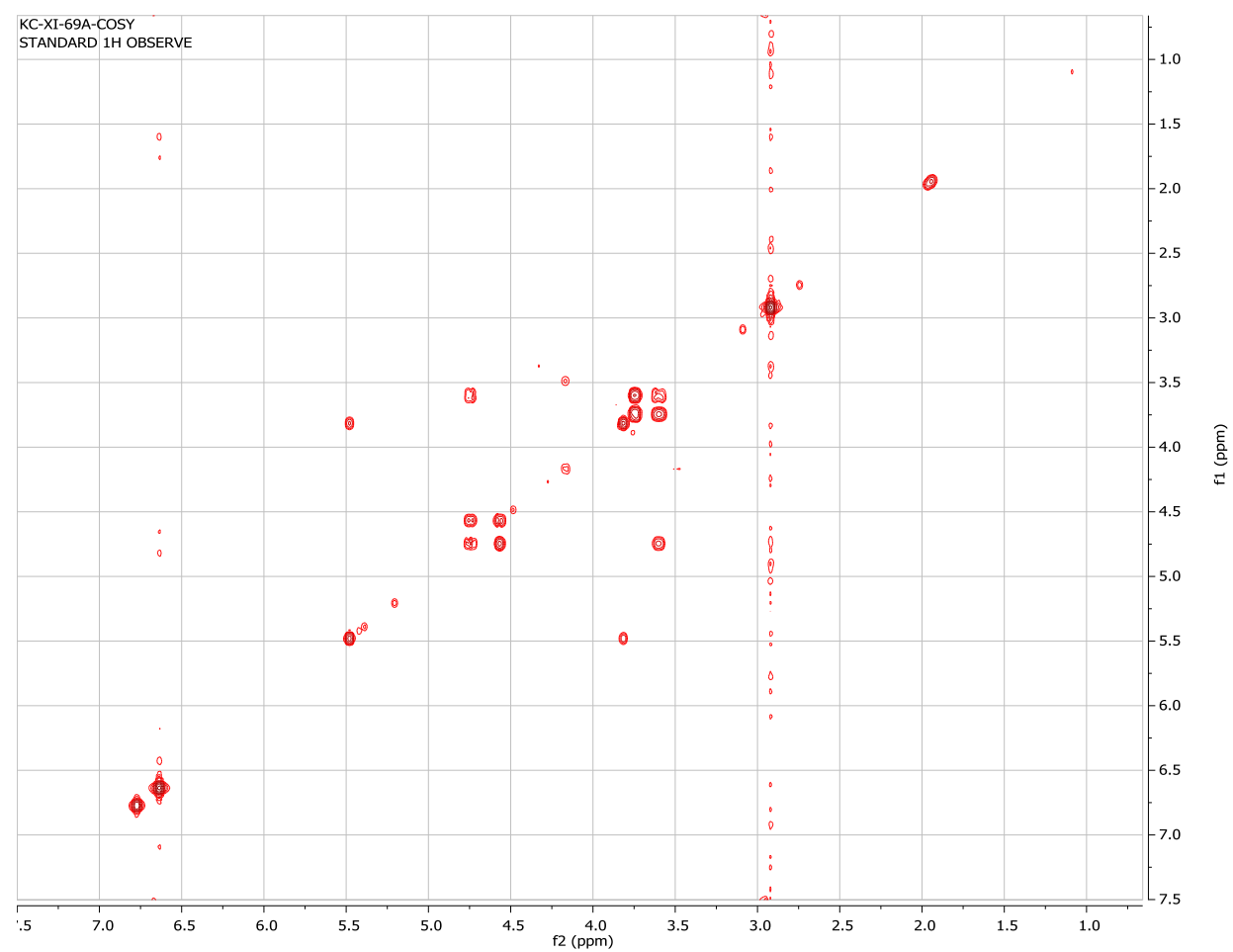

Figure S112. COSY spectrum: oxidation of 1,6-anhydro- $\beta$-D-galactopyranoside in $\mathrm{CD}_{3} \mathrm{CN}$

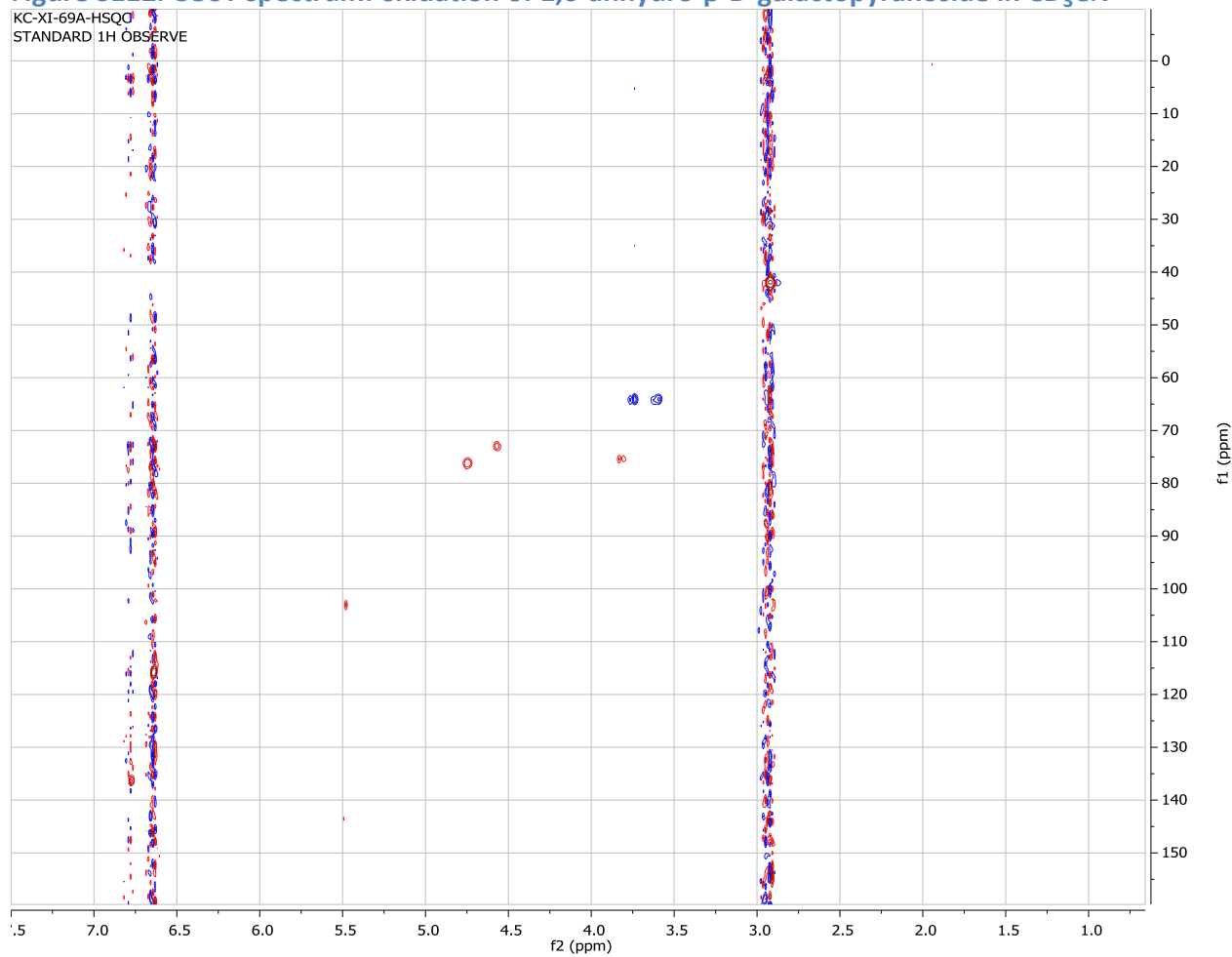

Figure S113. HSQC spectrum: oxidation of 1,6-anhydro- $\beta$-D-galactopyranoside in $\mathrm{CD}_{3} \mathrm{CN}$ 


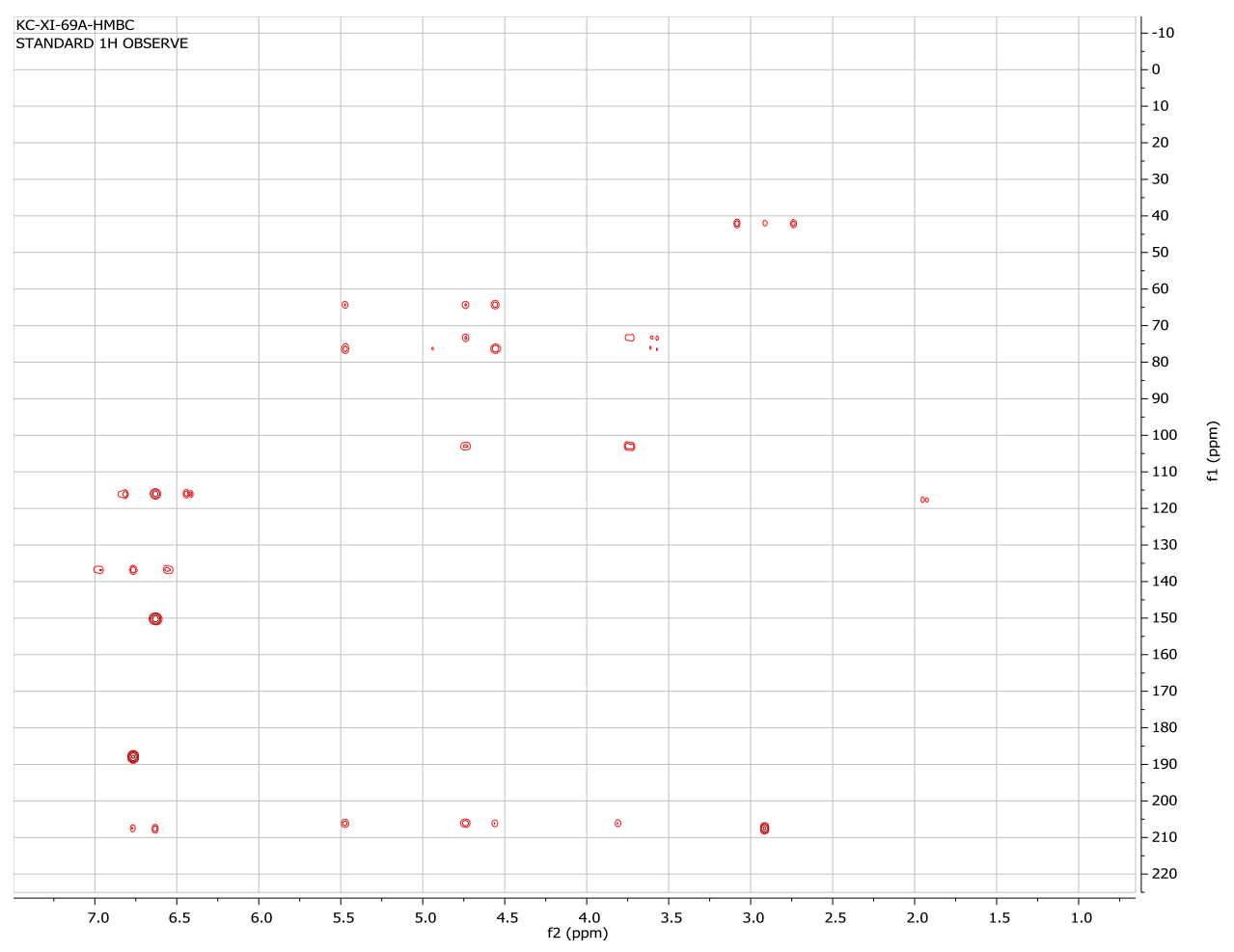

Figure S114. HMBC spectrum: oxidation of 1,6-anhydro- $\beta$-D-galactopyranoside in $\mathrm{CD}_{3} \mathrm{CN}$ 


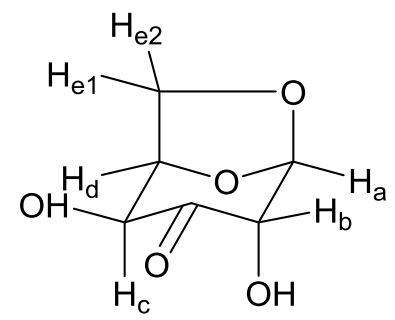

Solvent: $\mathrm{CD}_{3} \mathrm{CN}$

\begin{tabular}{|l|l|l|l|}
\hline C1 & 116.0 & $\mathrm{Ha}$ & 5.48 \\
\hline C2 & 75.5 & $\mathrm{Hb}$ & 3.81 \\
\hline C3 & 206.1 & $\mathrm{Hc}$ & 4.57 \\
\hline C4 & 76.4 & $\mathrm{Hd}$ & 4.75 \\
\hline C5 & 73.3 & $\mathrm{He} 1$ & 3.61 \\
\hline C6 & 64.3 & $\mathrm{He} 2$ & 3.75 \\
\hline
\end{tabular}

${ }^{13} \mathrm{CNMR}\left(101 \mathrm{MHz}, \mathrm{CD}_{3} \mathrm{CN}\right) \delta 206.10,116.04,103.00,76.37,75.51,73.27,64.29$.

${ }^{1} \mathrm{H}$ NMR $\left(400 \mathrm{MHz}, \mathrm{CD}_{3} \mathrm{CN}\right) \delta 5.48(\mathrm{~d}, \mathrm{~J}=2.1 \mathrm{~Hz}, 1 \mathrm{H}), 4.74(\mathrm{ddd}, \mathrm{J}=5.5,4.5,0.7 \mathrm{~Hz}, 1 \mathrm{H}), 4.56$ (dd, J = 5.7,

$1.1 \mathrm{~Hz}, 1 \mathrm{H}$ ), $3.81(\mathrm{~d}, \mathrm{~J}=2.1 \mathrm{~Hz}, 1 \mathrm{H}$ ), 3.74 (dd, J = 8.1, $0.8 \mathrm{~Hz}, 1 \mathrm{H}$ ), 3.59 (dddd, J = 8.1, 4.7, 1.3, $0.5 \mathrm{~Hz}, 1 \mathrm{H}$ ).

COSY (Figure S112):

$\mathrm{Ha}(5.48)-\mathrm{Hb}(3.81)(\mathrm{J}=2.1 \mathrm{~Hz})$

$\mathrm{Hc}(4.57)-\mathrm{Hd}(4.75)$

$\mathrm{Hd}(4.75)-\mathrm{He} 1(3.60)$

He1 (3.60) - He2 (3.75)

The low coupling constant between $\mathrm{Ha}$ and $\mathrm{Hb}$ suggests that both hydrogens are equatorial.

HSQC (Figure S113):

$\mathrm{C} 1(103.0)-\mathrm{Ha}(5.48)$

$\mathrm{C} 2(75.5)-\mathrm{Hb}(3.81)$

C4 (76.4) - Hd (4.75)

C5 (73.3) - Hc (4.57)

C6 (64.3) - He1 (3.61) He2 (3.75)

HMBC (Figure S114):

C1 (103.0) - Hd (4.75), He2 (3.75)

C3 (206.1) - Ha (5.48), Hb (3.81), Hc (4.57), Hd (4.75)

C4 (76.4) - Ha (5.48), Hc (4.57)

C5 (73.3) - Hd (4.75), He2 (3.75)

C6 (64.3) - Ha (5.48), Hc (4.57), Hd (4.75) 
Crude reaction mixture: oxidation of 1,6-anhydro- $\beta$-D-mannopyranoside (11) in $\mathrm{CD}_{3} \mathrm{CN}$ KC-XI-72D-1H-2.5hr
STANDARD 1 H OBSERVE

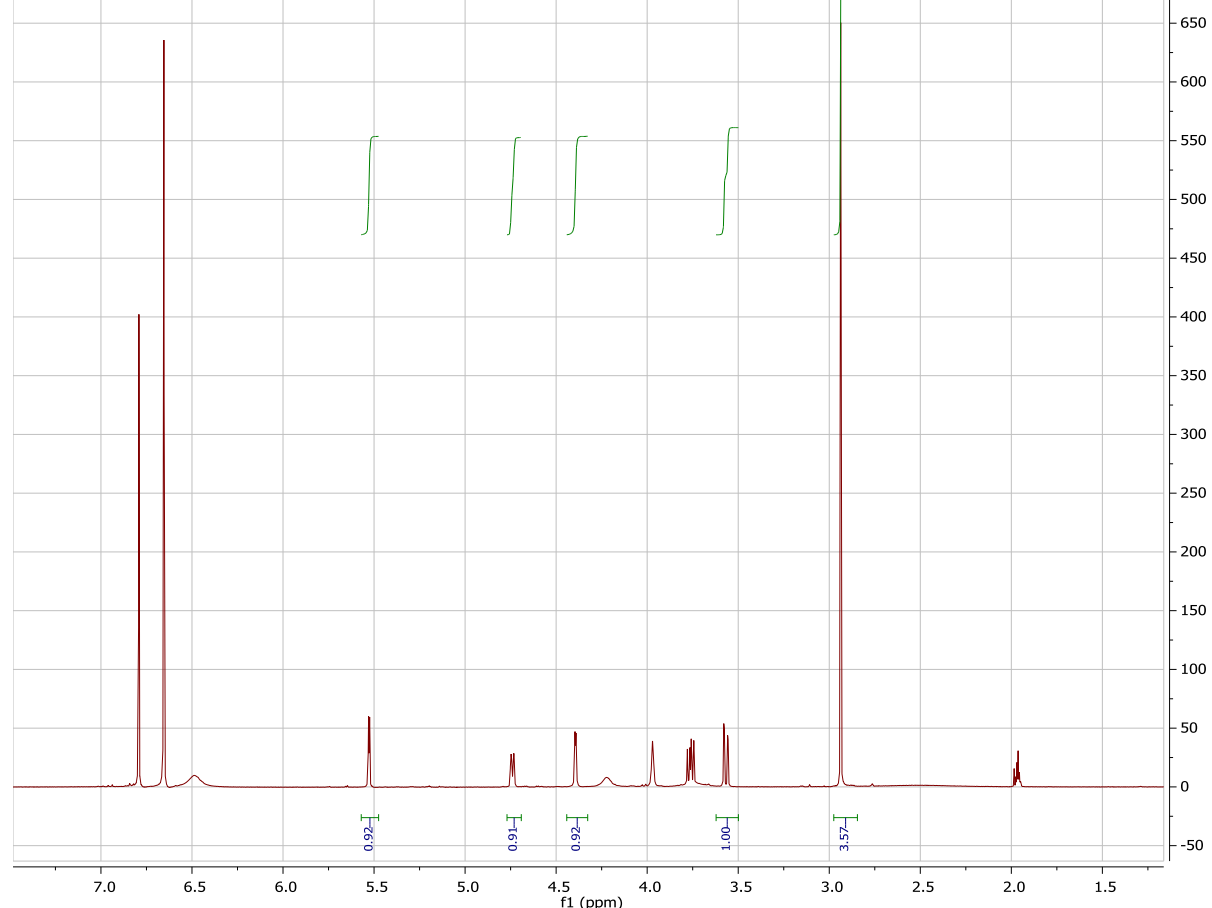

Figure S115. ${ }^{1} \mathrm{H}$ NMR spectrum: oxidation of 1,6 -anhydro- $\beta$-D-mannopyranoside in $\mathrm{CD}_{3} \mathrm{CN}$

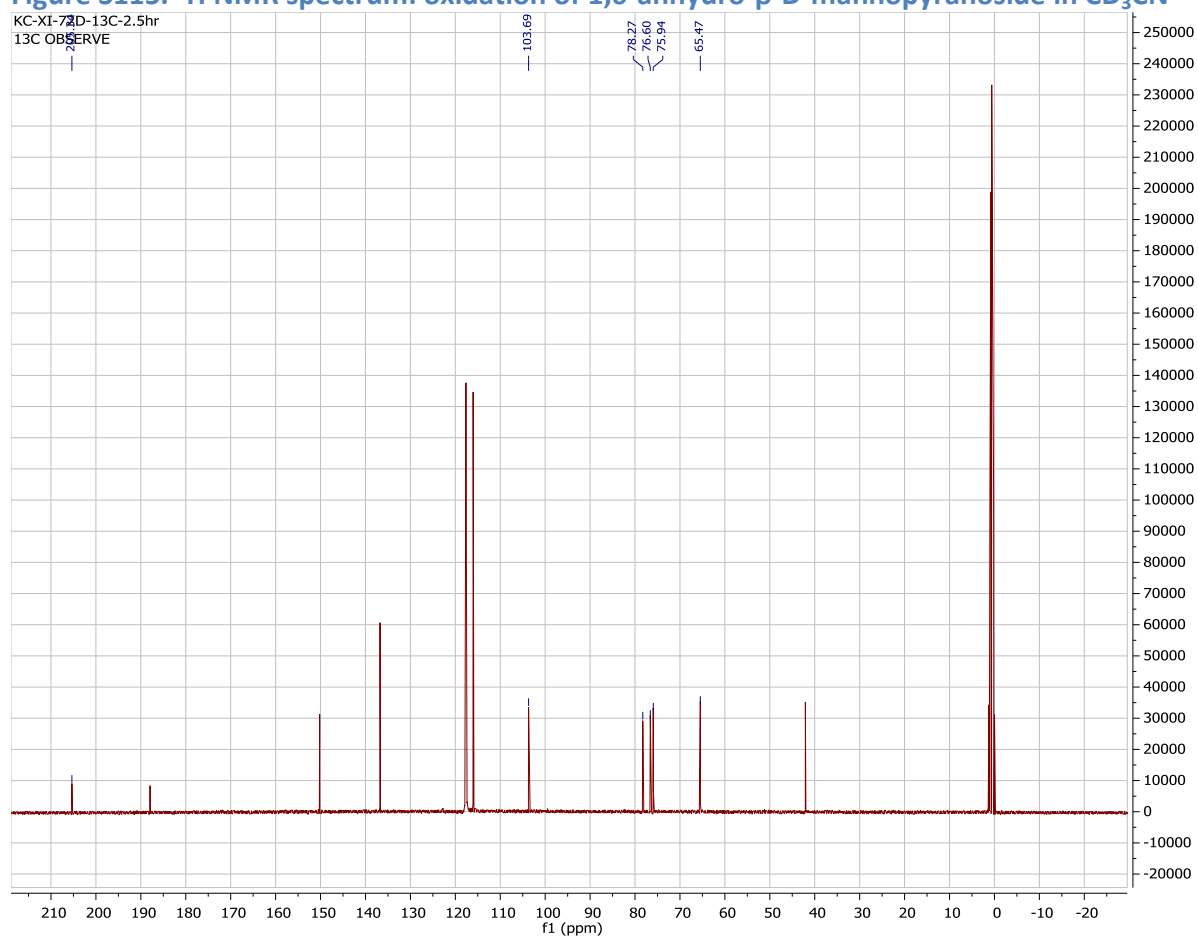

Figure S116. ${ }^{13} \mathrm{C}$ NMR spectrum: oxidation of 1,6 -anhydro- $\beta$-D-mannopyranoside in $\mathrm{CD}_{3} \mathrm{CN}$ 


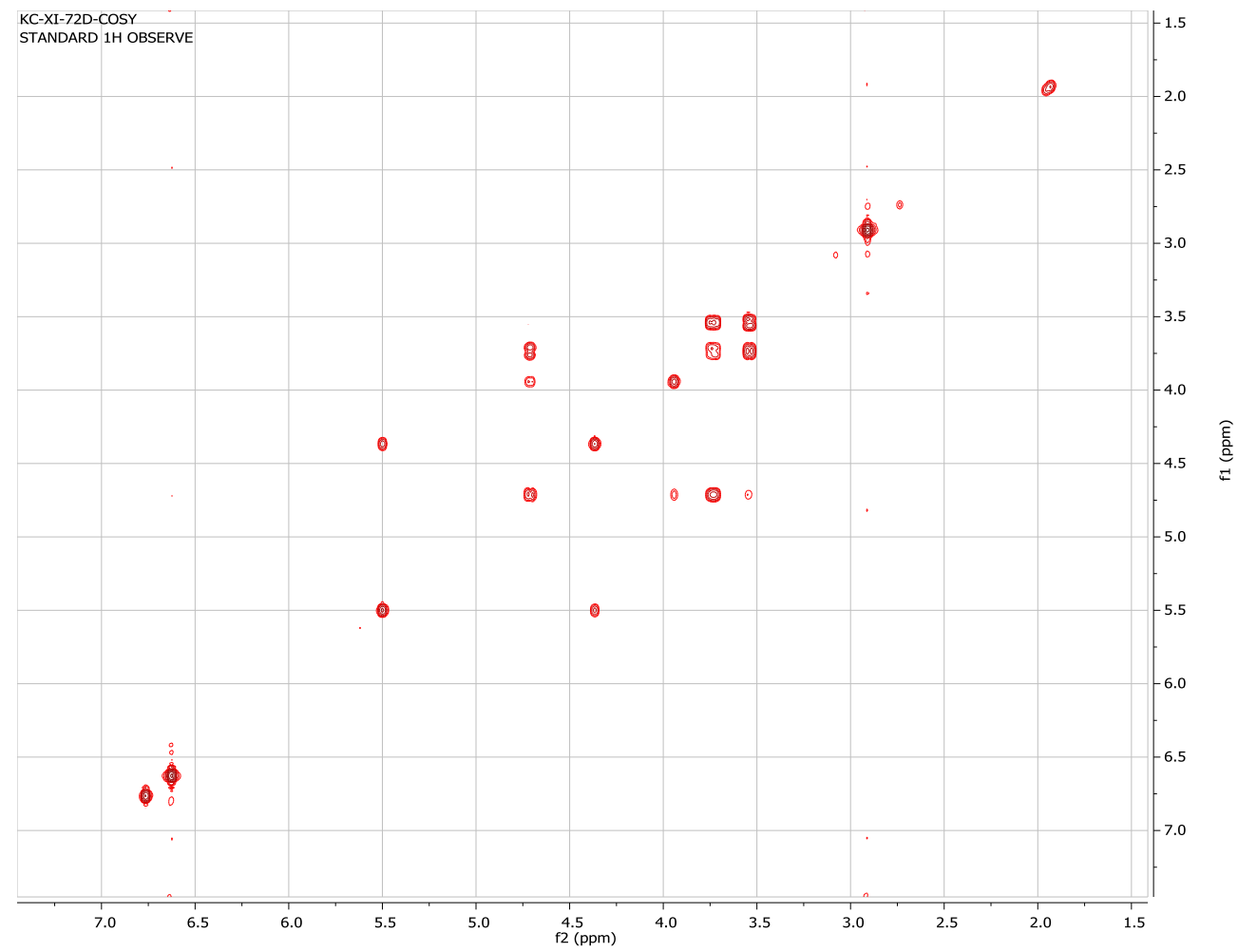

Figure S117. COSY NMR spectrum: oxidation of 1,6-anhydro- $\beta$-D-mannopyranoside in $\mathrm{CD}_{3} \mathrm{CN}$ KC-XI-72D-HSQC
STANDARD 1 H OBSERVE

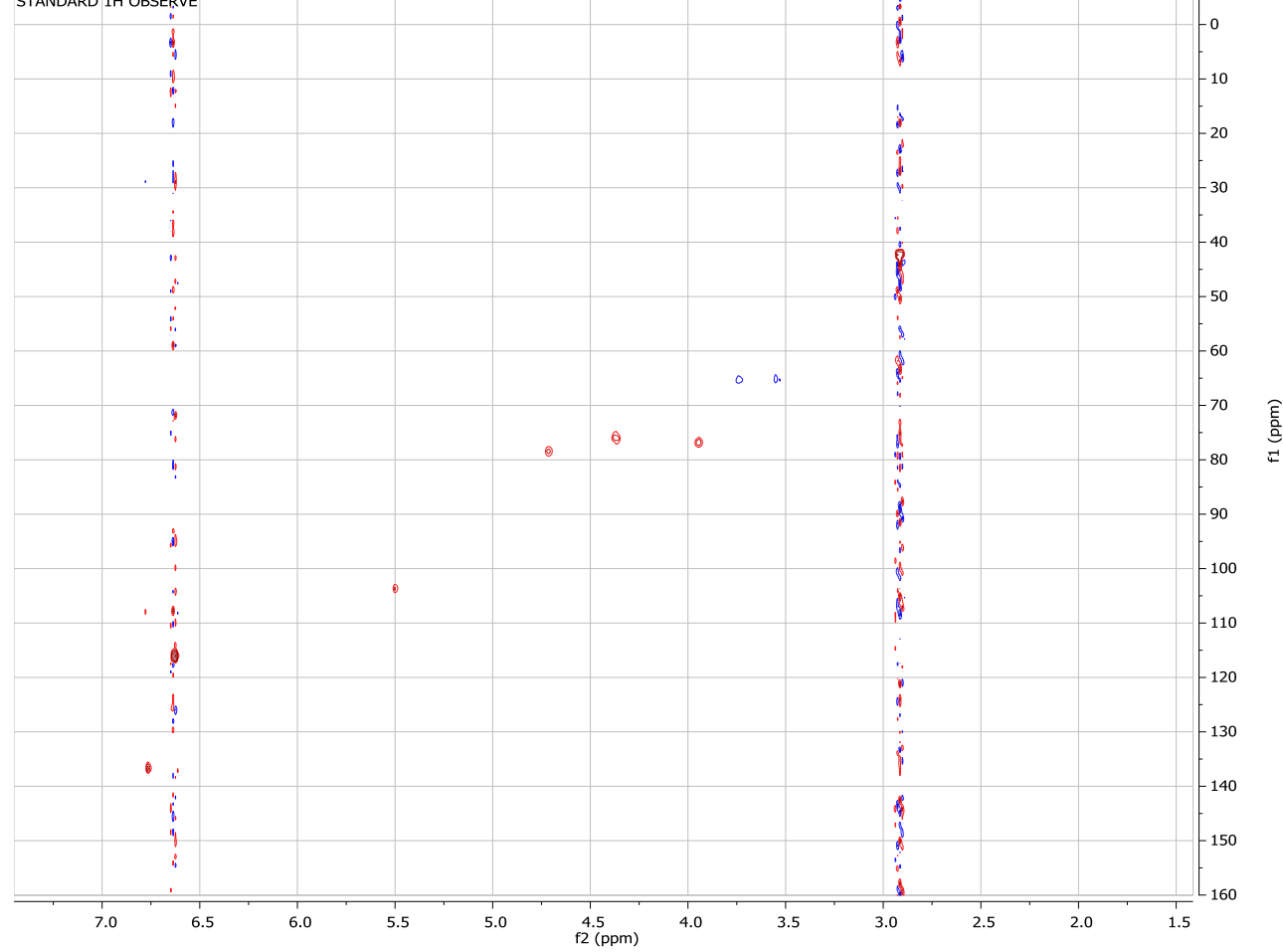

Figure S118. HSQC NMR spectrum: oxidation of 1,6-anhydro- $\beta$-D-mannopyranoside in $\mathrm{CD}_{3} \mathrm{CN}$ 


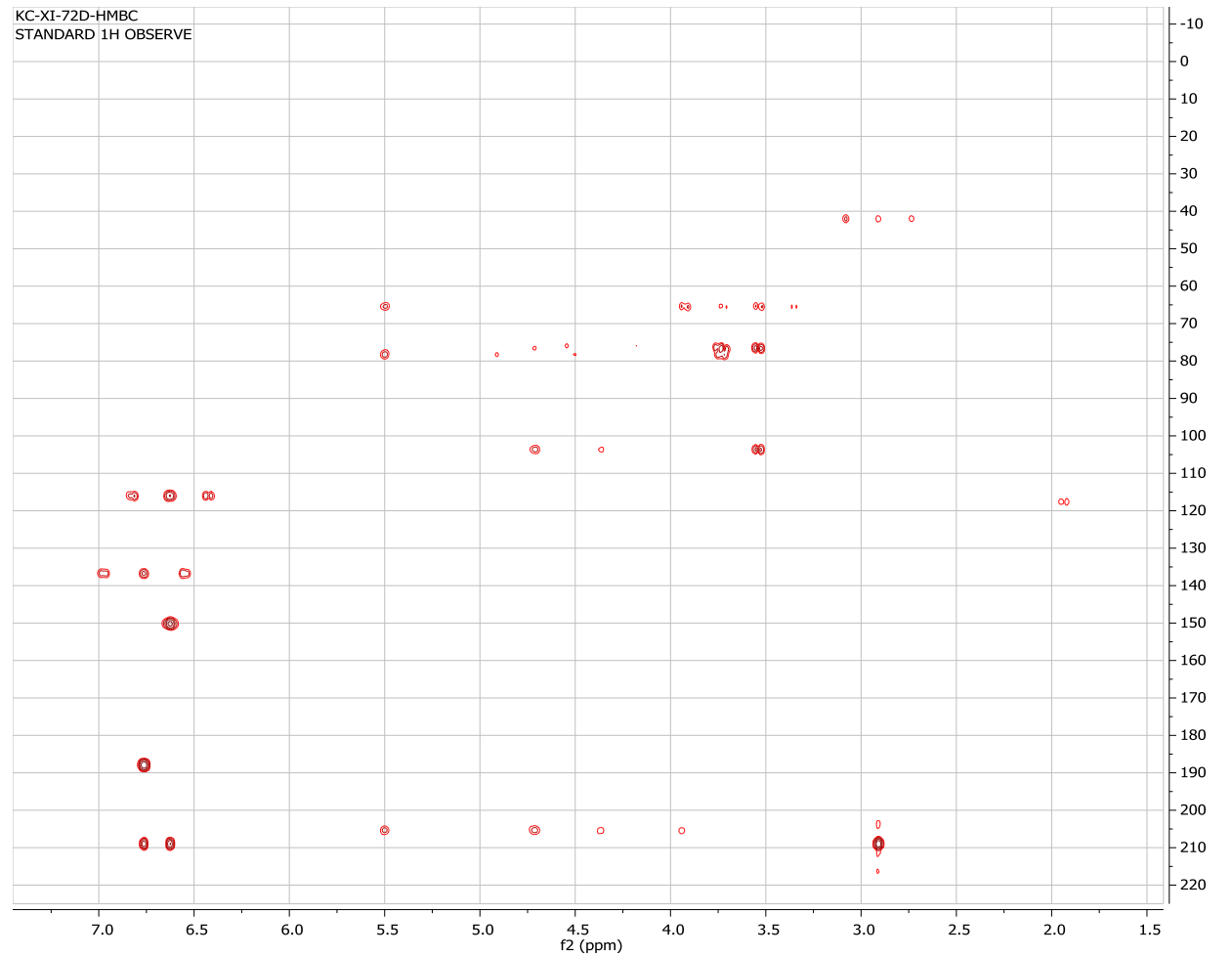

Figure S119. $\mathrm{HMBC}$ NMR spectrum: oxidation of 1,6-anhydro- $\beta-D-$ mannopyranoside in $\mathrm{CD}_{3} \mathrm{CN}$ 


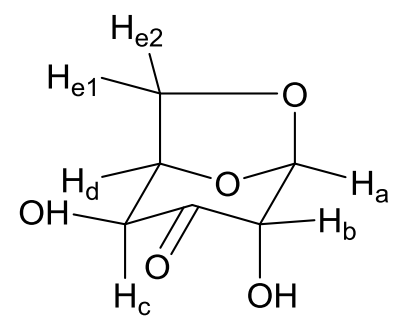

Solvent: $\mathrm{CD}_{3} \mathrm{CN}$

\begin{tabular}{|l|l|l|l|}
\hline C1 & 103.7 & $\mathrm{Ha}$ & 5.50 \\
\hline C2 & 75.9 & $\mathrm{Hb}$ & 4.37 \\
\hline C3 & 205.3 & $\mathrm{Hc}$ & 3.94 \\
\hline C4 & 76.8 & $\mathrm{Hd}$ & 4.72 \\
\hline C5 & 78.3 & $\mathrm{He} 1$ & 3.74 \\
\hline C6 & 65.5 & $\mathrm{He} 2$ & 3.54 \\
\hline
\end{tabular}

1H NMR (400 MHz, CD $\left.{ }_{3} \mathrm{CN}\right) \delta 5.50(\mathrm{~d}, \mathrm{~J}=2.3 \mathrm{~Hz}, 1 \mathrm{H}), 4.72$ (ddd, J = 5.7, 2.1, 1.3 Hz, 1H), 4.37 (d, J = 2.3 $\mathrm{Hz}, 1 \mathrm{H}), 4.20(\mathrm{~s}, 1 \mathrm{H}), 3.97-3.87(\mathrm{~m}, 1 \mathrm{H}), 3.74(\mathrm{dd}, \mathrm{J}=8.5,5.7 \mathrm{~Hz}, 2 \mathrm{H}), 3.54(\mathrm{dd}, \mathrm{J}=8.5,1.3 \mathrm{~Hz}, 1 \mathrm{H})$.

13C NMR (101 MHz, cd3cn) $\delta 205.34,103.69,78.27,76.60,75.94,65.47$.

COSY (Figure S117):

$\mathrm{Ha}(5.50)-\mathrm{Hb}(4.37)(\mathrm{J}=2.3 \mathrm{~Hz})$

$\mathrm{Hc}(3.94)-\mathrm{Hd}(4.72)$

Hd (4.72) - He1 (3.74), He2 (3.54)

He1 (3.74) - He2 (3.54)

The low coupling constant between $\mathrm{Ha}$ and $\mathrm{Hb}$ suggests that both hydrogens are equatorial.

HSQC (Figure S118):

C1 (103.7) - Ha (5.50)

$\mathrm{C} 2(75.9)-\mathrm{Hb}(4.37)$

$\mathrm{C} 4(76.8)-\mathrm{Hc}(3.94)$

C5 (78.3) - Hd (4.72)

C6 (65.5) - He1 (3.74), He2 (3.54)

HMBC (Figure S119):

$\mathrm{C} 1$ (103.7) - Hb (4.37), Hd (4.72), He2 (3.54)

C3 (205.3) - Ha (5.50), Hb (4.37), Hc (3.94), Hd (4.72)

C5 (78.3) - Ha (5.50), He1 (3.74)

C6 (65.5) - Ha (5.50), Hc (3.94) 
Crude reaction mixture: oxidation of 1,6-anhydro- $\beta$-D-glucopyranoside (14) in $C_{3} C N$

KC-XI-67C-1H-2.5hr2
STANDARD 1H OBSERVE

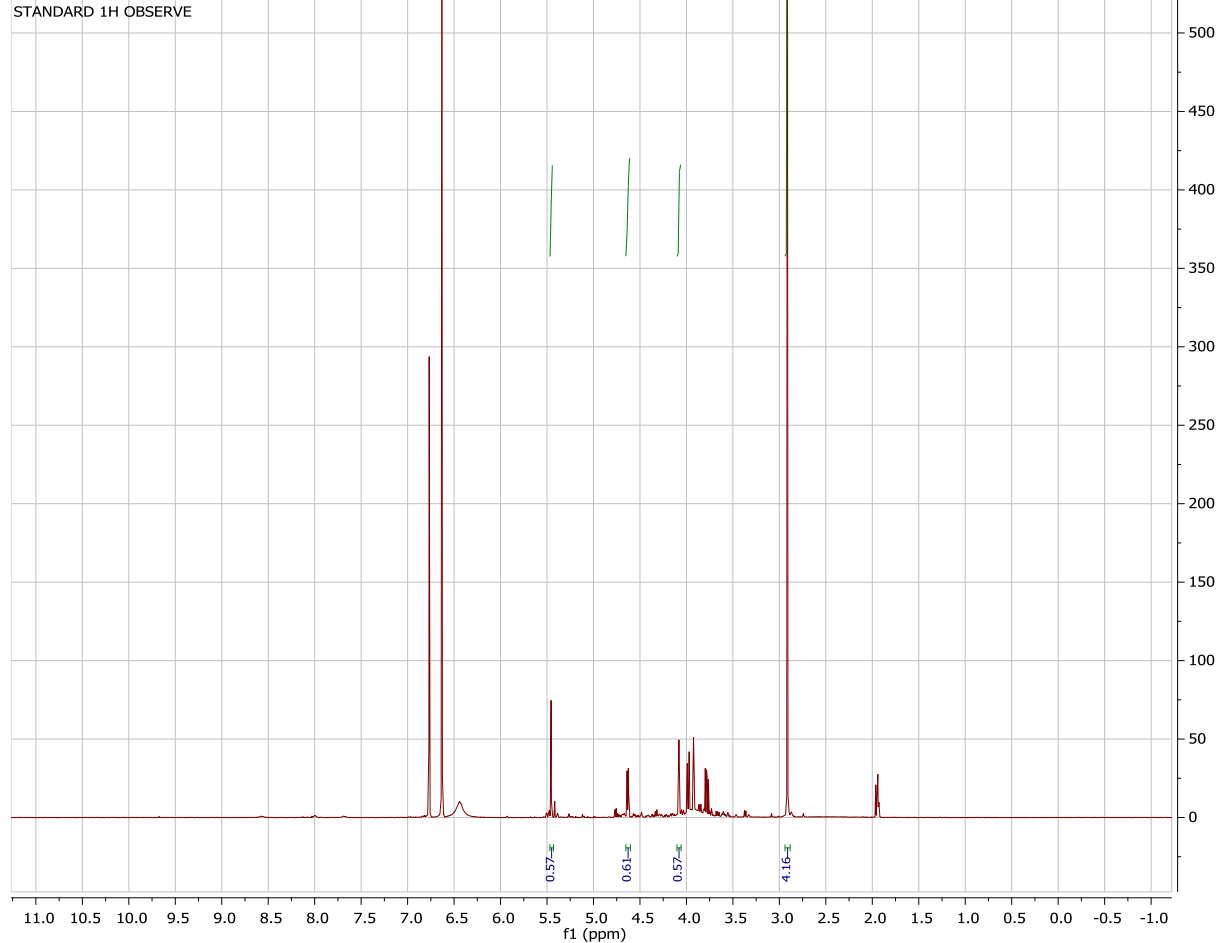

Figure S120. ${ }^{1} \mathrm{H}$ spectrum: oxidation of 1,6-anhydro- $\beta$-D-glucopyranoside in $\mathrm{CD}_{3} \mathrm{CN}$

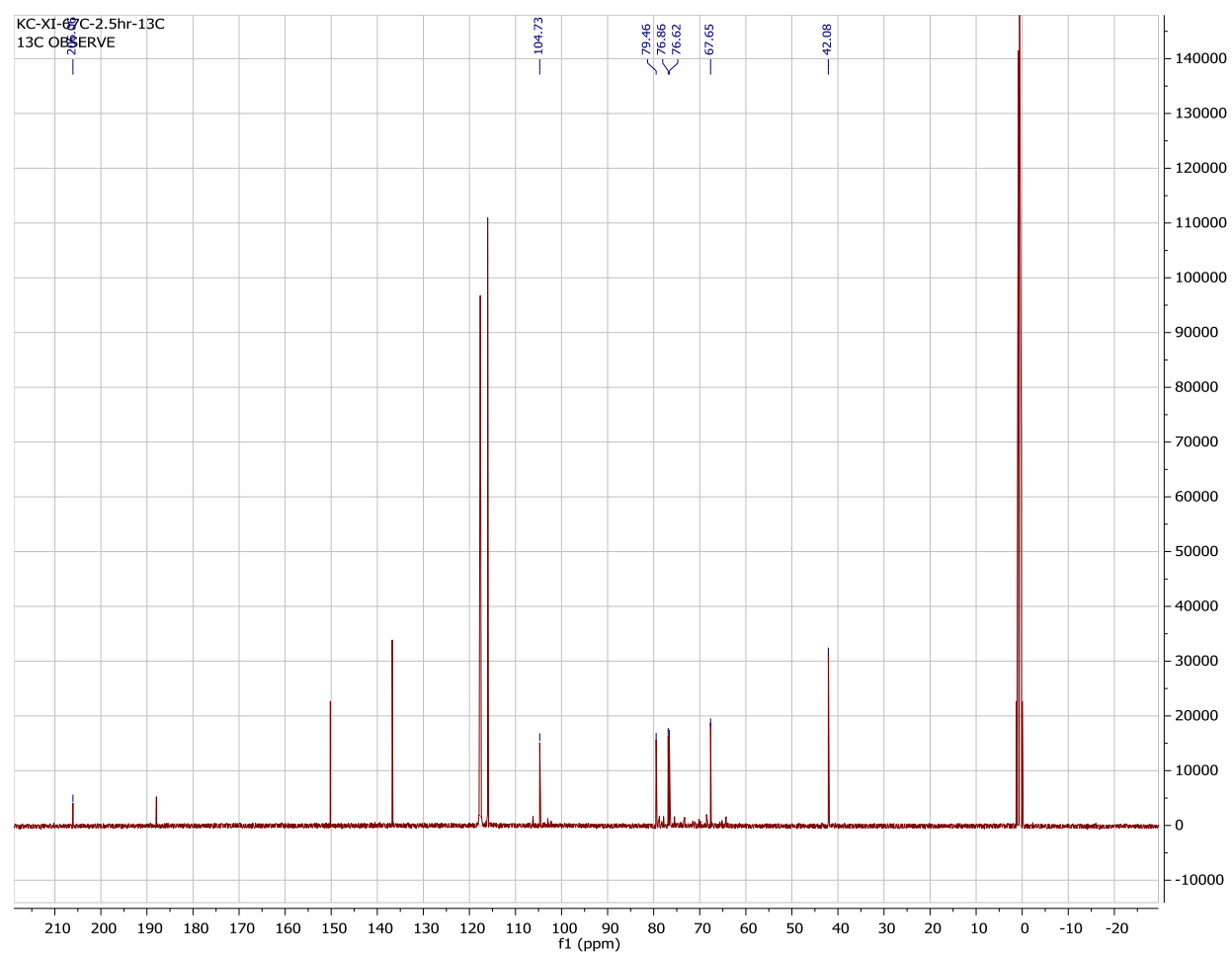

Figure $\$ 121 .{ }^{13} \mathrm{C}$ spectrum: oxidation of 1,6 -anhydro- $\beta$-D-glucopyranoside in $\mathrm{CD}_{3} \mathrm{CN}$ 


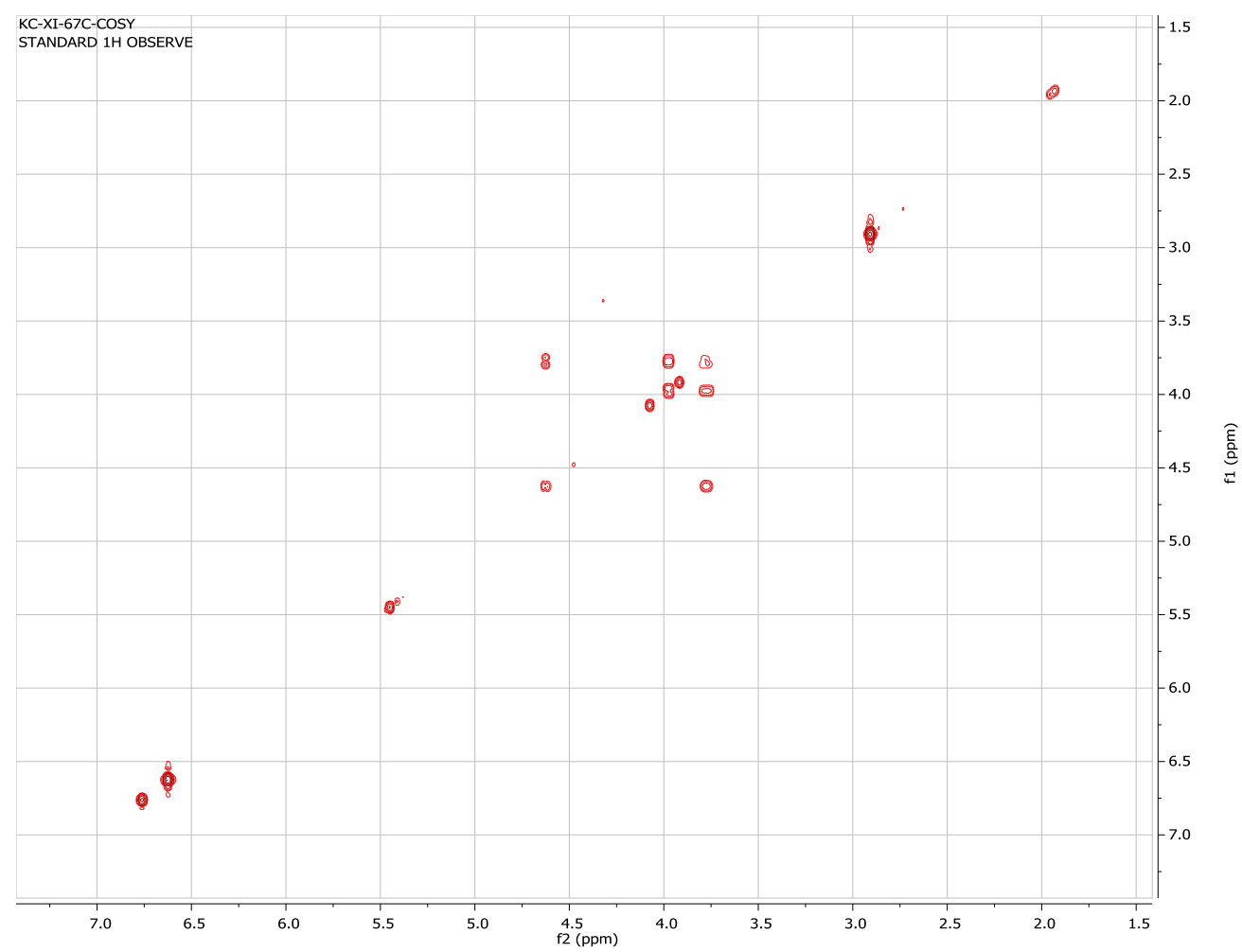

Figure S122. COSY spectrum: oxidation of 1,6-anhydro- $\beta$-D-glucopyranoside in $\mathrm{CD}_{3} \mathrm{CN}$ KC-XI-67C-HSQC

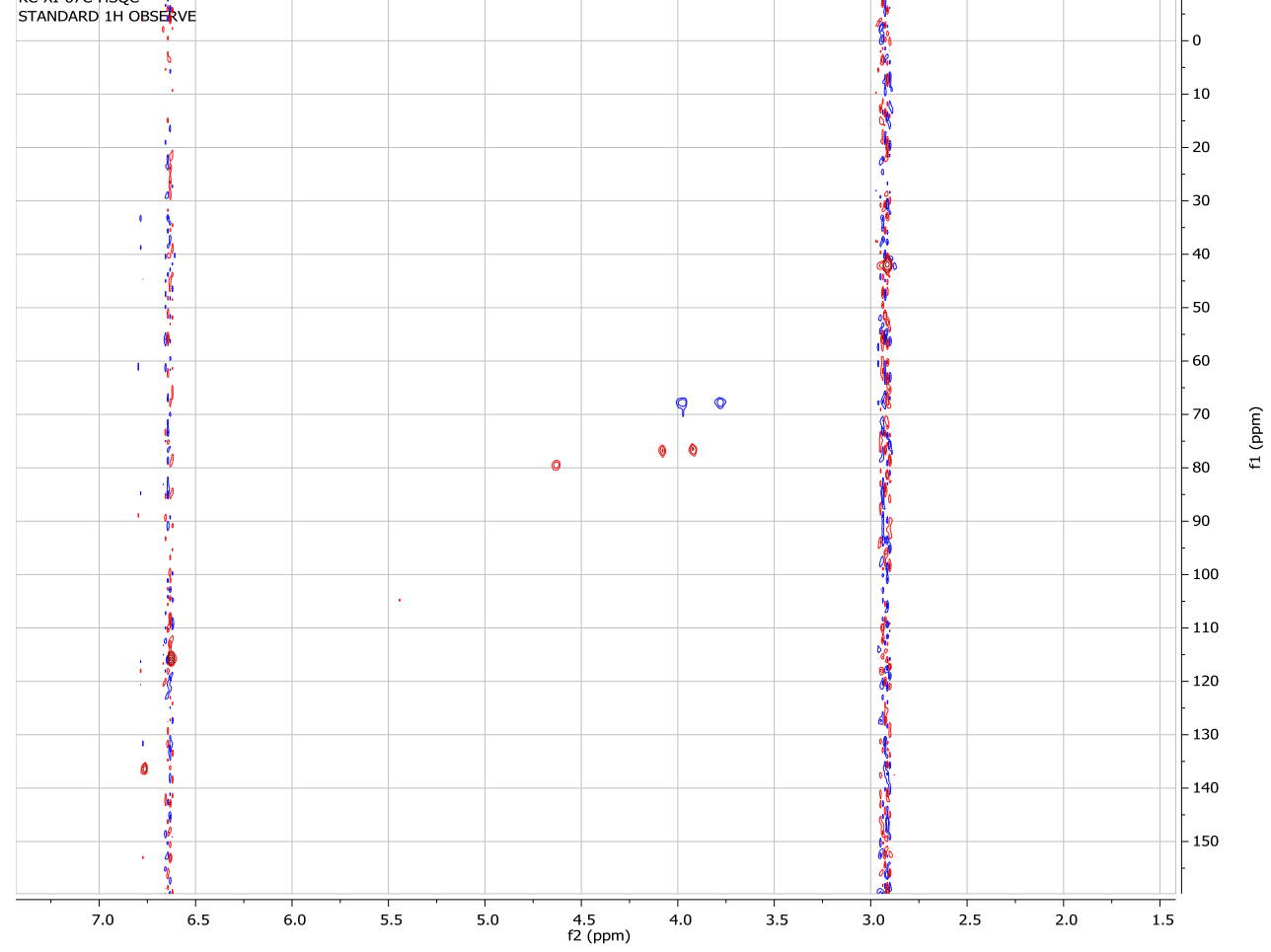

Figure S123. HSQC NMR spectrum: oxidation of 1,6-anhydro- $\beta$-D-glucopyranoside in $C_{3} C N$ 


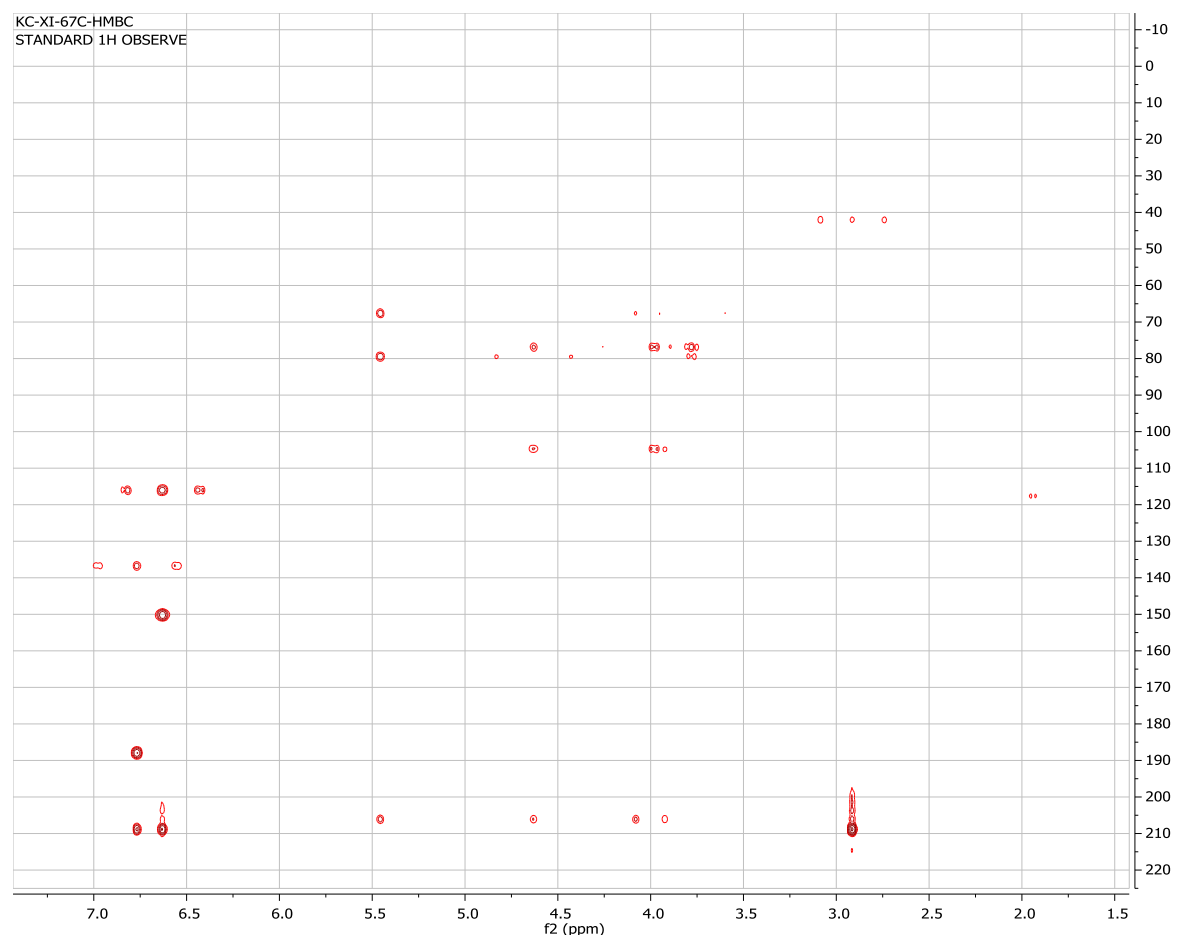

Figure S124. HMBC NMR spectrum: oxidation of 1,6-anhydro- $\beta$-D-glucopyranoside in $\mathrm{CD}_{3} C \mathrm{~N}$ 


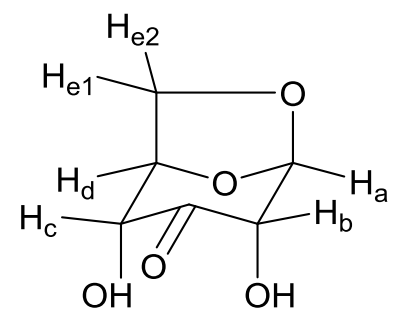

Solvent: $\mathrm{CD}_{3} \mathrm{CN}$

\begin{tabular}{|l|l|l|l|}
\hline C1 & 104.8 & $\mathrm{Ha}$ & 5.45 \\
\hline C2 & 76.5 & $\mathrm{Hb}$ & 3.92 \\
\hline C3 & 206.1 & $\mathrm{Hc}$ & 4.08 \\
\hline C4 & 76.8 & $\mathrm{Hd}$ & 4.63 \\
\hline C5 & 79.5 & $\mathrm{He} 1$ & 3.78 \\
\hline C6 & 67.8 & $\mathrm{He} 2$ & 3.98 \\
\hline
\end{tabular}

COSY (Figure S122):

$\mathrm{Ha} \mathrm{(5.45)-} \mathrm{Hb} \mathrm{(3.92)} \mathrm{(weak)}$

$\mathrm{Hc}$ (4.08) - Hd (4.63) (weak)

Hd (4.63) - He1 (3.78), He2 (3.98)

HSQC (Figure S123):

C1 (104.8) - Ha (5.45)

$\mathrm{C} 2(76.5)-\mathrm{Hb}(3.92)$

$\mathrm{C} 4(76.8)-\mathrm{Hc}(4.08)$

C5 (79.5) - Hd (4.63)

C6 (67.8) - He1 (3.78), He2 (3.98)

HMBC (Figure S124):

C1 (104.8) - Ha (5.45), Hb (3.92), He1 (3.78), He2 (3.98)

C4 (205.6) - Ha (5.45), Hb (3.92), Hc (4.08), Hd (4.63)

C5 (79.5) - Ha (5.45), He1 (3.78)

C6 (67.8) - Ha (5.45), Hc (4.08) 
Crude reaction mixture: oxidation of methyl- $\alpha$-D-glucopyranoside (12) in 2,2,2-trifluoroethanol

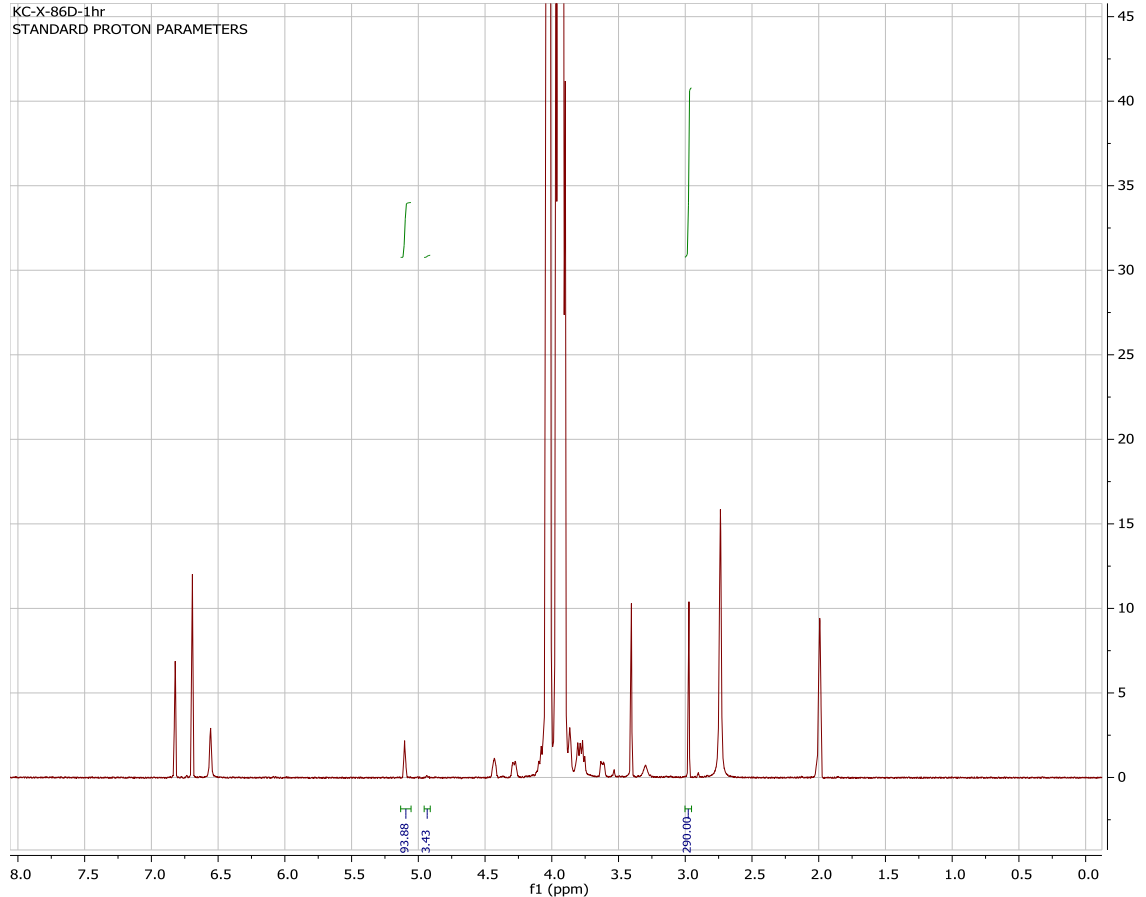

Figure S125. ${ }^{1} \mathrm{H}$ spectrum: oxidation of methyl- $\alpha$-D-glucopyranoside in 2,2,2-trifluoroethanol

Crude reaction mixture: oxidation of methyl-6-deoxy- $\alpha$-D-glucopyranoside (6) in 2,2,2-trifluoroethanol KC-X-78B-1H-1.5hr STANDARD $1 \mathrm{H}$ OBSERVE

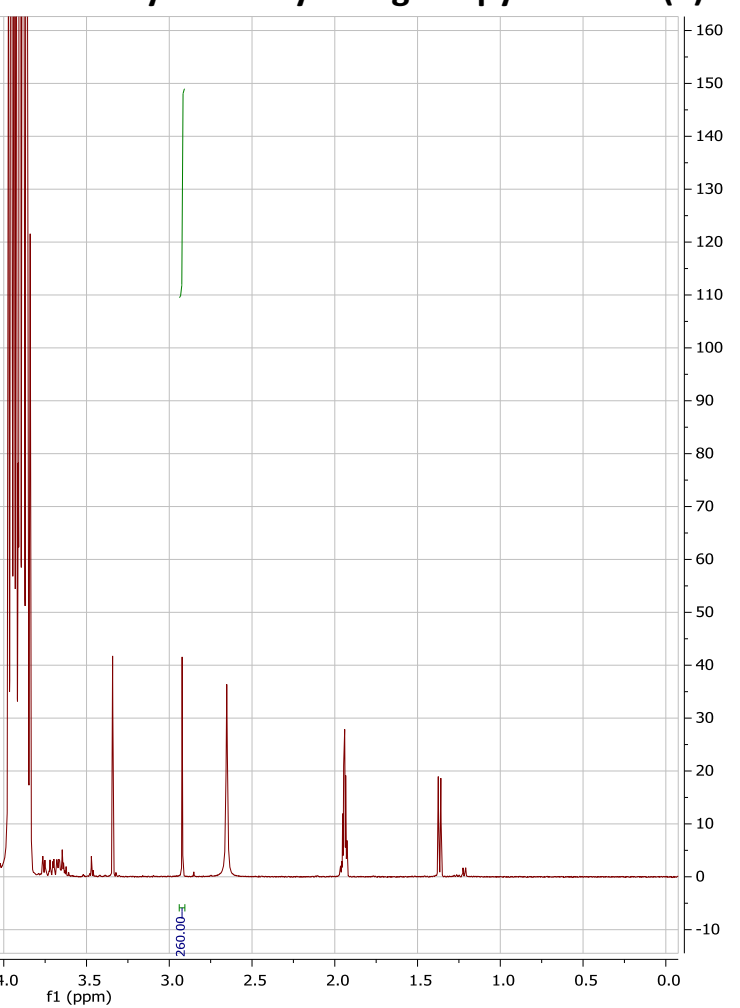

Figure S126. ${ }^{1} \mathrm{H}$ spectrum: oxidation of methyl-6-deoxy- $\alpha$-D-glucopyranoside in 2,2,2-trifluoroethanol 
Crude reaction mixture: oxidation of methyl- $\alpha$-D-xylopyranoside (7) in 2,2,2-trifluoroethanol KC-X-86B-1hr
STANDARD PROTON PARAMETERS

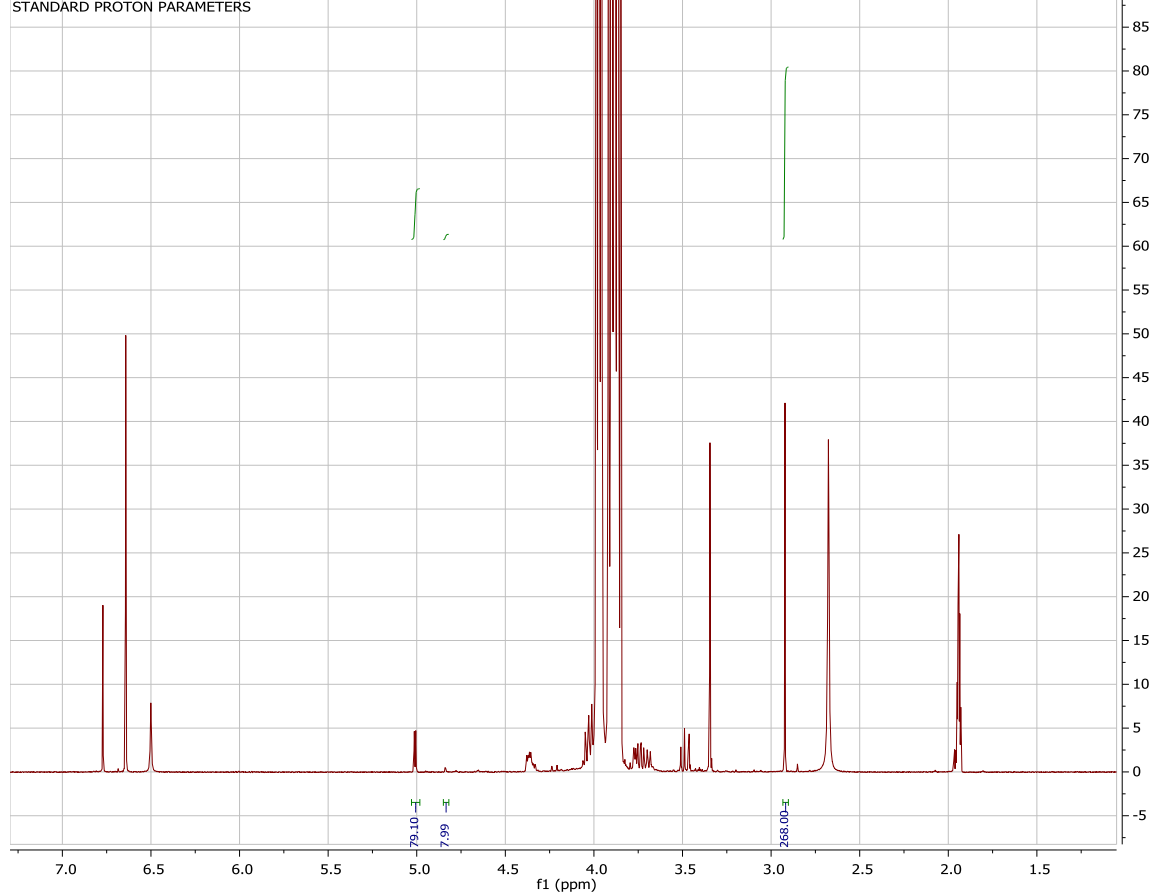

Figure S127. ${ }^{1} \mathrm{H}$ spectrum: oxidation of methyl- $\alpha$-D-xylopyranoside in 2,2,2-trifluoroethanol

Crude reaction mixture: oxidation of methyl- $\alpha$-L-fucopyranoside (8) in 2,2,2-trifluoroethanol $\mathrm{KC}-\mathrm{X}-86 \mathrm{G}-2 \mathrm{r}$

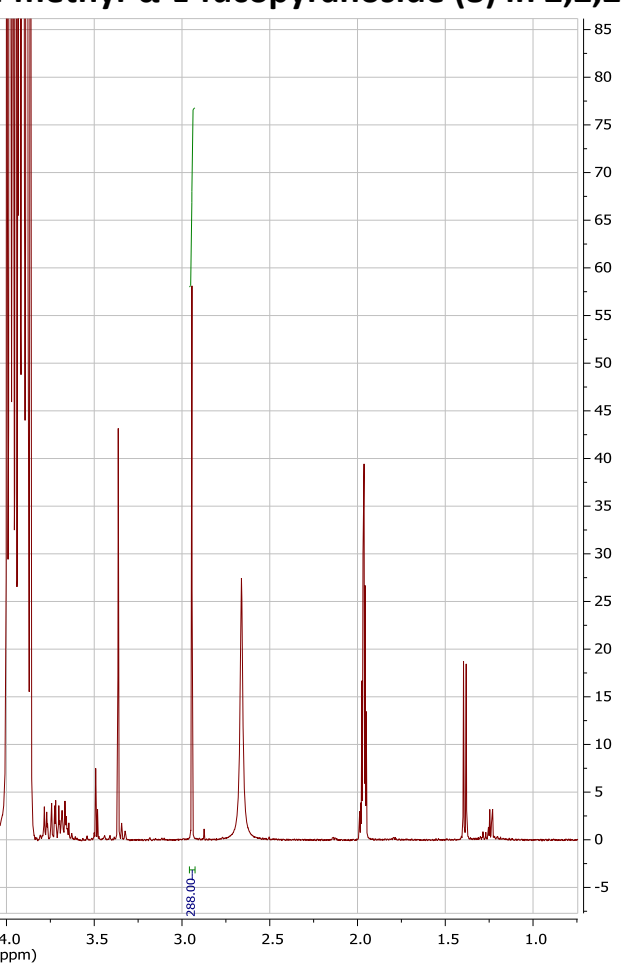

Figure S128. ${ }^{1} \mathrm{H}$ spectrum: oxidation of methyl- $\alpha$-L-fucopyranoside in 2,2,2-trifluoroethanol 
Optimization attempts for the oxidation of methyl 2-acetamido-2-deoxy-a-D-glucopyranoside (16)

Conditions A: The procedure prescribed by literature was closely followed. ${ }^{4} 7.05 \mathrm{mg}(0.03 \mathrm{mmol})$ of methyl 2-acetamido-2-deoxy- $\alpha$-D-glucopyranoside and $15.93 \mathrm{mg}(0.09 \mathrm{mmol}, 3 \mathrm{eq}) 2,6$ dichlorobenzoquinone was added to $100 \mu \mathrm{L}$ 10:1 acetonitrile:water (0.3 M substrate). The mixture was vigorously shaken in order to facilitate dissolving, but much of the starting material remained undissolved. $0.783 \mathrm{mg}$ of [(neocuproine) $\mathrm{Pd}(\mathrm{OAc})]_{2}(\mathrm{OTf})_{2}(0.0015 \mathrm{mmol} \mathrm{Pd}, 5 \% \mathrm{Pd})$ was added to the slurry, and the mixture was stirred at room temperature. After four hours, yield of the 3-ketose was at most 4\% (as [product]/[product + starting material] is the ceiling for NMR yield).

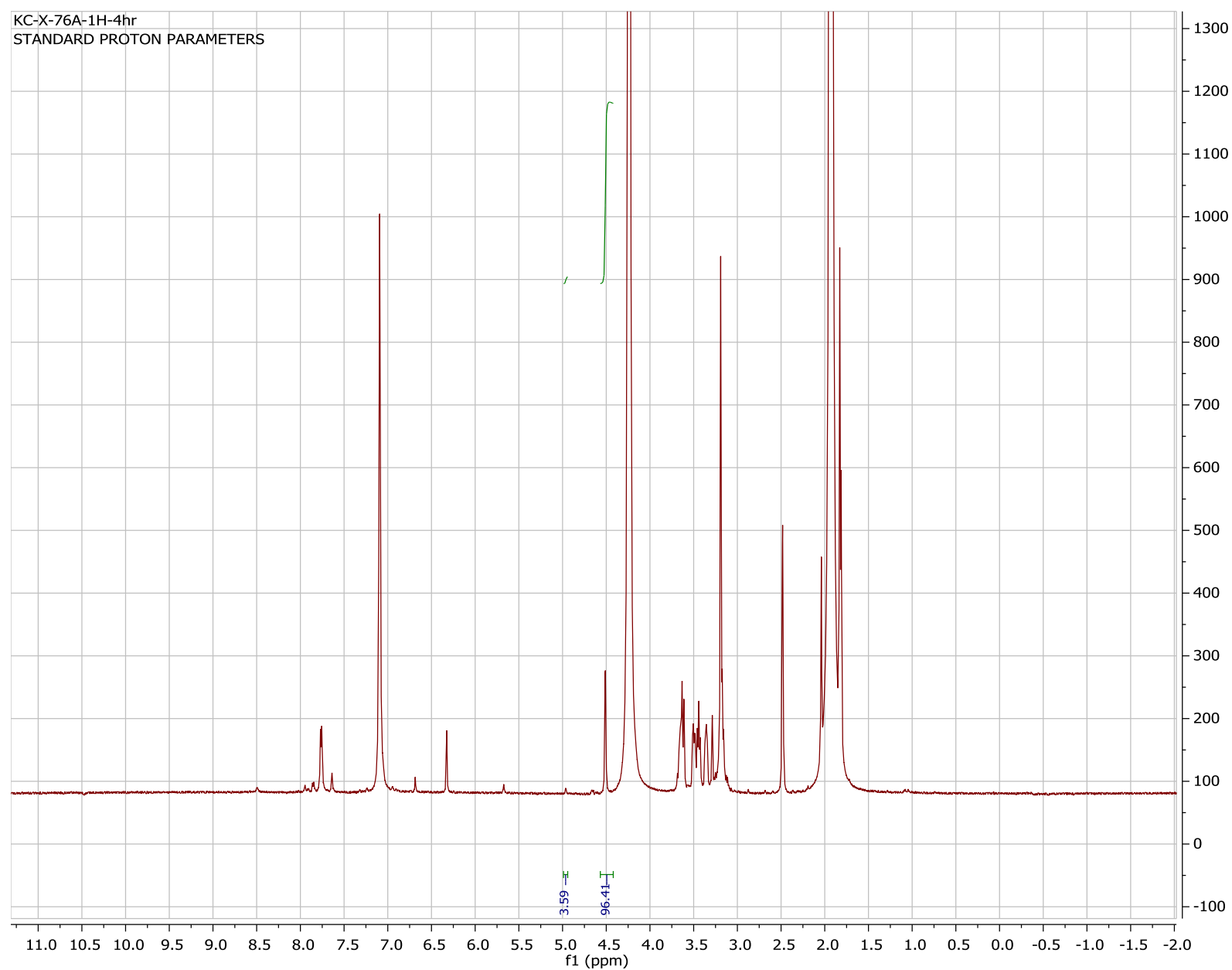

Figure S129. ${ }^{1} \mathrm{H}$ spectrum: oxidation of 0.3 M 2-deoxy-2-acetamido- $\beta$-d-glucopyranosyl azide in 10:1 acetonitrile:water using 2,6-dichlorobenzoquinone as terminal oxidant 
Conditions B: $7.05 \mathrm{mg}$ ( $0.03 \mathrm{mmol}$ ) of methyl 2-acetamido-2-deoxy- $\alpha$-D-glucopyranoside and $15.93 \mathrm{mg}$ (0.09 mmol, 3 eq) 2,6-dichlorobenzoquinone was added to $300 \mu \mathrm{L} 10: 1$ acetonitrile:water (0.1 M substrate $0.783 \mathrm{mg}$ of [(neocuproine) $\mathrm{Pd}(\mathrm{OAc})]_{2}(\mathrm{OTf})_{2}(0.0015 \mathrm{mmol} \mathrm{Pd}, 5 \% \mathrm{Pd})$ was added to the slurry, and the mixture was stirred at room temperature. After four hours, yield of the 3-ketose was at most $5 \%$ (as [product]/[product + starting material] is the ceiling for NMR yield).

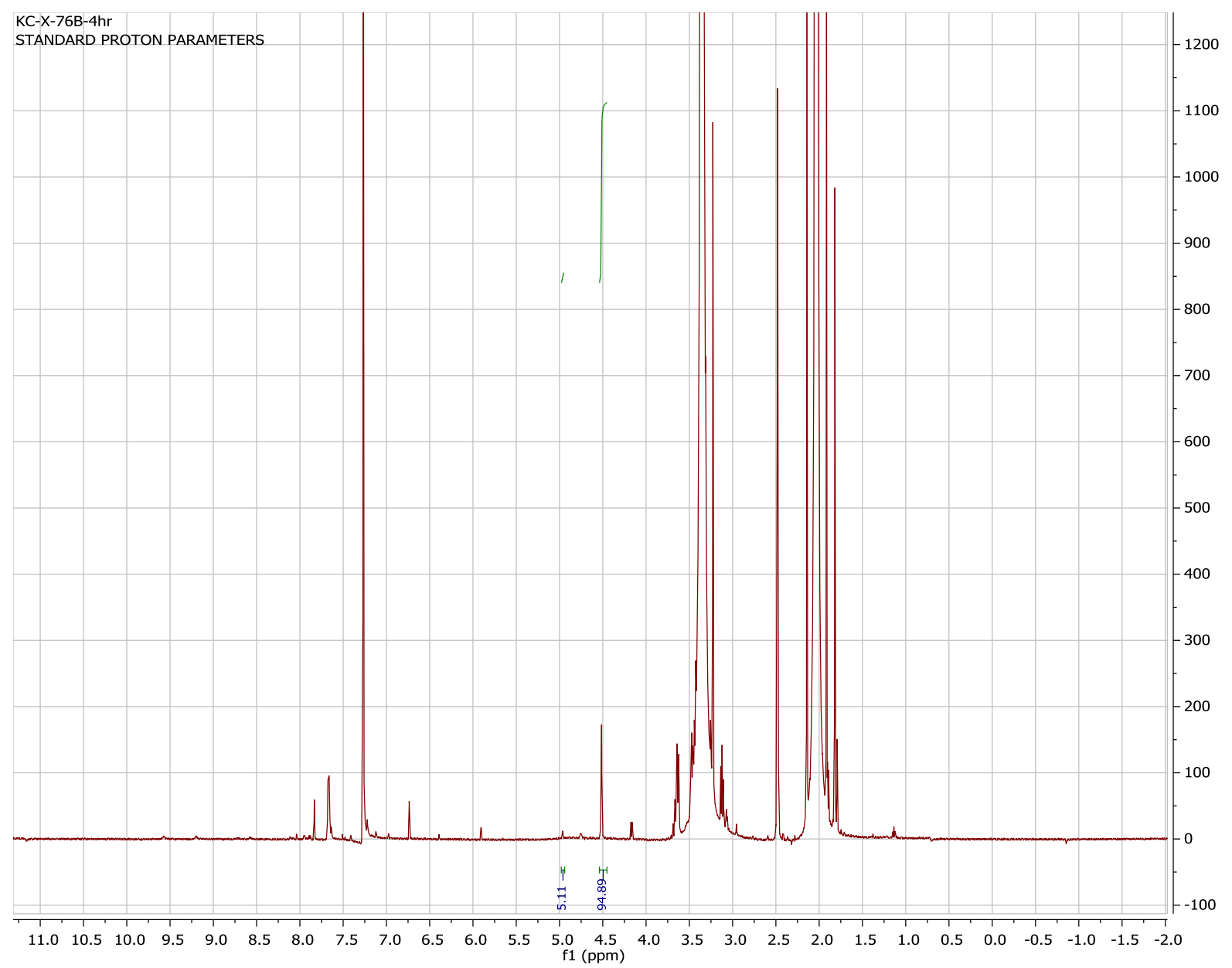

Figure S130. ${ }^{1} \mathrm{H}$ spectrum: oxidation of $0.1 \mathrm{M}$ 2-deoxy-2-acetamido- $\beta$-d-glucopyranosyl azide in 10:1 acetonitrile:water using 2,6-dichlorobenzoquinone as terminal oxidant 
Conditions C: $7.05 \mathrm{mg}(0.03 \mathrm{mmol})$ of methyl 2-acetamido-2-deoxy- $\alpha$-D-glucopyranoside and $17.2 \mathrm{mg}$ ( $0.09 \mathrm{mmol}, 3 \mathrm{eq}$ ) benzoquinone added to $300 \mu \mathrm{L}$ 10:1 acetonitrile:water (0.1 M substrate $0.783 \mathrm{mg}$ of [(neocuproine $) \mathrm{Pd}(\mathrm{OAc})]_{2}(\mathrm{OTf})_{2}(0.0015 \mathrm{mmol} \mathrm{Pd}, 5 \% \mathrm{Pd})$ was added to the slurry, and the mixture was stirred at room temperature. After four hours, yield of the 3-ketose was at most $33 \%$ (as [product]/[product + starting material] is the ceiling for NMR yield).

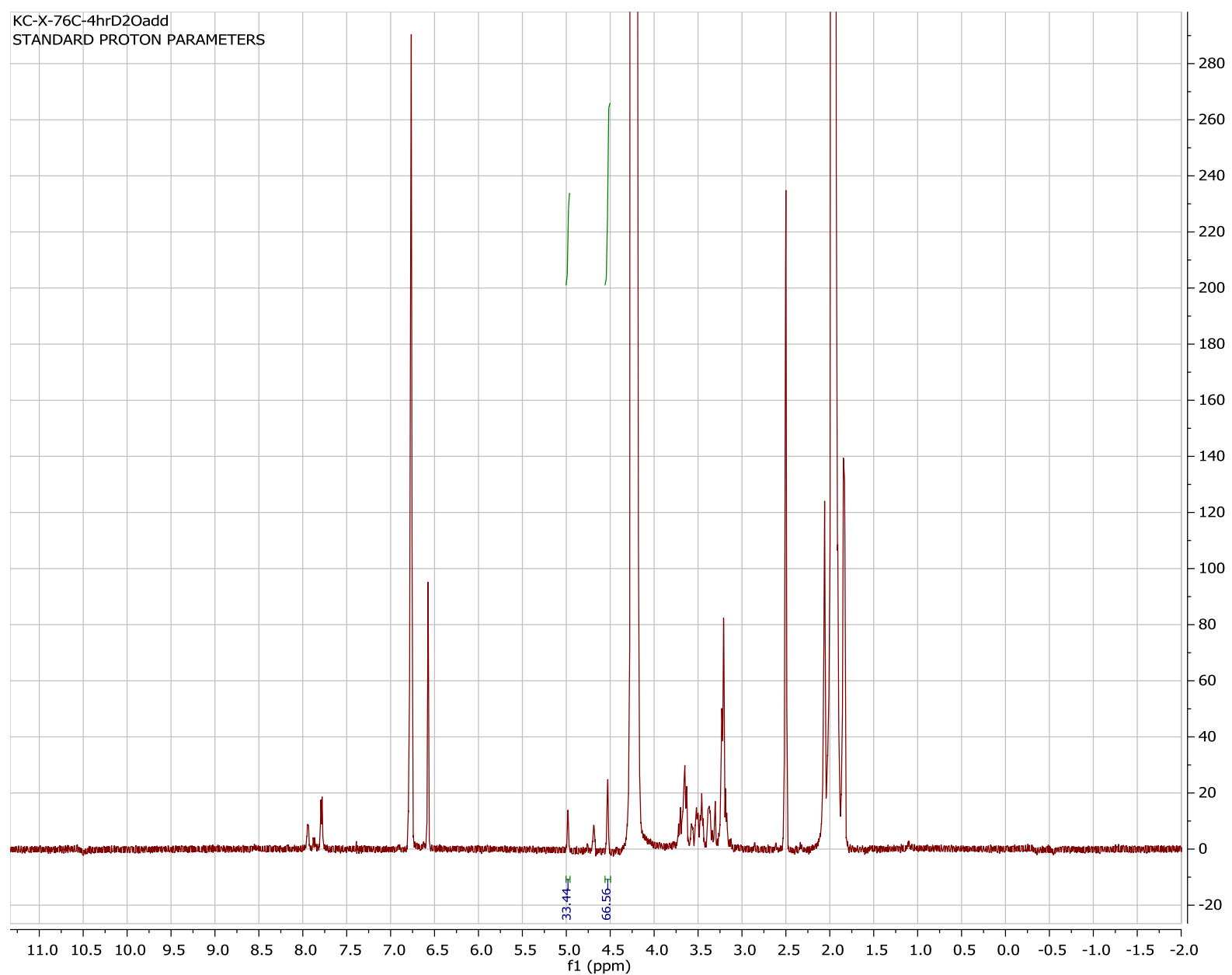

Figure S131. ${ }^{1} \mathrm{H}$ spectrum: oxidation of $0.1 \mathrm{M}$ 2-deoxy-2-acetamido- $\beta$-d-glucopyranosyl azide in 10:1 acetonitrile:water using benzoquinone as terminal oxidant 
Conditions D: $12.52 \mathrm{mg}$ (0.0532 mmol) of methyl 2-acetamido-2-deoxy- $\alpha$-D-glucopyranoside, $8.6 \mathrm{mg}$ ( $0.079 \mathrm{mmol}, 1.5 \mathrm{eq})$ benzoquinone, and $4.7 \mathrm{mg}$ dimethylsulfone $(0.05 \mathrm{mmol}$, internal standard) added to $535 \mu \mathrm{L}$ 2,2,2-trifluoroethanol (0.1 M substrate). $0.783 \mathrm{mg}$ of [(neocuproine) $\mathrm{Pd}(\mathrm{OAc})]_{2}(\mathrm{OTf})_{2}(0.00256$, $5 \% \mathrm{Pd}$ ) was added to the slurry, and the mixture was stirred at room temperature. After $1 \mathrm{hr}$, yield of the 3-ketoglycoside was $77 \%$ (integrated against internal standard).

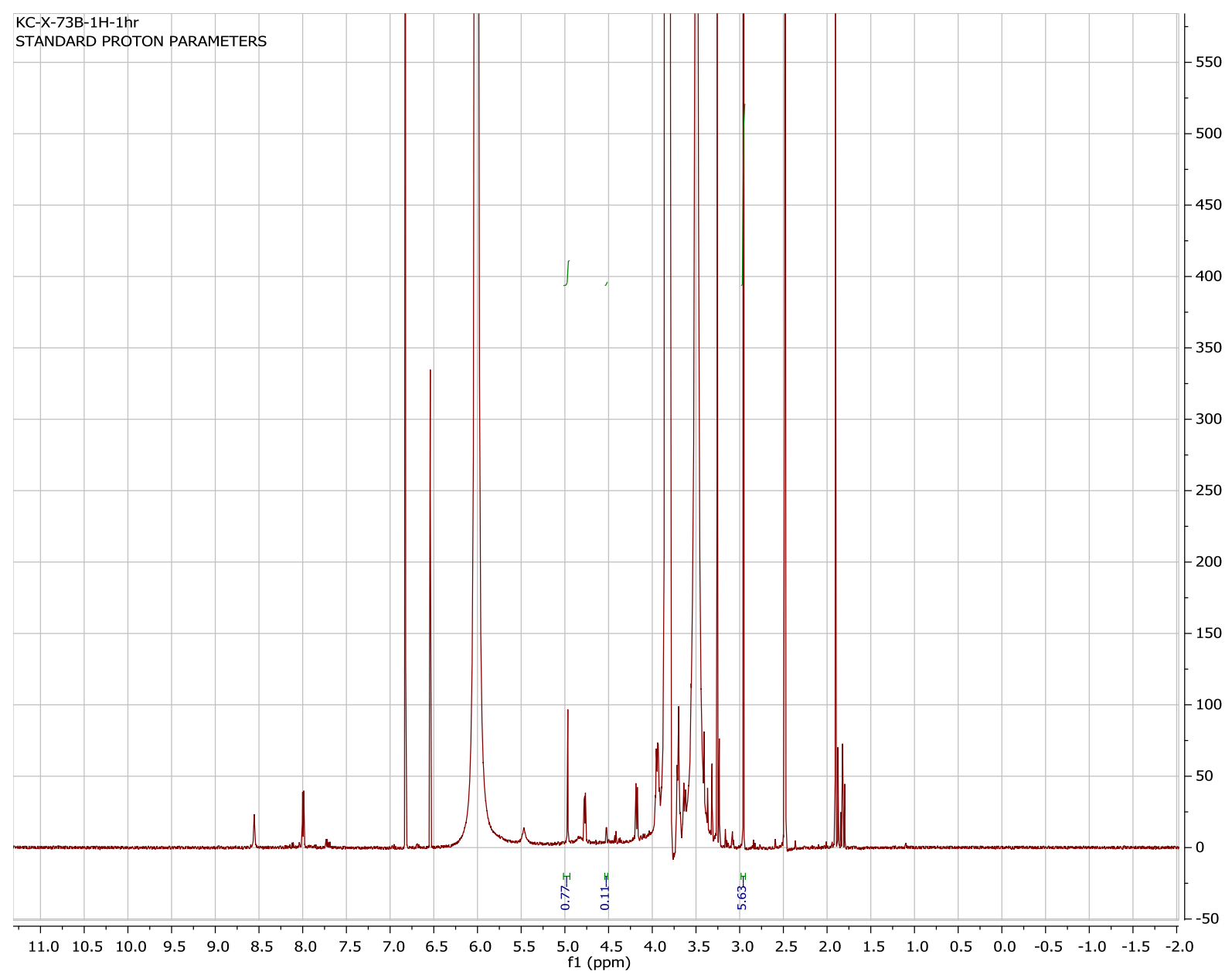

Figure S132. ${ }^{1} \mathrm{H}$ spectrum: oxidation of $0.1 \mathrm{M}$ 2-deoxy-2-acetamido- $\beta$-D-glucopyranosyl azide in 2,2,2-trifluoroethanol using benzoquinone as terminal oxidant 
Crude reaction mixture: oxidation of 2-deoxy-2-acetamido- $\beta$-D-glucopyranosyl azide (17) in 2,2,2trifluoroethanol

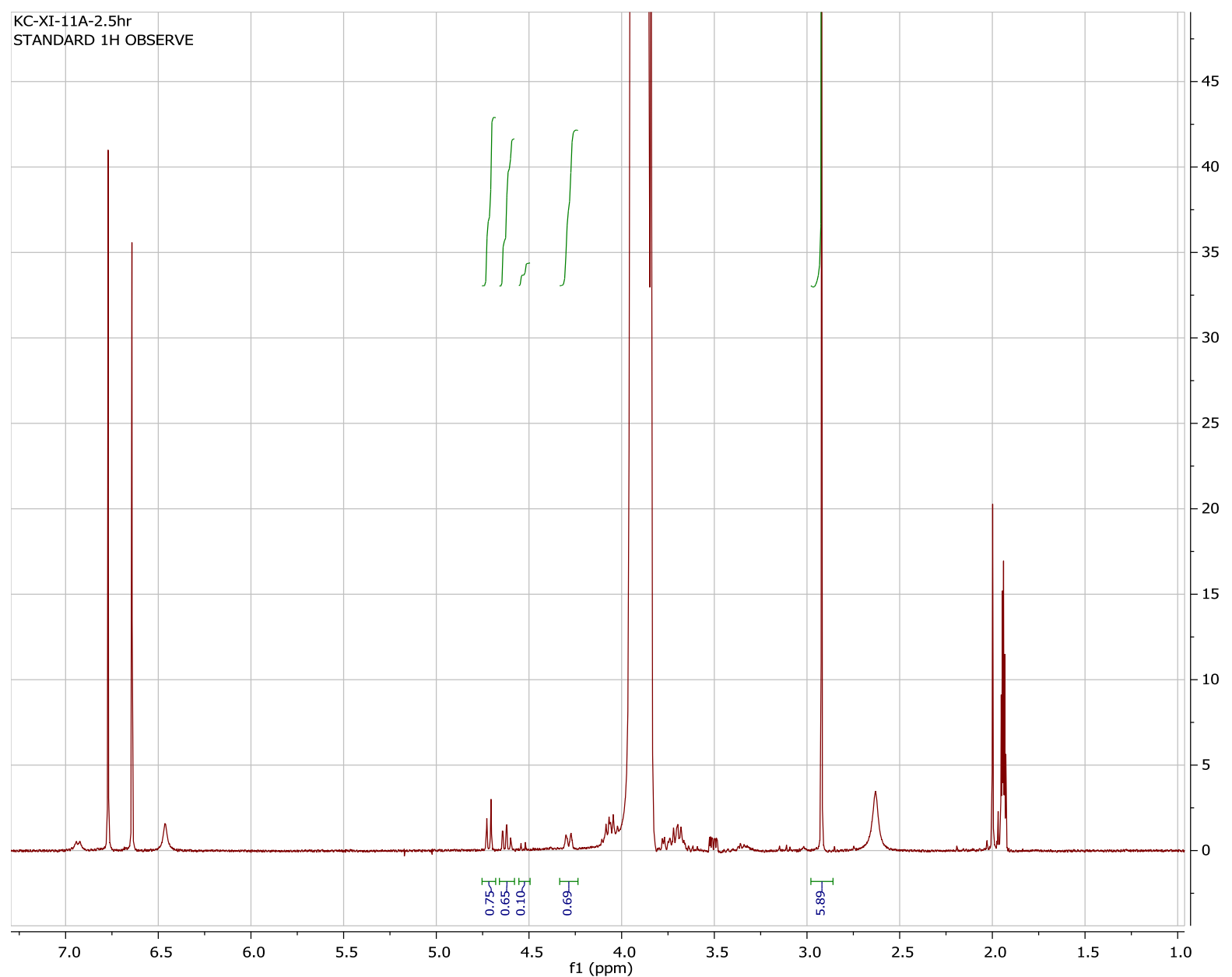

Figure S133. ${ }^{1} \mathrm{H}$ spectrum: oxidation of 2-deoxy-2-acetamido- $\beta$-d-glucopyranosyl azide in 2,2,2-trifluoroethanol 
Aerobic oxidation of methyl a-D-xylopyranoside in presence and absence of 2,6-di-isopropylphenol:

$16.4 \mathrm{mg}$ of methyl a-D-xylopyranoside $(0.1 \mathrm{mmol}), 100 \mathrm{uL}$ of a $0.5 \mathrm{M}$ dimethylsulfone solution in acetonitrile, $60 \mu \mathrm{L} \mathrm{Pd}$ of a $1.67 \mu \mathrm{M}$ solution of [(neocuproine) $\mathrm{Pd}(\mathrm{OAc})]_{2}(\mathrm{OTf})_{2}$ in acetonitrile $(0.001$ $\mathrm{mmol})$, and $9.3 \mathrm{uL}$ 2,6-di-isopropylphenol was added to $840 \mathrm{uL}$ acetonitrile, placed under an atmosphere of $\mathrm{O}_{2}$ and stirred at $50{ }^{\circ} \mathrm{C}$ for 6 hours, after which reaction progress was monitored by NMR. Under aerobic oxidation conditions with 2,6-di-isopropylphenol, 74\% NMR yield of the C3 oxidation product and 15\% NMR yield of the C4 oxidation product is observed. Similar preferential oxidation at C3 (in terms of C3 / C4 oxidation product ratios) is observed when oxygen is used as the terminal oxidant as compared to reactions utilizing benzoquinone as terminal oxidant (see page 67).

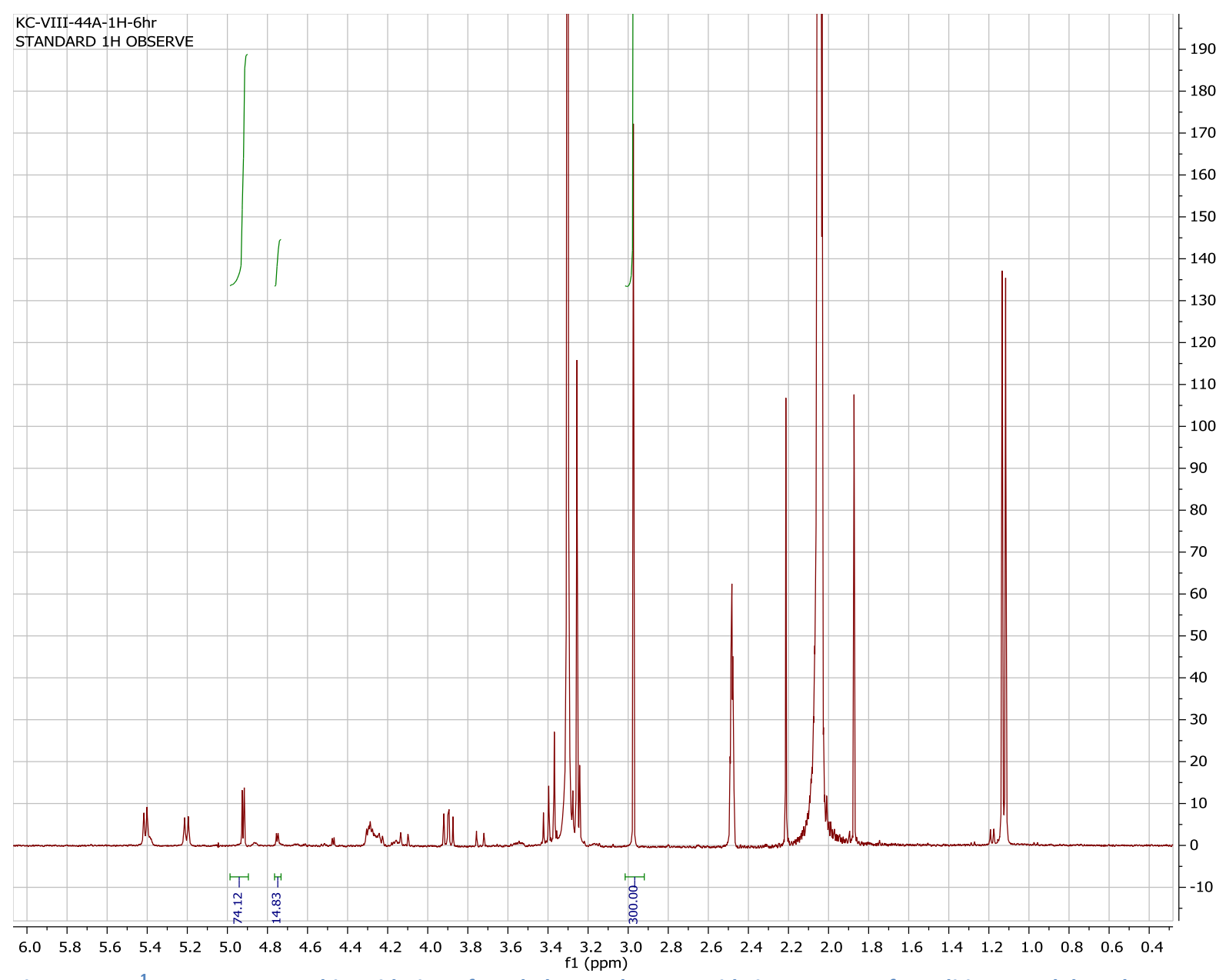

Figure S134. ${ }^{1} \mathrm{H}$ spectrum: aerobic oxidation of methyl a-D-xylopyranoside in presence of 2,6-di-isopropylphenol

Under analogous aerobic oxidation conditions lacking 2,6-di-isopropylphenol, only $12 \%$ NMR yield of the oxidized 3-ketoglycoside is observed. 


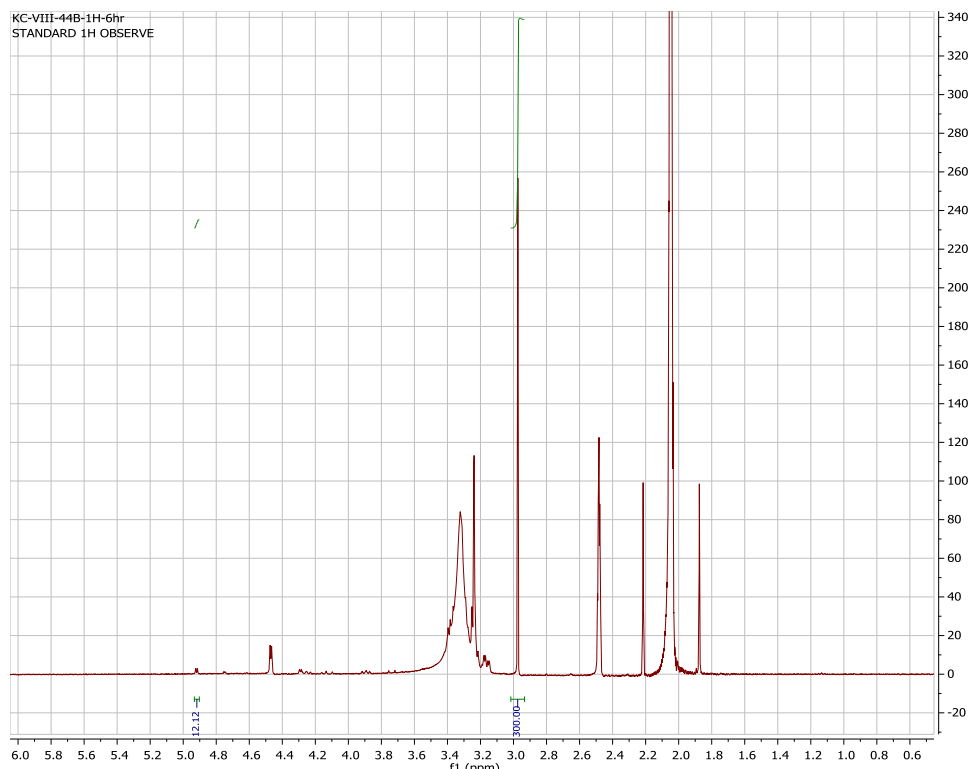

Figure S135. ${ }^{1} \mathrm{H}$ spectrum: aerobic oxidation of methyl a-D-xylopyranoside in absence of 2,6-di-isopropylphenol 


\section{Monitoring of methyl a-D-xylopyranoside oxidation in 9:1 $C D_{3} C N / D_{2} O$ over time}

Methyl- $\alpha$-D-xylopyranoside (in acetonitrile): $0.15 \mathrm{mmol}$ of the sugar substrate, $24.3 \mathrm{mg}$ (0.225 mmol) benzoquinone were dissolved in $900 \mu \mathrm{L}$ 9:1 $\mathrm{CD}_{3} \mathrm{CN} / \mathrm{D}_{2} \mathrm{O}$. Approximately $9.4 \mathrm{mg}(0.1 \mathrm{mmol})$ dimethylsulfone internal standard was weighed out and added to the mixture. Reaction was initiated by addition of a $100 \mu \mathrm{L}$ solution of $0.045 \mathrm{M}[(\text { neocuproine }) \mathrm{Pd}(\mathrm{OAc})]_{2}(\mathrm{OTf})_{2}$ in acetonitrile. The reaction was monitored using a ${ }^{1} \mathrm{H}$ NMR array sampling every 5 minutes $(\mathrm{nt}=16, \mathrm{~d} 1=8$, at=6).

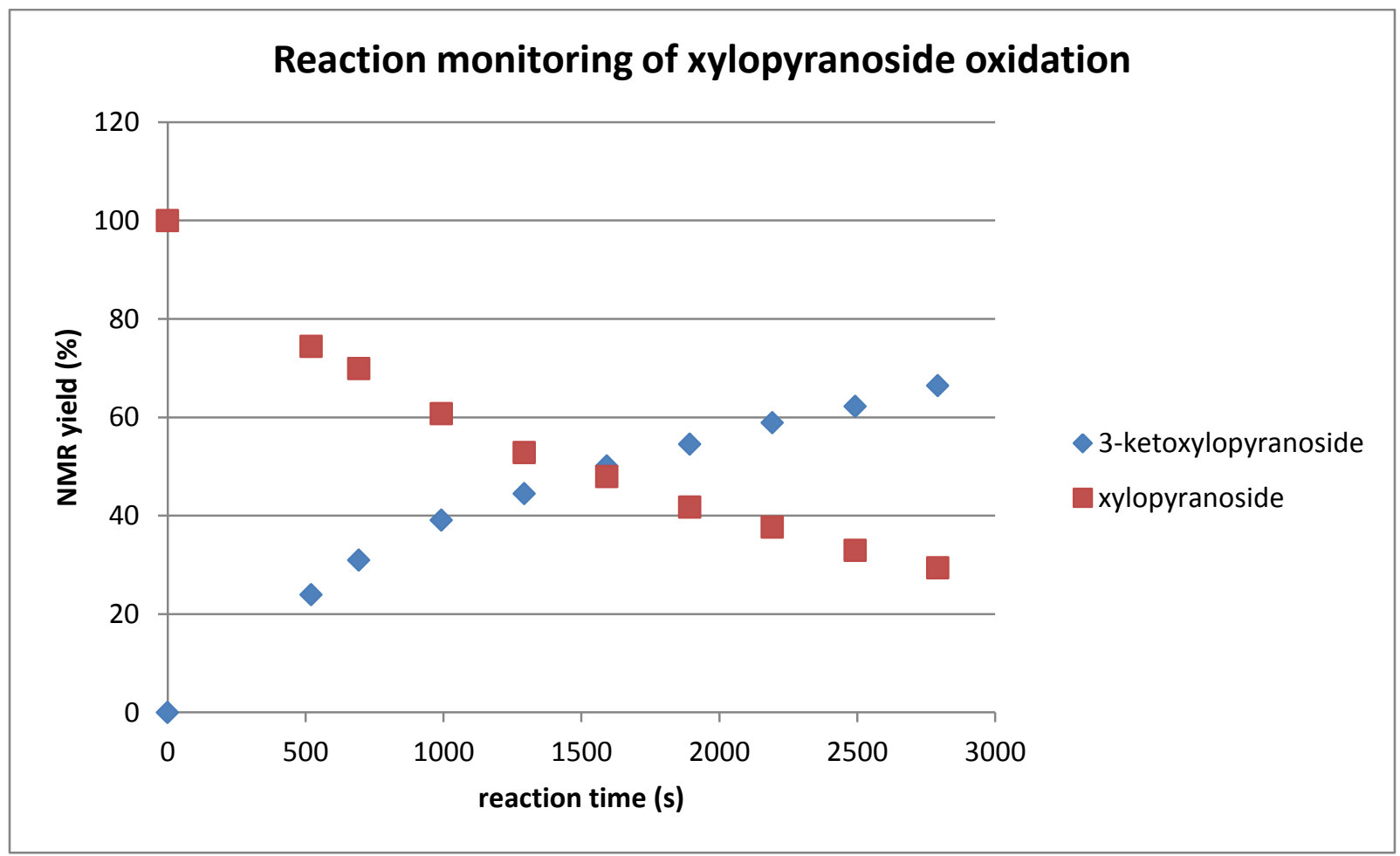

Figure S136. NMR yield vs. time of xylopyranoside oxidation products 
Further investigations of glycoside aerobic oxidations

Table S3. Investigations of glycoside aerobic oxidations at $50^{\circ} \mathrm{C}$

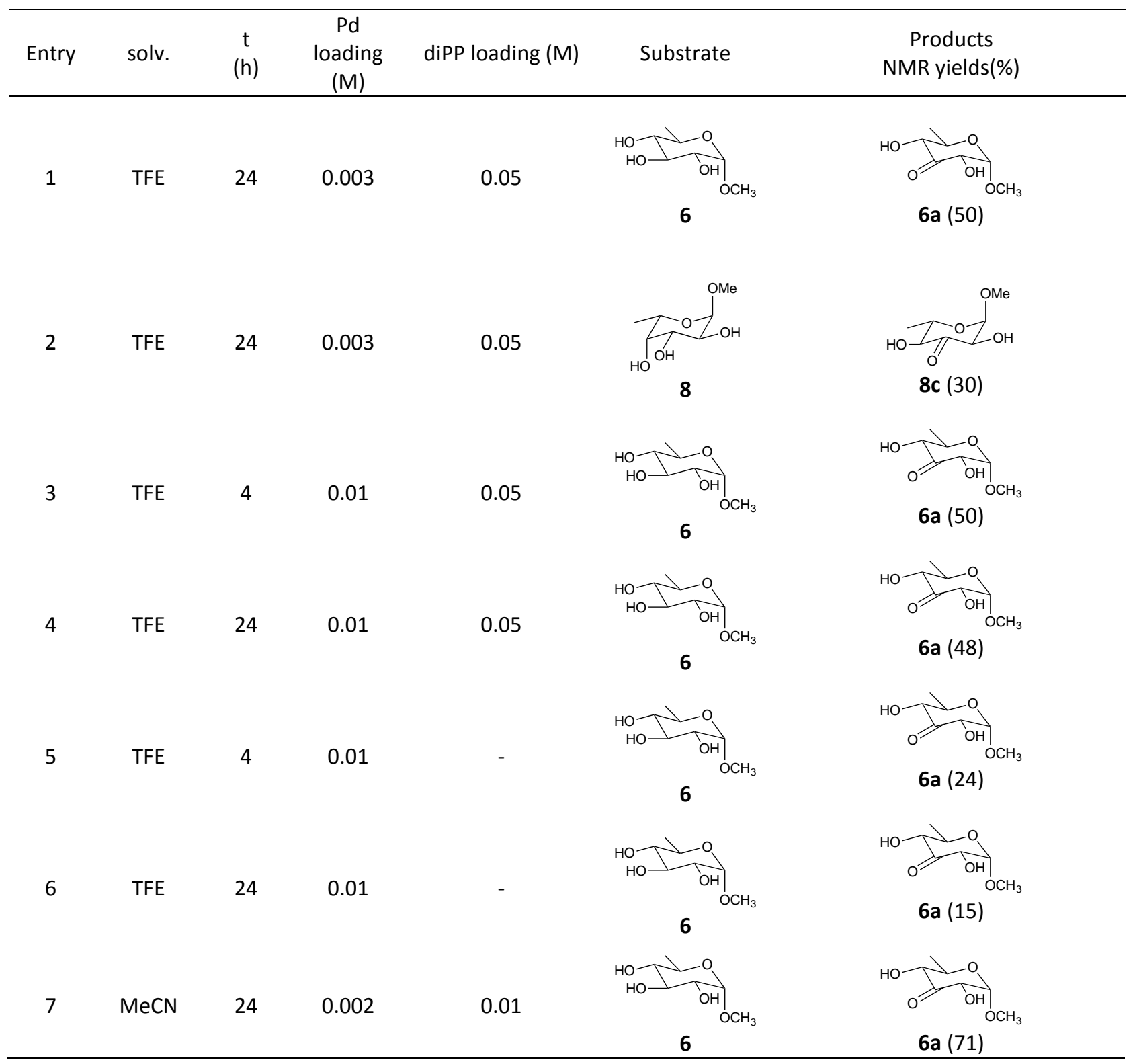


Entries 1-2. $0.1 \mathrm{mmol}$ of the sugar substrate, $9.3 \mu \mathrm{L}$ 2,6-di-isopropylphenol, and approximately $9.4 \mathrm{mg}$ (0.1 mmol) dimethylsulfone internal standard were dissolved in $1 \mathrm{~mL}$ 2,2,2-trifluoroethanol in a $20 \mathrm{~mL}$ septum-capped vial. Reaction was initiated by addition of $1.57 \mathrm{mg}$ [(neocuproine) $\mathrm{Pd}(\mathrm{OAc})]_{2}$ (OTf). The reaction was purged under an oxygen atmosphere for 20 seconds, and was stirred and heated at $50{ }^{\circ} \mathrm{C}$ for 24 hours. Products were characterized via ${ }^{1} \mathrm{H}$ in their crude reaction mixtures.

Entries 3-4. $0.1 \mathrm{mmol}$ of the sugar substrate, $9.3 \mu \mathrm{L}$ 2,6-di-isopropylphenol, and approximately $9.4 \mathrm{mg}$ (0.1 mmol) dimethylsulfone internal standard were dissolved in $1 \mathrm{~mL} \mathrm{2,2,2-trifluoroethanol} \mathrm{in} \mathrm{a} 20 \mathrm{~mL}$ septum-capped vial. Reaction was initiated by addition of $5.22 \mathrm{mg}$ [(neocuproine) $\mathrm{Pd}(\mathrm{OAc})]_{2}$ (OTf). The reaction was purged under an oxygen atmosphere for 20 seconds, and was stirred and heated at $50{ }^{\circ} \mathrm{C}$ for 4 hours. Products were characterized via ${ }^{1} \mathrm{H}$ in their crude reaction mixtures at 4 hours and 24 hours.

Entries 5-6. $0.1 \mathrm{mmol}$ of the sugar substrate, and approximately $9.4 \mathrm{mg}(0.1 \mathrm{mmol})$ dimethylsulfone internal standard were dissolved in $1 \mathrm{~mL}$ 2,2,2-trifluoroethanol in a $20 \mathrm{~mL}$ septum-capped vial. Reaction was initiated by addition of $5.22 \mathrm{mg}\left[(\text { neocuproine) } \mathrm{Pd}(\mathrm{OAc})]_{2}(\mathrm{OTf})\right.$. The reaction was purged under an oxygen atmosphere for 20 seconds, and was stirred and heated at $50{ }^{\circ} \mathrm{C}$. Products were characterized via ${ }^{1} \mathrm{H}$ in their crude reaction mixtures at 4 hours and 24 hours.

Entry 7. $17.4 \mathrm{mg}(0.1 \mathrm{mmol})$ of methyl-6-deoxy- $\alpha$-D-glucopyranoside, $1.9 \mu \mathrm{L}$ 2,6-di-isopropylphenol, and approximately $9.4 \mathrm{mg}(0.1 \mathrm{mmol})$ dimethylsulfone internal standard were dissolved in $1 \mathrm{~mL}$ acetonitrile in a $20 \mathrm{~mL}$ septum-capped vial. Reaction was initiated by addition of $0.52 \mathrm{mg}$ $[(\text { neocuproine }) \mathrm{Pd}(\mathrm{OAc})]_{2}(\mathrm{OTf})_{2}$. The reaction was purged under an oxygen atmosphere for 20 seconds, and stirred and heated at $50{ }^{\circ} \mathrm{C}$ for 20 hours, after which another $0.52 \mathrm{mg}$ portion of $[(\text { neocuproine }) \mathrm{Pd}(\mathrm{OAc})]_{2}(\mathrm{OTf})_{2}$ was added and the reaction was continued for another 4 hours. Products were characterized via ${ }^{1} \mathrm{H}$ in their crude reaction mixtures.

Complete starting material consumption, about $71 \%$ yield of the $\mathrm{C} 3$ oxidation product, and $16 \%$ yield of the $\mathrm{C} 4$ oxidation product is observed by NMR after 24 hours. 


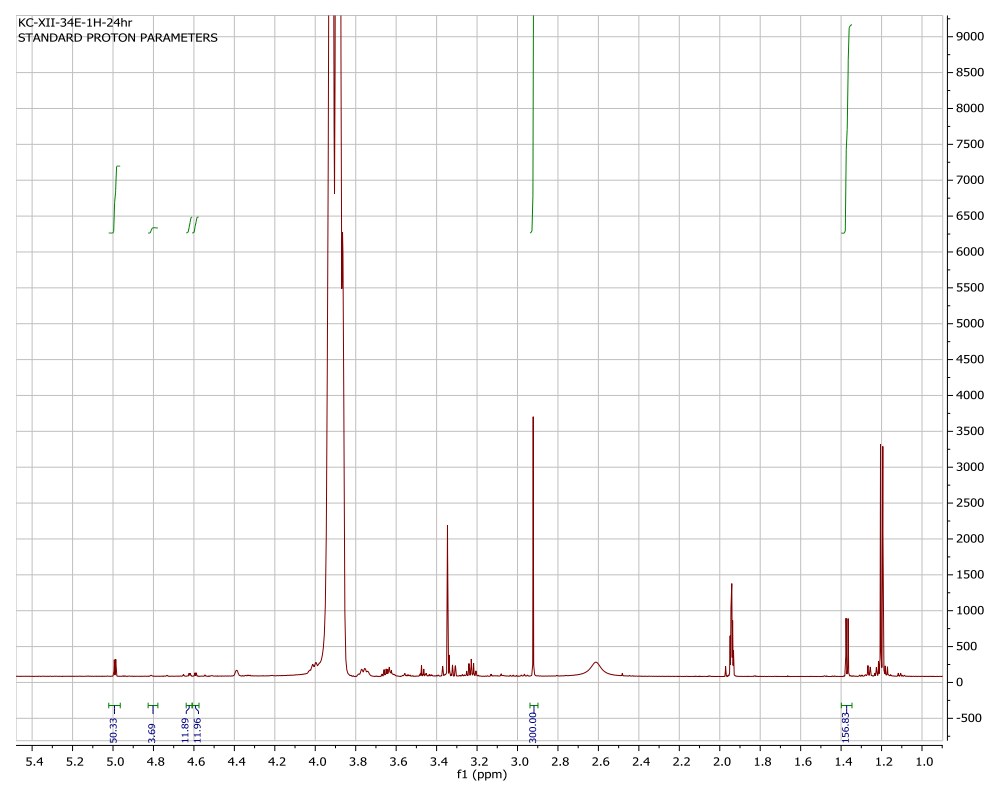

Figure S137. NMR spectrum of aerobic oxidation of methyl-6-deoxy-a-D-glucopyranoside in 2,2,2-trifluoroethanol after 24 hours (Entry 1)

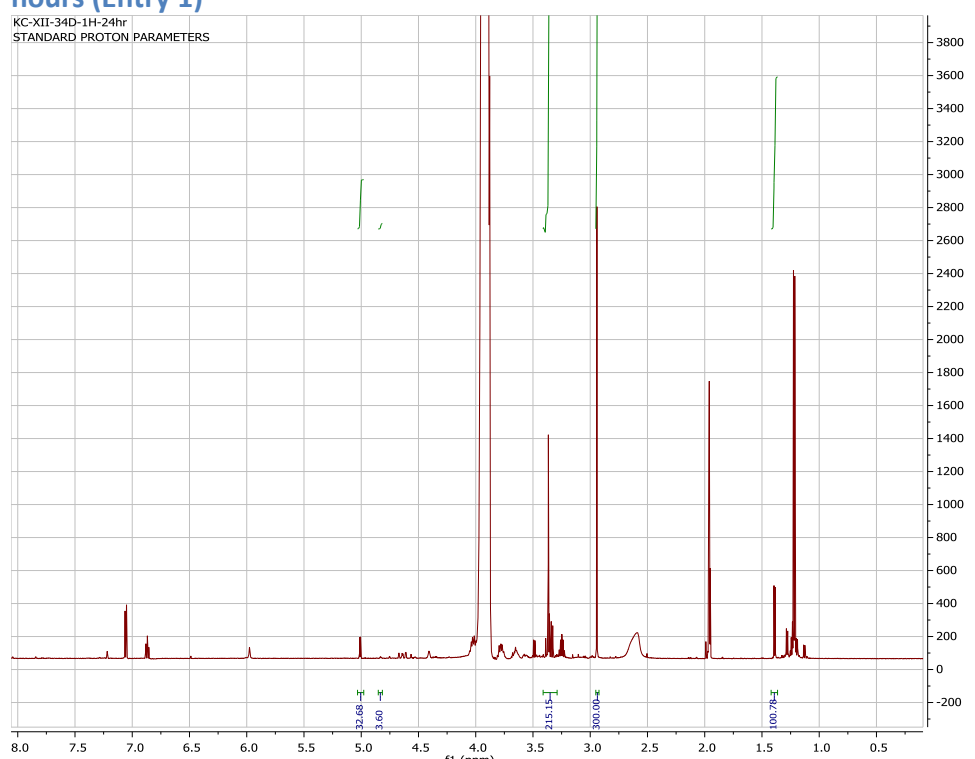

Figure S138. NMR spectrum of aerobic oxidation of methyl- $\alpha$-L-fucopyranoside in 2,2,2-trifluoroethanol after 24 hours (Entry 2) 


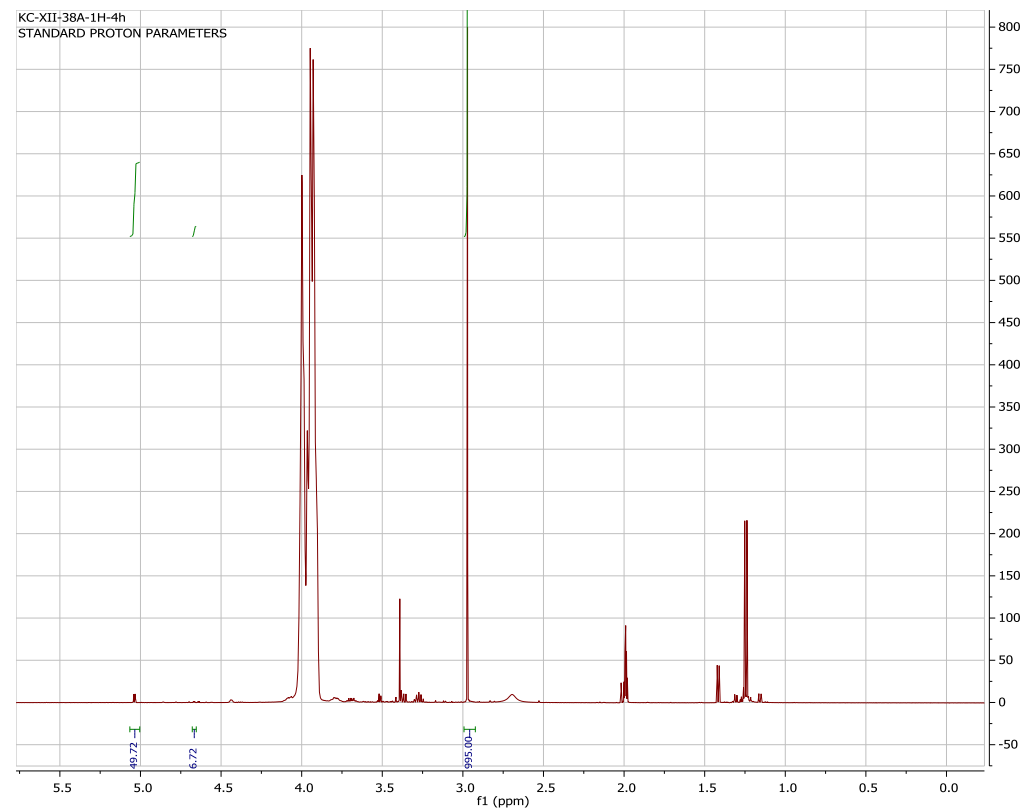

Figure S139. NMR spectrum of aerobic oxidation of methyl-6-deoxy- $\alpha$-D-glucopyranoside in 2,2,2-trifluoroethanol after 4 hours (Entry 3)

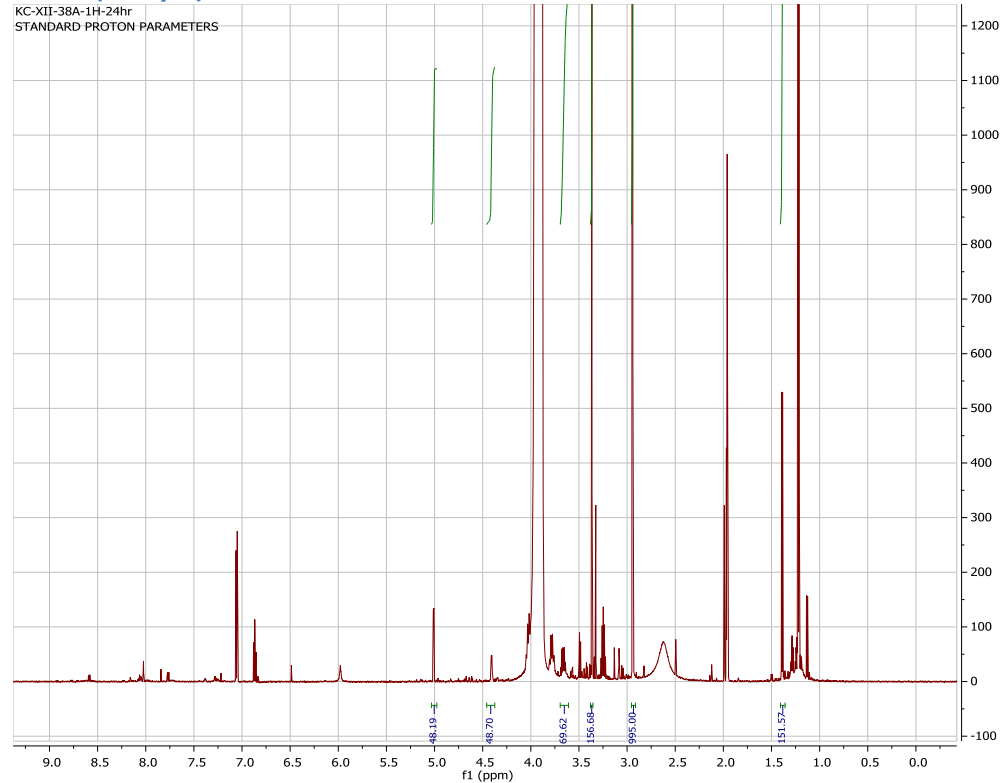

Figure S140. NMR spectrum of aerobic oxidation of methyl-6-deoxy- $\alpha$-D-glucopyranoside in 2,2,2-trifluoroethanol after 24 hours (Entry 4) 


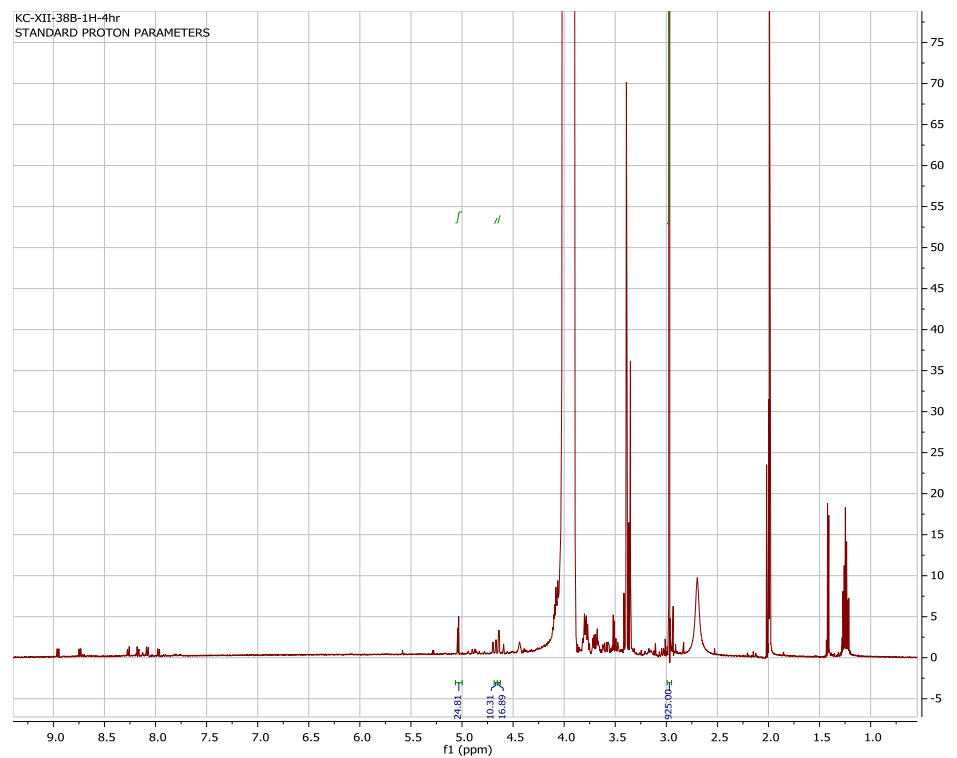

Figure S141. NMR spectrum of aerobic oxidation of methyl-6-deoxy- $\alpha$-D-glucopyranoside in 2,2,2-trifluoroethanol after 4 hours (Entry 5) 


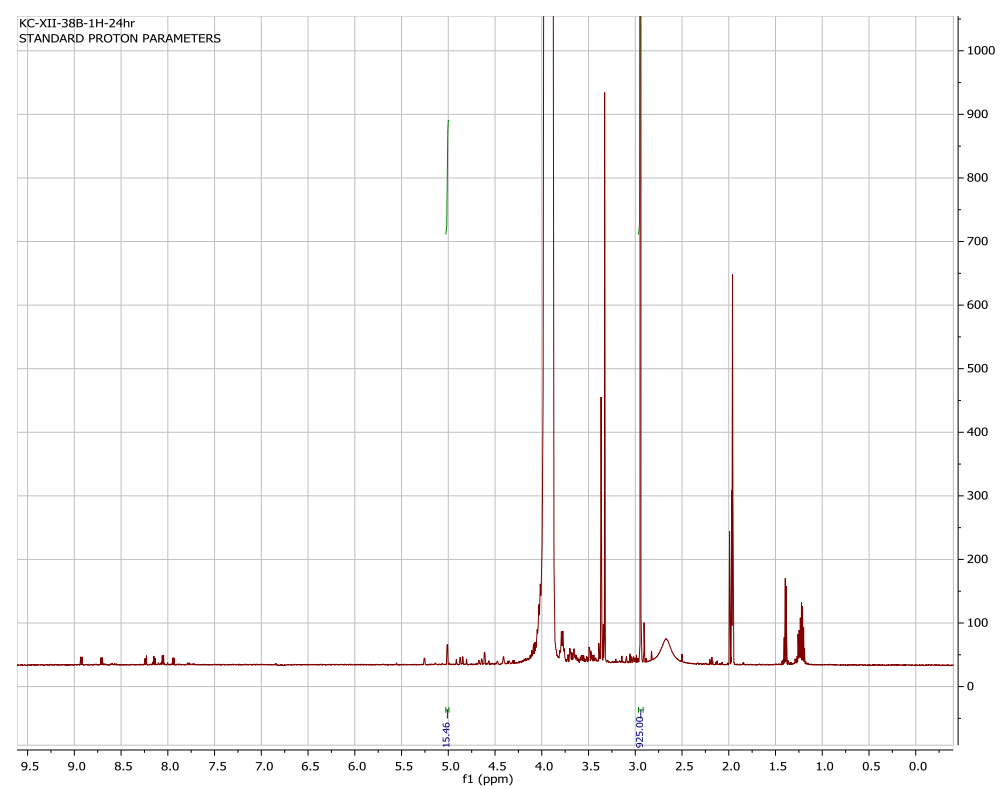

Figure S142. NMR spectrum of aerobic oxidation of methyl-6-deoxy-a-D-glucopyranoside in 2,2,2-trifluoroethanol after 24 hours (Entry 6)

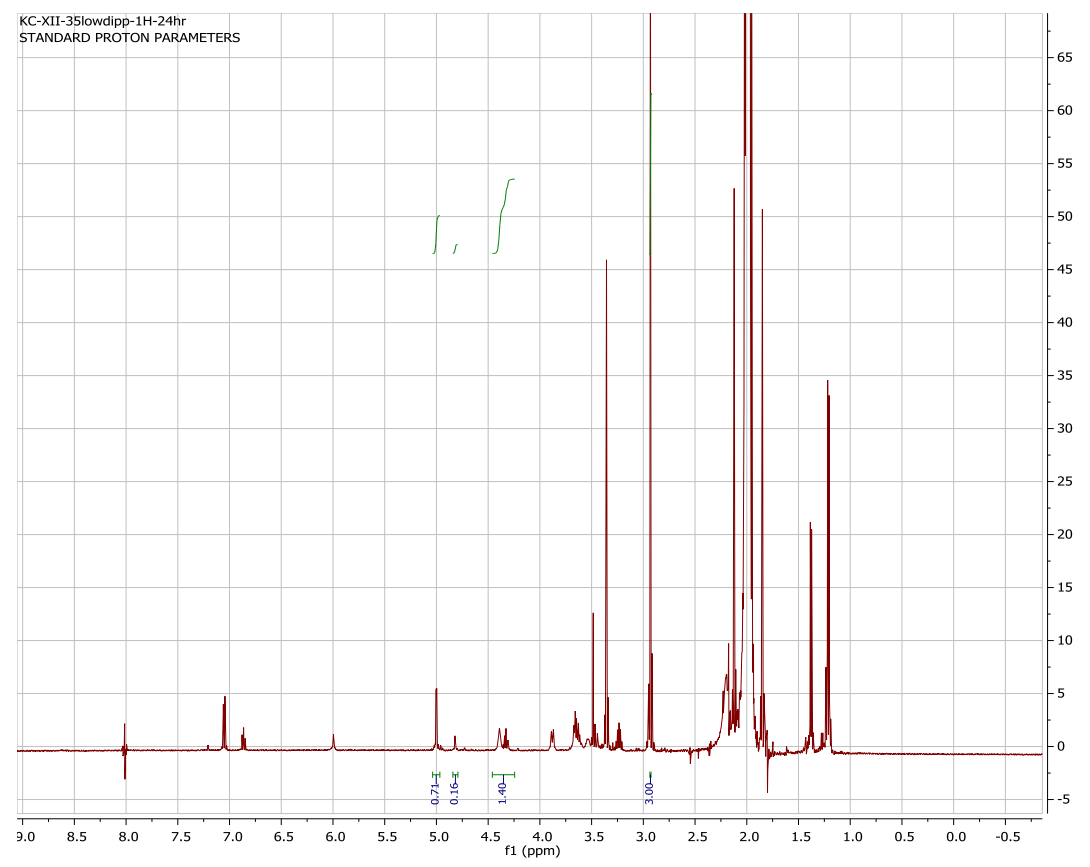

Figure S143. aerobic oxidation of methyl- $\alpha$-L-fucopyranoside in acetonitrile using 0.1 eq 2,6-di-isopropylphenol (Entry 7) 
Investigations of alternative solvents for glycoside oxidation

Table S4. Investigations of glycoside oxidations at $60^{\circ} \mathrm{C}$

\begin{tabular}{|c|c|c|c|c|c|c|}
\hline Entry & solv. & $\begin{array}{c}\mathrm{t} \\
(\mathrm{h})\end{array}$ & $\begin{array}{c}\text { Pd } \\
\text { loading } \\
\text { (M) }\end{array}$ & temperature & Substrate & $\begin{array}{c}\text { Products } \\
\text { NMR yields(\%) }\end{array}$ \\
\hline 1 & $\begin{array}{l}\text { propylene } \\
\text { carbonate }\end{array}$ & 20 & 0.003 & 50 & 6 & $\mathbf{6 a}(100)$ \\
\hline 2 & water & 20 & 0.003 & 50 & 6 & $\mathbf{6 a}(45)$ \\
\hline 3 & water & 24 & 0.010 & 60 & $6 \stackrel{\mathrm{OH}}{\mathrm{OCH}_{3}}$ & 6a (85) \\
\hline
\end{tabular}

Entry 1: $17.8 \mathrm{mg}$ methyl-6-deoxy- $\alpha$-D-glucopyranoside, $13.0 \mathrm{mg}$ benzoquinone and approximately 9.4 $\mathrm{mg}(0.1 \mathrm{mmol})$ dimethylsulfone internal standard were dissolved in $2 \mathrm{~mL}$ propylene carbonate in a $20 \mathrm{~mL}$ septum-capped vial. Reaction was initiated by addition of $1.52 \mathrm{mg}$ [(neocuproine) $\mathrm{Pd}(\mathrm{OAc})]_{2}(\mathrm{OTf})$. The reaction was stirred and heated at $50{ }^{\circ} \mathrm{C}$ for 20 hours.

Entry 2: $17.8 \mathrm{mg}$ methyl-6-deoxy- $\alpha$-D-glucopyranoside, $13.0 \mathrm{mg}$ benzoquinone and approximately 9.4 $\mathrm{mg}(0.1 \mathrm{mmol})$ dimethylsulfone internal standard were dissolved in $1 \mathrm{~mL}$ water in a $20 \mathrm{~mL}$ septumcapped vial. Reaction was initiated by addition of $1.52 \mathrm{mg}$ [(neocuproine) $\mathrm{Pd}(\mathrm{OAc})]_{2}(\mathrm{OTf})$. The reaction was stirred and heated at $50{ }^{\circ} \mathrm{C}$ for 20 hours.

Entry 3: $17.8 \mathrm{mg}$ methyl-6-deoxy- $\alpha$-D-glucopyranoside, $13.0 \mathrm{mg}$ benzoquinone and approximately 9.4 $\mathrm{mg}(0.1 \mathrm{mmol})$ dimethylsulfone internal standard were dissolved in $1 \mathrm{~mL}$ water in a $20 \mathrm{~mL}$ septumcapped vial. Reaction was initiated by addition of $5.22 \mathrm{mg}$ [(neocuproine) $\mathrm{Pd}(\mathrm{OAc})]_{2}(\mathrm{OTf})$. The reactionwas stirred and heated at $60^{\circ} \mathrm{C}$ for 24 hours. 


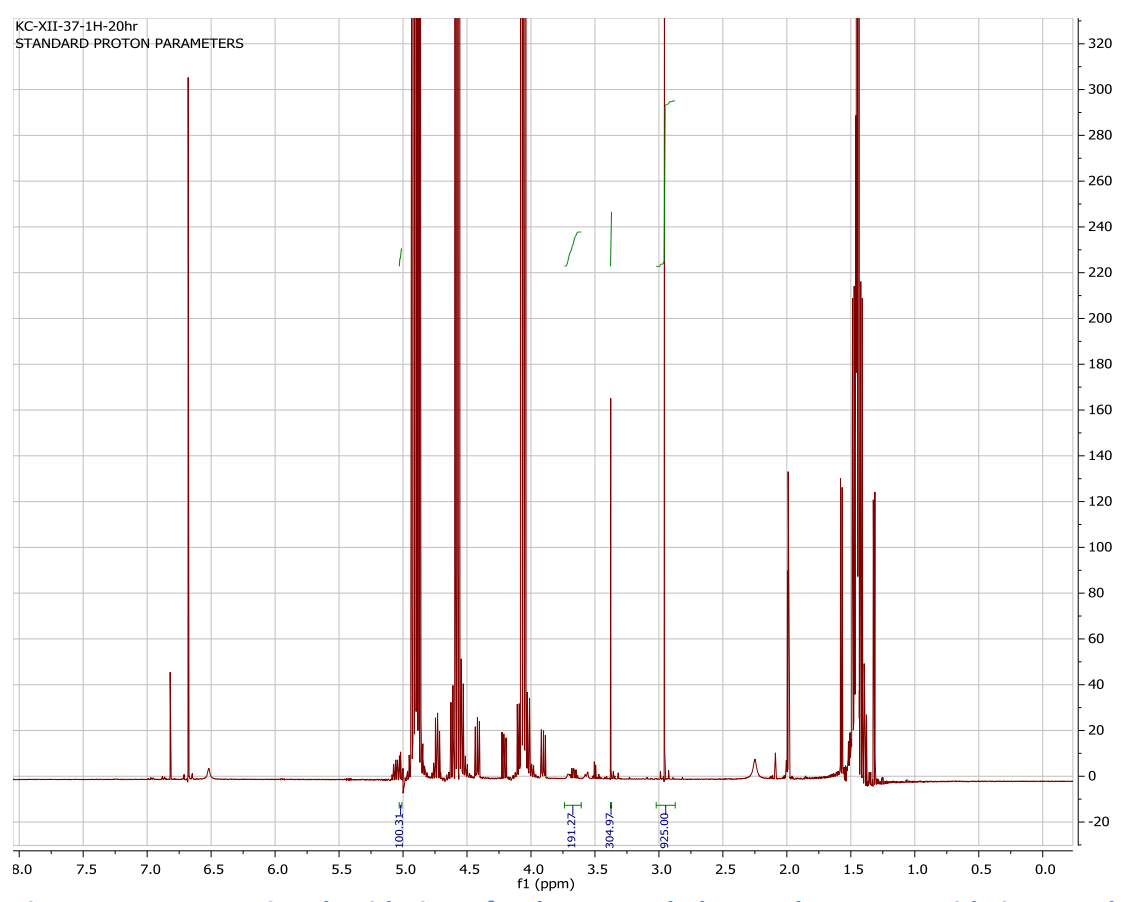

Figure S144. BQ-assisted oxidation of 6-deoxy-methyl- $\alpha$-D-glucopyranoside in propylene carbonate after 20 hours at $50{ }^{\circ} \mathrm{C}$ (3\% Pd loading)

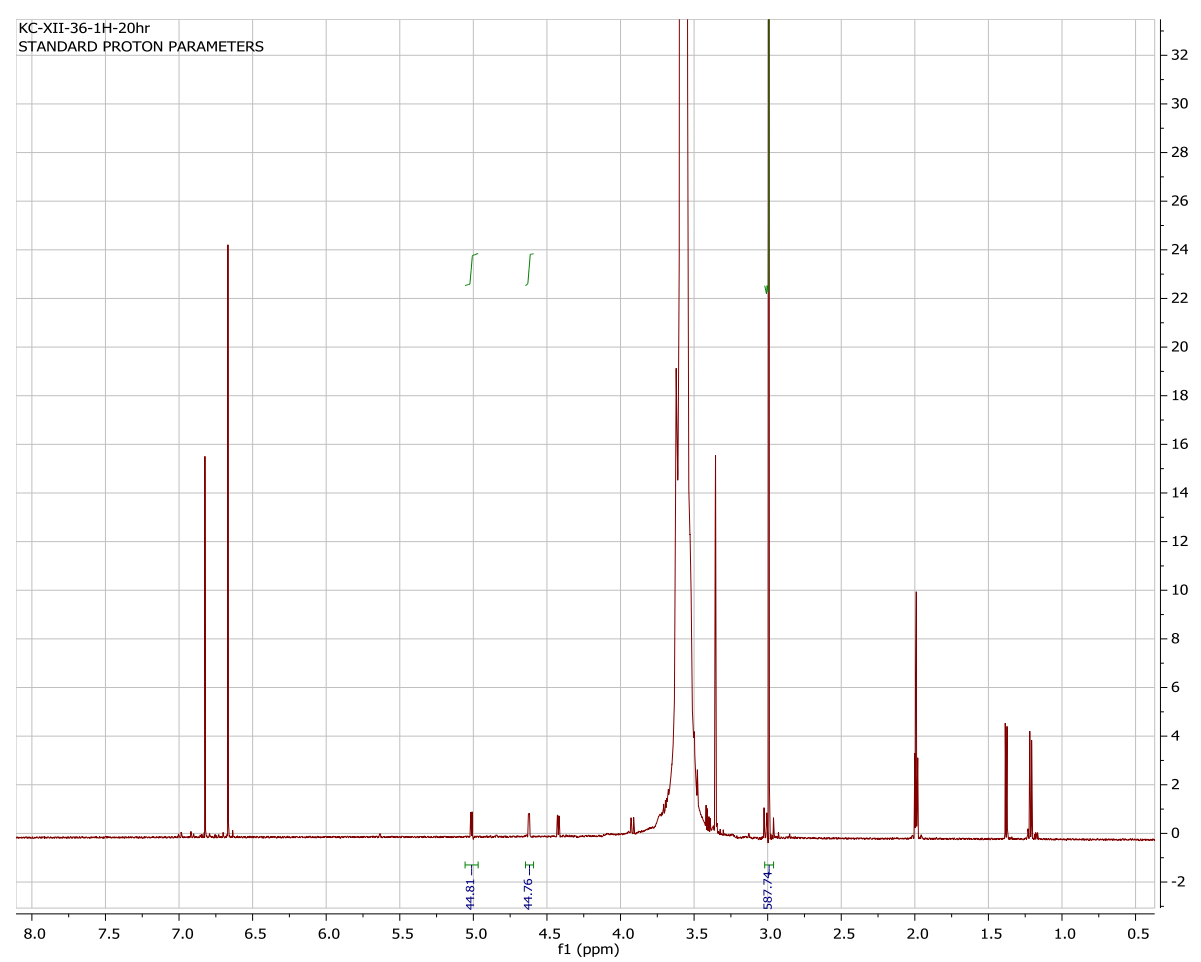

Figure S145. BQ-assisted oxidation of 6-deoxy-methyl- $\alpha$-D-glucopyranoside in water after 20 hours at $50{ }^{\circ} \mathrm{C}(3 \% \mathrm{Pd}$ loading) 


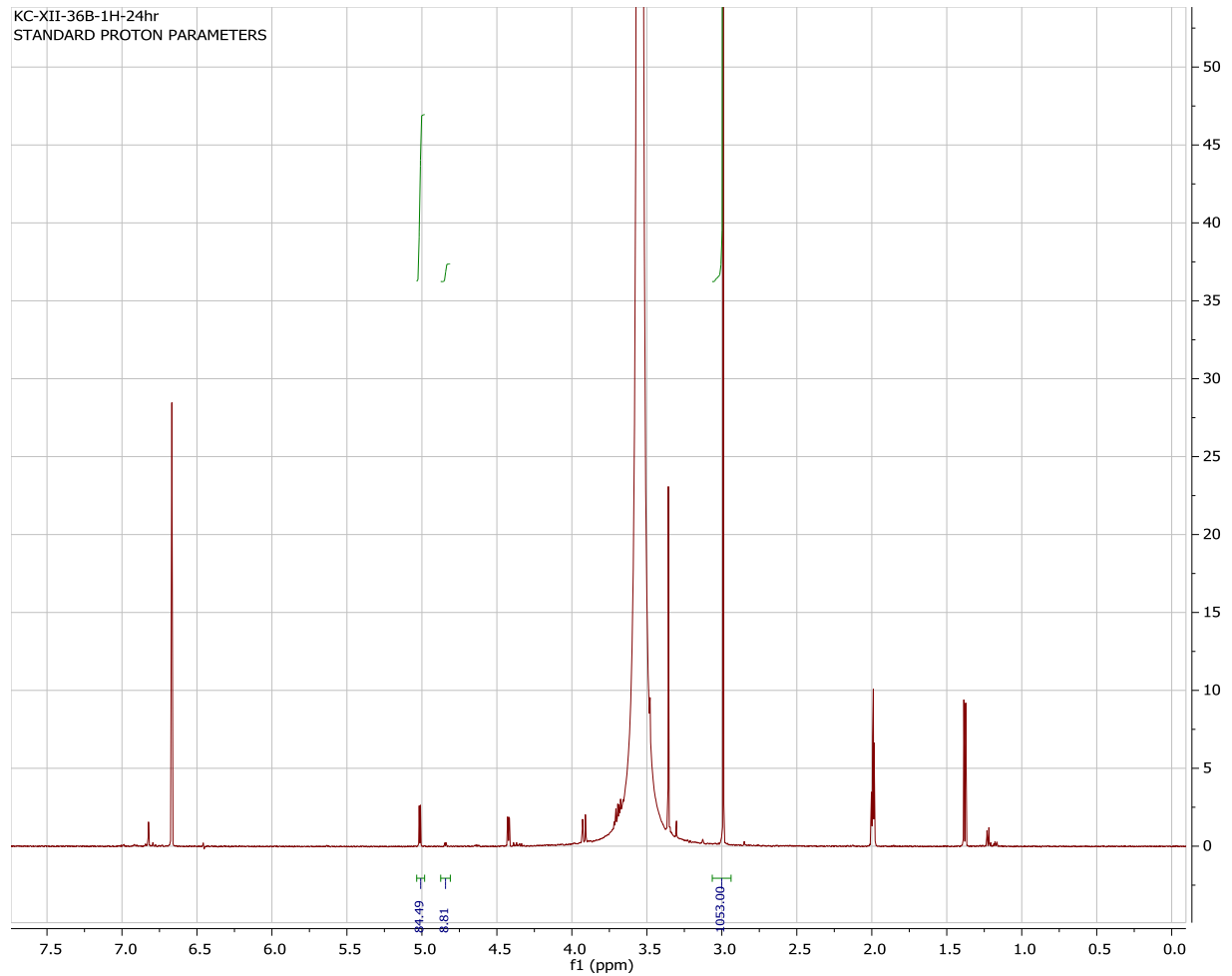

Figure S146. BQ-assisted oxidation of 6-deoxy methyl- $\alpha$-D-glucopyranoside in water after 24 hours at $60^{\circ} \mathrm{C}(10 \% \mathrm{Pd}$ loading) 


\section{References}

(1) Ferrières, V.; Bertho, J.-N.; Plusquellec, D. Carbohydrate Research 1998, 311, 25.

(2) Chung, K.; Banik, S. M.; De Crisci, A. G.; Pearson, D. M.; Blake, T. R.; Olsson, J. V.; Ingram, A. J.; Zare, R. N.; Waymouth, R. M. Journal of the American Chemical Society 2013, 135, 7593.

(3) Naundorf, A.; Klaffke, W. Carbohydrate Research 1996, 285, 141.

(4) Jäger, M.; Hartmann, M.; de Vries, J. G.; Minnaard, A. J. Angewandte Chemie International Edition 2013, 52, 7809.

(5) De Crisci, A. G.; Chung, K.; Oliver, A. G.; Solis-Ibarra, D.; Waymouth, R. M. Organometallics 2013, 32, 2257.

(6) Muramatsu, W. Organic Letters 2014, 16, 4846. 